COLUMBIA LIBRAFIES OFFSITE

\title{
PRINCIPLES OF HISTOLOGY
}

A. H. TUTTLE 
$(x+1)$ (4)

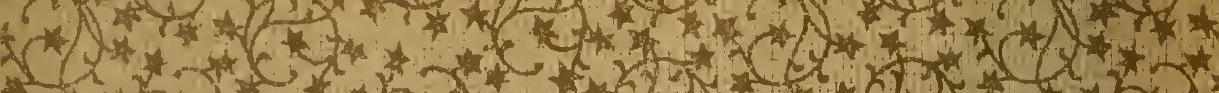

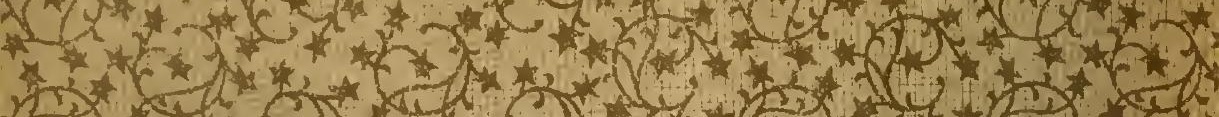

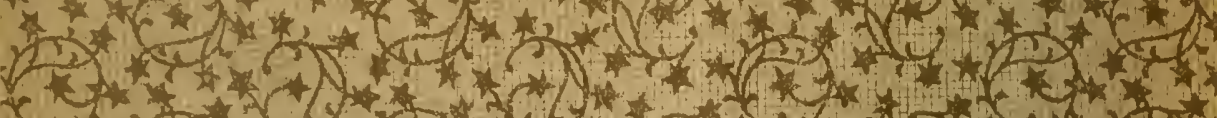

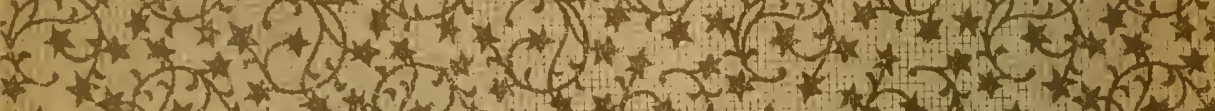
for , $(x+7)$

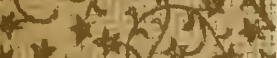
(2) $x+1+2$

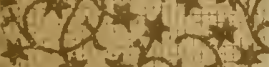
7) cor (t)

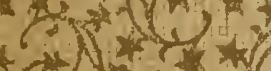
$\left(i+x^{2}+\ldots\right.$ $+$ ,

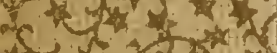

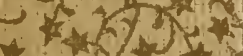

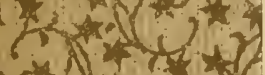
$+7+7$ (c.t. $2 x^{2}+12$

Columbia ofninersity inthe

THE LIBRARIES

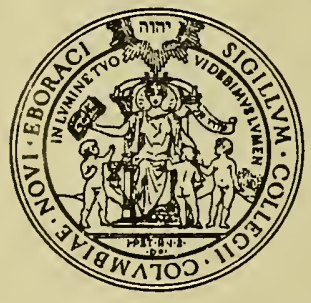

Atledical 五ibrary $57+\frac{1}{4}$

$x+2,1$

$(x+2)+2)^{2}$

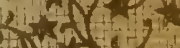

Natis

(x) 2. (1) $13 \times+1$ Not $3+2(a)$ $\mathrm{N}=\mathrm{N} \times \mathrm{C}$ $6 x^{2}, 5$ $x^{2}+2$ - $x^{2}+3=4$ $(2, x)$ $1+2(6)$ 2 atidy 6 Nitian $\left(1 \times 1+2 x^{4}\right.$ itition Dh. 13ind

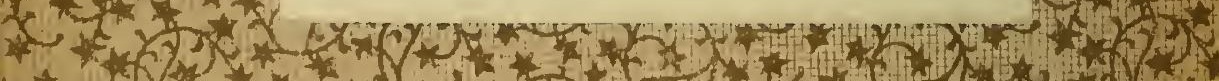
(*)

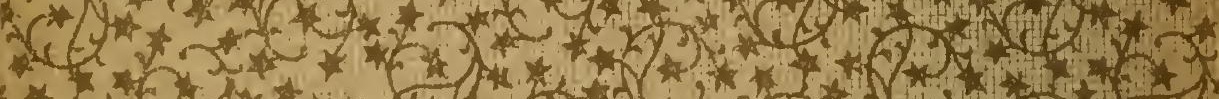
(

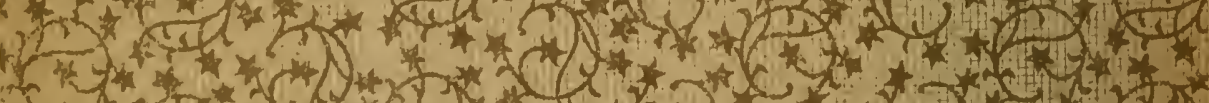

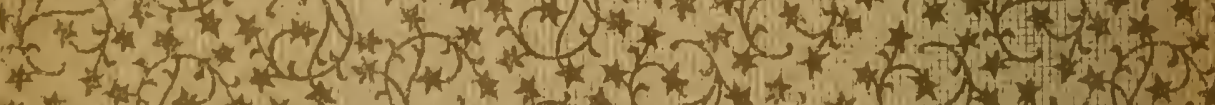
(t)

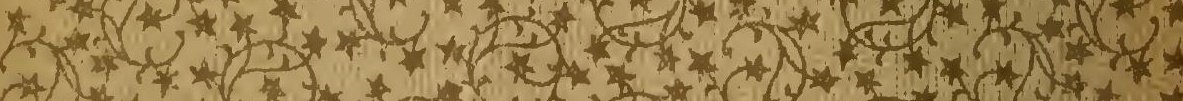
( (1)

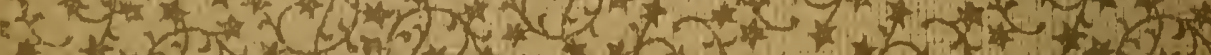




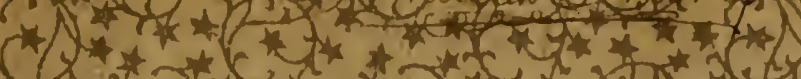

F, the

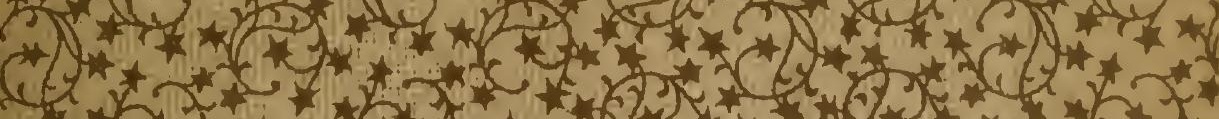

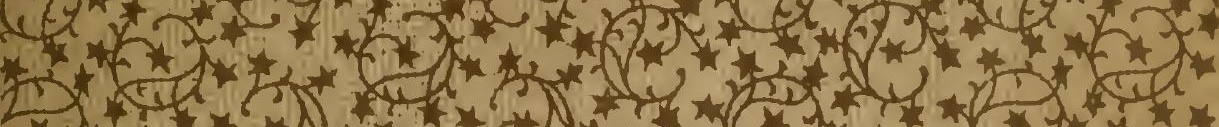

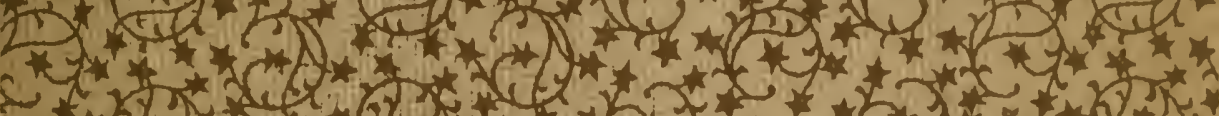

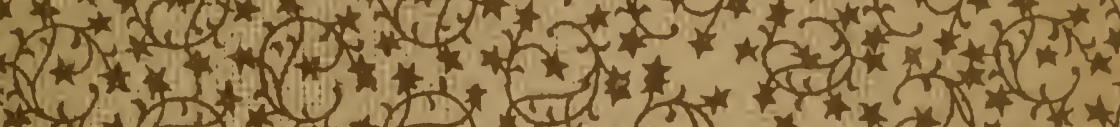

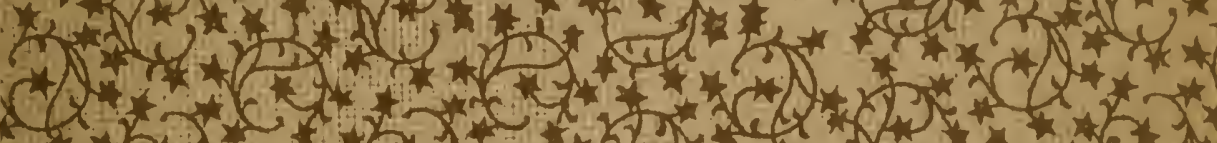

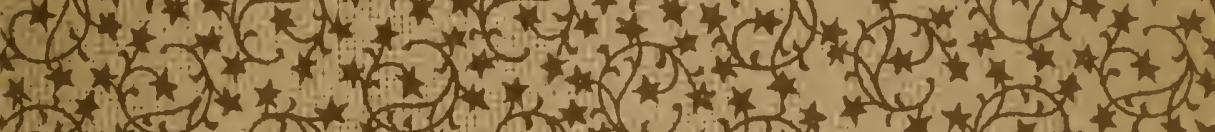
(15)

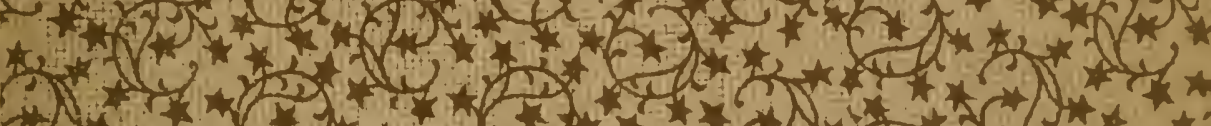
3)

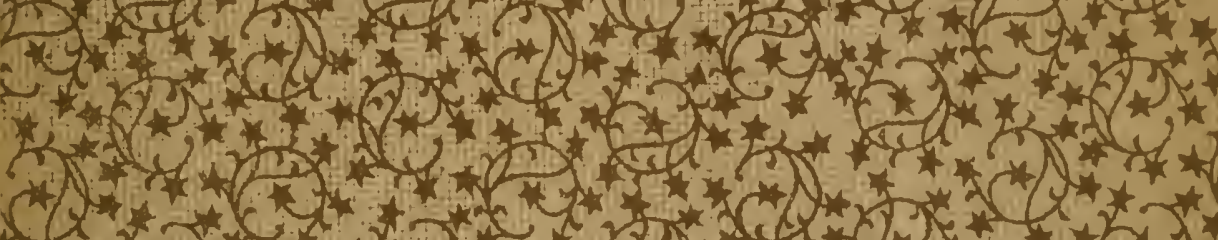
(1)

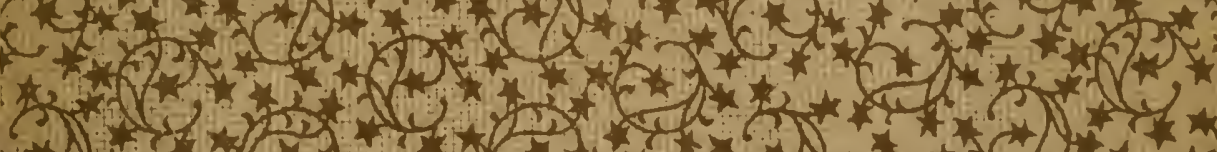

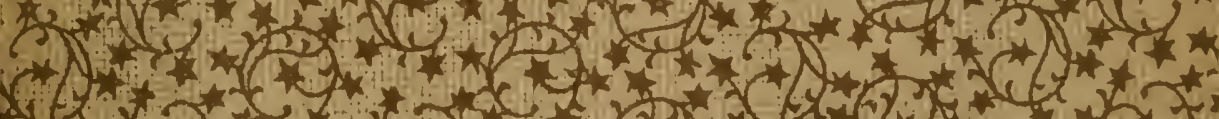

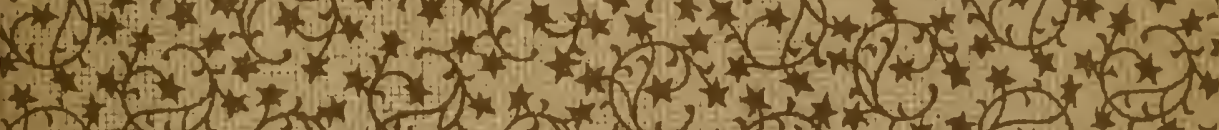
(2)

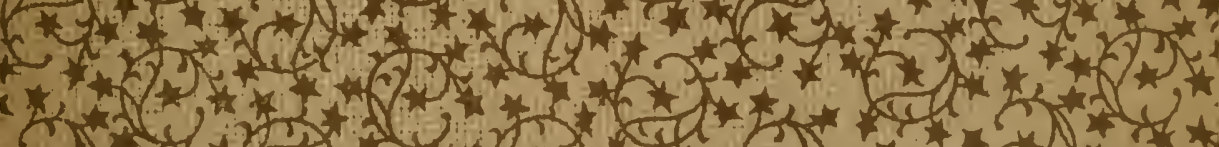

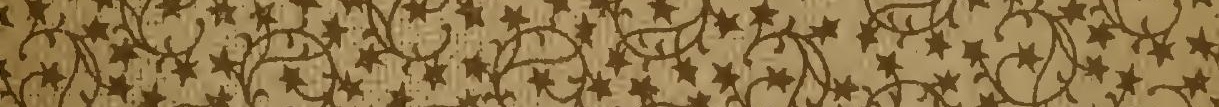

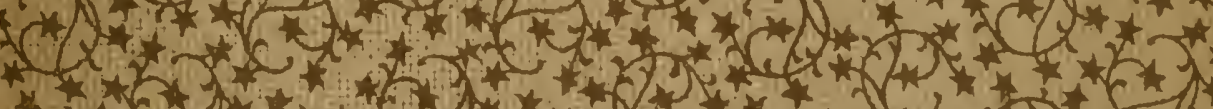
if

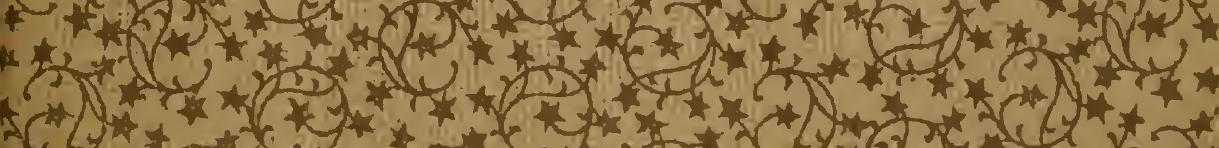


(14.1,5141:... (1) 


\title{
'THE PRINCIPLES OF HIS'TOLOGY
}

IIESCRIPTIVE: AND P'RAC'TICAL:

\author{
BOOK I.
}

\section{DESCRIPTIVE HISTOLOGY.}

BY

ALBERT H. TUTTLE.

PUBLISHED BY ANDERSON BROS.

UNIVERSITY OF VIRGINLA.

1898. 


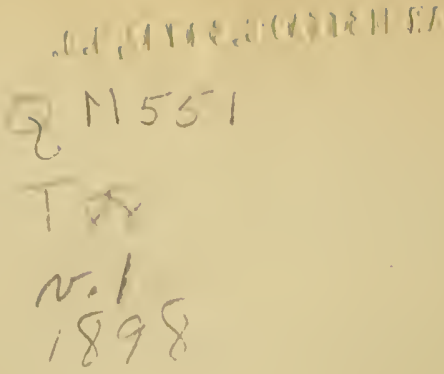

Entered according to Act of Congress by ALBERT H. TUTTLE, University of Virginia, 1898. 


\section{PREFACE.}

This manual represents an effort to state the most important facts of descriptive histology in a manner adapt-ed to the wants of my own classes of students, both acatdemic and medical. It lays no claim to originality save in the arrangement and mode of presentation, and acknowledgement is here made of the extensive use of the best modern treatises and monographs accessible in its preparation. In the portions dealing with the nervous system I am under special obligations to the writings of Cajal and Van Gehucten among others. I am indebted to Dr. Lyman J. Skeen for frequent and valuable aid in the preparation of the book.

This volume will be followed by a second, now in course of preparation, dealing with Practical Histology.

ALBERT H. TUTTLE.

Uxiversity of Virginia, May, 1898. 



\section{CONTENTS OF BOOK I.}

PART I: THE CELL AND THE TISSUES.

CHAPTER I.

Introductory : Definitions: The Cell, - - 14- 16;

CHAPTER II.

The Epithelia : Endothelium: Epitheliom And Exdothelioid Structures, - - - - - 17- 22

CHAPTER III.

The Cartilage Group: Car'tilages, - - - 23- 30

CHAPTER IV.

The, Fibrous Tissues: Areolar Tissue: AdIpose Tissue: Retiforar Tissue: Membranes: Texpons, - . . . . . - . - 31- 46

CHAPTER V.

The Lamellated Tissues: Corneal Tissue:

Osseous Tissue: Periosteum: Marrotr:

Bones, - . . - . - . . . . 47- 58

CHAPTER VI.

Ossification: of Membranes; in Cartilage, 59- 72 
CHAPTER VII.

THE BLOOD,

$73-82$

CHAPTER VIII.

The Contractile: Tissues: Muscles, - - 83- 90

CHAPTER IX.

The Salall Vesselas: Bloodvessfils; LyaPhatics: Serous Cavities, - . - - - - - 91- 98

CHAPTER X.

The Neryous Tissues: Nerve Fibres; Corpuscles: Terminals: Nerves; Ganglia: Néroglia, - - - - - - - - - - - 99-114

CHAPTER XI.

The Structure of the Cell: Niclear Division, -

PART II: HISTOLOGICAL ANATOMY.

CHAPTER XII.

Introinctory: The Limbryonic T'issue LaYERS: Sistems of Organs, - - - - - 127-134 
CHAPTER XIII.

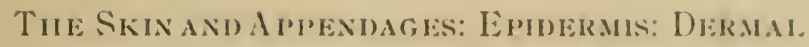

Glandos: Halrs: Nalls, - - - - - 135-15\%

CHAPTER XIV.

The Mouth and its Contents: Glands of the Mrcols and Serous Typles: Saltyary Glands: the Teetia : the Tongue, - - 153-171

CHAPTER XV.

The Almentary Canal: Component Strata: The Pharyx: The Oesorharus: The Stomach: The Duodenum: The Small INtestine: The Colon: The Rectua: The Paxcreas: The Liver, - - - - - - 153-190

CHAPTER XVI.

The Respiratury Apparatus: The Trachea: The Bronchi: The Lungs: The PulaonARY Bloon SUPPLy, - - - - - - - - - 191-202

\section{CHAPTER XVII.}

The Urinary Organs; The Kidneys: The Bladder: The UReTHRA. - - - - - 203-216

\section{CHAPTER XVIII.}

The Male Reproductive Organs: The Scrotum; The Testes: The Spermatic Ducts and Seminal Vesicles: The Male Urethra: The Penis: The Prostate: CowPER'S GLANDS, - - - - - - - - 217-232 
CHAPTER XIX.

The Fenale Rfproductive Organs: The Oraries: The Oviducts: The Uterus: The Vagina: The Vulva: ThF Mammary Glands: The Homologies of the UrinoGenital Organs, - - - - - - - - 233-258

\section{CHAPTER XX.}

The Vascular System; The Arteries; The Heart; TheVeins: The Lymphatic Trunks; Tine Serous Membranes: The Synovial Menbranes, - - - - - - - - . 259-268

\section{CHAPTER XXI.}

The Ductless Bonies: Lymphatic Nodules and Nodes: The Splene: The Thymus: The Thyroid: The Parathyroids, Carotid Glands, and Coccygeal Gland: The Adrenal Bodies: The Pituitary Bony: The Pineal Body, - - - - - - - - - - - 269-286

\section{CHAPTER XXII.}

The Nervous System: The Meninges: The Spinal Cord: The Cerfaellar Cortex: The Cerebral Cortex, - - - - - - 287-320

CHAPTER XXIII.

The Organs of Special Sexse; The Taste Buds; The Organs of Smell; The Eye; THE EAR, - " - - - . - - - . - 321-360 


\section{BOOIX I.}

DESCRIPTIVE HISTOLOGY. 



\section{PAR'T I.}

THE CELI AND THE TISSUES. 



\section{CHAPTER I. \\ INTRODUCTORY.}

Histology is the science that treats of tissues; their structure, their components, their development and modification, and their arrangement to form the organs of the body. We may distinguish between Animal and Vegetable and between Normal and Pathological Histology, as well as between Human and Comparative Histology; expressions which define themselves. As the term Histology is most commonly used in medical literature it signifies the normal histology of man.

In its most limited sense the term Histology is applied to the description of the tissues alone. This description is also sometimes called General Histology. The discussion of the arrangement of the tissues to form the organs of the body is distinguished as Histological Anatomy; or, (less appropriately) Physiological Anatomy.

A Tissue may be defined as a mass of similar structural elements (cells or cell-derivatives) having similar properties and functions; together with such substances as are characteristically present between the elements (and are, as a rule, formed by their action), serving to unite them together. 
This definition, while true of the great majority of tissues, cannot be universally applied in a literal sense. There are some tissues (e. g., adenoid tissue) regularly involving more than one kind of element. Such may with propriety be called Compound Tissues.

The combination of tissues gives rise to organs of definite structure and function; and, conversely, every organ is ultimately resolvable into its component tissues. There are, however, certain tissue-aggregates which, while themselves entitled to be regarded as organs, sustain a similar relation to the structure of the larger and more complex bodies to which that term is applied as do the tiśsues themselves. Among such are the smaller blood and lymph vessels, small glands, adenoid masses, etc. The consideration of these compound factors of structure may properly accompany that of the tissues.

There also occur in the body substances (notably the blood) which, while they lack that coherence properly associated with the idea of a tissue, contain cellular or corpuscular elements analogous to those forming the basis of tissue-structure. While they can hardly be classed as tissues, their study is clearly within the province of Histology.

The cells (or, more strictly, the corpuscles) to which reference has been made, although of exceedingly various form and size, are fundamentally similar in that each is a mass of (more or less modified) protoplasm provided for a 
portion if not the whole of its life with a nucleus. In some cases the outer layer of the protoplasm gives rise to or is modified to form a more or less well-defined membrane or wall of varying composition, thus forming a true cell; but the constant presence of a cell-wall of definite and approximately uniform composition characteristic of the tissue elements of plants cannot be affirmed of those of animals, the converse being more generally true.

The study of cells as living beings, their internal structure, activities and life-histories, or Cytology, is an important and rapidly growing branch of Biology. We are here concerned with them as components of the tissues and with their structure and activities as related thereto. Such discussion thereof as this implies, while it logically precedes an account of the tissues, is on the whole best deferred until some practical familiarity with them and with the elements that compose them has been acquired.

It is sufficient at this time to state that the term protoplasm is applied to what has until recently been regarded as one substance, of exceedingly complex chemical composition and apparently devoid of structure; clear or slightly granular in appearance under ordinary powers of the microscope; and viscid or semi-solid in consistency: improved methods and appliances of research have, however, shown that it is neither homogencous nor structureless. It is the seat of the processes which make up physical life; and it and its products compose the living body, which in its earliest stages consists of a number of apparently similar minute nucleated masses of protoplasm 
(embryonic cells): the specialization in each of these masses of some one function, and the associated modification in the form of the mass and of its solid products, if any, give rise to tissue-differentiation.

The nucleus is a body usually spheroidal in form, both physically and optically denser than the protoplasm by which it is surrounded. It is 'clearly seen, even with ordinary microscopes, to be more complex in structure than the latter: a nuclear membrane, a more or less definite intranuclear network, and occasional granules, the largest of which, when distinctly spheroidal in form, are known as nucleoli, being in many cases readily discernible. During cell-multiplication the nucleus is the seat of important changes, which will be discussed in a subsequent chapter, together with its structure and that of the surrounding protoplasm.

While we may recognize a large number of tissue-elements differing from each other in form and size, as, of course, in function, they can all be included in a very few primary groups, as follows.

Epithelial, those lining or investing a free surface.

Skeletal, those forming an investing, supporting or protective framework for an organ or for the whole body.

Contracilile or Muscular, those producing by their combined action definite movements.

Irritable or Nervous, those acting as reservoirs of energy, or as channels for its discharge, or as receivers and distributors of stimuli.

Reproductive (modified epithelial) elements. 


\section{CHAPTER II.}

THE EPITHELIA.

Epithelium may be defined as a continuous layer of cells always (a) disposed on a free surface; (b) united by an intercellular cement substance; (e) devoid of blood-ressels, though not necessarily of nerve-terminals.

Epithelium of one or another form is normally present on all free surfaces, save some of those known as synovial; it invests the skin and the mucous membranes with their various diverticula, lines the cavities of the nervous axis, occurs in the organs of special sense, in the cavities of the thyroid and similar bodies, and (as endothelium) lines the serous surfaces and the carities of the heart and vessels. There are also found in the structure of various solid organs (e. g., the thymus) masses of cells, which, while they no longer line free surfaces, are evidently epithelial in character, comparative and embryological studies demonstrating their epithelial origin. The same may be said of the cells which compose the greater portion of the substance of the liver.

The reproductive elements have already been mentioned as epithelial in origin. They are derived from epithelial layers by processes diametrically opposed in character; those of the male being set free from the layer in which 
they are formed, those of the female sinking (for a time) into the subjacent tissues. Further consideration of their formation will be deferred until the discussion of the organs in which they occur.

The classification of the epithelia is based on the form, arrangement, or special modification of some or all of the constituent cells.

As regards the form of the cells, epithelia may be

A. Flattened, with flattened nuclei, comprising

1. Squamous; flattened or scale-like, with bevelled edges; if with vertical borders, then more properly known as

2. Pavement; having the form and disposition of tiles. The terms squamous and pavement are often confounded; they are here used to distinguish clearly recognizable differences of form.

B. Isodiametric, or with nearly equal dimensions in various directions, the nuclei centrai and spherical or nearly so. Known as

3. Polyhedral; also called Cuboidal, Spheroidal, and, from its most frequent occurrence, Glandular; where found on curved surfaces the cells are not unfrequently wedge-shaped or pyramidal through compression.

C. Vertically elongated; the nucleus undergoing a similar change of form, and in some cases situated nearer the base than the free end of the cell. Termed

4. Columnar: the various modifications of form may be distinguished as cylindrical, prismatic, club-shaped, etc. 
As regards the arrangement of cells, epithelia may be

1. Simple; composed of a single layer of patrement, cuboidal, or columnar cells.

2. Transitional; composed of a layer a few cells in depth, the constituent cells varying but slightly in form.

3. Stratified: several cells deep, and more or less distinctly definable into layers. called Stratified Squamous or Stratified Columnar, according to the form of the most superficial cells.

There are numerous special modifications of epithelial cells occurring in particular localities, as in the organs of special sense: such will be described in their proper connections. Of more general occurrence are the following:

A. Ciliated epithelium; usually columnar, occasionally cuboidal, rarely flattened; the free surface of the cell is beset with hair-like or lash-like prolongations of its protoplasm (cilia), capable of vigorous flexion in one direction.

B. Goblet-cells: Columnar (rarely polyhedral) mucussecreting cells in which the undissolved mucigen accumulates in the distal extremity of the cell, forming a viscid transparent mass, while the protoplasm, together with the contained nucleus, is crowded down to the base of the cell. The extremity of the cell is finally forced off by the escaping mucigen, leaving a chalice-shaped structure.

C. Prickle-cells: the polyhedral cells in the deeper portion of stratified squamous epithelium have their surfaces beset with fine immobile processes (prickles) connecting adjacent cells; the latter being separated from each other 
by intercellular spaces and channels. By some these processes are regarded as continuations of the protoplasm, by others of the modified surface of the cell. They will be discussed more fully in connection with the skin.

The term Endothelium is applied to the pavement epithelium lining the vascular, serous and to some extent the synovial surfaces. Embryological considerations led the earlier histologists to regard it as quite distinct in origin from other epithelia; more extended knowledge has shown this distinction to be doubtful, and some have urged that the use of the term endothelium should be abandoned altogether. There are reasons why it appears to be well to retain the term with the significance above indicated: as thus applied, it can also be defined as a layer of connective tissue cells on a free surface, a definition that will receive further consideration in another chapter.

Serous endothelium, when viewed from above, presents a mosaic of polygons whose various dimensions are nearly equal, and whose boundary lines are straight and short. Vascular endothelium is made up of cells elongated in the direction of the vessel which they line, and tapering at each extremity. The boundary lines are long and sinuous.

The terms epithelioid and (more commonly) endothelioid are applied to layers of connective tissue-corpuscles which resemble epithelium in their regularity, but are not found upon a free surface. The description of these layers does not, however, properly belong to the discussion of the epithelia. 
The statements above made concerning the form and arrangement of epithelial cells are purposely quite general in claracter: it will readily be understood that within the groups indicated we may have great varicty of detail, the epithelia of different localities having in almost all cases their own individual characteristics, by which they can in many instances be clearly iclentified, as will be pointed out from time to time in the discussion of the organs containing them. It should also be clearly understood that the differences in form described are separated by no hard and fast lines; flattened, isodiametric, and elongated cells passing into each other by gradations at times so slight that it is often difficult if not impossible to say of a particular cell whether, for instance, it should be termed columnar or polyhedral; and the continuation of the same simple layer affording in some instances examples of each in turn of the three fundamental forms.

As regards the arrangement of the cells, epithelia can never be said to pass into each other so gradually, since a layer of cells must always be either one cell deep or more than one cell deep. The alternative is usually between a simple epithelium and one composed of more or less distinct strata, the cells on the surface differing markedly from those at the base: an arrangement transitional between these is usually defined, as stated on a preceding page. Practically the term transitional is by most histologists applied only to the epithelium, peculiar alike in structure and function, which lines the urinary tract, in connection with which it will be discussed. 
The various epithelia of the body are of exceedingly diverse embryonic origin, as will be pointed out in a subsequent chapter: but however diverse their origin, and however much they may differ in the form and arrangement of the elements of the adult structure, they in each case originate as a single layer of isodiametric cells resting upon the subjacent membrane or its precursor. Their subsequent multiplication, if by cleavage in a vertical plane only, gives rise to a simple layer of polyhedral, or, by lateral pressure, columnar cells: if cleavages occur also in a horizontal direction, or irregularly, a stratified epithelium is the result.

The power of multiplication is probably retained throughout life by all epithelia: by some, however, it may be manifested at times only as a process of repair, or, if normally constant, may proceed but slowly: by others, however, the constant and more or less rapid production of new cells is a part of its chief function. This is notably the case with the stratified squamous epithelia, whose outermost cells are continually being discharged from the surface, either by exfoliation or by their union to form such solid masses as the hairs and the nails. 
CHAPTER III.

TIE, CARTILAGE GROUP.

The presence of an intercellular cement-substance has been mentioned as characteristic of the structure of the epithelia: this substance, is, however, always small in quantity, and may or may not be the product of the activity of the cells themselves. Where the epithelial elenents give rise to formed products of any considerable extent, they are either deposited in a solid form as a direet investment of the cell itself (e. $g$., the keratin layer forming the wall of a squamous cell from the outer surface of a stratified epithelium), or are discharged on the free surface as secretions either in a semi-solid form (e. $g$., the mucigen of the goblet cells), or as a more complete solution (e. $g$, the products of most glands).

The tissues of the group now to be considered, on the other hand, have it as their chief if not as their sole conmon characteristic that, however much they may differ in appearance and consistency (from transparent, colorless, almost semi-fluid gelatinous tissue to hard, white, opaque dentine), they consist in every case of cells or corpuscles, which, as their chief activity, give rise to a relatively large amount of formed products deposited as an intercellular matrix. 
The matrix thus formed is at first of slight consistency, and homogeneous in structure. It may become strengthened by subsequent direct modification in density and tenacity; by calcification, lamination, or fibrillation; or by various combinations of these methods. The various changes in the structure of the matrix thus produced, with the concomitant changes in the form, number and arrangement of the corpuscles, give rise to a variety of tissues which have an essential community of function directly associated with their fundamental community of structure. The former is illustrated by the facts of comparative anatomy, which show that these tissues replace each other to a very great extent in different vertebrates; and the latter by the substitutions and adventitious growths that occur abnormally in the human body. As will readily be supposed, they have a common embryonic origin.

The term Skeletal Tissues is here applied to the members of this group because of their chief function. They are the framework tissues of the body, investing and penetrating every organ, and supporting and protecting every other tissue. On account of their continuity, and the part they play in binding the organs of the body to each other they are also widely known as the Connective Tissues; a term, however, more appropriately used in its original significance, as applied to one of the principal divisions of the group.

As will be readily inferred from what has already been stated, the classification of the skeletal tissues is based in part on differences in the form and disposition of the cor- 
puscles, and in part on differences in the structure of the matrix. It is characteristic of the group ats a whole that the corpuscles tend to branch irregularly and to remain or become united by the prolongation of their branches into more or less extensive protoplasmic networks whose nodes are the nucleated bodies of the corpuscles. It is within the meshes of this network that the matrix, whether simile or complex in structure, is deposited.

While, however, the branching and intercommunication of the corpuscles just mentioned is shown by the evidence alike of comparative anatomy, of embryology, and of pathology to be characteristic of each of the skeletal tissues in some animals or in some stages and conditions, we find in the healthy adult body of man and the mammals generally differences in this and associated respects which divide the tissues in question into two principal groups quite sharply distinguished from each other as regards the primary structure of the forms included in each, although in some cases the two types are secondarily intermingled.

In the first, or Cartilage Group, the corpuscles, which are always of one kind only, (fixed corpuscles) are usually either spheroidal in form, or, as the result of pressure, polyhedral or flattened: in either case, however, they are simple in outline; and are isolated or at least disconnected: in rare cases they are sparingly branched and connected. The matrix is firm, elastic, primarily homogeneous and finely granular, apparenty structureless (though some facts indicate an internal structure not yet clearly demonstrated): whether more or less dense, it is 
always permeable by diffusion to the nutrient plasma on which the corpuscles depend for sustena ice, lymph-channels being absent (or very doubtfully present), and a regularblood-supply wanting, although large masses are sometimes sparingly penetrated by blood-ressels: it is sometimes secondarily reinforced by the intermingling of fibrous bundles, or the deposition of lime salts.

According to the extent to which the matrix is dereloped, and, to the character of its reïnforcement, when this occurs, the various members of the cartilage group may be classified as follows:

A. Matrix simple, or not reïnforced by fibres :

1. Cellular Cartilage: Matrix very scanty, consisting only of thin layers deposited around the corpuscles, which are numerous and relatively large: sometimes called parenchymatous cartilage from its resemblance to the parenchyma of plants: occurs in the embryos of man and many vertebrates and in the auricular cartilages of small mammals, as well as elsewhere in the permanent skeleton of some of the lower vertebrates.

2. Hyaline Cartilage: Matrix abundant, though varying in quantity, the corpuscles solitary or gathered into small groups as the result of recent subdivisions: translucent, white or bluish-white in color, brittle, firm and elastic: the typical form of cartilage. Occurs in the encrusting cartilages of all freely movable joints (the corpuscles in them being numerous, small and near the surface flattened vertically); in the laryngeal cartilages, with two 
exceptions to be noted later; in the nasal, costal, tracheal and bronchial cartilages; and in nearl! all toetal cartilages.

3. Calcified Cartilage: Hyaline cartilage is frequently reinforced in old age, both in man and in the mammals generally, by the regular deposition in the matrix of nodules of lime salts. This process occurs regularly in some of the lower vertebrates to such an extent as to give rise to a tissue almost bonelike in density and forming the principal framework of the body.

B. Matrix reinforced by the intermingling with it in smaller or larger proportions of fibrous bundles:

4. Reticular Cartilage: Matrix continuous, penetrated irregularly by a network of rellow elastic fibres; the corpuscles relatively large and near together, approaching cellular cartilage in this respect. Occurs where great flexibility and toughness combined with elasticity arecalled for; in the cartilages of the external ear, in the Eustachian tube, in the epiglottis and in the cartilages of Wrisberg and of Santorini in the larynx. On account of its color and structure this tissue is sometimes spoken of as yellow fibro-cartilage, and on account of its physical properties as elastic cartilage.

5. Fibro-Cartilage proper: Matrix largely replaced by bundles of white fibres; the corpuscles small and few in number, resembling those of hyaline cartilage in appearance. Occurs where great tenacity combined with elasticity and moderate flexi- 
bility are needed; in the intervertebral disks, in interarticular masses, at the margins of ball-andsocket joints, in the sacro-iliac articulations, in the symphysis pubis. As distinguished from the preceding it is sometimes termed white fibro-cartilage.

Fibro-cartilage may also be described as consisting of masses of interwoven bundles of fibrous tissue with small nodules of hyaline cartilage interspersed sparingly in the meshes. So considered, it may be regarded as a mixture of fibrous and cartilage tissues.

Cartilage always originates as a mass of contiguous spheroidal or polyhedral cells. As development proceeds the cells are seen to be separated by thin layers of a colorless substance, which is formed by the deposition about each cell of a layer of matrix substance known as the capsule of the cell; cellular cartilage never proceeds beyond this stage: in the case of hyaline cartilage the matrix substance accumulates between the capsules by external deposition, or else is formed by the gradual transformation and removal of the capsules. Reticular cartilage is always pre-formed as hyaline cartilage, the elastic fibres afterwards appearing in the matrix. In fibro-cartilage the cartilaginous substance and the fibrous tissue are said to appear simultancously.

Cartilage grows by cell-division, which can without difficulty be seen to have been in progress during life in any good section of hyaline cartilage, the corpuscles being 
found in groups of two, four or more, so related as to clearly indicate their recent origin: in some instances two cells each with a proper capsule can be found within the capsule of the cell from whose division they were devired. Such interstitial growth doubtless proceeds more rapidly in most cases near the surface than in the deeper portions of the cartilage: it may suffice merely for the constant renewal of the tissue, or may proceed with sufficient rapidity to give rise to actual increase in size. Growth in this sense is beliered by some to take place chiefly by apposition: that is by the deposition upon the surface of new cartilage substance.

It is customary to mention in connection with the description of cartilage that the matrix consists chicfly of a substance frequently" called chondrogen, and said to vield chondrin on boiling; the latter is defined as a nember of the gelatin group of compounds. Gelatin is itself obtained chiefly by boiling the fibrous tissues, which are rich in its antecedent, collagen. By some chemists the matrix of cartilage is regarded as also consisting largely of collatgen, the so-called chondrin being regarded as only an impure or slighty modified gelatin. The matter is one that has no direct bearing "1pon the structure of the tissues in question (as far as our present knowledge goes) but it is well for the student to understand what is meant by the terms mentioned.

A cartilage, in the anatomical sense of the word, is an organ: that is to say, a particular part of the body haying a definite form and function. As such, its description 
might with propriety be deferred to the second part of this book: in the case of this, however, as of some other organs consisting chiefly (though not solely) of a single tissue, it will be for various reasons desirable to discuss its structure in connection with that of its prevalent tissue.

A cartilage, then, may be defined as a mass of cartilage tissue having a definite and regular form. It is, especially where composed of hyaline, calcified, or reticular cartilage, usually covered by the perichondrium, a thin fibrous membrane moderately rich in blood vessels, which are the sole or chief source of nutriment for the mass : the elastic fibres of reticular cartilage are continuous with this membrane. A cartilage is always devoid of bloodvessels, though large cartilages are sometimes excavated by spaces of greater or less extent, through which bloodvessels pass, accompanied by lymph-vessels and sometimes by fat, forming what is sometimes termed a "cartilage marrow." It is always devoid of nerves and insensitive to pain. 


\section{CHAPTER IV.}

THE FIIROIS TISSUES.

In the second of the two groups of skeletal tissues above indicated, the Fibrous Tissue Group, in addition to the corpuscles primarily associated with the formation of the tissue and permanently located in it (hence called fixed corpuscles), there may be present, in some members of the group at least, characteristic accessory or adventitious corpuscles of various kinds. The fixed corpuscles are always irregular in form, with lamellar or filamentous branches, the latter frequently connecting with similar processes from adjacent cells, thus forming a more or less continuous network. The matrix is always homogencous, transparent and yielding in the embryonic state, but very early becomes penetrated by fine fibrillae running irregularly in various directions: the fibrillation is in most eases extensive, the matrix finally consisting ehiefly of a mass of fibres variously disposed in bundles, in more or less closely felted layers, or in clearly defined laminac. In some cases the fibrillation of the matrix is regularly followed by ealcification.

The number of tissues which agree in having the general structure indicated as eliaracteristic of the Fibrous Tissue group is larger than that of all the other tissues of the 
body put together. Three of them, namely, corneal tissue, bone tissue and dentine, resemble each other and differ from all the rest in the fact that the fibres formed by the union of the fibrillae are always very minute and are closely felted together to form definite lamellae between which or exterior to which the fixed corpuscles are situated: the first of these is remarkable for its extreme transparency; the other two are normally and extensively calcified, forming tissues of great density and firmness. Their further description will best be deferred to a subsequent chapter.

The remaining members of the group constitute the Fibrous Tissues proper or the Connective Tissues in the more limited sense in which the term may best be used. Of these one is chiefly if not entirely embryonic, existing in the adult human body only in an extremely modified form. As it is an essential constituent of an important foetal structure, it merits a description as a distinct form of connective tissue: and since it is the precursor of most of the others, its discussion may properly precede their classification and description.

Mucous Tissue (or, as it is also called, gelatinous tissue): the matrix is at first homogeneous, transparent and semi-fluid in consistency; it is described as albuminous in composition, with the addition of mucin : fibres very early begin to appear in it, their mode of formation being not yet fully determined: the fixed corpuscles are irregular, branching, connected by their slender processes into a network: in addition there are to be seen here and there in the"matrix scattered isolated corpuscles which in the fresh 
tissue may be seen to move through the jelly-like substance with an irregular or amoeboid motion; these are the migratory. corpuscles or leucocytes which, as we shall see, are eharacteristic of the connective tissues as a group. Mucous tissue constitutes an important factor of the umbilical cord, where it forms, under the name of the jelly of Wharton, the largest portion of the mass lying between the epithelinm upon the surface and the blood vessels in the centre, ip to the fifth month; later the fibrillation' which has already begun about the ressels and near the surface penetrates the whole mass more and more extensively: but a certain amount of sparingly fibrillated nucous tissue always persists. While mucous tissue is a freqient constituent of the skeletal framewrork some of the lower animals, it is represented in the adult human body (save as a constituent of morbid growths) by the following structures, if at all.

The vitreous body (or so-called vitreous humor) of the eye may best be regarded as a modified form of mucous tissue. In the embryo it possesses for a time all the characteristics of that structure; but in the adult the matrix undergoes watery degeneration, and fibres are extremely rare: fixed corpuscles are altogether wanting, the only corpuseular elements present being a few leucocytes. The centre of the intervertebral dises of fibro-cartilage contáins a soft and yielding mass sometimes regarded as a form of mucous tissue: it lacks, however, some of the essential features of that structure and may best be regarded as the remains of the notochord, the embryonic precursor of the vertebral colımn, which, while it differs 
in some respects from cellular cartilage, approaches more nearly to it than to mucous tissue as here defined. The pulp of the teeth also consists in part of a modified form of gelatinous tissue, which will be more fully described in connection with those organs.

Passing now to the consideration of the fibrous tissues proper, as defined by the limitations recently indicated, it is important to note at the outset that the fibres which in every case enter so largely into their composition are of two kinds, both of which are present in most of the tissues in question, though their proportions may vary exceedingly; the characters of the tissues included in the group being in great measure based upon the proportion of the two kinds of fibres, and the modes of their disposition. These are known respectively as white fibres and yellow or elastic fibres.

The former are exceedingly delicate unbranching filaments of collagen (which, as has been stated, is convertible into gelatin by boiling), rarely more than a micron in diameter, and often much less; they are almost always united into bundles of varying size; when so united the fibres have a silky appearance, and tend to assume a characteristic waviness in which all the fibres of the bundle participate in such manner as to retain their almost strictly parallel arrangement: the bundles are again frequently united together in larger aggregates sometimes termed trabeculae: white fibres are very tenacious and entirely devoid of elasticity.

The elastic fibres are coarser than the white and more variable in thickness, being from one to six micra in diam- 
eter in man, and in some animals as much as fifteen micra: they are prismatic in form, and under some circumstances appear to be transversely striated: they branch occasionally, and not unfrequently anastomose: when not on the stretch they tend to assume large sweeping curves, and the free ends, which break square across, curl up in a characteristic manner: like the white fibres, they are often associated in bundles. They are, as their name implies, eminently elastic, but are of only moderate tenacity, a bundle of them being far more easily broken across than a bundle of white fibres of the same size. They are composed of a substance known as elastin, a complex nitrogenous compound which is not converted into gelatin on boiling. The elastic fibres are not readily affected by weak acids, as are the white fibres.

But little is as yet known of the mode of formation of either kind of fibres. It is by some held that they are in all cases formed by the transformation of a portion of the protoplasm of embryonic cells, the remainders of which, either with or without subsequent increase in size, become the fixed corpuscles of the tissue in which they are found; this view, however, is urged not so much on account of observations directly supporting it as of the conviction on the part of its most positive adherents that the entire living body consists and must consist only of protoplasm and the immediate products of protoplasmic changes: there are, moreover, some facts very difficult of explanation from this standpoint. On the other hand, it is claimed that fibrillation may and does result from a chemical and physical change in a part of the homogeneous ground- 
substance of the matrix along lines not in actual contact with any mass of protoplasm; although it is freely admitted that the proximity of such masses (the corpuscles) may have a decided influence in initiating and determining such a process. In the case of the elastic fibres, there is good reason for the view (first proposed by Ranvier) that the elastin is deposited in the matrix in the form of small globules, which later fuse together to form fibres: this, if true, will account for the transverse striation already mentioned.

The corpuscles of the fibrous tissues also demand preliminary consideration. It has already been indicated that each tissue is characterized by the presence of a specific form of fixed corpuscle peculiar to it; in the case of mucous tissue the presence of migratory corpuscles, or, as they are very frequently termed, leucocytes has been mentioned as a feature in which this tissue may be taken as a type of the group: and reference has been made to other accessory or adventitious corpuscles. The fixed corpuscles proper to each tissue may best be described in connection with its definition: the nature and origin of leucocytes will be considered later in connection with the description of the lymph and the blood: the accessory corpuscles now call for discussion. They are often spoken of as modified fixed corpuscles: but while one form is certainly and others are possibly derived from these bodies, there is reason to question whether those of one (if not of more than one) kind are not modified leucocytes: omitting further discussion of their origin (save in one instance) they may be described as follows. 
What are known as fat cells are formed by the fatty transformation of the protoplasm of ecrtain of the fixed corpuscles of one or more of the fibrous tissues: small droplets of oil at first appear scattered in the cell-body; these become more numerous or larger, finally fusing in one large mass, the nucleus being crowded to one side, and the residual protoplasm forming a thin pellicle or cell-wall.

Under the name of plasma cells are included eertain corpuseles having elongated and sometimes slightly branching bodies with central oval nuclei, the protoplasm of which contains a large number of small vacuoles (of varying size) which contain a clear fluid probably similar in composition to the lymph or blood-plasma, whence the name of these corpuscles.

Plasma cells were first deseribed by Waldeyer. He included under that term not only vacuolated cells, but also what are now known as granule cells: these are usually spheroidal in form and devoid of branches; their protoplasm is highly granular: on account of the marked affinity of the granules for cosin (as well as for many aniline dyes) they are sometimes termed eosinophile cells; the same term has been otherwise applied in connection with the blood, as will be indicated later.

The name of pigment cells has been given to connective tissue corpuscles (and to some epithelial cells as well) characterized by the presence in their protoplasm of numerous rounded brown or black granules of a substance termed melanin. Pigment cells are of very irregular form, commonly branched, and often exhibiting amoeboid motion when examined in a living condition: the pigment 
granules are often so numerous and so closely packed that the nucleus and other structural features are entirely hidden; in some cases, however, they are much less abundant.

The following classification of the fibrous tissues is based upon the general disposition of the fibres present, their abundance, the proportionate anount of the two kinds of fibres, the details of their distribution, and on the kinds and relative quantities of the associated corpuscles.

A. Fibres varying in abundance, solitary or aggregated into bundles and trabeculae running irregularly in various directions, loosely interwoven or more or less closely felted together.

1. Areolar Tissue: called by the older histologists cellular tissue: found beneath the fibrous layer of the skin as subcutaneous, beneath the mucous membranes as submucous, and the serous membranes as subserous, in the interspaces between adjacent organs as intermediate, upon their surfaces as investing and forming their internal framework as penetrating areolar tissue, it is well nigh continuous throughout the entire body and merits in the strictest sense the name of connective tissue. The matrix consists in part of a semi-solid homogeneous ground-substance, penetrated in every direction by interlacing bundles and trabeculae of white fibres and by elastic fibres either solitary or in bundles: the bundles of fibres may vary greatly both in their total amount and in the proportion of the two varieties; but they are never so numerous but that irregular spaces of varying 
A. Fibres varying in quantity, loosely interwoven, or lelted (continued).

size termed areolae occur in so great numbers as to be practically continuous; a fact of great importance in the history of dropsical and other effusions. The whole structure is penetrated by blood vessels, lymphaties, and by nerves passing through it: it is colorless or whitish, filmy in texture and of but slight tenacity.

The fixed corpuscles, or areolar tissue corpuseles proper, are quite numerous: they are frequently flattened upon the surface of bundles of fibres or. situated in the angles where two or more bundles come together, in either case the processes extending along the bundles and their subdivisions: leucocytes are of frequent occurrence: plasma cells and granule cells less so, except in particular localitics. Pigment cells are not common in areolar tissue proper in the human hody except in certain places: fat-cells are very common here and there in the areolar tissue of well nourished individuals: where they accumulate in particular localitics they give rise to

2. Adipose Tissue: this, which may under favorable conditions be formed wherever areolar tissue occurs, but which is most common in connection with the subcutaneous, subserous, and intermediate regions, is in effect little else than areolar tissue in which the fixed corpuseles in particular localities become greatly increased in number, filling 
A. Fibres varying in quantity, loosely interwoven or felted (continued).

up the areolae, and undergo fatty transformation, giving rise to small fat lobules which are gathered together to form the fat masses visible to the naked eye: the blood supply of these localities is always greatly increased, each lobule having a capillary system of its own, while the fibres between the corpuscles undergo no corresponding increase in number, and in some cases are exceedingly scanty.

3. Retiform Tissue, or, as it is also called, reticular tissue: this, as its name implies, consists chiefly of a network of fibres, or rather of fibre bundles and trabeculae composed chiefly of what are in all probability most nearly allied to white fibres; true elastic fibres are very sparingly present or are wanting altogether, as is the homogeneous ground substance characteristic of areolar tissue. The fixed corpuscles are flattened, adhering closely to the surfaces of the bundles and trabeculae, and are often so numerous as to form an endothelioid investment. Retiform tissue may perhaps be regarded as a modification in the direction of greater stability of areolar tissue (with which it is often directly continuous), and forms the internal framework of some organs, as well as the basis of the two compound tissues known respectively as adenoid tissue and marrow. The former of these will be described in connection with the lymphatic system, and the latter in connection with bone. 
A. Fibres varying in quantity, loosely interwoven, or felted (continued).

4. Fibrous Membrane: this differs from areolar tissue chiefly in the fact that the bundles and trabeculae of fibres, both white and elastic, are far more numerous and elosely felted together, obliterating the areolac and leaving small space for the interfascicular ground substance: the fixed corpuscles are quite numerous, but are, as a rule, smaller than those of areolar tissue, and, with their nuelei, generally flattened in the direction of the membrane in which they lie; both plasma and granule cells may be occasionally present, and in some cases pigment cells occur in great numbers : fat cells but rarcly.

The principal membranous tracts of the body (e. g., the mucous membranes) which support epithelial or endothelial layers are sometimes more or less clearly divisible into a stroma, which makes up by far the greatest part of the layer, and a delicate film situated just beneath the epithelium and known as the basement membrane, or membrana propria; this is sometimes an endothelioid layer of corpuscles, and in other instances a special condensation of the fibres, either white or elastic. Such differentiation does not occur in those investing membranes such as the perichondrium already referred to in connection with cartilages, the similar periosteum of bones, etc., which are not associated with a free surface. Elastic membranes consist 
A. Fibres varying in quantity, loosely interwoven, or felted (continued).

chiefly or entirely of elastic fibres, or, in some cases, of continuous layers of elastin.

5. Fenestrated membrane: this form of membrane is produced where, in an otherwise normally formed fibrous membrane, there are at intervals of greater or less extent neither fibre bundles nor ground-substance, thus leaving rounded openings of various size and frequency, as in the omentum of man and of numerous mammals. Fenestrated membranes may also consist chiefly, if not entirely, of elastic tissue, in which the fibrous structure at times disappears in great measure, as in the fenestrated elastic membranes of the blood vessels.

B. Fibres exceedingly abundant, one or the other kind predominating, aggregated into smaller and larger bundles, which are in a generally way disposed parallelwise: ground-substance very scanty. Fixed corpuscles few, flattened between the bundles of fibres.

6. Tendon tissue or white fibrous tissue: as areolar tissue merits in the strictest sense the name of connective tissue, so this, above all others, merits that of fibrous tissue. It consists almost exclusively of white fibres: these are united together in small bundles by a small quantity of groundsubstance, each being covered by an endothelioid layer of flattened corpuscles: the smaller bundles are gathered together with occasional anastomo- 
B. Fibres abundant, chiefly of one kind, in parallel bundles (continued).

ses into larger ones of varying size, which are sep)arated by interstitial areolar tissue continuous with the investing sheath of the whole mass: elastic fibres are very sparingly present, chiefly in the penetrating areolar tissue. The characteristic fixed corpuscles or tendon cells are generally found in rows which occupy the spaces between two or three contiguous bundles, their branches taking the form of interfascicular lamellac: leucocytes are rarely present, and other forms of corpuscles are wanting. Blood vessels and lymphatics, and, in some cases at least, nerve fibres follow the interstitial areolar tissue. White fibrous tissue is found in tendons and ligaments and also in tendinous aponeuroses and fasciae, which form a transition to fascicular investing membranes.

7. Elastic tissue: this, as its name implies, is composed chiefly of elastic or yellow fibres, which are arranged in bundles of varying size and complexity, the interstitial connective tissue penetrating not only the larger but also the smaller bundles, and in some cases separating individual fibres: small bundles of white fibres run in the connective tissue in various directions, and in some cases at least there are well defined bundles arranged in groups as in tendon tissue and running throughout the whole length of the structure. Elastic tissue is generally regarded as differing from all other 
B, Fibres abundant, chiefly of one kind, in parallel bundles (continued).

forms of skeletal tissue in having no characteristic fixed corpuscles, none being found in that can with certainty be regarded as such: some authors have described in this connection flattened corpuscles found scattered in the ground-substance between the fibres and in close apposition with the latter; it is not, however, certain that these do not more properly belong with the interstitial connective tissue. The term elastic tissue is by some histologists applied alike to the chief constituent of elastic ligaments (in which sense it is here defined), and to that of elastic membranes.

We may now with profit revert to the definition of endothelium given in a previous chapter, which described it as a layer of connective tissue corpuscles on a free surface. We have seen that the association of corpuscles with fibrous structures is characteristic of the connective tissues: embryological evidence shows that the serous and vascular cavities are alike formed by cleavages or excavations of the mass of embryonic cells from which the skeletal tissues are derived: the tendency of connective-tissue corpuscles to arrange themselves in layers (properly termed endothelioid) has been mentioned in connection with such structures as basement membranes, the investing layers of small tendons and tendon-bundles, etc. : and, as we shall see later, the direct continuity between endothelioid cells and connective tissne corpuscles can be observed 
at the free extremitics of lymphatics and at the margins of synovial surfaces: it can, therefore, be readily understood how connective tissue corpuscles should form a continuous layer under such exceptionally favorable conditions as those found on the free surface of a membrane. Some characteristic activities of the corpuscles found upon serous surfaces will be described in connection with the lymph and the blood.

We know at present but little of the duration of any of the fibrous tissues, or, indeed, of the skeletal tissues in general. Consisting largely of the constituents of the matrix, which some histologists regard as formed and in a certain sense not-living substances, it has been held that, once established, they may endure as long as the body lasts. It is possible that this is the case, to some extent at least, and that the tendon fibres, for example, of our old age are the identical tendon fibres of our childhood: on the other hand, the tendons of the child certainly increase both in thickness and in length toward manhood; and the mechanism by which interstitial increase takes place is certainly adequate for interstitial replacement as well; we have, however, at present no certain evidence of any such mechanism of absorption or removal of wornout fibres (if such there be) as a method of replacement would imply. Whether the matrix of a fibrous tissue is to be regarded as living or not depends entirely on what we mean by a word for which no generally accepted definition has yet been given : it is certain, however, that under certain conditions of defective nutrition such structures 
undergo marked changes to which the name of death is certainly not inappropriate.

These changes are generally regarded as due primarily to the death of the corpuscles: but this merely shifts the problem. It is difficult to conceive that any single nucleated mass of protoplasm should retain its powers unabated for half a century or more; but if it may, what are its probable activities in the case, for example, of a tendon cell? If, on the contrary (as seems more probable), it is constantly renewed, what are the activities of the successive generations? The phenomena of tissue-repair in the case of injuries throw some light on the problem, but it is, on the whole, at present unsolved. It is desirable, however for the student to know of its existence.

Before dismissing the discussion of the fibrous tissues it is proper briefly to mention a form of tissue at first supposed to be a member of this group, and described as a modification of retiform tissue: subsequent investigations have shown, however, that it differs in important respects from any of the trueconnective tissues in structure, and is of widely differing embryonic origin. It is the sustentacular tissue of the brain and spinal cord, and is known at present by the name of neuroglia. It is composed entirely of branching corpuscles and their fibrillar processes, known as glia-cells: their full description can best be given in connection with the nervous tissues with which they are associated. 


\section{CHAPTER $V$.}

THE LAMELLATED TISSUES.

As was stated in the preceding chapter, there are three members of the skeletal tissue group (namely, corneal tissue, bone tissue and dentine), which, like most of the fibrous tissues described in that chapter, are characterized by extensive fibrillation of the matrix, the fibrillae being even more closely intermingled than are those of ordinary membranes: they differ from these structures. however, as already indicated, in the facts that the fibrillae, which are always excedingly fine and resemble most nearly those composing white fibres, are never aggregated into the bundles and trabeculae which are interwoven to form membranes, but are felted togrether to form dense layers, having in each case the characteristic fixed corpuscles situated between them or exterior to them.

These lamellar structures have evidently much in common with and are originally derived from the modification of membranes, as the facts of comparative anatomy and embryology plainly demonstrate (two of them being clearly dermal in origin in man and the lower animals alike): the characters above stated, are, nevertheless, of such importance as to warrant their separate consideration. The name at the head of this chapter is, therefore, 
proposed for the group: but it should always be borne clearly in mind that they are more nearly related to the fibrous tissue group than are either of them to the car-tilages: this is the more important because of the fact that one of them, osseous tissue, largely replaces cartilage in the formation of most of the bones of the body, thus giving rise to the impression that these two tissues are closely allied, and that the latter is in some way transformable into the former, an error which leads to much unnecessary confusion.

The formation of dentine, the most peculiar member of the group, is so intimately related to that of the other tissues of the teeth, (of which it forms the largest part), and especially with that of the pulp contained in the toothcavity that it cannot well be discussed apart from these associated structures: they will be considered together when the teeth are described in connection with the other organs of the region in which they occur.

Since corneal tissue is found only in the structure from which it derives its name, its consideration might in like manner with propriety be deferred until the description of the eye. There are, however, points of resemblance between it and bone tissue which make its study desirable as a preliminary to that of the latter, particularly as the absence of calcification renders far easier the recognition of important details.

The transparent lamellae which form almost its entire bulk are quite uniform in thickness throughout the entire cornea: they are composed of white fibres running parallel 
to each other in each lamella, so disposed that those of one lamella cross those of the next at right angles, or nearly so, in the centre of the cornea; toward the margins they cross at varying legrees of obliquity: the lamellae near the outer surface of the cornea are traversed oblicpuely by occasional bundles of fibres, which thus unite them together. Adjacent lamellae are separated here and there by shallow lens-shaped spaces which occur frequently, but it irregular intervals; these may be designated as lacunae: those lying between the same two lanellate are connected with each other by numerous branching chamnels, which may with equal propriety be termed canaliculi: there is thus formed a continuous system of canals and spaces across the entire cornea between each two lamellae, the lacunac of one such system having no definite relation in position or otherwise to those of the next.

In the lacunae lie the corneal corpuscles, apparently adhering to the surface of one or the other of the two adjacent lamellac. They are flattened, with flattened nuclei, and irregular in outline; they branch freely, the branches extending into the eanaliculi and in many cases connecting with those from adjacent corpuscles, thus forming a protoplasmic network, which is possibly coextensive with the canal-system, but does not completely fill it. The remainder of the space forms a means of distribution of plasma from the blood ressels at the margin of the cornea; leucocytes also wander through the larger canals from lacuna to lacuna. Neither blood vessels nor lymphaties penetrate the substance of the comea, nor are there transverse canals which bring into communication the 
canal-systems separated by the lamellae. The surfaces of the cornea, both anterior and posterior, are invested by membranes in direct contact with the most superficial lamellae; but there is no genetic relationship between the membranes and the lamellae beneath. Farther description of these membranes, and of the epithelia supported by them, will be deferred to a subsequent portion of this work.

It should be stated before leaving the description of corneal tissue that the use of the terms lacunae and canaliculi, as here applied to the corneal spaces and lymph channels, is unusual. It is warranted by the resemblance between these spaces and channels and those occurring in osseous tissue to which these names are commonly applied; and is offered here from the conviction that a clear idea of the resemblances (and also of the differences) of the two tissues will aid materially in a clearer understanding of the structure of the latter.

The terms bone tissue and osseous tissue are applied indifferently to the chief constituent of the organs well known as bones: like all skeletal tissues, it can be defined by the structure of the matrix and the forms and relations of the fixed corpuscles.

The matrix consists of thin lamellac composed in part of fibres (the mode of whose arrangement is not clearly demonstrable), and in part of a homogeneous groundsubstance which is strongly impregnated with lime and other salts, calcium phosphate being the chief. Prolonged boiling converts the fibres into a substance which has been 
called ossein. but which is probably an impure form of gelatin: the fibres are therefore allied to if not identical with white filres.

Between adjacent lamellate are found frequent lenticular spaces of exceedingly irregular outline, the lacunae (formerly erroneously termed the bone-cells); like the similar spaces in corneal tissue, these are comnected together beween the lamellae by branching channels, or canaliculi: in boue, however, such canaliculi are not only present between the lamellae, but also penetrate them in great numbers, thus bringing into free communication lacunac of different systems; the transverse canaliculi in some cases traversing two or more lamellae before their termination. The transverse canaliculi are both larger and more numerous than the interlamellar, in accordance, as will be seen, with the mode of nutrition characteristic of osseous tissue.

Within the lacunae are found the characteristic bone corpuscles: these, like the cavities which contain then, are flattened and irregular in outline, with Hattened nuclei; they can be seen to branch in some cases, but this occurs far less freely than in the case of the corneal corpuscles; nor is there good evidence of the connection of the branche's through the canaliculi to any considerable extent, as has been supposed. Leucocytes do not traverse the lymph channels of bone, nor are any other corpuscles present.

The lamellated and calcified fibrous matrix, with its characteristic lacunae and canaliculi, and the enclosed corpuscles, are the essential structural factors of osseous tissue wherever found: and in some of the lower vertebrates 
bones occur which consist simply of a few parallel lamellae. In man and the higher animals, however, these factors are always arranged in one of two methods which are so constant as to constitute two distinct forms of osseous tissue called respectively dense and spongy bone.

In the former the great majority of the lamellae are arranged concentrically to narrow tubular spaces known as Haversian canals; these contain blood vessels, lymphatics and a small quantity of another tissue presently to be described; they are of varying length, running in a general way parallel to the surface of the mass in which they occur, and anastomosing frequently: Each is surrounded by several lamellae whose lacunae are put into communication with it by means of transverse canaliculi. A Haversian canal and its surrounding lamellae constitute a $\mathbf{H a -}$ versian system. In the irregular spaces between the Haversian systems of dense bone are found discontinuous lamellae also as a rule lying in a general way parallel to the surface of the mass: these are known as interstitial lamellae; and beneath the outer surface are always found more or fewer lamellae parallel therewith and exterior to the Haversian systems : these are known as circumferential lamellae.

The circumferential lamellae in all large masses of dense bone are pierced here and there by oblique canals for blood ressels, etc., which communicate with the Haversion canals, but differ from them in having no surrounding lamellae: these are known as Volkmann's canals. They are also penetrated transversely by bundles of white fibres (which have undergone calcification) proceed- 
ing from without inwards, and by occasional bundles of elastic fibres. The name of Sharpey's fibres is applierl to both, but more especially to the former. Dense bone constitutes the shafts of all long bones and forms a layer of varying thickness on the surface of the flat and the short bones.

In spongy bone the structure is more open, as the name implies. The solid portion consists of a meshwork of trabeculae, or bars and plates of varying width and of great irregularity of form, each of which is several lamellae in thickness, the lamellae being in a general way parallel to the surface and the lacunac communicating therewith by means of the transverse canaliculi. The cavities between the trabeculae, which are quite irregular in form and size. are known as Haversian spaces. Spongy bone fills the interior of the short and the flat bones and the ends of the long bones.

Just are cartilage tissue is found in masses of definite form and function (organs), which are known as cartilages, so dense and spongy osseous tissues are combined in the definite masses which, with certain associated tissues, make up the organs well known as bones. As in the case of the cartilages just referred to, so in this instance it will be expedient to describe the organs in connection with the tissues of which they are chiefly composed.

A bone may be defined as a mass of osseous tissue surrounded by a proper investing and genetic membrane known as the periosteum; permeated by blood vessels and lymphatics: and containing the tissue called marrow. 
The periosteum, as found upon the surface of the bones of adult and particularly of elderly individuals, is a thin, tough, closely felted membrane which adheres tenaciously to the structure beneath; it can, nevertheless, be in most cases resolved into two distinct layers. In adolescence, childhood, and notably in foetal life these are clearly distinguishable. The outer or fibrous layer has the structure of an ordinary membrane, the constituent bundles (chiefly of white fibres) being closely interwoven, and the fixed corpuscles flattened, with flattened nuclei: here and there occasional fat cells may be seen, with numerous blood vessels and lymphatics, as well as delicate nerves: the outer surface frequently exhibits extensive areas having an endothelioid investment.

The inner or osteogenetic layer is more loosely felted, and contains a larger proportion of elastic fibres : toward the surface of the osseous tissue it contains numerous corpuscles which (particularly in young bone) are larger and more irregular in form than those of the outer layer; the protoplasm is granular and the nuclei are spheroidal: these are know as osteoblasts, and in youth are directly concerned in the formation of new bone, as their name and that of the layer which includes them implies. In adult bone they become flattened and inactive, forming a layer just without the osseous tissue.

The complex tissue known as marrow fills the internal cavities of all bones: those in the shafts of the long bones are filled with yellow marrow; the Haversian spaces of spongy bone, in most places where it occurs, with red 
marrow: the larger Haversian canals on the inner side of dense bone are lined with a layer of modified marrow, which is prolonged in the smaller canals by a peculiar form of connective tissue containing osteoblasts, and finally continuous on the outer surface with the osteogenetic layer of the periosteum; the narrow, as will be shown later, being originally derived from an ingrowth of that layer. The two kinds of marrow are closely related in structure, the yellow being derived from the modification of the red: the latter will therefore be described first.

The basis of structure of red marrow is a delicate framework of retiform tissue associated with an abundant vascular network, which will be described more fully in another connection: the interstices contain corpuscles of at least three different kinds. Throughout the mass, and particularly near the surface, are the marrow cells, properly so called: these are relatively large, with faintly granular protoplasm and oval nuclei; those upon the surface of the mass have the appearance and perform the function of osteoblasts in young bone. The interior of the marrow contains numerous smaller cells with granular nuclei, to which the name of erythroblasts has been given, on account of the part they play in the formation of colored blood corpuscles: associated with these are great numbers of the immature blood corpuscles themselves; to these the color of the marrow is largely due.

Upon the surface and more rarely in the interior of the marrow are found occasional masses of protoplasm, several times larger than the ordinary marrow cells, best known as giant cells: they were called myeloplaxes by 
Robin, who believed them to be peculiar to marrow; but bodies to all appearances similar to them have since been found in other tissues. It was proposed by Kölliker to call them osteoclasts, from the belief that they were agents in the absorption of bone; where, as sometimes occurs in embryonic bone, the marrow lies in contact with temporary cartilage which has begun to be absorbed, it has been proposed to call them chondroclasts for a similar reason: this view of theirfunction is supported by the fact that they not infrequently (but by no means invariably) lie in little pits or depressions of the surface of the bone or cartilage undergoing absorption: these pits have been called Howship's lacunae or foveolae. Nothing, however, has yet been certainly proven concerning the function of these bodies: the name first given is therefore for the present at least the most desirable.

The giant cells are of two kinds, differing chiefly as to their nuclei. Some show a large number of these bodies ; others have but a single nucleus, which is alvays very large, and frequently of an exceedingly irregular shape: the former are termed multinuclear and the latter uninuclear giant cells. It has been supposed that the former are derived from the latter by the fragmentation of the large irregular nucleus; but Howell has shown that this view is certainly very doubtful and probably erroneous.

From the description given it will be seen that the red marrow is a very important tissue of quite complex function, having important relations not only to the surrounding bone, but also to the elaboration of the blood. The yellow marrow, on the other hand, is, as far as our pres- 
ent knowledge goes, one of the most passive tissues of the borly. It differs from the red marrow, from which it is derived, ehiefly by the facts that the erythroblasts and inmature blood corpuscles arealike wanting, and that the great majority of marrow cells in the interior of the mass have undergone fatty transformation. Cpon and near the surface both marrow cells and giant cells are found.

From the description above given it will be seen that the nutrition of dense bone is maintained hy the ressels of the periostenm directly for the corpuscles of circumferential lamellac, and by the vessels of the Haversian canals for the concentric lamellac, and thus indirectly by the periostem, from which these ressels are deriverl; the periosteum is thus seen to be not only a protective, but also a nutrient investing membrane: this is conspicuously shown by the fact that whenever the periosteum is removed by accident or disease from any considerable area of bone the subjacent osseous tissue perishes. In like manner the corpuscles of lamellac which male up the spicules and trabeculac of spongy bone depend upon the blood vessels of the adjacent marrow for their food supply, the Haversian spaces occupving the same relation to them as the Haversian canals to the concentric lamellae of the lense bone: these spaces are in a certain sense the expansions of the canals, as the nuarrow which they contain is the continuation of their lining, and thus, in a roundabout way, of the inner layer of the periosteum. It is also to be noted that the lamellae in each case depend for their nutrition upon supplies drawn from a surface to which they are 
parallel: the importance of the transverse canaliculi and the reason for their number and extent thus becomes evident.

In speaking of tendon tissue it was stated that while a mechanism of interstitial increase was known to exist, we had no clear evidence of any continuous process of interstitial removal and replacement. The case of bone is different: no one can examine a transverse section of dense bone, and note the manner in which what appear to be recent Haversian systems cut into the territory of what are probably older, and how both the interstitial and the circumferential lamellae are interrupted by both, without the conviction that a process of replacement is involved: and this conviction is confirmed when we compare the cross section of the femur (for example) of a child with that of an adult, into the central marrow space of which it could be thrust, each with its Haversian systems, its interstitial and its circumferential lamellae. Dense bone shows us, however, no tissue in process of removal, and no Haversian systems in process of formation: and the means by which both removal and replacement take place are yet to be discovered. 


\section{CHAPTER VI.}

\section{OSSIFICATION.}

Attention has already been called to the fact that the periosteum is at once an investing and nutrient, and a genetic membrane; and to the terms applied to its inner layer and the corpuscles contained therein. It has also been pointed out that the marrow cells upon and near the surface of the red marrow agree with osteoblasts in form and also in function. The function of an osteoblast may now be briefly stated by saying that it is normal destiny to become a bone corpuscle. Bone is laid down in lamellae by the activity, probably periodical in character, of an osteo* genetic layer, the osteoblasts nearest the lamella just previously formed being enelosed by the new layer of fibrillated and calcified matrix, and thus converted into bone eorpuseles.

It has already been stated and should always be born in mind that the marrow, as will shortly be seen, is a development from the osteogenetic layer of the periosteum: its outer surface, with its layer of osteoblasts, is as truly. alu osteogenetic layer as that from which it is derived: attempts have, indeed, been made to define it as a distinet membrane under the name of the endosteum; but this is unnecessary: and is not advisable, if for no other reason. 
on account of the fact that it cannot be anatomically separated from the tissue below, nor its boundary on that side at all clearly defined.

The formation of osseous tissue by the enclosure of osteoblasts in a fibrillated and calcified matrix is called ossification, wherever it occurs, as, for instance, in the bones of a growing child or young animal. The term is more especially applied, however, to the original formation and early development of bone as it takes place in the embryo. Used in this sense, the name is applied to two processes often regarded as essentially different, and designated respectively as intramembranous ossification, or the development of bone in previously existing connective tissue, and ossification in cartilage, or the development of bone in previously existing cartilage. It is of the highest importance, however, to keep clearly in mind the fact just stated, that bone is always formed in a peculiar kind of connective tissue, the osteogenetic laycr already defined as in every instance derived directly or indirectly from a membrane. Bone is therefore always derived from the modification of a membrane: and the facts of comparative anatomy and of pathology, on the other hand, show that almost any membrane may under certain circumstances become osteogenetic.

The so-called ossification in cartilage, or, as it is often termed (and the expression is still more apt to mislead), the ossification of cartilage, is in reality the replacement of cartilage by bone, the cartilage itself being absorbed and disappearing in great measure before bone formation takes place. It is particularly important to avoid 
the erroneous impression that is sometimes cansed by the expression in question, to the effect that the previously existing cartilage is in some mamer transformed into bone: if this be bornc constantly in mind, there is no objection to the use of the term in either form: nor, with this qualification, to the use of the terms "membrane bone" and "cartilage bone," frequently employed for convenience to designate briefly bones formed respectively in the two methods above defined.

Since bone is to be regarded as the result of a developnent originating in connection with a membrane, we may properly first consider the process of intramembranous ossification: this takes place in the human body and in that of the higher vertebrates generally in a very small number of bones, the great majority of those entering into the structure of the adult skeleton being preceded by cartilage: the tegmental bones of the skull, the squamous portion of the temporal bone, the bones of the face and jaws (excepting a small portion of the lower jaw), and the clavicle are the only bones not so preceded, or, in other words, the only so called membrane bones.

A study of the development in the embryo of any one of these bones gives substantially the following results. The place of the future bone is at first occupied by a mass of embryonic connective tissue not yet possessing the density and structure of membrane, permeated by a network of blood-ressels. At one or more places, known as centres of ossification, bundles of stout fibres are formed, radiating outward from a point midway between the adjacent 
ressels: these, which are known as osteogenetic fibres, resemble white fibres in appearance, but are less distinctly fibrillated: between them, and crowded upon the surfaces of the bundles, are large numbers of connective corpuscles, modified to form osteoblasts. The homogeneous substance which forms their matrix now begins to undergo calcification, the salts being at first deposited in the form of minute globules; as these become more and more numerous, they fuse together forming a continuous and apparently homogenous mass: the osteoblasts imbedded therein becoming the bone corpuscles. and the modified. bundles of fibres becoming spicules of bone.

The formation of new fibres, with their associated corpuscles, continues to go on in advance of calcification at the extremities of the spicules, the tufts of bundles diverging in such manner as to anastomose with those of adjacent spicules, their growth taking such direction as to pass between the meshes of the vascular network. As a result, there is formed a spongy net work of bone interlacing with the network of blood vessels, the interstitial embryonic connective tissue forning the basis of the primary marrow which fills the spaces and in which the blood vessels are imbedded. While this is taking place in the interior of the mass, the embryonic connective tissue upon its surface becomes converted into a well defined laycr of fibrous nembranc, the fibrons layer of the periosteum: from the osteogenetic tissue immediately beneath dense periosteal bone is formed. The ossification thus set up is continued outward from the centre or centres of ossification until the whole territory involved is converted into osseous tissue, 
with the associated periostemm, marow and blood vessels : as the bone increases in thickness new layers of dense bone are deposited by the periosteum, while that first formed is absorbed and replaced by the spongy bone of the interior.

In the replacement of cartilage by bone, or, as it has been sometimes termed, intracartilaginous ossification, blood ressels also play a conspicuous part, as we shall presently see; the centres of ossification in this, as in the preceding case, arising by the development of highly vascular areas of osteogenetic tissue: the formation of these areas and their subsequent extension, known as the vascularization of cartilage, is the immediate preliminary to the deposition of bone. The process is rendered more complex by the fact that the previously existing cartilage must necessarily be removed, at least in great measure, before bone can be deposited in its stead; and the additional fact that the receding cartilage is itself the seat of noteworthy changes which invariably take place, although their direct relation to the formation of bone is by no means clear. It should also be mentioned, before beginning a cletailed discussion of the process in question, that the replacement proper of the cartilage is also accompanied or followed at a very carly stage by its investment with bone formed by the newiy developed periosteum: and that this takes place at the outset in a manner somewhat resembling the process of intramembranous ossification just described; whereas, at a later stage, the formation of dense bone takes place. 
We may, therefore, recognize four distinct and definite stages in the process of intracartilaginous ossification, socalled (to the second of which alone, however, the term is strictly applicable): these stages are in the main successive for any particular point; though all may be in progress at the same time at points adjacent to each other; they are definable as follow's.

The first, which may be called the transformation of cartilage, includes all those changes which take place in that tissue from the first disturbance of its normal condition to its final dissolution in great measure. The second is the development of spongy bone in the spaces formed by the dissolution of the cartilage and upon its remains, or the formation of endochondral bone. The deposition of spongy bone beneath tbe newly developed periosteum as an investment of the endochondral bone and the transforming cartilage is the third: from the position where it occurs this is designated the formation of perichondral bone, or, as it is sometimes called, primary periosteal bone. The fourth and last stage is the formation of dense bone surrounding the perichondral bone, through the continued activity of the periosteum; the transition from the one to the other being in some cases exceedingly gradual.

We may now enter upon a discussion of the changes which take place in the formation of the shaft of one of the long bones, such as the humerus, the tibia, or one of the metatarsal bones. The bone is preformed, to use a current expression, in cartilage: that is to say, its future place is occupied by a mass of hyaline cartilage having in a general way the form and relations of the bone that is 
to replace it: the mass of cartilage is covered by a single and closely adhering fibrous layer, the perichondrium, which is moderately rich in blood ressels. The transformation of the cartilage involves four recognizable changes, which may be designated as the rearrangement of the corpuscles, the calcification of the matrix, the formation of primary areolae, accompanied by the degeneration of the corpuscles, and the formation of secondary areolae by the partial dissolution of the matrix.

At a point near the centre of the mass the corpuscles begin to multiply and to increase in size, and (in a manner not yet clearly understood) to arrange thenselves in columns or rows which at first radiate from the central point, with intervening regions consisting of matrix only, thus forming a spheroidal region of transformation which continues to increase: when the surface of the mass is reached on the adjacent sides the region of transformation is of course restricted to the cartilage lying in the direction of the ends: and as it advances toward them in both directions the columns of rearranged corpuscles and the intervening regions of matrix soon take on a direction parallel to the axis of the bone.

Very shortly after the rearrangement of the corpuscles just described, the deposition of lime salts in the matrix takes place, particularly in those tracts which lie between the corpuscular rows, bars and plates of calcified cartilage thus being formed: At the same time the cavities in which the cartilage corpuscles lie begin to be enlarged, while the corpuscles themselves undergo degeneration, becoming shrunken and irregular in form, and lying in the enlarged 
cavities, which are now known as the primary areolae above referred to. In some cases the areolae consist of two or three cavities in the same row, united by the dissolution of the thin lamella of matrix lying between them. The farther dissolution of the matrix, and the formation of the secondary areolae, in which the deposition of endochondral bone begins, depends upon the development of other structures presently to be described.

About the time that the transformation of cartilage is set up in the centre of the mass important changes take place in the surrounding membrane, beginning in a zone immediately adjacent, and proceeding thence toward either extremity simultaneously with the advancing transformation of the mass within. The fibrous layer becomes thicker and more highly vascular: its inner portion becomes looser, and the corpuscles rapidly increase in number and in size, with associated changes in form and structure: in other words, the perichondrium of the embryonic cartilage becomes converted into the periosteum of the future bone, with an outer fibrous and inner osteogenetic layer.

By the time the central spheroidal area of transforming cartilage has reached the lateral surfaces of the mass, the adjacent zone of periosteum is fully formed; and the deposition of a delicate network of spongy bone may have already taken place. As the two regions of activity come in contact, one or more loops of blood vessels grow out toward the transformed cartilage, carrying with them an investment of osteogenetic tissue: before their advance the transformed cartilage is absorbed, and they quickly reach 
the centre of the mass. This is sometimes termed the primary vascular invasion. From the centre the formation of vascular loops and the associated development of the investing osteogenetic tissue is directed toward the ends of the bone, following the advancing areas of transformation of cartilage; the thin lamellae of matrix lying between the primary areolae in the longitudinal rows are absorbed, as well as (to some extent) those lying between adjacent rows: there is thus formed a network of elongated spaces, the secondary areolae, separated by intercommunicating bars and plates (trabeculac) of ealcified cartilage matrix, and opening toward the ecntre of the bone.

These spaces are rapidly filled by the advancing blood ressels and associated osteogenetic tissue, which together form the primary marrow: the surface of the mass is invested with numerous osteolblasts, which are brought directly in contact with the trabeculae of calcified cartilage matrix: upon the surfaces of the latter the reposition of thin lamellae of true bone substance begins. There is thus formed a spongy mass of bone trabeculate having a small quantity of calcified cartilage included in their structure, and forming an area which advances towards the end of the body just behind the area in which the last steps in the transformation of the cartilage are taking place: this is the endochondral bone. In the long bones with hollow shafts it is itself a more or less temporary structure, being absorbed from behind almost as rapidly as it is formed along the area of advance, its place heing taken by the permanent marrow. This is formed from the modifi- 
cation of the primary marrow, which at first consists only of the blood vessels and the associated osteogenetic tissue, which is quite delicate and almost gelatinous in structure: later, its retiform framework becomes more fully developed, giant cells and erythroblasts appear, and the characters of ordinary red marrow are assumed; these in turn (in the region referred to) giving place to those of the yellow marrow which finally occupies the cavity.

It has already been stated that the newly developed zone of periosteum begins shortly after its formation to deposit a layer of spongy bone upon the surface of the transforming cartilage in the middle of the shaft, similar to that first formed where the seat of ossification is a membrane. Along with the progress of the areas of the transforming cartilage toward the extremities of the bone, and the immediately successive development of endochondral bone in the interior of the mass, there is a corresponding advance in both directions of the change which converts the fibrous membrane investing the cartilage into periosteum. This, again, is inmediately followed by the deposition of a layer of spongy bone, or, rather, by the extension of the layer already begun. While the layer so formed is in this manner steadily increasing in extent, it also undergoes increase in thickness in the region where it was first formed. There is thus formed a sheath of spongy bone; shaped like a dice box open at both ends, thickest in the middle and gradually becoming thinner towards its extremities, which contains in its middle the newly formed permanent marrow : its ends surround the masses of endochondral bone previously described; immediately beyond lies the area of 
transforming eartilage: and still beyond (and invested as yet by perichondrium) the hyaline eartilage which has thus far undergone no change. This sheath of spongy bone is the perichondral bone, or as it is sometimes called, the primary periosteal bone.

As the periosteum extends its borders toward the ends of the future bone, its newly formed osteogenetic layer making the deposit of perichondral bone just described, a change, more or less gradual, takes place in the activity of its central and older portion. The meshes of the vascular network within its inner layer become more and more elongated in the direction of the long axis of the bone: the osteogenetic tissue which surrounds the vessels, instead of continuing to occupy a large portion of the intervascular spaces as marrow, deposits successive lamellae of bone substance concentric to the vessels, until the spaces are reduced to slender canals. Haversian systems are thus developed; while from the immediate surface of the periosteum interstitial and circumferential lamellae are produced, and the sheath of perichondral bone is itself invested with a layer of dense bone, or permanent periosteal bone. The perichondral bone is but little more enduring than the endochondral bone which it for a time surrounds: it has already been stated that as the latter advances toward the degenerating cartilage, it is itself, in the long bones, sooner or later absorbed and replaced by the permanent marrow: the perichondral bone suffers a like fate, the mass of marrow becoming enlarged in diameter as well as in length, and the surrounding spongy bone being absorbed about it until the marrow lies directly beneath 
the tube of dense bone which forms the permanent shaft of the femur or tibia, as the case may be.

It will be remembered that the mass of cartilage which in the foetus represents one of the long bones under consideration, is very much smaller than the bone which we find in its place even in the newborn child: the increase in thickness will be readily understood. It should be borne in mind, however, that this increase in thickness is for quite a while due to the formation of bone of the perichondral type only: it is not until some months after birth that dense bone of the ordinary type is deposited, the shafts of the long bones remaining up to that time more or less spongy throughout.

The increase in length is due to a continuous growth of the primary cartilaginous mass itself, which up to birth and for some time after continues to increase in length and also in thickness in the part which has not as yet begun to undergo transformation. This growth continues at a constantly decreasing rate, the region of untransformed cartilage thus becoming smaller and smaller. It is encroached upon alike by the advancing endochondral bone of the shaft, and the similarly formed but more permanent mass of spongy bone in the epiphysis, until finally the two areas of ossification meet, and the union of the epiphysis with the shaft is accomplished, the two masses of spungy bone and their investing layers of dense bone alike becoming confluent.

The table on the opposite page presents a summary of the various processes which have been described above as taking place in the formation of the shaft of a long bone. 
REPLACENHAT OH CARTILAGE TO FORM THE SHAFT OF A LONG HONE (C.g. IFMUR.)

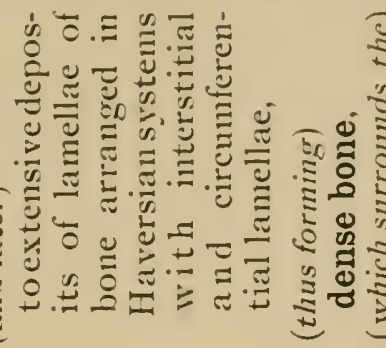

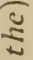

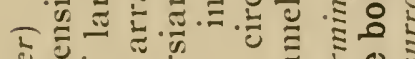

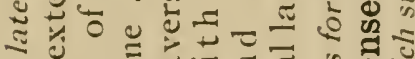

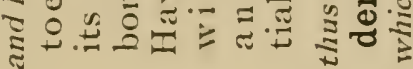
จ 2 气

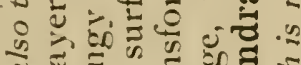

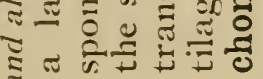

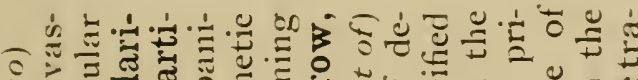

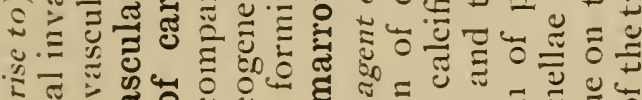

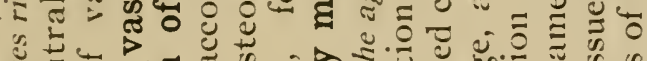

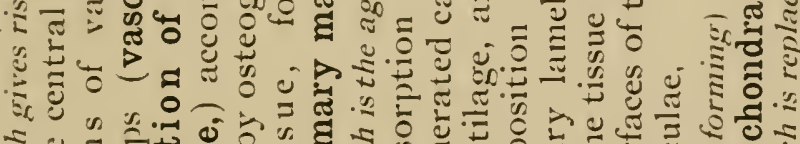

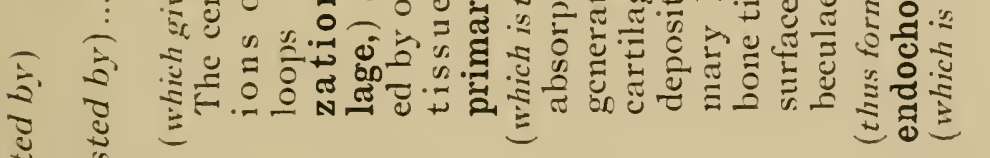

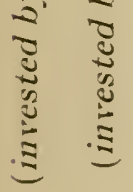

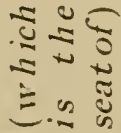

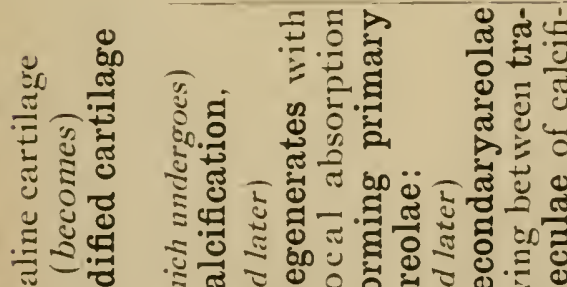

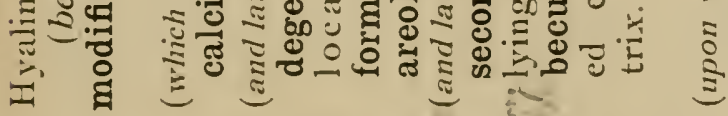


In the short bones, and in the epiphyses of the long bones, the replacement of cartilage takes place in an essentially similar manner, the vascular invasions reaching the centre of the mass of transforming cartilage, and the development of spongy endochondral bone taking place on all sides. Some of the trabeculae thus formed are shortly afterwards absorbed, while others become larger, and form part of the permanent framework of the interior of the bone. It is probable even here, however, that there is in the earlier part of adult life at least more or less of absorption and rebuilding continuously going on. An investing layer of perichondral bone is formed, and contributes to the permanent spongy mass : and later a thin layer of dense bone is superimposed. There are some very interesting variations in detail as to the manner in which ossification arises in some of the bones, but their consideration would be foreign to the purpose of this work. 
CHAPTEK VH.

THE BLOOL.

The blood consists of a fluid portion, the plasma, and numerous corpuscles found floating therein. It has sometimes been described as a tissue with a fluid matrix. It is perhaps a straining of the use of these terms to apply them to the blood: it is certain, however, that a deseription of the structural elements of the body would be incomplete without an account of those contained in that fluid. While they cannot be strictly defined as connective tissue elements, their origin is such as to warrant their description at this time.

The plasma is during life and in health a perfect fluid as long as it is contained in the blood vessels. When allowed to escape therefrom, or more rarely under certain abnormal conditions while contained therein, it undergroes coagulation, an important process, which concerns us chiefly hecause of the formation of a solid substance whose appearance should be familiar to the student of histologs: It is known as fibrin, and when present in small quantities can be plainly seen to consist of exceedingly delicate filaments interlacing in every direction; as the quantity increases, the meshes of the network thus formed becone filled with fibres, until a practically continuous solid mass 
is formed: when hardened and stained such a mass presents in section a granular appearance due to the crosssection of the fibres.

The corpuscular elements contained in the plasma and constituting normally a little over one-third of the volume of the blood, are chiefly of two kinds, the colored (or so-called red) corpuscles, or, as they have been termed, the erythrocytes, and the colorless (or so-called white) corpuscles, which are also commonly known as leucocytes. There are also present in normal blood smaller or larger quantities of minute bodies known by various names, the most common of which is the blood platelets.

The colored corpuscles are by far the most numerous, about five millions being contained in a cubic millimetre of the blood of a healthy man: the number in the blood of women is about ten per cent. less: in certain forms of disease their number may be very greatly reduced. When seen singly under the microscope each colored corpuscle is seen to be of a yellowish green color, the former tint prevailing in arterial, the latter in venous blood. The form of each is that of a biconcave circular disk, the central portion being slightly hollowed on each side and the margin rounded.

The size of the colored corpuscles varies within rather wide limits, the same sample of human blood exhibiting incliviclual corpuscles whose transverse diameter is as great as ten micra, and others that are but half as broad: by far the great majority, however, will be found to be 
from seven to eight micra in breadth: the average measurement has been variously stated by different observers after a very large number of measurements; it is not far from the truth to say that it is about seven and threefourths micra. Little difference, if any, is found in this respect in the blood of persons of different age or sex, nor is any noticeable in that of the various races of mankind. The greatest thickness of the blood corpuscle is about one-fourth its breadth. The smallest corpuscles found are sometimes distinguished as a separate form of elements under the name of microcytes; but this distinction is of doubtful significance.

The colored corpuscles of the blood of all mammals save those of the camel family resemble those of human blood in form and general appearance: they vary, however, greatly in size in different species, the differences that are found to occur having no relation to the differences in size of the animals themselves; those of the mouse, for example, being distinctly larger than those of the horse. The largest known are those of the elephant (between nine and ten micra in diameter) and the smallest those of the musk deer (about two and one-half micra). There is, also, no necessary close resemblance in this respect between nearly allied animals; thus, while the colored corpuscles of the blood of oxen, sheep and goats are very nearly of the same size, those of dogs and cats differ greatly.

While the colored corpuscles of the blood of many manmals differ in size so decidedly from those of human blowd as to make their distinction a matter of absolute certainty, there are several species of mammals whose colored blood 
corpuscles approximate so closely in size to those of man as to render impossible a certain distinction between them. While, therefore, it might be possible under certain circumstances to testify that a given stain was not caused by human blood, the converse is not justifiable in the present state of our knowledge.

The structure of the colored corpuscles has been and still is a matter of much debate. By some the disk is regarded as consisting of a denser colorless portion, spongy in structure, the stroma, whose meshes contain the fluid colored portion, a solution of the substance known as haemoglobin: its behavior towards certain reagents (notably toward water) leads others to the conviction that what we have is really a closed sac (or cell in the true sense of the word) filled with the colored fluid. It is at least certain that the corpuscle is far from being a mass of protoplasm, being as greatly modified therefrom as a fat cell. It should also be noted that a nucleus is wanting in the ordinary colored blood corpuscles of all mammalia: in which respect they differ from those of all other vertebrates.

When blood is drawn from the vessels, or when, from any cause, it stagnates for a time within them, the colored corpuscles show a tendency to adhere together by their sides in masses resembling piles of coin; this formation of rouleaux, as it is termed, was once supposed to be peculiar to blood corpuscles; but it has been shown that under certain circumstances the same process may be caused to take place with floating disks of cork or other substances under conditions that are purely mechanical. The rouleaux thus formed not unfrequently arrange themselves in 
a coarse network in whose meshes the colorless corpuscles may be seen, and the first formed filaments of fibrin detected as coagulation begins. The formation of rouleaux does not take place in the blood of vertebrates other than mammals, the thickening of the centre of the corpuscles due to the presence of the nucleus acting as an obstacle thereto.

If sodium chloride or any other salt, sugar, glycerine, or any other reagent that tends to increase the specific gravity of the plasma be added to fresh blood, or if the same effect is produced by circumstances faroring rapid cvaporation, the colored corpuscles undergo a characteristic change of form known as crenation, the corpusele becoming shrivelled and the surface studded with minute projections, the whole being in appearance not unlike the fruit of a thorn-apple or a horse-chestnut. This change may possibly take place in the ressels themselves nnder circumstances temporarily causing an appreciable difference in the proportion of water in the blood.

The colorless corpuscles, or leucocytes, are nucleated masses of protoplasm which may be regarded as typical animal cells. When at rest they are spheroidal in form, but, as will be seen later, are capable of very great modification in this respect. They are far less numerous than the colored, a cubic millimetre of healthy human blood containing on an average about ten thousand: the number varies greatly, however, not only in different individnals, but in the same individual under different conditions; thus, the number is greatly inereased shortly after eating 
and markedly diminished by prolonged fasting: we may therefore find in the blood of a healthy person at one time trvice as many to the cubic millimetre, at another even less than half as many as the average above given. Since the number of the colored corpuscles is not subject to such marked fluctuation, the ratio between the two varies therewith; and the number of colorless corpuscles is often stated in terms of that ratio as ranging between one colorless to two hundred and fifty colored and one colorless to over one thousand colored corpuscles: the average being about one colorless to five hundred colored corpuscles. This mode of statement is, however, unsatisfactory, for the reason that, as will be readily seen, a like change of ratio would result from a marked diminution in the number of colored corpuscles or an undue increase in the number of the colorless, changes in each case of very great importance, but of quite different significance.

The colorless corpuscles vary also in size to a great extent: their average diameter, when in the spheroidal state, may be stated as about ten micra. The smallest, sometimes distinguished specifically as small leucocytes, have large spheroidal nuclei, surrounded by a small amount of protoplasm: they may be regarded as newly formed elements that have only recently entered the blood stream; they are somewhat smaller than the average colored corpuscles. When fully developed they may become as much as twice as large, the increase being chicfly in the amount of protoplasm: they are then sometimes termed large leucocytes; still retaining the single spherical nucleus. 
The smaller and larger uninuclear elements make up in all about twenty-five per cent. of the lencocytes of the blood. Almost all of the remainder (about seventy per cent. of the whole number) are what are sometimes termed multinuclear leucocytes: these, which are comparatively uniform in size and somewhat larger than the colored corpuscles, have either two or three small nuclei or one large nucleus of irregular form and apparently about to undergo fragmentation. In addition there may. be found (occurring but sparsely in normal blood) a small number of leucocytes with pale nuclei and highly granular protoplasm, the contained granules staining deeply with eosin and similar reagents. These are sometimes known as granular or (from their affinity for the substance just mentioned) eosinophilous leucocytes.

When human blood or that of any manmal is examined at an ordinary temperature the colorless corpuscles are spheroilal and motionless: if, however, the stage of the microscope be so heated as to maintain the temperature of the blood at that of the living body, the spheroidal form is no longer maintained. The living corpuscle puts out one or more stout lobular processes, thus assuming an irregular form bounded by sweeping curves: these curves are seen to change slowly but constantly, the outline not remaining the same for any length of time. This shifting of form may go on about equally in all directions, the corpuscles as a whole renaining stationary; or there may be a flowing movement of the protoplasmic body toward one of the lobular processes, and a consequent change of position, as irregular and indefinite as the movements by 
which it is caused. This mode of motion, characteristic of leucocytes wherever found (and of some other elements as well) is identical in its nature with that seen to take place in the members of the genus amoeba, a group of very lowly organized unicellular animals: it is, herefore, termed amoeboid.

All the other forms of colorless corpuscles are probably derived from the modification of the small unicellular elements. These, in turn, are brought into the blood stream by the lymphatics, where, under the name of lymphocytes, they constitute the corpuscular elements of the lymph, some, however, attaining their full size while in that fluid.

The origin of the lymphocytes is well known. They are formed chiefly, if not solely, in those organs which consist in great measure of what is known as lymphoid or adenoid tissue: those known as lymphatic glands, or, more properly, as lymphatic nodes, having the formation of lymphocytes as their principal if not their sole function. The histological anatomy of these organs will be described in a subsequent chapter: it is sufficient here to say that they consist in the main of masses of adenoid tissue well supplied with blood vessels and enclosed in each instance in a capsule, into which several small lymphatic vessels enter and from which a single larger lymphatic vessel lcads, the current of $1 \mathrm{ymph}$ which thus passes through the mass, carrying with it the newly formed lymph corpuscles.

What is here termed adenoid tissue is, like the marrow of bone, a compound structure of which retiform tissue is the basis. In addition to the flattened connective tissue corpuscles which form an endothelioid layer upon the reti- 
culum, and which have been deseribed in a previous chap)ter as the fixed corpuseles proper of retilorm tissuc, the trabeculate which make up the framework of the mass are * in most cases so numerous as to entirely fill the meshes of the network. These cells, properly known as lymphoblasts, multiply rapilly ly cell division, the older gratually falling into the lymph channels which penetrate the mass and becoming young lymph corpuscles or lymphoeytes. At this stage they are spheroidal, with large nuclei and a very small amount of investing protoplasm: the latter substance increases in quantity as they are carried to the heart: but, as we have already secu, many enter the blood stream before they are fully matured.

The origin of the colored corpuseles of the blood is now also well established. During the early stages of embryonic life large nucleated colored eorpuscles are formed in the newly forming blood ressels. Later, colored corpuscles of the ordinary type ard formed first in the liver, later in the spleen, and finally in the red marrow. After birth the last named structure is the chief and probably the sole place of their formation in most if not all mammals, at least during health; it is possible that their formation may be temporarily resumed by the spleen it not by the liver under certain abnormal conditions.

In the description of the marrow already given it was stated that the interior of that structure contains numerous small cells with granular nuelei known as erythroblasts: these are formed by cell division from larger cells not distinguishable from ordinary marrow cells. The erythroblasts so formed multiply rapidly by the ordinary 
method of cell division, the cells thus formed being spheroidal and nucleated and gradually becoming converted into immature blood corpuscles by the formation within them of haemoglobin. Later the nucleus is extruded from the corpuscle and the spheroidal mass becomes converted into the biconcave disk which we find in the blood stream.

Reference has been made to the blood platelets. These are minute rounded and colorless bodies (from one-third to one-fourth the diameter of a colored corpuscle) which are found in the blood either singly or adhering together in masses of considerable size: their total number in normal human blood is but small. They have been described under a number of names, as the elementary particles of Zimmermann, the granules of Osler, the haematcblasts of Hayem. The name of blood platelets was proposed for them by Bizzozero. They have been regarded by Hayem and others as concerned in the formation of red corpuscles within the blood stream, but the evidence for this view is not conclusive. Perhaps the most probable explanation of them is that they are the disintegrating fragments of broken down colorless corpuscles. Our knowledge of them is, however, exceedingly imperfect. 


\section{CHAPTER VIII.}

THE CONTRAC'TILE TISSUES.

What is in physiological language termed contractility consists in a change of forn but not of volume. Irregulat contractility, or change of form in any direction and in an indefinite manner, is one of the powers which are inherent in living matter and may be nanifested by any cell which is still in an embryonic condition: that specialization of function and structure which converts the embryonic cell into the tissue element is in many cases accompanied by the disappearance of this power: it is retained, however, in some cases, as in the contractility of pigment corpuscles in many vertebrates, and notably in the amoeboid movements of leucocytes which has been described in the preceding chapter.

In one group of elements, however, this power is specialized and becomes their distinctive function. This specialization is of more than one kind: there is probably an increase in the actual amount of contraction, and certainly an increase in its rate; but the most important feature is its definiteness of direction, one axis of the mass (the longest) always becoming shorter, while the mass as a whole becomes thicker. From the fact that elenents belonging to this group are the essentials of structure of the organs known as muscles, the tissues formed of them are known 
as muscular tissues, although the elements of which they are composed sometimes occur singly and are frequently fonnd in masses that cannot with propriety be called muscles.

There are three distinct kinds of muscular elements or fibres (as they are commonly termed, from the elongation generally characteristic of them) the smooth, the cardiac, and the striped or striated muscular fibres. The elements of the first two kinds have in each instance a single nucleus, and may therefore be regarded as resulting from the direct modification of a single embryonic cell. Those of the third kind are much longer as well as thicker than the others, and while they arise in each instance from a single embryonic cell, this becomes greatly elongated and the nucleus divides repeatedly; the resulting strand of protoplasm thus becoming multinuclear.

What is variously called smooth, unstriped, plain or involuntary muscular tissue is composed of spindle shaped cells or fibres whose protoplasmic bodies show at times quite distinct evidences of longitudinal striation, but are at other times perfectly plain. The existence of a very delicate investing membrane or sheath has been demonstrated. The nucleus is elongated, sometimes oval but in many cases distinctly rod shaped, and is situated in the centre of the mass. Smooth muscular fibres vary somewhat in size and particularly in length: the transverse diameter usually ranging between five and ten micra, while the length may be less than ten or more than twenty times the diameter. When so sitnated as to escape lateral 
pressure the smooth fibres are circular in cross section: when, however, as is frequently the calse, they are pressed together, the sides become flattened and their cross sections polygonal. When seen in transverse section, therefore, the investing membrane forms a circle or polygon, within which is seen the protoplasm of the hody of the fibre, devoid of any clearly discernible strueture, and in the centre the circular section of the nucleus.

Smooth muscular fibres are usually associated in bundles, the tapering extremities (which are sometimes forked) overlapping upon the bodies of adjacent fibres and adhering elosely thereto; a suall amount of intercellular cement substance intervenes, as can be demonstrated by the use of silver nitrate. Little if any skeletal tissue pervades the bundles. The latter are in some cases more or less loosely interwoven: their most common arrangenent, however, is in more or less extensive layers; as, for instance, in the muscular wall of the intestine: such layers are penetrated by areolar tissue accompanying the blood vessels and nervous supply of the muscle fibres. It is very rarely the case that smooth muscular fibres are aggregated together into definite masses that can with propricty be called muscles, their most common occurrence being in the blood vessels and the viscera. In no case are they under the control of the will.

The cardiac fibres are found, as their name implies, in the muscular substance of the heart, both the auricles and the ventricles being chiefly composed of them: they alsoconstitute an important portion of the walls of the pulmon- 
ary veins and the superior and inferior venae cavae for a short distance previous to their openings into the auricles. What are known anatomically as fibres are in this case as in others aggregates of structures not visible to the naked eye. In this instance, however, a confusion sometimes arises from the application of the term fibre to bodies which are thus compared with ordinary striped fibres: they are in reality rows of shorter elements more nearly comparable to the smooth muscular fibres.

The cardiac muscular elements are short, stout, irregularly prisniatic bodies, intermediate in diameter between smooth and striped fibres and three or four times as long as wide. Their ends in some cases terminate squarely, in others are quite jagged and irregular. They are sometimes of uniform diameter throughout, but many give off short branches which unite with those from adjacent elements. Nothing like an investing membrane or sarcolemma has been demonstrated. The elements are faintly striated longitudinally and more distinctly transversely. Each element has a single nucleus, surrounded by a comparatively large amount of protoplasm showing no trace of the structure which in the superficial portion gives rise to the appearance of striation.

The cardiac elements are joined together by their ends to form the cardiac fibres to which reference has been made, a larger or smaller quantity of intervening cement. substance being clearly demonstrable. As many of the elements branch and anastomose with those of adjacent fibres, the appearance presented is that of a network with elongated and narrow meshes. 
The varions natnes of striped, striated, voluntary or skeletal muscular fibres are applied to those multinucleated fibres which form the organs ordinarily called muscles and usually attaclud to the bony or cartilaginous skeleton, the majority of them being under the control of the will. They are much larger than the smooth or the cardiac unseular elements, their transverse diameter ranging from ten to seventy micra, while they are in some cases as much as three or four centimetres long: they are prismatic in form, the ends tapering more or less gradually. Each fibre is invested by a thin homogeneous membrane known as the sarcolemma: within this is the mass of modified protoplasm which is the seat of the function of contraction: its most couspicuous feature is the transverse striping or striation which gives to the fibres the name most commonly applied. This, when seen by moderate powers of the microscope, presents to the eye the appearance of alternating dim and clear bands; while through the middle of the elear band may be seen a narrow black line: a longitudinal striation may also be seen, but usually less distinctly.

Beneath the sarcolemma, lying between it and the contractile substance, may be seen here and there elongated oval nuclei: these may be shown to be surrounded with a small amount of granular protoplasm which extends as al thin disk for a short distance around the nucleus. The protoplasm and the nucleus together make np what is known as a muscle corpuscle: these, like the similar masses in the centre of the cardiac elements, may be regarded as the residuum after the formation of the contrac- 
tile substance. Wthen a cross section of a bundle of striped muscular fibres is examined the nuclei are seen between the sarcolemma and the contractile substance, the latter being subdivided into small polygonal areas, the fields or areas of Cohnheim.

The appearances above described are easily seen: the explanation of the structure of the contractile substance upon which most of them depend is still a matter of dispute. The following facts are, however, quite generally conceded, and will probably form the basis of any further positive addition to our knowledge. The contractile substance may be regarded as made up of a clear viscid or semi-fluid portion, the sarcoplasm: imbedded in this are great numbers of elongated or rod-like bodies (whose exact forn is not yet certainly demonstrated, and probably varies with different animals); these are known as the sarcous elements. They are quite uniform in length and lie in disk-like groups which compose the dim bands or zones of the fibre, the clear zones being filled chiefly by sarcoplasm : the exact cause of the dark line in the middle of the clear zone (known as Dobie's line or as the membrane of Krause) is not yet certainly known. The sarcous elements are not only regularly grouped across the fibre, but also succeed each other regularly along its length, and are possibly united end to end; the rows of sarcous elements constituting the fibrillae.

The sarcous elements are not uniformly distributed across the fibre, the fibrillae which they compose being grouped together in strands known as muscle columns: 'These are separated from each other by sarcoplasm, and 
the columns themselves are somewhat irregularly aggregated in a similar manner. This may best be seen in the cross section of a fibre, where the areas of Cohnheim are the cross sections of the columns, the finely granular appearance of their interiors representing the ends of the fibrillae; the lines which bound the areas are composed of sarcoplasu, those which are thickest separating the groups of columns above mentioned.

The conversion of the whole of the interior of the fibre into sarcoplasm and sarcous elements and the consequent lateral position of the muscle corpuscles is characteristic of most striped fibres of adult mammals, if not of all. In the young of most mammals, however, and particularly in the embryo, this conversion is not entire, and the nuclei are still found in the interior of the filbre: a condition that is permanent for many of the lower vertebrates. Such fibres have also been described in certain museles of some species of mammals when fully grown.

A muscle, in the ordinary sense of the term, is an organ consisting substantially of a mass of striped muscular fibre and its associated skeletal structures. It will therefore be convenient in this case, as in those of the cartilages and the bones, to describe the histologieal anatomy of the muscles in connection with their single elaracteristic tissue.

When seen with the naked eye a muscle appears to be niade up of readily distinguishable fibres of varying fineness: these, which are the anatomical fibres, are bundles or fasciculi of the elements which are termed fibres in the 
histological sense. Each fasciculus is invested by a layer of areolar tissue continuous upon 1ts outer surface with that of those adjacent and giving off from its inner surface delicate septa which lie between the individual fibres. The investing layer of the fasciculus is known as the perimysium; the internal skeletal tissue as the endomysium. The aggregated fasciculi which make up the body of the muscle are invested as a whole by a layer of connective tissue continuous with the outer perimysial layers, termed the epimysium. The arteries and veins proper to the muscle are chiefly located in the perimysium, while the capillary network, whose meshes are as a rule greatly elongated in the direction of the fasculi, are situated in the endomysium in such a manner as to be in close proximity to every fibre.

The striped muscular fibres terminate by rounded or obliquely truncated ends, which are closely applied to the correspondingly shaped extremities of white fibre bundles, the sarcolemma of the muscular fibre being directly continuous therewith: these bundles are in some cases almost immediately connected with the periosteum of a bone or some similar place of attachment: in other instances they are prolonged beyond the muscle in a fibrous mass, the tendon of origin or of insertion, as the case may be. 


\section{CHAPTIR IX}

THE SAAL,L VESSLLS.

Mention was made in the introductory chapter of the lact that certain tissue aggregates, while themselves deserving to rank as organs, sustain the same relation to larger and more complex organs as do the tissues themselves. Among these compound factors of structure, as they were there termed, the most important are the small blood and lymph vessels, particularly the former. As they are built up of endothelial, skeletal and muscular tissues, their structure may now properly be described. The following statements apply, however, only to those smaller ressels which enter the strueture of other organs. The litrger vascular trunks will be deseribed in a subsequent chapter in connection with the other organs of the eireulatory system.

The blood vessels are commonly distinguished as arteries, which earry the blood from the heart, veins, which return it to the heart, and capillaries, which intervene between the arteries and the veins, and in which the blood is brought into the closest proximity to the tissues possible in a closed system of ressels. The lymph ressels originate in the interstitial spaces of the tissues (chiefly if not solely the connective tissues), these communicating directly with the open months of very small and thin-walled 
vessels known as the lymph capillaries: these unite to to form the larger vessels sometimes called lymph veins since they convey their contents toward the heart, but more commonly spoken of as lymphatics.

The interior of a small artery, such, for example, as can be just distinguished with the unaided eye, is lined with a layer of endothelium, whose cells are as a rule greatly elongated in the direction of the ressel; the nuclei also being elongated. Beneath this is a layer of elastic tissue usually in the form of a membrane, either homogeneous: or fenestrated, but occasionally composed of reticulated fibres. The endothelium and the elastic layer make up what is usually called the intima, or inner coat; the term is, however, applied by some histologists to the elastic layer, to the exclusion of the endothelium.

Beneath the intima is the middle coat, or media; this, in the vessels under consideration, consists almost entirely. of smooth muscular fibres, arranged in a layer several cells deep, the long axes of the fibres crossing the vessel at right angles or nearly so. Like all layers of muscular tissue, this is highly elastic; during life it is always upon the stretch; and the contraction which usually takes place in it after death throws the intima into longitudinal folds, which, when seen in cross section, give an undulating outline to the interior of the artery which is highly characteristic.

External to the media is the adventitia, or outer coat: this consists in the smaller arteries of a layer of connective tissue in most cases clearly definable on the one hand as 
pertaining to the artery, on the other passing over more or less gradually into the arljacent interstitial tissue.

As the small arteries divide and subdivide, finally becoming lost in the capillaries, there is a gradual reduction alike of the adventitia, the media and the intima. The former becomes reduced to a layer of extreme thimess: the media diminishes until it is reduced to a single layer of transverse smooth muscular fibres and later to scattered fibres not in contact and not forming a continuous layer: the elastic layer of the intima is similarly reduced in extent, and finally disappears; the last and least of the vessels that may with propriety be called arterial consisting merely of the endothelial lining and an imperfectlycontinuous layer of sumooth muscular fibres, surrounded more or less definitely by a few branched connective tissue corpuscles.

The capillaries are the direct continuation of the arteries, arising either by the farther subdivision of the structures just described or springing directly, as in some cases, from the sides of vessels still distinctly arterial in their structure. In either case they branch freely, forming a network, whose meshes have a size, form and direction in direct relation with the structure of the organ in which they occur. They do not, like the arteries, become smaller as they branch, those of any one network being approximately of the same size, though they may vary considerably in different parts of the same organ. Their size in life is not easily determined, but the majority of them are probably not over ten micra in diameter, though in some 
tissues, notably in the marrow, they may be as much as twice as large.

- In structure the capillaries are simple tubes (usually cylindrical in form) of elongated endothelial cells of such width that from two to four may be seen in the cross section of a single capillary. As in other endothelial layers, the cells are united by an intercellular cement substance: here and there patches of this substance may be demonstrated by the silver method which may be regarded as indicating gaps between the cells; these have been termed stigmata; and it is probable that such places offer favorable opportunity for that migration of the leucocytes from the blood-stream into the tissues which is known to be normal to them. Capillaries are almost alvays situated in interstitial areolar tissue or its equivalent, and are in direct relation with the connective tissue corpuscles: in some organs branched corpuscles appear to form an almost continuous layer investing the capillaries: such a layer has been termed an adventitia capillaris.

As the capillaries originate by the subdivision of the arteries, so their union forms the origin of the veins. A small vein resembles a small artery in its general structure, its wall, like that of the latter, being distinguishable into an intima, a media, and an adventitia: the chief differences between them may be stated briefly as follows. The endothelium of the veins is, as a rule, composed of shorter and broader cells than that of the arteries, and the elastic layer of the intima is thinner: the media is very much thinner, the amount of muscular tissue being very much 
reduced: the adventitiat, which is the principal coat of the veins, is, if anything, thicker than that of the corresponding artery, and is composed largely of fibrous tissuc. The veins are as a rule of a greater cliameter than the arteries which they accompany.

Inlike the arteries, the veins are not during life continually on the streteh; and the recoilmentioned in connection with the former vessels does not take place after death: this reaction on the part of the arterial wall tends $t 0$ drive the eontained blood through the capillaries and into the veins: as a rule, therefore, the arteries are empty after death, but retain their pateney on account of the thickness and elasticity of their walls. The veins, on the other hand, are usually filled with blood; or if empty become collapsed and flattened on account of the thimess and inelasticity of their walls.

A small artery and a small vein may therefore usually be distinguished when seen in cross section by the following differences: The artery is circular in form: it is in most cases empty, or contains but a small amount of blood clot: the intima is thrown into folds, giving the elastic layer a sinuous contour, upon which the nuclei of the endothelial cells are often peculiarly conspicuous: the media is quite thick, consisting chiefly of numerous muscular fibres: the arlventitia is comparatively weak, and the least conspicuous of the three coats. The vein may be either circular or more or less irregular in form : if the former, it is usually filled with blood clot, readily recognizable from the numerous colored corpuscles, deroid of nuclei and appearing as clear circles, and the few leucocytes with distinct nuclei: 
the intima is thin and simple in contour : the media is also thin, containing but few smooth muscular fibres: the adventitia is often the thickest and most conspicuous of the three coats. Where the artery and vein lie side by side, the latter is usually the larger.

A similar application of the principles of structure above described will enable the student to interpret the different appearances seen when a vessel is cut obliquely or longitudinally, and with practice to recognize an artery or a vein wherever met with in a section passing through one of the organs of the body.

The interstitial spaces of the tissues form in many cases an irregular network, in others definite lacunae or channels for the lymph, a rather indcfinite term applied to the fluid originally derived from the blood and destined to be returned to it again by way of the lymphatic vessels. The smallest of these, the lymph capillaries, arise from the lymph-spaces of the tissues in an exceedingly irregular manner, the connective tissue corpuscles in many cases passing by an insensible transition into their endothelium. When fully formed they consist of tubes which resemble blood capillaries in consisting solely of endothelial cells, but differ from those structures in the fact that they are rarely if ever cylindrical, being exceedingly irregular in form, though usually flattened, and very often quite variab!e in diameter: they anastomose freely, forming networks of very irregular meshes. The cells of which they are composed are usually about as long as broad, but are usually characterized by a distinct sinuosity of outline. 
The limph capillaries unite to form the larger vessels known as the lymphatics. These do not differ materially from the former except in size and in the presence of valvular folds. Like the eapillaries, they consist almost entirely of endothelial cells, which are, however, more elongated in the direction of the vessel than those forming the eapillaries, but having the same sinuous outline. It should be stated here that by some histologists it is held that the characteristic irregular outlines seen in preparations of the lymphatic endothelium by the silver method are due solely to shrinkage of the tissues after death, the outlines of the cells in the living tissues being far simpler.

A lymphatic when seen in cross section in the interior of an organ appears as an opening of irregular form, its sides usually approaching each other (due to the flatness of the ressel); it can in many cases hardly be distinguished from a simple tear or fissure in the connective tissue, save by the definiteness of its outline: this, except in cases where the ressel is quite collapsed, is made up of simple curves; and in it may oceasionally be seen the nuclei of the endothelial cells of which it is composed. In some cases the opening is larger and more nearly equal in its various diameters, resembling the cross section of a vein: it can then be distinguished from the latter by the greater thinness and sinplicity of its walls and by the fact that any clot which may be present consists almost entirely of fibrin, appearing granular in the section, with here and there a few lymphocytes with large nuclei and a small amount of surrounding protoplasm. 
The structure of the larger lymphatic vessels will be described in connection with the circulatory system.

The lymphatics have a distribution closely related to that of the blood vessels: and it is not unusual to see a small artery, its companion vein, and one or more lymphatics in close proximity. In some cases a blood vessel may be situated within a lymphatic vessel. Such lymphatics are termed perivascular.

The serous cavities of the body are in reality enlarged lymph cavities. They are lined by the serous membranes, which are known by distinctive names (e. g., pleura), according to their position. These consist in each case of connective tissue which contains a more or less well developed network of fine elastic fibres, surmounted by a homogeneous basement membrane. On this rests the serous endothelium, a layer of polygonal pavement cells of varying size. Here and there may be found small openings called stomata, which put the serous cavities in communication with the lymph channels of the membrane and thus with the lymphatic system: they are surrounded by cells which are usually more tumid and granular than those adjacent.

In addition to the tumid cells which surround the stomata there may sometimes be found on the serous surfaces patches of granular cells, which may be cuboidal if not columnar in form: these give evidence of rapid cell division, and may be regarded as local centres for the formation of the leucocytes which may be found in the serous cavities. 


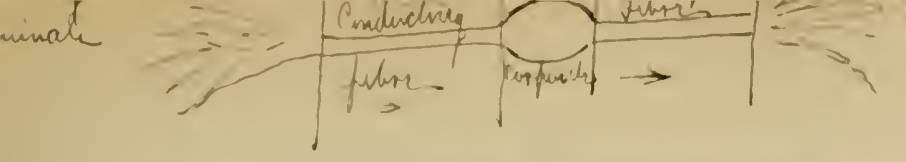

CHAITER $X$. NERVOCS TISSUES.

99

\section{CHAPTER X.}

THE NERVOUS TISSUES.

The nervous tissues have for their characteristic function the reception, conduction, distribution, and discharge of impulses or stimuli. The stimuli received may be such as, when manifested in consciousness, we know as sensations; or they may be such as are never reported to our consciousness: in either case they may be either mechanical, physical, or chenical in their origin: the distance to which they are transmitted may vary greatly in different cases, as may also the cxtent and nature of their distribution. The impulses which are discharged (with or without previous distribution) must be regarded as liberations of energy due to changes set up in the central nervous elements by the ingoing stimuli: they may or may not result in associated and more conspicuous liberations of energy in the muscular tissues.

The nervous elements, are, then, like the muscular elements, reservoirs of energy: they differ from them both functionally and structurally by what has been termed their polarity, by which is expressed the fact that the impulses received enter in a more or less definite direction, while the ensuing discharge takes place along a definite line which is in a general way in an opposite direction to that along which the incoming stimulus enters. A nervous 
element of the simplest type may be conceived of as comprising a spheroidal or spindle-shaped mass of protoplasm provided with a nucleus, each of whose extremities is continued into a filament of more or less length. Along one of these filaments stimulitravel toward the central corpuscle, and the extremity of the filament is modified for their reception: along the other, nervous impulses pass outward to their appropriate place of discharge, its extremity showing corresponding modification. The whole structure, from one set of terminals to the other (and including both) is the result of the modification of a single embryonic cell: on account of the delicacy of the various parts, however, and the great length in many cases of the conducting filament, it is rarely (if ever) possible to isolate such a nervous element in its entirety, as we can isolate a smooth muscular fibre or an epithelial cell: nor can nervous elements (with a few exceptions) be so prepared that they can be seen in their entirety in a single section: in most cases our study must at any one time be chiefly directed to one or the other of the regions above indicated. Practically, it has been customary to distinguish, as the structural factors of the nervous system, the conducting strands of greater or less length along which impulses are transmitted; the central corpuscular masses; and the terminals of reception and discharge: and al though these are now known not to be independent parts, it is convenient to retain this distinction as a basis for their description : according, therefore, to the form and associated function of the various components of the nervous system, it is customary to classify them as follows. 
1. Conducting elements, or nerve fibres: these consist in everyease of continuous eylindrical (or rounded) strands which run without interruption Irom the central corpuscles to the terminal modifications of their free extremities. The presence or absence of certain in resting structures distinguishes two kinds of nerve fibres, known as

1. Non-medullated fibres: also called gray or gelatinous fibres, or (lrom their discoverer) the fibres of Remak: the axis consists of a grayish cylinder or a band with rounded edges, showing delicate longitudinal striations: they are invested, if at all, by a very delicate primitive sheath whose exist. ence is questioned by many histologists. Upon the surface of the fibre are seen numerous nuclei. The gray fibres not unfrequently branch and anastomose with adjacent fibres.

2. Medullated fibres: also called white fibres: the Ars the lus axis-cylinder is gravish and longitudinally striated: it is surrounded bya layer of a fatty substance termed myelin, the layer being called the medullary sheath or white substance of Schwann: outside of this is the clearly defined primitive sheath or neurilemma. The medullary sheath is interrupted at frequent intervals, the points where this occurs being termed the nodes of Ranvier; the intervening segments are called internodes: each exhibits one or two so-called nerve-fibre corpuscles situated between the medullary sheath and the neurilemma and consisting of oval nuclei sparingly invested with protoplasm. Medullated fibres rarely branch, except near their extremities. 
B. Central elements, or nerve corpuscles: these are variously shaped bodies with conspicuous nuclei: they vary greatly in size also, some being among the smallest and others among the largest of the tissue elements. Their surfaces alvays give off one or more processes termed poles: according to the number of these processes they are commonly distinguished as unipolar, bipolar, and multipolar corpuscles. Most nerve corpuscles (in the higher vertebrates, at least) are multipolar; and in the great majority of instances one of the poles of a multipolar corpuscle can be distinguished from the others as the process of Deiters, or, better, as its axis-cylinder process : the rest are then known as protoplasmic processes and rapidly divide into irregular branches termed dendrites: in some multipolar corpuscles no axis-cylinder process can be distinguished; such corpuscles are termed amacrine. Other features will be discussed in a subsequent paragraph.

C. Peripheral elements, or nerve terminals, formed by the modification of the extremities of nerve fibres with or without epithelial or skeletal elements. According as they are situated at the extremities of fibres which conduct impulses toward the nerve centres (afferent fibres) or away from them (efferent fibres) they are distinguished as

1. Receiving terminals: of these various kinds are known, composing two groups which differ from each other alike in the form and in the arrangement of the structures included. In one group large numbers of similar terminals are associated with modified epithelial cells to form the essential structures of the three great organs of special sense, the nose, 
C. Peripheral elements or nerve terminals (continued). the eye, and the ear: these will be deseribed in a subsefuent clapter, together with the less highly specialized organs of taste. In the other the terminals are always either solitary or in groups of two or three, though they may be more or less abundant. Sone of these forms of terminals have been regarded as associated with specific morles of sensation, but the function of most of them is altogether unknown: they are therefore usually distinguished by peculiarities of form or of location, or by the names of their discoverers. The principal forms may conveniently be described here.

a. The simplest form of receiving terminal is seen in what are known as free endings. In these the nerve fibre first looses the investing white substance of Schwann, and later the neurilemma, though the nerve-fibre corpuscles are still seen for a while before the axis-cylinder becomes entirely naked. When the latter stage is reached, the fibrils are rapidly split up into small bundles, and finally form a tuft or pencil of delicate more or less varicose filaments which ramify among the cells of the epithelium in the case of the skin, a mucous membrane, or the substance of a gland; or among the elements of other organs. Branching terminals, essentially similar, found in tendons, are known as organs of Golgi.

b. Closely allied to the preceding are the terminals associated with what are known as tactile cells : these are spheroidal cells found in the deeper portion of the epidermis and probably epithelial in character. The nerve fibre in relation with a group 
C. Peripheral elements or nerve terminals (continued). of them looses its investments and breaks up into a number of slender branches, each of which ends in a saucer-shaped disk, the tactile meniscus, which embraces the proximal surface of the tactile cell, so called. There is no positive evidence that these, rather than other cutaneous terminals, are the special organs of touch.

c. The bodies known as compound tactile cells, also sometimes called the corpuscles of Grandry, found in the skin of certain birds, and also described as occurring in mammals, may be regarded as composed of two or more lavers of tactile cells, and having between adjacent layers terminal expansions known as tactile disks. The neurilemma of the nerve fibre of which the tactile disks are the termination becomes continuous with a connective tissue capsule that invests the whole structure.

d. The name of tactile corpuscles has long been given to largeovoid bodies found in the papillae of the skin of the hand and foot and in other places where the sense of touch is well developed: they are also called the corpuscles of Meissner. Each is com posed of a mass of connective tissue about which a medullated fibre winds spirally once or twice, the sheaths of the fibre then becoming merged in the mass or continuous with its capsule: the axiscylinder passes as a nonmedullated fibre into the interior, where it branches more or less freely, the branches becoming varicose. Two, three, or even four medullated fibres may be connected with a single large corpuscle of Meissner.

e. What are termed end-bulbs are spheroidal or cylindroidal bodies of simple structure in which the axis cylinder of a medullated fibre enters the proxi- 
C. Peripheral elements or nerve terminals (continued). mal end of a matss of connective tissue which is continuous with the sheaths of the fibre, and extends thronghout its length, branching but little if at all. They are found in the conjunctiva of the eye, and in other modified dermal structures, as well as internally. The articular corpuscles found in the vicinity of joints, as well as the genital corpuscles of the nuale and the female sexual organs are probably to be regarded as modified end-bulbs, though both are held by sone histologists to approach more nearly in structure to the corpuscles of Meissner.

f. The Pacinian bodies, or, as they are sometimes called, the corpuscles of Vater, are the largest of the terminals, being easily visible to the naked eye in many cases. They are irregularly ovoid in form, each having for its axis the axis-cylinder of a medwllated nerve-fibre, which may terminate near the extremity of the corpusele by a bulbous enlargement or may divide near the end into short irregular branches with pyriform extremities. The axial structure is imbedded in a eylindrical core of doubtful nature: it is faintly granular and contains scattered nuclei, and is possibly homologous with the principal mass of an end-bulb. Surrounding this is a series of concentric tunics which may be fifty or more in number, each consisting of a fibrous layer and an endothelial investment: the whole may be regarded as a highly specialized modification of the capsule of the end-bulb. Pacinian bodies are found widely distributed throughout the body. As is the case with the other forms of receiving terminals, we have as yet no certain knowledge of their specific function. 
C. Peripheral elements or nerve terminals (continued). 2. Discharging terminals: Impulses sent out from the nerve centres may give rise to muscular, glan. dular, or other activities. The terminals by which discharge is made upon the elements of the tissues involved have in every case, as far as linown, the form of ramifieations or arborizations of the extremities of efferent fibres. In the case of glands or other secretory structures the terminal subdivisions are situated among the epitheliai cells. In the case of smooth muscular tissue, nonmedullated filores irom an adjacent ganglion or ganglionic plexus enter the muscular layer, between whose elements the ramifications of the fibre are situated.

The mechanism of discharge in the case of striped muscular tissue is somewhat more complex. Medullated fibres from the intramuscular plexus, following the endomysium, divide in each instance into two or more branches, each branch passing to a single muscular fibre. The medullary sheath disappears, the neurilemma apparently becomes continuous with the sarcolemma of the muscular fibre, and the axis-cylinder breaks up into a number of fine varicose branches: the latter rest upon or are imbedded in the sole-plate, a flattened granular mass of protoplasm containing several nuclei and lying between the sarcolemma and the body of the fibre: the whole structure is termed a motor end-plate. By some histologists the end-plates are believed to be situated altogether outside of the sarcolemma. 
Attention has been called to the delicate longitudinal striation of the axis cylinder of the medullated fibre and of the corresponding portion of the gray fibre. This is the expression of a distinct fibrillation, the primitive fibrillae being imbedded in an intervening homogeneous substance, the neuroplasm (the resemblance to the fibrillae and sarcoplasn of striated muscular fibre is noteworthy). The terminal subdivision common to medullated and nonmedullated fibres consists of a breaking up of the axis into smaller bundles of these fibrillae and erentually, in some cases, to the separation of each individual fibrilla.

The gray or nonmedullated fibres consist of little more than bundles of fibrils and neuroplasm. Those which compose the branches of the olfactory nerves have a welldefined and nucleated primitive sheath: in most gray fibres no such sheath can be demonstrated. Scattered nuclei are seen upon the surface of the gray fibres: these, like the sheatl, when present must be regarded as skeletal rather than nervous in character. Gray fibres show well marked varicosities, which are possibly due to local accumulations of neuroplasm, the fibrillae being correspondingly separated at such points. Where gray fibres branch and anastomose bundles of fibrillate accompanied by neuroplasm pass over from one fibre to another: the angles formed by the branches are frequently filled for a short distance with neuroplasm, and investing nuclei are often relatively abundant at such points.

The axis cylinders of white fibres show under certain methods of treatment transverse striation curiously like 
that of a striped muscular fibre: if a reality, and not due merely to the reagents used for its demonstration, this must be caused by regular variations in the size of the fibrillae. The axis cylinder may also be shown to be suddenly thickened at the nodes of Ranvier, the spindle-shaped enlargement being apparently due to an increase in the amount of neuroplasm with an accompanying separation of the fibrillae. Some histologists maintain that the axis cylinder is invested with a delicate structureless sheath, for which Kuehne has proposed the name of the axilemma: whether this structure exists in the living fibre is still a matter of question.

The medullary sheath also presents (under certain treitment) apparent evidence of a structure that would hardly be inferred from its semifluid character as seen in the fresh nerve. A reticular framework of a substance of a horny nature known as neurokeratin can be demonstrated, whose meshes and filaments vary greatly in size in different parts of the same fibre. That the substance in question exists as a component of myelin is probably true: but the solid framework described is quite possibly due to its coagulation by the reagents employed. Far more conspicuous are the obliqueclefts seen in the medullary sheath after treatment with certain reagents, notably osmic acid: these are evidently the view in section of conical cleavage spaces running from the primitive sheath to the axis cylinder, and dividing the medullary sheath into the medullary segments of Schmidt and Lantermann, a number of which may befound in each internode: whether these are real or artificial must, however, be regarded as still unsettled. 
The newrilenuma exlubits no special structural features worthy of renark. It should be noter that when a medullated fibre joins the brain or cord, while the medullary sheath is continued within the axial structure ats far ats the graty matter, the neurilemma disappears: thus the columns of the cord are made up in great measure of medullated fibresderoid of neurilemma. At the distal extremities of the fibres the medullary sheath is the first to disappear, the ncurilemma being continued for some distance toward the terminal.

Nerve fibres, both gray and medullated, vary considerably in size, their diameters ranging from two to twenty micra; the difference appears to be associated with a corresponding difference in the length of the fibres.

Corpuscles, fibres, and terminals are now known to be continuous structures and components of what may properly be called true tissue elements, meaning by that term in each case the result of the modification of a single embryonic cell. As indicated at the outset, such an element may consist of a receiving terminal, an afferent fibre (medullated or nommedullated), a central corpuscle, an efferent fibre (of either kind) and a discharging terminal. The simplest form of terminal is in either case a tuft of fibrillae: if the subdivisions of the receiving terminal are c alled dendrites, and the discharging cluster an arborization, the two can readily be distinguished by these terms. A corpuscle so situated would be essentially bipolar; such corpuscles exist, though not in great numbers, in the nervous tissues of the higher vertebrates: more frequently the points of attachment of the two fibres become approx- 
imated and finally consolidated for a short distance, forming what is apparently a unipolar corpuscle with what is termed either a Y-or a T-connection accorling to the mode of separation of the two fibres. In certain superficially situated elements of a sensory character in some of the lower animals (and possibly in higher forms as well) the receiving terminal and afferent filament become so shortened and condensed as to form a mere eminence only on the body of the corpuscle: such elements may be said to be in form (but even then not in function) unipolar. What have been called in the past apolar corpuscles probably do not exist.

In the ganglia of the sympathetic system corpuscles are found with more than two processes, each of which becomes an axis cylinder (or a gray fibre): such corpuscles are in thestrictest sense multipolar: whether the majority of the poles are afferent or efferent is unknown: both conditions may possibly occur.

The term multipolar has long been applied to the corpuscles found chiefly in the brain and spinal cord in which a distinction can be made, as has been pointed out, between a single axis-cylinder process and a number of so called protoplasmic processes which subdivide into a group of dendrites. It has been suggested that the latter have for their function some connection with the nutrition of the corpuscle: but a more reasonable interpretation is one which regards such a corpuscle as resulting from the disappearance of the afferent fibre, its primary subdivisions thus becoming processes of the corpuscle itself. The axis cylinder process may in its course give off one or more 
slender branches; these leave the process at well marked angles, but soon after bend strongly to become approximately parallel to it in most cases: they are known as collaterals, and like the processes from which they arise terminate in arborizations.

Axis-cylinder processes which pass from the gray into the white matter of the cord become invested with a medullary sheath and are then true axis cylinders: elements in which this is the case are known as corpuscles of the first type: in other cases the efferent process is quite short, the terminal aborization being situated in the gray matter: such elements are called corpuscles of the second type. The disappearance of the process altogether, making the arborization sessile, like the dendrites, gives rise to the amacrine corpuscles of Cajal.

Nerve corpuscles always have large and conspicuous nuclei, in the vicinity of which a patch of pigment granules is very commonly present. The fibrillae of the processes may be traced into the interior of the corpuseles, but their internal distribution is as yet unknown. The corpuscles are almost always situated in well defined lymph spaces which agree closely with them in contour. The forms of the corpuscles of the brain and eord will be described in the chapter deroted to those organs.

The nerres are definite aggregates of nerve fibres: like the blood ressels, they penetrate the organs of the body and are consequently to be regarded among the factors of structure thereof: the same is true of many ganglia: botl will therefore be described at this time. 
A nerve is a bundle of nerve fibres or an aggregate of such bundles. Each bundle is termed a funiculus, and is composed of a number of fibres surrounded by a cylindrical sheath called the perineurium. The latter is lamellated in structure, the number of lamellae never being less than three save in the smallest branches of the nerves: they are separated by distinct lymph spaces lined with endothelioid corpuscles. The inner lamella is continued into the funiculus by the connective tissue which lies between the fibres and supports their capillaries, called the endoneurium. In small funiculi this connective tissue is homogeneous in composition, approaching gelatinous tissue in consistency : such funiculi are termed simple: larger funiculi, called compound, show here and there in the endoneurium connective tissue septa which divide the funiculus irregularly.

In small nerves, consisting of but a single funiculus, the outer lamella of the perineurium is continuous with the adjacent areolar tissue: where several or more bundles are associated, however, as in the larger nerves, a definite mass of connective tissue, containing more or less fat, and definitely compacted on its outer surface, invests and supports the funiculi, becoming continuous with their outer lamellae: this is known as the epineurium. Within it the associated funiculi divide and anastomose from time to time, each large nerve being thus in reality a greatly elongated plexus.

As the funiculi divide into small groups of fibres and finally into single fibres in the vicinity of their destination, the perineurium becomes greatly reduced, being finally continued for a short distance on the single fibres either as 
a single lamella or as a mere layer of endothelioid cells: such an investment is known by the name of Henle's sheath.

A ganglion is a mass of nerve corpuseles invested with a definite sheath or capsule of connective tissuecontinuous with the epincurium of the nerves with which it is associated; or, in the case of nerres consisting of single funiculi, with the perineurium. These may be but two in $n u m b e r$, the ganglion in sucheases heing practically seated upon a nerve trunk; or there may be three or more, the ganglion being situated at their intersection. In almost all the larger ganglia there ma be clearly distinguished at cortical portion, consisting chicfly of nerve corpuscles, and a central portion, consisting largely of nerve fibres. Of these some pass directly through the ganglion, while others pass into or out from the cortical portion, being connected with the corpuscles. Each corpusele is, as a rule, contained in a delicate capsule continuous with the neurilemma of the associated fibre or fibres and enclosing, as has already been stated, a pericorpuscular lymph space.

The neuroglia, or sustentacular tissue of the brain and corrl, hats been referred to in the chapter devoted to the fibrous tissues. It differs from all the tissues of that group in its origin and in the absence of anything like the matrix characteristic of them; consisting, as was stated, entirely of peculiar branched corpuscles known as glia-cells. These are stellate or irregularly shaped cells with large unclei, which stain conspicuously with some reagents. Their branches, which are quite numerous, terminate in 
long slender processes: these are stated by Ranvier to be fibrillated, the fibrillae passing through the body of the cell from one process to another: they are variously arranged upon glia-cells from different parts of the cerebrospinal axis, those of the gray matter of the cord, for example, differing from those of the white in the number and disposition of their processes. In a general way it may be said that the latter form a dense reticulum of closely interwoven fibres: this in sections has a finely granular appearance conspicuously seen in the gray matter..

The glia-cells are found in the cerebrospinal axis and are derived from the same embryonic layer as the nervous elements themselves. While, therefore, their function is probably purely mechanical, or, in a sense, skeletal, they must be regarded as closely related to the nervous tissues rather than to the skeletal tissues proper. These latter also penetrate the cerebrospinal axis, in the form of connective-tissue trabeculae which compose a proper skeletal framework: and although they gradually diminish by subdivision and become reduced to delicate fibrils intermingled with those of the neuroglia, nothing like a transition from one tissue to the other has ever been observed.

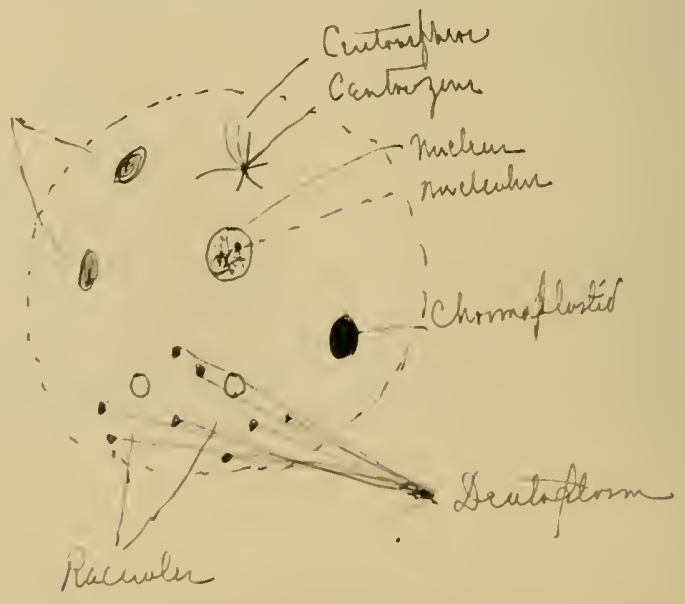




\section{CHAP'TER XI.}

THE STRUC'TURE OF THE CELL.

We have now passed briefly in review the various tissue elements, consiclering both their form and characters and their mion to compose the tissues of the body; as also the structure of some of the simpler aggregates of tissues, or organs. The elements of the tissues were at the outset defined as cells or as derived from the modification of cells; and a cell was defined as a nucleated mass of protoplasm. It is important now for us to consider the structure of the protoplasm itself, and of the nucleus as well; and to learn something of the process by means of which new cells are formed.

It was stated in the opening chapter that the protoplasm which makes up the body of the cell is neither homogeneous or structureless, as it was once supposed to be. The delicate granulation generally characteristic of its appearance as seen by ordinary powers proves with more improved means of research to be the expression of a delicate reticulum or network of a somewhat denser substance which has been given the name of spongioplasm; its meshes are filled with a less dense or semifluid substance designated as hyaloplasm: the proportion between the amounts of these two substances may vary greatly: as a 
general rule the relative amount of the former increases with the age of the cell. The meshes of the spongioplasm may vary greatly in size and in the coarseness or fineness of their constituent fibrils: the accumulations at their intersections are the granules most readily seen.

In cells which become surrounded by a cell wall con1posed of some formed product (e. g., an epidermal cell), the reticulum becomes quite close and dense near the surface: but in many cases (e. g., a leucocyte) the converse is the case, the exterior of the cell consisting almost, if not quite wholly, of hyaloplasm. Such a clear outer portion is sometimes termed ectoplasm, in distinction from the granular inner portion known as endoplasm: the distinction is, however, of questionable value, since in some of the lowest animals the conditions are reversed, the same terms being applied to a denser outer and a more fluid inner portion of the cell. The terms paraplasm and deutoplasm are also sometimes macle use of in connection with the structure of the cell body to designate granules imbedded in the protoplasm, and consisting either of substances taken up by the protoplasm in a solid form, or of formed products temporarily stored in the cell; such, for example, as yolk granules in the ovum.

The nucleus gives evidence of a reticular structure even with ordinary powers; and this structure is also clearly seen to vary in the different nuclei of adjacent cells or in the same cell at different times if watched while still living. Under ordinary conditions, however, the nucleus when seen in what is usually designated the "resting" condi- 
tion is a spheroicial vesicular body bounded by a well defined wall, and contaning the network above referred to: this is sometimes fune and close meshed; at others conposed of but a few coarse fibrils, which are in some cases quite irregularly disposed; in some cases the fibrils form a continuous filament which is arranged in a tangled skcin. The nodes of the network in many cases form coarse granules, which are quite conspicuous: in addition there are often seen in the nuelei distinet spheroidal bodies apparently different in composition from the network: such a body is called a nucleolus.

The meshes of the network are filled with a clear semifluid substance which is not readily colored by the staining fluids which render the network and nucleoli conspicuous. This difference between the two principal substances of the nucleas led Flemming to propose for the substance composing the filaments the name of chromatin, and for the clear substance that of achromatin. More recent researches have made clear, howerer, the fact that the denser portion of the nucleus itself consists in part of a substance which does not stain any more readily than the more fluid portion: while the latter, now usually termed the nuclear matrix, is regarded as possibly similar in composition to the hyaloplasin of the cell-body. The name of chromoplasm has therefore been proposed by Carnoy for the substance which forms the filaments, that portion which is readily stained being designated by the term chromatin, and that which resists ordinary stains by the term achromatin; a different application of these terms from that originally proposed by Flemming. 
The nuclear wall is composed of chromoplasm: by some it is regarded as consisting merely of a fine and close network of that substance; by others as a definite and continuous layer. Its continuity with the network is evident from its comportment at the time of nuclear division. Whether the nucleoli consist of chromoplasm must for the present be regarded as an open question.

While the arrangement of the filaments of the nuclear network is often exceedingly irregular, especially in the resting stage, it can often if not always be seen at the time of its greatest development to have a definite plan, whose basis is the formation of a larger or smaller number of elongated loops having a meridian-like arrangement in relation to a definite axis. The turns of the loops are directed toward one end of the axis, termed the pole of the nucleus: the free extremities meet (and frequently interdigitate) in the region around the opposite end of the axis, the anti-pole. The sides of the loops are often exceedingly irregular in their course, and may in addition branch frequently, the branches anastomosing and thus forming the irregular network commonly seen. Where the ends of adjacent loops become continuous the convoluted filament sometimes seen is produced.

The division of older cells to form new ones is preceded in man and the higher animals generally by nuclear division. The older observers (whose imperfect microscopes showed them in the interior of the nucleus only the nucleoli and the coarser nodal granules) believed this process to be quite simple in its nature, consisting merely in 
the passage of a cleavage-plane through the nucleus in the same way as is seen in the cell body itself. This, which is ealled direct division, may possibly sometimes oceur; but the constant advance of our knowledge makes it yearly more and more evident that the common mode of nuclear division as it occurs in plants and animals, and in normal and pathological changes alike, is an exceedingly complex process, to which the rather unfortmate name of indirect division is commonly applied: and it is quite possible, if not probable, that this is the sole method. The series of changes involved in this process has been termed karyokinesis. The name of mitotic division has also been applied to the process, the successive stages being called mitoses: the so-called direct division being distinguished as amitotic.

The successive steps that can be recognized in what is really one continuous process have becu designated by special names, based on the appearances presented by the nucleus from time to time. The first step is the formation of what has heen variously termed the spirem, or close skein: the secondary filaments are retracted into the primary filaments or loops; the nuclear membrane is also absorbed, as are the nuclcoli; the latter fact indicating the possible identity of these bories with the chromoplasm of the network. The next step is the formation of the open skein, or wreath: the primary filaments contract, becoming shorter and stouter, and having a less tortuous course: they gradually assume the form of an equatorial wreath of loops with, as has been stated, their flexures 
turned toward the region of the pole. To these loops the name of chromosomes has been given.

While the chromosomes are thus being defined, there appears in the polar area a group of fibres of achromatin, known from its form by the name of the achromatic spindle: this gradually moves toward the centre of the nucleus, taking an axial position with its extremities directed toward the pole and the anti-pole respectively. The chromosomes having by this time become quite short and stout, and V-shaped from the divergence of the limbs of the loops, attach themselves to the spindle, eventually assuming a radial position at its equator. When the nucleus is viewed at this stage from a polar or an anti-polar direction the radiating arms of the chromosomes together form a starlike figure to which the name of the aster has been given.

During the formation of the aster or immediately thereafter, the cleavage of the chromosomes take place, each loop being split into two similar (but of course more slender) loops by a plane passing through them all equatorially. This is the central process in the division of the nucleus: the changes which follow have therefore been sometimes designated by the term metakinesis: they are in a certain sense the retracing of the processes already described. In its more limited sense the term metakinesis is applied only to the cleavage of the chromosomes, and the changes immediately connected therewith.

The daughter-loops formed by the cleavage of the chromosomes begin to separate first at their apices, these being turned toward the extremities of the spindle: they then 
travel slowly along the achromatic fibres in each direction, two sets of chromosomes thus being formed; these gradually arrange thenselves about the poles of the spindle, which have now become the polar areas of the two daughter-11uclei. The limbs of associated loops remain for some time conneeted together by delicate achromatic uniting filaments: the whole figure seen from the side has a resultant barrel-shaped appearance; at either extremity the chromosomes have a stellate arrangement, and this stage is therefore designated the dyaster.

As the dyaster is formed, a cleavage plane passes through the body of the cell, whose course in the nuclear region is sometime marked by nodal points on the uniting filaments. As their separation is completed, the free extremities of the chromosomes of the daughter-nuclei bend inward toward the new antipolar areas, which face the plane of clearage and therefore, also, each other. Changes now ensuc in the inverse order of those described as taking place at the beginning of the process, the chromosomes becoming first converted into open skeins, and later into the closed skeins whose farther modification gives rise in each to a reticulum by the formation of anastomosing secondary filaments, accompanied with or followed by the formation of a nuclear membrane, the appearance in some cases of nucleoli, and the final assumption of the resting stage. The stage in which two adjacent and parallel skeins are secn is sometimes termed the double skein or dispirem: but it is evident that we are here dealing with structures which, though genetically associated, are now parts of separate and distinct nuclei. 
The number of the chromosomes varies considerably in different plants and animals, but is probably constant for the same tissues in each species: their form may also vary greatly, particularly as regards the length of the branches of the loops. The changes above described may in many cases be followed step by step with a good microscope of ordinary powers, either as they take place in living cells, or as they may be found in adjacent cells of suitably prepared tissues, each of the characteristic figures mentioned being clearly recognizable: in some instances, however, owing to the irregularity in the form of the chromosomes, or to variations in the rate of their transformation, some of the phases may be so far modified as to be no longer distinguishable. The essential features of the process are, nevertheless, always to be discerned, and should be distinctly borne in mind: they are, in their order, as follows : first, the collection of the chromatin of the nuclear network into chromosomes; second, the equatorial arrangement of the latter in what has been termed the nuclear plate; third, their metakinetic cleavage; fourth, the separation of the two sets of chromosomes thusformed; and finally their resolution into the nuclear networks of the two resultant daughter-nuclei, whose formation by this method is accompanied by the cleavage of the protoplasmic body of the parent cell, thus completing the formation of new cells.

It has recently been made fully evident that the changes taking place in the chromatin of the nucleus during karyokinesis are accompanied and preceded by other equally complicated changes in structures made up wholly of ach- 
romatin, the formation of the achromatic spindle being a portion thereof. While these changes are dloubtless as important as those already described, their nature is as yet far less elearly understood. A description of them wil therefore not be necessary at this time.
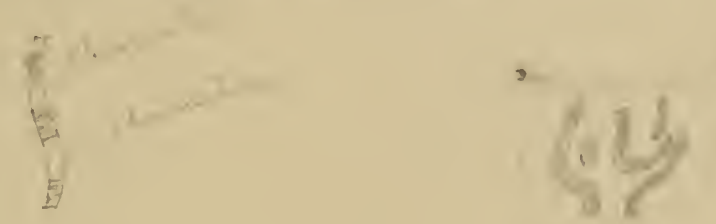

END OF PART I.

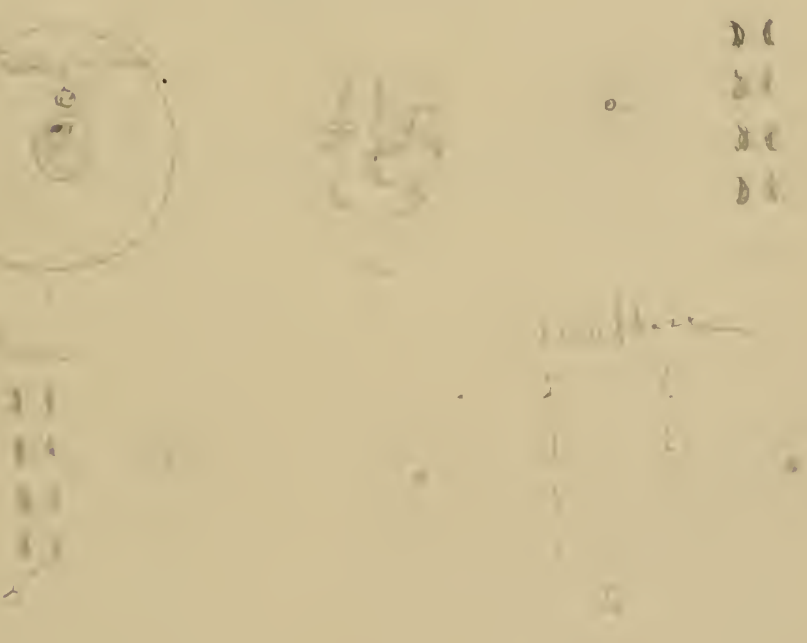





\section{PART II.}

HISTOLOGICAL ANATOMY. 



\section{CHAPTER XII.}

INTRODUCTORY.

Histological Anatomy has already been defined as the study of the arrangement of the tissues to form the organs of the body: an organ has also been defined as a particulat part of the body having a definite form and function: and it is a familiar fact that organs having common or essentially similar functions are associated together under the name of a system, whether they are continuous. as in the case of the nervous, or discontinuous, as in that of the muscular system.

While the study of the histological anatomy of the organs can in most cases be pursued most naturally by considering them in their relations as components of the various physiological systems, on account of the community of structure which, in most cases, characterizes associated organs, and while structure and function are without question closely (though not always evidently) related, it should always be kept clearly in mind that we are here concerned with structure only; and particularly with structure as composed of tissues: our constant endeavor should be, in the first place, to analyze the organs into the tissues of which they are composed, and to determine the relations of each to the others; and in the second place to note any characteristic peculiarities exhibited by any of 
the tissues present; this should be accompanied in each instance by a careful consideration of the disposition and characters of the compound factors of structure present, such as the blood, lymph, and nervous supply.

Tissues have already been defined as masses of cells or of cell-derivatives; and since tissues compose the organs, and organs make up the whole body, it follows that the body is to be regarded as a mass of more or less modified cells. The innumerable cellular elements which make up the adult human organism are in every case derived from the division of previously existing cells, and are therefore necessarily the descendents of a single ancestral cell. That cell is the fertilized ovum or, as it is sometimes termed, the oosperm. The study of fertilization, of the segmentation of the oosperm, and of the subsequent development of the tissues and organs of the body lie strictly within the province of the science of Embryology; but a brief statement of the origin of the various tissues may with advantage be given here, as throwing light on the structure and relations of the organs of the body.

Repeated cell division or segmentation in a short time divides the oosperm into a spheroidal mass of apparently similar cells: these soon arrange themselves in two distinct layers, from which a third intermediate layer is shortly afterward derived: the outer of these layers is called the epiblast or ectoderm, the middle the mesoblast or mesoderm, and the inner the hypoblast or entoderm; the whole trilaminar structure receiving the name of the blastoderm. 
From the cells which compose the epiblast are derived the following structures:

The epidermis, and its appendages the hairs and the nails, and the epithelium lining the tegumentary glands (sweat glands, sebaccous glands, mammary glands).

The epithelium of the nasal passages and the associated cavities and glands.

The epithelium of the mouth and of the glands continuous therewith, and of a portion of the tongue: the taste organs: the enamel of the teeth.

The epithelimm of the conjunctiva and of the glands of the erelicl, and of the front of the cornea: the lens of the eye: the retina (secondarily as an outgrowth from the brain).

The epithelium of the membranous labyrinth of the ear.

The epithelium lining the cavities contained in the cerebrospinal axis: the nerrous tissues: the neuroglia: the pineal body: the pituitary body.

From the cells which compose the mididle layer or mesoblast are derived the following structures:

The epithelium of the urinary and genital organs (with the exceptions of the epithelium of the bladder and urethra), including the reproductive elements of both sexes.

All the muscular tissues of the body, with the exceptions of the cells (doubtfully muscular) found in the sweat glands.

The skeletal tissues of all sorts throughout the body. 
The blood-vascular and lymph-vascular system: the serous membranes: the spleen and other adenoid bodies: the blood and lymph corpuscles.

It should be stated that by some histologists the cells which give rise to the tissues of the first two groups are regarded as having an origin somewhat different from those giving rise to the last two: the name mesoblast has been retained by them as a collective title for the former, while for the latter the name of parablast was proposed by His, and later that of mesenchyma by the Hertwigs. While this is probably true of the tissues of birds, it has not yet been proven for any mammal: and there are special reasons why it might be true in one case and not in the other.

From the cells which compose the hypoblast are derived the following structures:

The epithelium of the back of the tongue, the lover part of the pharynx, the oesophagus, stomach and intestines: that of all the glandular appendages of the alimentary canal.

The epithelium of the Eustachian tube and middle ear.

The epithelium of the larynx, the trachea, the bronchi, the bronchial tubes and the air sacs of the lungs.

The epithelium lining the urinary bladder and the urethra.

The epithelium lining the vesicular alveoli of the thyroid body.

The concentric corpuscles or epithelial nests of the thymus. 
Even a brief study of the tabular statement of the origin of the tissues of the body abore given will make clear the facts that most organs are nude up of tissues derived from more than one of the primary tissue-layers, and that in some cases at least, tissues which are structurally continu. ous and to all appearances similar are of different embryonic origin: this is notably the case with the transitional epithelium found in the ureters and the bladder; and other instances might be mentioned.

The order of study pursued in acquiring a knowledge of the histological anatomy of the various organs and systenis of the body is plainly a matter of convenience. That which will be here pursued is one shown by experience to be desirable on some accounts: but it should be understood that it may be readily varied at will. Omitting from farther consideration the simpler organs already described in the preceding part in connection with the tissues which chiefly compose them, such as the cartilages, the bones, the muscles, etc., the various regions, systems or groups of organs will be successively described as follows:

The tegumentary system will first receive attention: this includes not only the skin, but also those solid appendages, the hairs and the nails, which are derived from the special modifications of its outer layer; and those ingrowths of the same layer which constitute the sudoriparous, sebaceous and mammary glands. 
The skin upon the outer surface of the lips is continuous with the so-called mucous membrane of its inner surface: a transition which brings us naturally to the mouth and its contents: this includes the study of the lining membrane above referred to; the buccal and other glands which open thereon; the teeth and the tongue.

The mouth is the antechamber of the alimentary canal, though it is often regarded as a part of it. Beginning with the pharynx, we naturally consider in their order the oesophagus, the stomach, the small intestine in its various regions, and the large intestine (including the rectum); and also the glandular appendages of the canal, the liver and the pancreas.

The pharynx is not only a portion of the alimentary canal, but of the respiratory tract as well: the latter being, as embryology shows, an outgrowth of the digestive tube; its study includes that of the larynx, the trachea and bronchi, the bronchial tubes in their various ramifications, and the terminal sacs which make up with them the proper substance of the lungs.

The bladder and the urethra are parts of an outgrowth from the posterior region of the alimentary canal, as the respiratory tract is of the anterior. With them as median structures are closely associated the paired organs which complete the urinary apparatus: and intimately related therewith are the male and female reproductive glands, and the accessory organs connected with reproduction and micturition. This group will next be studied. 
Following the groups of organs above indicated, the circulatory system may next receive attention. This includes the study of the heart, the larger blood vessels, and the greater lymphatic trunks, the smaller hlood ressels and lymphatics having been already considered. Since the great serous cavities, such as that of the thorax or of the abdomen, may best be regarded as lymph spaces, the special discussion of their lining membranes may appropriately be considered here.

In addition to the lymph nodes, there are found in the body larger organs apparently allied to them or derived from their modification, such as the spleen and the thymus. The name of ductless glands has long been applied to these and to other soft organs of uncertain function, such as the thyroid, the pituitary body, and the adrenals (the so-called suprarenal capsules). The group (to which the name of the adenoid bodies is sometimes applied) is a heterogeneous one, its members in some cases having little in common: but they may for convenience be considered together.

The structure of the central nervous system is at present being worked out chicfly by histological methods: it is not as yet always easy to distinguish between what may be regarded as physiological, and what as histological anatomy in some cases. Imperfect as our knowledge is at present, the briefest statement of its details would transcend the limits of an elementary course in histology; but some knowlede of itgs most salient features is 
essential: the structure of the spinal cord will be discussed, together with that of the principal regions of the brain. On account of their intimate relation to the cerebrospinal axis, the membranes which invest it and which form the lining of the spinal canal will be taken up in this connection.

Finally the study of the central nervous axis may properly be followed by that of the complex outlying structures which are the essential parts of the organs of special sense, such as the eye, the ear and the nose. Beginning our course with the common investment of the body, we close it with organs which are in a great measure specializations thereof.

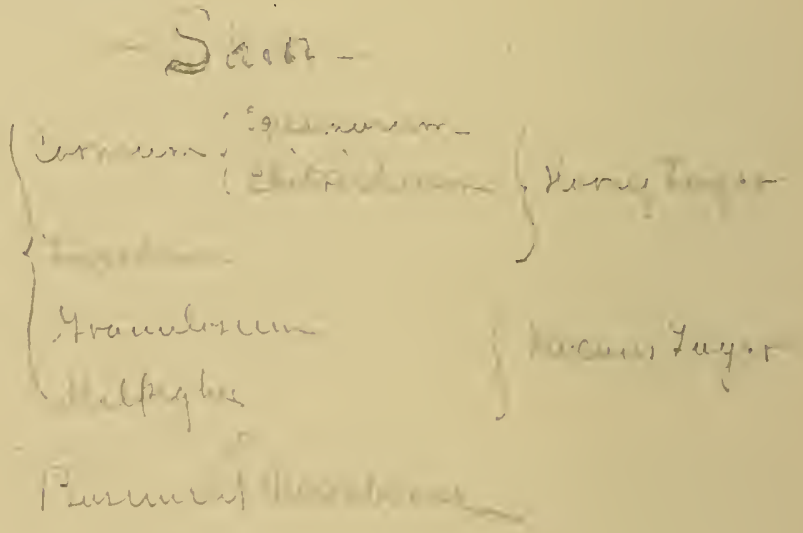




\section{CHAPTER XIH.}

THE SKIN AND APPENDAGES.

The skin, which is the investing and protecting nembrane of the body, is, like other membranes found upon free surfaces, composed of two primary layers, one of which is epithelial, the other skeletal : each of them being capable of division into more or less well marked secondary layers or strata. The outer or epithelial layer is known variously as the epidermis, cuticle, or scarf skin : the inner or skeletal layer as the derma, corium, or cutis (or less properly the cutis vera or "true" skin).

The epidermis can under favorable circumstances be seen even with the naked eye to be made up of two distinet layers, an inner moist or mucous layer (sometimes called the rete mucosum), and an outer dry or horny layer; and each of these layers can be resolved by the microscope into strata characterized by differences in the form and arrangement of the component cells : it may therefore be regarded as the best example of a stratified squamous epithelium in the whole body. Beginning with the mucous layer, we find next the corium cells which are columnar in form, and which are constantly undergoing division; the new cells formed at their free extremities are at first vertically elongated, then polyhedral in shape, and later somewhat flattened vertically: they form with the basal cells 
the first or lowermost stratum of the epidermis, known as the stratum Malpighii: the elements composing this stratum have the form of prickle-cells, their numerous short processes preventing the actual contact of the surfaces of adjacent cells, thus forming channels for the circulation of $1 \mathrm{ymph}$ and the nutrition of the elements: all the cells of this stratum may be regarded as living. Here and there leucocytes may sometimes be found; they have wandered into the epithelium from below and occupy irregular intercellular spaces. The cells of the deepest portions of the stratum Malpighii contain pigment granules, the color of the skin in different races depending chiefly on the relative abundance and color of the pigment. Delicate nerve fibrils enter this stratum of the epidermis, and, as stated in a previous chapter, Merkel has described special terminals thereto under the name of tactile cells.

As new cells are constantly formed in the deeper portions of the stratum Malpighii, the older cells are as constantly pushed farther and farther from the blood vessels of the corium which constitute their basis of nutritive supply through the agency of the $1 \mathrm{ymph}$ channels already mentioned. At a certain distance, which varies in different portions of the body, they begin to yield more conspicuously to the mechanical pressure from without, becoming more flattened in form, and at the same time to undergo degenerative changes, granules of a fat-like compound termed eleidin appearing in their substance in great numbers. There is thus formed a definite layer never more than a few cells deep to which the name of stratum granulosum is applied: the stratum granulosum and the 
stratum Malpighii together make up the mucous layer, and in most parts of the body the greater portion of the epidermis.

Immediately above the stratum granulosum and sharply distinguished from it is a thin layer of cells which resemble those of that stratum in bsing compressed in form, but differ from them in greater homogeneity of substance and therefore in translucency: this is the stratum lucidum, the lower of the stratii of the horny layer. According to Ranvier the formation of eleidin is followed by its transformation into keratin, the characteristic substance of horn, nails, claws, etc., which are, as we shall see, in the main developments of the stratum lucidum.

While the stratum lucidum is constantly receiving accessions from the cells of the stratum granulosum upon its lower or inner side, it is as constantly undergoing modifications on its upper or outer surface; and the line which marks this transformation is equally well defined in either case, the stratum lucidum remaining like the stratum granulosum of nearly constant thickness and definite limitations. The cells as they pass from its outer surface become somewhat swollen and more loosely disposed, forming a layer in which the outlines of the individual cells may be clearly discerned : the nuclei have disappeared and all traces of protoplasmic structure. This layer is sometimes designated the stratum corneum: in places where there are no hairs upon the surface it can be divided into two layers, the lower, or stratum epitrichium, consisting of thicker cells, more loosely disposed, and the outer or 
stratum squamssum of thin closely oppressed scales, which are eventually and constantly cast off. The stratum lucidum and stratum corneum (with the subdivisions of the latter) together make up the horny layer.

The epidermis varies greatly in thickness in different parts of the body: it may be no more than a tenth of a millimetre in thickness, or may be as much as a millimetre or more in places where the pressure and friction upon the surface is greatest, even under ordinary circumstances: and under special conditions the cells of the stratum squamosum of the palms of the hand or the soles of the feet, instead of being exfoliated, may become impacted to form layers two or three millimetres in thickness. The external surface shows irregularities which in some measure correspond to the conformation of the corium belcw, but as a rule differ therefrom by their less extent: the surface of the corium is, as we shall see, covered by projections known as papillae, into the spaces between which the stratum Malpighii descends: but this stratum varies correspondingly in thickness to such an extent that the papillary elevations are reduced on its upper surface to mere undulations, to which the remaining strata conform. The deeper lines upon the surface of the epidermis correspond to definite folds in the corium.

Like the epidermis, the corium can be divided into strata, which are not, however, so clearly defined in the case of the latter as of the former, consisting as they do in modifications of a fibrous layer. Upon the surface the fibres are 
fine and very closely felted, forming a thin, homogeneous and almost translucent stratum, which may be distinguished as the basement membrane of the epidermis. Its surface is closely beset with minute projections, which interlock with corresponding irregularities at the lower extremities of the colummar cells which lie at the base of the stratım Malpighii.

Beneath the basement membrane above referred to the corium consists of a felted mass of rather coarse bundles of white fibrous tissue, reinforced by elastic fibres in varying quantity, and containing in some localities a greater or less amount of smooth inuscular fibres, notably in connection with the hair-follicles. The outer portion is denser, the bundles being smaller and more closely felted and lying in the main parallel to the surface: it bears the papillae already referred to in anotherconnection, and has therefore been variously designated from its structure and conformation as the dense stratum or the stratum papillare: below it passes rather abruptly, but with no welldefined line of demarkation, into a region in which the bundles are coarser and less numerous, being more loosely and irregularly disposed: from its structure this is known as the stratum reticulare. The papillae are conical or club-shaped projections upward of the dense layer: in many cases they are more or less subdivided at their free extremities, in which case they are known as compound papillae: they are most abundant in the regions of the skin where the sense of touch is most acute, and also in a modified form make up the dermal portion of the nailbed. In some places, notably on the tips of the fingers, 
they are arranged in single or double rows along ridges of the corium, forming the familiar patterns readily seen with the naked eye: these patterns remain constant for each digit of each individual throughout life, and have therefore been used as marks of identification. Where best developed the papillae are from an eighth to a fourth of a millimetre in height.

The connective tissue corpuscles of the corium, like those of other fibrous membranes, are small, and as a rule compressed, their long axes lying parallel to the direction of the bundles with which they are associated: leucocytes are also present, as are pigment cells in moderate numbers.

The meshes of the stratum reticulare not unfrequently contain clusters of fat-cells of varying extent: immediately beneath, in most portions of the body, we come to a layer of larger or smaller ovoid or polyhedral fat-lobules separated by a coarse meshwork of fibre bundles. This layer, frequently termed the panniculus adiposus, is often spoken of as subcutaneous: it is, however, in many cases no more clearly marked off from the stratum reticulare than is the latter from the stratum papillare: it may with good reason be regarded as a portion of the skin, and as such be distinguished as the stratum adiposum: whether it shall be regarded as cutaneous or subcutaneous is largely a matter of definition; the fact of its association with the other structures of the skin as a part of the temperature regulating mechanism of the body is important. Below it passes into the loose layer of subcutaneous areolar tissue, which, save in a very few localities, intervenes 
between the slin and the structures beneath, permitting of its more or less free moxement upon them.

The skin, exclusive of the stratum arliposum, varies in thickness froin half a millimetre to two or three millimetres: and may even occasionally be as much as twice the latter quantity in thickness. It is thickest upon the shoullers and back.

The arteries which pass to the skin branch and subdivide in the subcutaneous tissue, the small vessels thus formed proceeding toward the surface: on their way they give off twigs which supply the fat-lobes above mentioned, and the hair follicles, sweat glands, etc., presently to be described. As they approach the surface they branch and anastomose, and finally break up into a meshwork of capillaries, situated just below the bascment membrane, supplying the papillae together with the other portions of the dense layer. The capillaries unite to form a superficial venous network, the larger veins arising therefrom passing to the deeper portions of the skin in such a way as to accompany the arteries in large measure.

Lymphatics arise in the spaces between the bundles of fibres which make up the dense layer. These are so disposed as to form a lymphatic network just below the superficial capillary network just mentioned: lymphatics have also been demonstrated in some of the larger papillae. A second network is said to exist in the decper portion of the corium, the two communicating freely with each other and with the subcutancous lymphatics. 
The nerve supply of the skin varies greatly in different portions of the body. Like the blood vessels, the nerves form plexuses in the papillary region, the meshes immediately beneath the epidermis becoming very fine and close: from the fibres composing them fibrillae are sent up into the stratum Malpighii in the manner already described. As stated in a previous chapter, it is not yet certain how these fibrils terminate.

In certain (if not all) portions of the body, more or fewer of the papillae are supplied with nerve fibres which there terminate in the so-called tactile corpuscles of Meissner: these are most abundant in the papillae of the fingers and toes. Other fibres terminate in end bulbs, while many others are distributed to the hair follicles and the sweat glands. In the deeper or subcutaneous region fibres are found which end in Pacinian bodies.

The glands of the skin are chiefly of two kinds: the sudoriparous or sweat glands, distributed in varying abundance over the whole surface of the body; and the sebaceons glands, found chiefly at the bases of the hairs. In certain localities specialized glands are found which may be regarded as modifications of one or the other of these two types.

The sudoriparous glands are situated in the reticular stratum and the outer portion of the adipose layer: they are spheroidal bodies, from one-half of a nillimetre to two millimetres in diameter, each consisting of a small tube coiled into a ball: from this the tube proceeds (as the duct of the gland) with slight deviations from a direct 
course tirough the corium, at whose surface it beemes continuous with a closely coiled spiral opening through the epidermis; the whole structure consisting, therefore, of a tubular depression of the surface, whose basement membrane is a continuation of that which forms elsewhere the outer limit of the corium, while its lining epithelium is a direct continuation of the epidermis.

The glandular (or the greater part of the coiled portion) is considerably larger than the rest of the tube, being sixty or seventy miera in diameter: immediately upon the basement membrane in this region is found a simple layer of elongated elements resembling smooth unuseular fibres in appearance, and commonly regarded as such; their long axes are parallel with the direction of the tube. Upon this, and surrounding the lumen of the tube, is a layer of columnar glandular cells about fiftcen micra in diameter, which are frequently pigmented. The duct is from twenty to thirty micra in diameter: it consists of a basement membrane upon which is scated a stratified epithelium of a very simple order: immediately next the membrane is a layer usually two cells thick, composed of polyhedral cells; while upon this is a single layer of flattened cells often designated the cuticle. On reaching the epidermis the basement membrane is, of course, continued into that of the surrounding region: the decper portion of the epithelium becomes continuous with the stratum Malpighii: the cuticular layer lines the passage through the epidermis, which is from the first over twice the diameter of the lumen of the duct, and in the stratum corneum flares to form a trumpet-shaped opening at the surface. 
Each sweat gland has a network of capillaries which penetrates the coil, following the interstitial connective tissue; and is also provided with a proper nerve supply. The number of the glands varies in different portions of the body from four or five hundred to the square inch (or more than a millimetre apart) upon the back of the neck and trunk to five or six time as many (or less than half a millimetre apart) on the palm of the hand or the sole of the foot. Those of the armpits are quite large, as are those at the root of the penis in the male and on the labia majores in the female. About the anus are found glands identical with the sweat glands in structure, but still larger than those just mentioned: they are sometimes distinguished as the circumanal glands. In the larger sudoriparous glands (and sometimes in the smaller) branching of the coiled portion occasionally occurs: and in some cases the duct is bifurcated, either before or after it enters the epidermis. The ceruminous glands of the external auditory meatus of the ear resemble the sweat glands in their structure, though differing from them to a marked degree in the nature of their secretion.

The sebaceous glands occur, as has been stated, at the roots of the hairs: they are also found upon the labia minores and the prepuce and occasionally in other hairless localities. 'Each consists of a short duct usually opening into the outer portion of a hair follicle and connecting internally with the adjacent secreting portion: this commonly consists of from three or four to eighteen or twenty saccules, or, rarely, a single spheroidal sac. The basement membrane, which is continuous with that of the corium, 
supports a compound layer of polyhedral eells, which in the glandular portion are constantly being renewed by the division of the cells next the basement membrane. The cells thus cast off undergo a sort of fatty degeneration, the interior of the gland thus becoming filled with a semifluid mass consisting of oil droplets, fragrments of brokendown cells, etc., which is discharged upou the surfice through the duct. The Meibomian glands of the evelid are to be regarded as enlarged and modified sebaceous glands. The mammary glands are also to be regarded as originally derived from the modification of bodies essentially similar to sebaceous glands and are properly to be considered as tegumentary organs. On account of their size and complexity, however, their structure will be better understood after the discussion of the general structure of glands in a subsequent chapter. They will, therefore, be discussed later in connection with the female reproductive organs.

Both sudoriparous and sebaceous glands are formed by solid ingrowths of the epidermis which in the case of the former penetrate the corium, the cavity being formed in the centre of the club-shaped mass and later communicating with the surface, while the inner end becomes coiled into the shape characteristic of the adult structure. In a similar manner the mass of cells which is the precursor of the sebaceous gland becomes divided in to lobules, the fatty transformation of the central cells already described beginning in them and adrancing along the axis of the pedicle, which thus becomes converted into the duct. 
While the hairs are practically outgrowths from the skin they are in reality derived from the modification of ingrowths resembling in some respects those which give rise to the sebaceous and sudoriparous glands. A hair is a mass of epidermal cells which cohere together to form a cylindrical or more or less flattened rod: these cells are formed upon and around a papilla situated at the bottom of a depression of the corium known as a hair-follicle, whose sides are lined with a specially modified layer of epidermal cells, continuing the Malpighian layer of the epidermis and the stratum lucidum to the region around the papilla at its base. The portion of the hair which projects beyond the surface is termed the shaft: that which is contained in the follicle is known as the root: the epidermic portion of the follicle surrounding the root is commonly called the root-sheath.

The fully formed hair, whether within or without the follicle, has on its surface a layer of imbricated scales, with their free edges directed toward the outer end of the hair; this layer is known as the cuticle: on the form and arrangement of the free margin of the cuticular cells depends the pattern of the superficial markings seen on the hairs of man and of different animals. Immediately beneath the cuticle lies the cortical substance of the hair: this is composed of greatly elongated fusiform cells in which traces of the nucleus are still visible, though the body of the cell has largely undergone horny transformation: these cells are so closely united that their limits are not ordinarily distinguishable, the cortex appearing to be made up of elongated fibres; it is to the color of the cortical cells that 
the color of the hair is largely duc. The cortical substance in some hairs extends clear to the centre: in others it surrounds (as its name implies) an axial mass of cuboidal or polyhedral cells, the medulla: the bodies of these cells usually contain small air-vesicles, rendering the medulla white by reflected light. Such air spaces may also be present in the elongated cells of the cortex.

The formation of the hair at the papilla will be more clearly understood if its description is preceded by that of the follicle with whose epidermis it is continuous: this, like the structure of which it is a modification, consists of a fibrous or dermal portion and an epithelial or cpidermal portion. The dermal portion may be resolved into three layers: of these the outer fibrous layer consists of bundles of white fibrous tissue running chiefly in the direction of the follicle and containing numerous connective-tissue corpuscles; it resembles the corium in most respects, save in the absence of elastic fibres: the middle layer, sometimes called the muscular layer, consists of connective tissue whose fibres run transversely, and of transversely-disposed elongated cells with rod-shaped nuclei which much resemble smooth muscular fibres and have been described as such, but which may perhaps be regarded as modified connective-tissue corpuscles; this layer extends from the bottom of the follicle to the point where the sebaceous gland opens, beyond which it is wanting: the inner or hyaline layer, or glassy membrane, as it is sometimes termed, is thin, homogeneous and transparent; it corresponds to the basement membrane of the corium. 
The epithelial portion of the follicle, while it is structurally free from the hair within, is generally brought away with the latter if it be pulled ont of the skin during life: it is therefore commonly termed the root-sheath of the hair. It consists of two layers, comparable in a general way to the mucous and the horny layers of the epidermis. The outer of these, or outer root-sheath, is much thicker than the inner, being a layer several cells deep; of these the cells next the hyaline layer (or basement membrane) are columnar, like those at the base of the stratum Malpighii; while those within are polyhedral prickle cells like the majority of those in the stratum just mentioned.

The inner layer of the epithelium, or inner root-sheath, may be divided into three strata: the outer of these, known as Henle's layer, is a single layer of flattened cells of a horny appearance, in which nuclei are not distinguishable: within this is Huxley's layer, composed of polyhedral cells with small nuclei, the layer being two or three cells deep: this is lined on the inside by the cuticle of the root-sheath a single layer of flattened cells which are imbricated in a manner similar to that of the cells of the cuticle of the hair, but in the opposite direction, the free edges of the cells in question being directed toward the bottom of the follicle; as a consequence, their edges interlock with those of the cells on the surface of the hair. The name of inner root-sheath is sometimes restricted to the part which comprises Henle's and Huxley's layers, the two becoming confluent at base of the follicle; the cuticle of the root-sheath is in such cases described as third layer thereof; but this is entirely a question of names: no satis- 
factory attempt has been marle to identify either of these layers with the various strata of the skin in the way that the outer root-sheath can be iclentified with the stratum Malpighii.

As we pass to the base of the follicle the outer fibrous layer is continued around its curving extrenity to be continued into the hair papilla, a large club-shaped papilla which projects upward into the lower end of the follicle: the middle layer becomes thinner and terminates near the lower end of the follicle: the hyaline layer, now resting on the fibrous layer, invests the surface of the papilla as a basement membrane. The whole follicle is slightly enlarged or bulbous at the base; the thickening being chiefly due to an enlargement of the epithelial portion of the follicle and of the lower end of the hatir itself. The outer root-sheath is continued downward with little change, the columnar cells at its base passing around the curve of the valley which surrounds the base of the papilla and over the surface of that body, acting here as elsewhere as the generative layer of the epithelium: the polyhedral cells become confluent with those which form the layers of Huxley and of Henle, these latter having previously become merged into one, and with the cells of the cuticle of the root-sheath. The valley at the base of the papilla is thus filled with a mass of newly formed cells, which, as they are rapidly multiplied, are pushed off as a cylindrical mass, the hair, from around the papilla. The medulla of the hair is formed from the cells developed upon the upper end of the papilla itself, and is in a certain sense the continuation of the col- 
umnar layer of the outer root-sheath: the cortex of the hair represents the polyhedral layer and the layers of $\mathrm{Hux}$ ley and Henle; while the cuticle of the hair corresponds to that of the root-sheath.

The outer fibrous layer of the hair follicles is richly supplied with blood vessels and nerves: some fibres of the latter pass to the outer root-sheath, where they appear to terminate among the epithelial cells in a manner similar to that found in the stratum Malpighii of the epidermis, chiefly in the immediate vicinity of the sebaceous glands. In some of the lower animals large hairs, chiefly about the face, are provided with special forms of nerve terminals: such hairs are termed tactile hairs.

The hair follicles are rarely vertical to the surface of the skin, the degree of their obliquity varying in different localities and, in consequence, the position of the hair upon the surface. Many hairs have small bundles of smooth muscular fibres passing from a point on the papillary layer of the corium near the opening of the follicle and on the side toward which the hair is inclined, to be inserted in the outer fibrous layer of the follicle near the bulb. The contraction of these muscles, known as the arrectores pili, tends to erect the hairs.

Hairs are formed as solid club-shaped downgrowths of the stratum Malpighii of the epidermis, which meet with specially formed papillae around which the hair-bulb is moulded: the young hair is developed as a conical mass 
above the papilla, the solid epithelial plug first formed undergoing sebaceous degeneration in its centre and thus permitting the escape of the hair: its lateral portions become the root-sheath, outgrowths therefrom giving rise to the sebaceous glands. When a hair ceases to grow, the papilla gradually disappears and the hair finally drops out of the follicle: this may or may not have been preceded by the formation of a new downgrowth from the bottom of the follicle and the derelopment of a new pailla, thus giving rise to a replacing hair.

The nails, like hairs, are masses of epidermal cells, consisting chiefly of a thickened and otherwise modified extension of the stratum lucidum. Each nail can be regarded as composed of three portions: the free margin, in which growth has entirely ceased, the nail-body, which constitutes its greater portion, but which receives but slight additions to its under surface, and the nail-root, which is the region of greatest increase. The body of the wail is continuous below with a modification of the stratum Malpighii, which rests upon a modified portion of the corium, called the nail-bed: laterally this fibrous layer is folded "pward to form the lateral nail-grooves, and posteriorly. upward and forward to form the posterior nail-groove; the lower portion of which is termed the nail-matrix, including the whitish curved area at the base of the nail known as the lunula.

The nail-bed and nail-matrix are continuations of the corium which has become highly vascular and is well sup- 
plied with nerves: the papillae upon its surface are simple and closely crowded together: as far as the outer margin of the lunula they show no definite arrangement, but throughout the nail-bed proper are arranged in longitudinal rows, their extremities inclining toward the free end of the nail: they are so closely set in the rows as to appear to be confluent in ridges, which are sometimes said to replace them. Below, the nuil-bed is connected with the distal extremity of the last phalangeal bone by numerous strong bands of fibrous tissue: as it passes around the margin of the nail to enter the walls of the nail-grooves, it assumes the structure commonly characteristic of it.

The stratum Malpighii is by some histologists defined as a part of the nail-bed: it is a question of names merely, but it is perhaps better on the whole to divide the two regions by the natural boundary between dermal and epidermal structures. The columnar cells of this stratum are closely packed together, and multiply rapidly, particularly in the region of the matrix: very few polyhedral cells are to be seen, the newly formed cells passing over rapidly into the substance of the nail without an intervening stratum granulosum. Like the stratum lucidum, the body of the nail consists of flattened horny cells, in which traces of nuclei can be seen after dissociation. During foetal life the nail is invested by the stratum epitrichium, traces of which overlie its margins at birth. 


\section{CHAPTER XIV.}

THE MOUTH AND ITS CONTENTS.

The mouth is formed by an ingrowth from the surface of the head; its lining is therefore epiblastic in origin and directly continuous with the epidermis: the cavity of the mouth does not at first conmunicate with that of the pharynx, but the two are connected later by the perforation of their common wall at the fauces. Within the cavity of the mouth are found the jaw arches, covered by the gums and bearing the teeth, and the tongue, which rises from its floor; and in the so-called mucous membrane which lines it throughout are found the labial, buccal, palatal and lingual glands: while other and larger glands more remotely . situated discharge their secretion into the cavity of the mouth by means of duets.

As we pass from the skin upon the outer surface of the lip to the mucous membrane which is found upon its inner surface marked changes are to be noted in both the epithelial and the fibrous layer. Near the margin of the lip the hair follicles are wanting, though sebaceous glands are present; the derma becomes thinner and highly vascular; while the epidernis becomes much more transparent, allowing the red color of the blood in the dermal capillaries to shine through. As the transition is made from a surface constantly dry from exposure to the air to one con- 
stantly moist, the stratification of the epithelium becomes less distinct: and on the inside of the mouth is found a layer of protoplasmic cells corresponding to the stratum Malpighii passing by insensible gradations into a layer of horny cells, flattened, and with small nuclei, that are constantly being exfoliated, corresponding to the stratum corneum: all trace of the intervening stratum granulosum and stratum lucidum disappearing The cells at the base of the layer are columnar, like those in the corresponding portion of the epidermis, and, like them, are constantly forming new cells to replace those lost from the outer surface.

Underneath the epithelium is the fibrous layer, corresponding to the corium, to which the name of mucosa or mucous membrane is sometime restricted: it is in most cases thinner than the corium, but bears upon its surface numerous papillae: below it breaks up into looser connective tissue as a rule, the meshes being occupied by the glands of the mucosa and by fat lobules: to this looser subjacent tissue the names of submucosa is applied: in the region of the fauces, the soft palate, and the uvula, adenoid tissue is present in great abundance in the mucous membrane; a feature never found in connection with the corium of the skin.

Where the mucous membrane invests the hard palate, and where it passes over the arch of either jav to form the gums, the fibrous layer becomes firm and dense, glands and fat lobules alike being absent or very sparingly present, and the deeper portion becomes directly continuous with the periosteum of the subjacent bone. The papillae and the investing epidermis of the dorsal surface of the 
tongue undergo special modifications best deseribed in connection with that organ.

The term mucosa, or its equivalent, mucous membrane, above applied to the lining of the month, is also used to designate the lining of all those cavities which communieate directly or indirectly with the outside of the body (with the exception of the abdominal cavity of the female). It thus includes the inrestment of the nasal passages and the associated sinuses, the respiratory tract, the oral cavity and the alimentary canal, the urinogenital tract, and the middle ear with the Eustachian tube. By some histologists the term is even applied to the lining of the hair follicles and the dermal glands. Excluding the latter, it may in general terms be described as consisting, like the skin, and as seen in the lining of the mouth, of an epithelial and a skeletal portion. The epithelium of the mouth and of the nasal passages is epiblastic in its origin: that of the kiclneys and genital glands, and of their proper ducts, mesoblastic: that of all the rest of the surfaces named hypoblastic. It is to the regions lined with hypoblastic epithelium that the term mucosa is chiefly applied.

The epithelium of a mucous surface may be simple and flattened, polyhedral, or columnar; or transitional; or stratified. The skeletal layer consists usually of a basement membrane (sometimes termed a membrana propria,) which may be either a homogeneous layer of closely felted fibres, or an endothelioid layer of connective tissue corpuscles; beneath this is the felted fibrous layer termed variously the corium, the stroma, or the tunica propria, or, by some, the mucosa in a limited sense. It consists of a 
thicker or thinner layer of rather loosely felted bundles of white fibres, rich in blood vessels and in some cases having its surface raised into papillae. Elastic fibres are sometimes present in such great numbers as to form a definite elastic layer, and at other times are almost entirely wanting. Adenoid tissue may be present in varying quantity, sometimes forming definite nodules or clusters of nodules. Smooth muscular fibres may also be present, forming a stratum in the deeper part of the membrane one or more layers in thickness and known as the muscularis mucosae. In exceptional cases, such as that above described in connection with the hard palate and the jaw arches, the mucosa is firmly united to the subjacent structures: as a rule the deeper portion passes over into a layer of loose areolar tissue known as the submucosa, thus permitting of the free movement of the mucosa on the structures beneath.

Where the epithelium of a mucous surface is columnar a varying proportion of the elements have the form of goblet cells, as described in a previous chapter: these are perhaps the simplest form of special secreting organs found in the human body; and are sometimes spoken of as unicellular glands: the term gland being often loosely employed to designate any secreting organ and, indeed, some organs that are not at all secretory in function.

Increase of secreting surface is obtained by ingrowths of the epithelium which penetrate the fibrous layer to a greater or less extent, in a manner similar to that described in connection with the skin; like those referred to these ingrowths may be either tubular or saccular. Where 
such ingrowths are not sub-divided internally they are commonly called simple tubular or simple saccular glands, as the case may be. A distinction of importance, both structural and physiological, ought, however, to be noted in this connection. Some such simple secreting organs are lined with cells that are similar in form and alike secretory in function throughout their whole extent: while in others the work of secretion is restricted to specialized cells in the epithelium of the deeper portions. that which is found upon the portion next the surface having lost its secretory activity and become morlified to form the lining of a conducting tube through which the secretion of the deeper portion is discharged. This distinction can be kept in view if we always apply to the structure which secretes throughout its whole extent the name of a follicle, and define a gland as a secreting organ provided with a duct.

Glands, as thus defined, may be either tubular or saccular, and either simple or, by the subdivision of the secreting portion, multiple or compound: the secreting porof a simple gland is called the fundus: those of a compound gland are called acini or alveoli. Where the final divisions of a compound gland are saccular in form, the gland is frequently designated as acinous or racemose; where they are elongated, the gland is called compound tubular; and where both forms of alveolus are present the term acino-tubular is applied. By many histologists, however, the distinctions which these terms imply are regarded as of questionable value.

Follicles, simple glands, and the smaller compound glands 
rarely penetrate deeper than the submucous or subcutaneous tissue of the membrane trom which they are derived. Large compound glands, on the contrary, are usually sitwated at some distance from the surface where their secretions are discharged. Glands which are thus situated outside of the organs to which their ducts lead are called extrinsic, the term intrinsic being applied to thosecontained within the organs in question.

With the exception of the tegumentary glands discussed or mentioned in the preceding chapter, all the glands of the body open upon mucous surfaces; and with the farther exception of the kidneys and the genital glands are derived from the modification of a mucous membrane. The secretions discharged by them have alvays one or both of two functions: to lubricate and preserve the sur. face in question, which is a general function, or to act as ferments upon food stuffs taken into the body, which is a special function restricted to the alimentary tract. Two principal types of glands are therefore distinguishable both structurally and functionally. Those of the first sort are known as mucous glands; those of the second (from the more watery character of their secretions, but less properly) as serous glands. In the case of some compound glands some of the alveoli are of the mucous and some of the serous type: such are designated mixed glands.

In glands of the mucous type the acini or alveoli are lined with polyhedral cells which do not extend quite to the centre of the cavity, thus leaving a well defined central 
opening or lumen: the free extremity of the cell is transparent and does not stain readily with most reagents, while the protoplasm and the somewhat flattened nucleus which it surrounds are crowded down to the base. of the cell; in other words, the general appearance is like that previously described as characteristic of gob]et cells, which, it should be recalled, are mucigenous in function. In addition, there may in some cases be seen batwen the glandular cells and the basement membrane crescent shaped groups of granular cells which stain deeply: these were described independently by two observers, who gave them nantes associated with their form; they are therefore called the crescents of Gianuzzi, or the demilunes of Heidenhain: their nature and functions are not yet fully understood: the constituent cells (sometimes solitary) are called marginal cells.

In glands of the serous type the secreting epitlelium consists of polyhedral cells which when at rest extend clear to the centre of the alveolus: a distinct lumen cannot, therefore, be recognized. The whole body of the cell is granular, the substance which is to become the characteristic secretion being thus stored up in the protoplasm: the nucleus is spherical, and situated near the centre of the mass; and the whole cell stains readily. No trace of anything like the crescentic cell-masses above mentioned or of marginal cells is to be found in any serous gland.

The appearances above described are those seen in sections of glands previously hardened by reagents, and taken 
from organs which had not been actively stimulated immediately before the preparation was made. If a piece of the fresh gland be examined in blood serum the mucigen is seen in the case of the mucigenous cells to be present in the form of very large granules: while the ferment secreting cells are so swollen that not only the lumen of the acinus but also the outlines of the cells are obliterated: otherwise the appearances are much as described above. As the result of prolonged stimulation the mucigenous cells discharge their secretion, and the nuclei approach a central position: while the cells of the serous type become smaller after discharge, and a distinct lumen becomes visible in the acinus. The two types of alveoli, become therefore much more nearly alike, though not so much so as to prevent their distinct recognition.

It is in the mouth that we first meet with a mucosa; and its discussion has therefore been deferred until after a description of the lining membrane of that cavity. The glands of the mouth also furnish us with examples of both mucous and serous, and both intrinsic and extrinsic glands.

The intrinsic glands of the mouth are the labial, buccal, palatal (including those of the uvula), and lingual. These are all racemose glands situated in the submucosa, with the exception of the lingual, which lie between the muscular bundles of the tongue. They are all of the mucons type save those on the posterior part of the tongue, which are serous. Their secretion contributes to form the saliva of the mouth. 
The extrinsic glands of the mouth are those commonly referred to under the name of the salivary glands: they are designated, from their positions as the sublingual, the submaxillary, and the parotid glands: the firstnaned are doubtfully to be called extrinsic, on account of their structure and position, since they consist in each instance of a group of small glands opening by several ducts, and aresituated just beneath the mucous membrane on either side of the base of the frenum of the tongue. The nature of the salivary glands differs in different mam1nals: in man the sublingual and submaxillary are mixed glands, and the parotid is of the serous type.

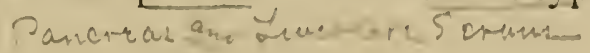

The acini or alveoli of one of the larger or extrinsic salivary glands vary greatly in form from flask-shaped sacs to wavy, contorted, or eren branched tubules: the basement membrane is reticulated and the epithelium varies with the type of gland in question. Each alveolus leads into a tubule smaller than itself known variously as the ductule, the connecting or intermediate tubule or the intercalary duct: the basement membrane of the ductule is continuous with that of the alveolus; its epithelium consists of a single layer of flattened cells. The ductules of a number of alveoli enter a common tube known as an intralobular duct or salivary tube of Pflueger, the alveoli and ductules with the duct just mentioned together making up a lobule. An intralobular duct consists of a basement membrane continuous with that of the ductules, and a single layer of columnar epithelial cells: the latter have spherical nuclei situated near the centre of the cell; 
the outer extremity of the cell is finely granular, while that next the basement membrane is vertically striated. The basement membrane of the alveoli, the ductules and the intralobular duct alike rest upon the interstitial connective tissue, which contains rich networks of capillaries surrounding the alveoli.

The intralobular ducts lead into larger conducting tubes known as interlobular ducts, around which the lobules are aggregated into lobes, their boundaries within the lobe being marked by septa of fibrous tissue. The interlobular lead into the interlobar ducts, which finally enter the chief duct of the gland. The larger ducts have beneath the basement membrane a definite fibrous layer which in some cases contains smooth muscular fibres: the epithelium is columnar and simple, save in the largest ducts, in which a layer of polyhedral cells lies between the columnar cells and the basement membrane.

The interstitial connective tissue which fills the spaces between the alveoli passes into thin laminae of fibrous tissue which separate the lobules: these septa are again continuous with stouter structures of the same nature which lie between the lobes of the gland. The interlobar septa are continuous internally with the stroma of connective tissue which immediately surrounds the proper fibrous tunic of the chief duct and its principal subdivisions, and externally with a membranous layer which surrounds the whole gland and is known as its capsule. The place where the chief duct leaves the interior of the gland is known as the hilum: the nerves, arteries, veins, and lymphatics of the gland also enter or leave at this point, 
the capsule here becoming continuous with the stroma of fibrous tissue (above nentioned as surrounding the duct and its branches) in which they lie, and in which occasional smatl nervous ganglia maly be found.

The saliva contained in the mouth is a mixture of the secretions of the various intrinsic and extrinsic glands. With the nature and properties of the fluid itself we are not here concerned: it constantly contains, however, certain histological elements which may with propricty be mentioned in this connection. The most abundant of these are the squamous cells which are constantly being exfoliated from the surface of the stratified epithelium of the nouth: they oceur singly and in patehes; and when found in the latter form the overlapping of their bevelled edges can be plainly seen: the nuclei are small and flattened, and stain readily. Less numerous, but quite abundant in the saliva from the back part of the mouth are the so-called salivary corpuscles, spheroidal bodies but little larger than colorless blood corpuscles, each containing one or two spheroidal nuclei and numerous minute granules which exhibit a constant dancing movement within the interior of the cell. The salivary corpuscles are really modified lencocytes that have escaped into the oral cavity from the tonsils or similar adjacent structures, and have become swollen by the imbibition of the watery saliva; the granules of the protoplasm being suspended in the imbibed fluid and exhibiting Brownian motion in consequence.

The mouth contains certain organs by means of which 
the food is masticated and prepared for swallowing by the thorough admixture of the saliva. These are the teeth and the tongue. A tooth is a vertically elongated mass of the tissue mentioned in a previous chapter by the name of dentine, having a solid free portion, the crown, projecting above the gum and covered with a layer of enamel: and a hollow portion, the fang, imbedded in a socket in the jaw known as an alveolus; the outer surface of the fang is covered with a layer of cementum, and the internal cavity occupied by the pulp. The slightly constricted region where the crown and the fang meet and the tooth pierces the gum is called the neck of the tooth.

The pulp which fills the central cavity of the tooth is a mass of connective tissue approaching in character more nearly to the gelatinous tissue of the embryo than any other structure in the adult human body, its soft and sparingly fibrillated matrix containing numerous branching corpuscles whose processes are connected. It contains a rich network of bloodvessels, and a small bundle of nerve fibres, entering its substance through the minute canal at the tip of the fang. Toward its surface the corpuscles rapidly increase in number and in size, forming a superficial layer of crowded cells much resembling a columnar epithelium: these are the odontoblasts; they are in all probability directly associated with the formation of dentine.

Like osseous tissue, dentine is characterized by a lamellated and calcified matrix traversed by canaliculi: it differs essentially from the substance of bone, however, in the mode of calcification and the definiteness of the lamel- 
lae, and particularly in that the characteristic corpuscles associated with its formation, the odontoblasts, do not, like the osteoblasts of bone tissue, becone imbedded between the lamellae, but remain situated upon the inner surface of the mass, their long and sparingly branched processes, the fibres of Tomes, occupying the canals, called dentinal tubules, which traverse the dentinal lamellae. Calcification takes place, at least in the outer portion of the mass, by the deposition of globular nodules of lime salts; these at first do not oceupy the whole of the matrix, learing numerous irregularly stellate spaces, the interglobular spaces, the outer layer in which they abound being known as the granular layer. The interglobular spaces communicate outwardly with the surface of the dentine and inwardly with the dentinal tubules: corpuscles have been described as contained in them and communicating with the extremities of the fibres of Tomes. Decper the calcification becomes more nearly continuous: at certain intervals it is, however, incomplete, irregular lines in a general way parallel to the surface being seen: these, known as the incremental lines of Salter, may be regarded as marking the boundaries of the lamellae. The dentinal tubules are lined by a condensation of the fibres of the matrix sometimes described as a distinct membrane; they have a way or spiral course across the lamellac and give off branches occasionally at acute angles which pursue a similar course; their waviness gives rise to a striated appearance when a tooth is seen in longitudinal section with the naked eye, or a low power of the nicroscope: the alternating dark bands scen are known as the lines of 
Schreger. The general direction of the tubules is in the fang at right angles to the lamellae; in the crown they pass obliquely upward.

The enamel consists of a layer of elongated calcified prisms, usually hexagonal in cross section, set in a general way vertical to the surface of the dentine of the crown of the tooth; they are alternately lighter and darker throughout their extent, giving to the enamel as a whole a banded appearance. In addition, occasional dark brown lines may be seen crossing the enamel columns parallel-wise to the surface; these, known as the stripes of Retzius, may indicate lines of growth. Here and there vertical spaces may be seen slightly separating the enamel columns near the dentine, with which the interglobular spaces of the latter possibly communicate. At the time of irruption the surface of the enamel is covered with a thin cuticular layer known as Nasmyth's membrane; it is rapidly worn away as soon as the teeth are put to active use.

The cementum, cement-substance, or crusta petrosa, as it is variously termed, investing the surface of the fang, is composed of tissue essentially similar in structure to that of dense bone: the lamellae are few and irregularly arranged, the lacunae varying in size and form; the canaliculi of the latter are said to communicate with the interglobular spaces of the adjacent dentine: there are no clearly defined Haversian systems. The layer is formed by the so-called periodontal membrane, which is practically continuous outwardly with the periosteum lining the alveolus which contains the tooth. 
The enamel is epithelial in its origin, being derived from the calcification of a layer of cells or formed by their secretion. The dentine and cementum are true skeletal structures. The margin of the foetal jaw early shows a thickening of the stratified epithelium which grows downward into a groove into the mesoblastic tissue beneath, the dental groove: the curved rod of epithelial cells thus formed is known as the primary enamel germ. At regular intervals along the under side of this rod further prolifcrations of the epithelial cells occur, with localized downgrowths, the special enamel germs, at first flask-shaped. At the same time a condensation in the mesoblastic tissue beneath each gives rise to a conical dental papilla which grows upward to meet the epithelial downgrowth. The latter grows down about the papilla, thus becoming converted into a cap-like mass, the enamel organ, connected with the epithelial ridge above by a slender stalk: the stalk is attached to one side of the enamel organ, cwing to the mode of growth of the latter. A condensation of the mesoblastic tissues surrounding the newly formed enamel organ and papilla gives rise to a membrane which soon becomes rich in bloodvessels, and is known as the dental sac.

The papilla, thus invested by the enamel organ, assumes the general shape of the crown of the future tootli: the corpuscles near the surface become more numerous and larger than those of the interior, and the layer of odontoblasts is formed, after which the deposition of dentine is begun. Important changes hare in the meantime taken place in the enamel organ: the cells upon the concave sur- 
face next the papilla become greatly elongated vertically, and by their activity begin the deposition of the enamel; whether by a process of secretion or by the transformation of their own substance is still a matter of debate; the layer of enamel-forming cells is known as the inner layer of the enamel organ: the margin of this layer is continued over the convex surface of the enamel organ by the outer layer of cuboidal epithelial cells, which is in turn continuous through the stalk with the epithelium of the jaw, and which lies in contact with the dental sac: the interior of the enamel organ contains a mass of cells, the so-called middle layer, which becomes converted into branching corpuscles, their interspaces being filled with a watery fluid. From the side of the enamel organ or from the adjacent stalk a bud arises early in the history of the tooth, and grows downward to form a second enamel organ in the case of those teeth which are succeeded by others.

As the time of irruption approaches, the middle layer of the enamel organ becomes greatly compressed, and the enamel forming cells of the inner layer reduced in depths to flattened scale-like bodies, forming the membrane of Nasmyth. The papilla rapidly elongates, forming the fang, thus pushing the first formed crown upward toward its final position. After the dentinal portion of the fang is fully formed the cementum is deposited upon its outer surface in a manner practically the same as that of the formation of bone elsewhere.

The tongue is a mass of striped muscular tissue in- 
vested with the mucous membrane of the mouth, which upon its upper surface is specially modified. The muscular fibres which make up its bulk are divided into two symmetrical masses by a median vertical partition of fibrous tissue, the lingual septum, which is better developed below than above: right and left of this they lie in interwoven bundles some of which run longitudinally, others transversely, and a third set vertically; their arrangement to form the lingual muscles is a matter anatomical rather than of histological discussion.

The mucous membrane of the lower surface and sides of the tongue does not differ essentially from that of the rest of the mouth. At the margin of the upper or dorsal surface, however, it suddenly becomes modified, the majority of the papillae becoming greatly enlarged to form the projections of the surface visible to the naked eye and known as the lingual papillae. Of these there are three kinds: those most abundant, and covering the whole surface of the tongue with a velvety layer, are known as conical or filiform from their shape; they are tapering upgrowths of the corium, covered with a corresponding layer of epithelium, and are frequently bifid at their tips: scattered here and there among them are spheroidal elevations of the surface about the size of a small pin's head; these are termed fungiform, and are invested with a thin layer of stratified epithelium. Near the root of the tongue, and arranged in a V-shaped figure whose apex is directed backward, are eight to twelve large papillae, roughly cylindrical in form, which are sunk in depressions of the surface and surrounded by circular trenches or grooves; these are the 
circumvallate papillae: the stratified epithelium of their sides forms a deep layer in which are imbedded the tastebuds or gustatory organs. The description of these structures will be given in the chapter devoted to the organs of special sense.

The papillae all contain capillary networks, the fungiform and circumvallate papillae having a specially abundant blood supply. The mucous membrane of the posterior part of the tongue contains diffuse adenoid tissue with here and there occasional nodules of the same. The lingual glands of the anterior part of the tongue are all of the mucous type: some of those of the posterior part, known as the glands of Ebner, are of the serous type, their ducts opening into the grooves which surround the circumvallate papillae. The tongue is formed in part by an upgrowth from the floor of the mouth, in part by a growth forward from the ventral wall of the pharynx: its epithelium is therefore in part epiblastic and in part hypoblastic in origin; but the two regions cannot be distinguished in the adult

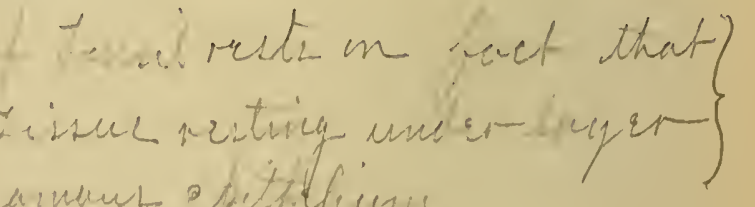




\section{CHAPTER XY.}

- THE ALIMENTARY CANAL.

As we pass from the mouth through the opening of the fauces we enter the tube lined with hypoblastic epithelium of which the mouth is the antechamber, and to which the name of the alimentary canal is strictly applicable. The anterior and posterior pillars of the fauces are folds of the mucons membrane rich in mucous glands and containing some diffuse adenoid tissue: between them on either side of the mouth is situated a tonsil: a rounded body of variable size consisting of a mass of fibrous tissue richly infiltrated with adenoid tissue and containing a variable number (from ten to twenty) well-defined nodules of the same structure, like those found in the mucous membrane of the rest of the tongue. The surface of the adenoid mass thus formed is covered with stratified epithelium continuous with that adjacent, which is in places invaded by numbers of leucocytes passing through it into the oral cavity to become the bodies described above as salivary corpuscles. Deep folds or depressions of the surface occur, lined with stratified epithelium: these are termed crypts, and receire the secretions of subjacent mucous glands.

The alimentary canal, properly so-called, is a tube which, beginning at the pharyn and ending with the rectum, 
varies in size and form in different portions. Its structure varies correspondingly in detail, as will be stated in the descriptions of the various regions. In general plan it is a tube having essentially a double wall whose divisions are connected by a stratum of areolar tissue, and invested throughout a portion of its extent by the serous membrane which lines the abdominal cavity.

The inner or glandular layer, the mucosa, is a mucous membrane whose epithelium varies greatly in different parts: the fibrous portion is in all the various regions more or less infiltrated with adenoid tissue which is in places quite scanty in amount or wanting altogether, in places so abundant as to form conspicuous nodular masses. Smooth muscular fibres are also present in all the regions, usually in such quantity as to form a well-defined muscularis mucosae, which may consist of two or even three distinct layers.

The stratum of areolar tissue into which the loose and folded mucosa passes, the submucosa, varies in extent in different regions, but always permits of free movement of the folds of the mucosa. It is characterized throughout the greater portion of its extent by the presence of a network of nonmedullated nervous fibres with small ganglia at the nodes, the plexus of Meissner: and contains the larger blood and lymph vessels from which those of the mucosa are derived.

Beyond the submucosa, which is continuous with its internal skeletal framework, is the outer principal layer of the tube, the musculosa, or muscular layer. The anterior portion is composed of striped fibres; the remainder (and 
greater portion) of smooth fibres. Except in the pharynx, where definite muscles are found, the bundles of fibres, whether smooth or striped, are arranged in two continuous strata, the inner of which is composed of circular and the outer of longitudinal fibres: between them is a thin layer of connective tissue containing blood vessels and a second and larger nervous network known as the plexus of Auerbach.

In the neck and thorax the connective tissue adjacent forms a more or less well defined membranous layer just without the musculosa sometimes described as a separate layer of the canal under the name of the fibrosa; while the term serosa is commonly applied to the peritoneal fold which rests upon the musculosa throughout the abdominal cavity.

The pharny $x$ is the first region of the alimentary canal. Its upper or respiratory portion is lined with ciliated columnarepithelium; while that of the lower and larger portion is stratified squamous: the latter is throughout a large part of its extent more or less infiltrated with leucocytes. The fibrous membranecontains a large amount of adenoid tissue, which in the upper and posterior part of the pharynx is collected into a large patch containing adenoid nodules and crypt-like depressions, to which the name of the pharyngeal tonsil has been given: glands of the mucous type are abundant. Beneath the submucosa is found a dense layer of fibrous tissue, the pharyngeal aponeurosis, separating the mucous membrane from the muscular coat. Vithout are the well defined pharyngeal muscles, com- 
posed of striped muscular fibres. The structure of the pharynx may perhaps be best understood if we regard the musculosa proper of the alimentary tract as entirely deficient, the aponeurosis representing the fibrosa, and the constrictor muscles as external additions thereto.

The oesophagus, like the lower part of the pharynx, is lined with stratified squamous epithelium. The mucous membrane, which is thrown into longitudinal folds, bears numerous small papillae upon the surface, covered by a homogeneous basement membrane. Adenoid tissue is very sparingly present in the mucosa, but occasional solitary nodules may be found. The muscularis mucosae is wanting in the uppermost part of the oesophagus: lower it at first appears in the form of scattered longitudinal bundles, which near the lower end of the oesophagus become so numerous as to form a continuous layer of longitudinal fibres.

The submucosa, which is well developed, contains the intrinsic glands of the oesophagus, which are of the mucous type; their ducts traverse the mucosa: blood vessels and lymphatics are numerous: the plexus of Meissner is wanting or very scantily developed throughout the greater part of the oesophagus.

The musculosa consists throughout the upper third of a transverse and a longitudinal layer of striped muscular fibres; lower down the layers are made up wholly of smooth fibres. The plexus of Auerbach is present, though its ganglia are smaller and less numerous than those of the rest of the alimentary canal. There is a more or less 
well defined fibrosa just without the extermal nusscular layer.

The oesophagus opens into the stomach, a saccular dilation of the alimentary canal whose wall is greatly modified, chiefly in the mucosa: this layer is much thickened, owing to the development of long tubular glands which open upon its surface, are imberded in it, and make up the greater part of its substance; it is thrown into numerous folds, or rugae, and is covered with a simple laver of columnar epithelium containing numerous goblet cells, the transition between which and the stratified epithelium of the ocsoplıagus is abrupt: its surface is dotted all over with the minute openings of the gastric glands previously inentioned.

The gastric glands are distinguished by their structure into two kinds, designated according to their position as cardiac (also called peptic), occupying the region extending from the oesophageal opening to beyond the middle of the stomach, and the pyloric, which occupy the lower third. The former have short ducts lined with columnar epithelium similar to that of the surface of the stomach: the glandular portion is a long wavy or slightly coiled tubule, whose end is sometimes strongly bent; from two to four such secreting tubules commonly opening into a single duct: lining the tubule throughout its whole extent is a single layer of polyhedral cells, while scattered along the tubule here and there between the layer of cells just mentioned and the basement membrane are larger spheroidal or ovoidal cells. The cells first mentioned are called 
the chief or from their position the central cells, or, from their probableferment-secreting function, the peptic cells: the others are knuwn as the accessory or parietal cells; they have also been called the oxyntic cells, and are supposed to produce the acid of the gastric juice.

The pyloric glands differ from the cardiac in the proportions of their parts; the ducts being much longer and the tubules shorter: in the form of the secreting tubules, which are much more contorted; and in the absence of parietal cells. Between the region of well defined cardiac and pyloric glands is a narrow intermediate zone of transition in which the ducts become longer and the tubules shorter than in the cardiac region, while the parietal cells become less numerous and finally are wanting altogether.

The interstices between the gastric glands are filled with interstitial areolar tissue containing a rich network of capillaries and lymphatics and a small amount of adenoid tissue, with occasional slender bundles of smooth muscular fibres. About the bases of the secreting tubules the adenoid tissue is more abundant, and here and there forms small nodules with ill-defined boundaries. Below, there is a well-developed muscularis mucosae, consisting of two distinct layers, an inner transverse and an outer longitudinal layer: the inner is to some extent subdivided into two laminae, the fibres of one running somewhat obliquely to those of the other; from its inmost surface the slender bundles above mentioned as running up between the gastric glands are given off. 
The submucosa of the stomach is a rather thick layer of areolar tissue which extends upwards into the folds of the mucosa which form the rugae. It contains the larger bloodvessels and lymphatics connected with the vascular supply of the mucosa, and a well developed plexus of Meissner situated nearer to the mucosa than to the muscular coat.

The musculosa is thicker in the stomach than in any other portion of the alimentary canal, the increase in thickness being chiefly in the inner or transverse coat. This, in addition to being greatly increased in volume is in the cardiac portion more or less clearly divicled into two layers lying obliquely to each other and to the longitudinalcoat. The plexus of Auerbach is conspicuously seen between the two coats. On the outer surface is the serosa, a thin fibrous membrane covered by endothelium, and adhering closely to the longitudinal muscular coat except along a narrowstrip at the attachment of the mesogaster and the omentum.

As we pass from the stomach to the duodenum the mucosa becomes much thinner, the glands present in the upper portion of the latter being situated in the submucosa; a narrow zonc of transition is seen between the pyloric glands of the stomach and the duodenal glands, or glands of Brunner. The mucosa, which is thrown into folds, the valvulae conniventes, is covered with finger-like or leaf-like projections, the villi, between which are tubular depressions, the intestinal follicles or crypts of Lieberkuhn: the surface of the villi and the lining of the crypts are alike covered with simple columnar epithelium con- 
taining large numbers of goblet cells, the columnar cells having vertically striated caps or borders. Beneath the epithelium of both crypts and villi is an endothelial basement membrane, sometimes called the subepithelial endothelium of De Bove.

The centre of a villus contains a lymphatic with a widely opened extremity: around it are scattered bundles of smooth muscular fibres proceeding from the muscularis mucosae below: near the surface is a network of capillaries formed from the breaking up of a small artery at the base of the villus and uniting to form a vein near its tip: the interstices are filled with loose adenoid tissue. Between the crypts at the base of the villi is a rich network of capillaries and lymphatics and imbedded, like those of the villi, in adenoid tissue, which becomes quite dense about the bases of the crypts; here and there well defined nodules are found.

Immediately beneath the layer of adenoid tissue upon which the crypts abut is situated the muscularis mucosae, which is not so thick as in the stomach, but presents two distinct layers, an inner transverse and an outer longitudinal.

The submucosa of the upper portion of the duodenum is quite thick: in addition to the blood vessels and lymphatics and the plexus of Meissner, it contains the glands of Brunner already mentioned. These are compound tubular glands, whose short alveoli, lined with polyhedral cells surrounding a distinct lumen, open into slender branching ducts which pass to the centre of the gland, there to open 
into the central duct: this, which is lined with short columnar cells, penetrates the mucosa to open between the villi. The glandular epithelium resembles that of the pyloric glands, between which and the glands in question there is a distinct transition at the pylorus: the epithclial cells contain fine gramules similar to those found in the cells of glands of the serous type, which these glands resemble save in the non-essential feature of the larger size of the lumen.

The transverse layer of the musculosa, as it reaches the lower end of the stomach, becomes suddenly thickened to form a muscular ring, the pylorus or gastro-duodenal valve: passing into the intestine it becomes as quickly reduced in thickness, forming a layer much thinner than that found in the gastric wall: a similar diminution is found in the thickness of the longitudinal layer. The musculosa of the small intestine does not otherwise differ from that of the stomach, like which it is invested by a serosa formed from the peritoneum.

In the lower portion of the duodenum the glands of Brunner are wanting, and the submucosa becomes greatly reduced, the canal assuming the structural character common to the greater portion of the small intestine, whose division into the regions recognized by the anatonist is not marked by any histological characters. The only noteworthy feature in this respect is the specialization seen in the quantity and disposition of the adenoid tissue of the mucosa, which attains its highest development in the lower portion of the small intestine, the ileum. 
Throughout the whole of the small intestine adenoid tis. sue is found in the villi and between the crypts, as in the upper portions of the duodenum just described: and as in that structure, there is a continuous layer thereof between thecrypts and the muscularis mucosae. This, however, becomes much thinner and less dense, while here and there appear well defined nodules commonly known as solitary follicles or (by the use of a term equally unfortunate) solitary glands: it should of course be understood that these bodies have functionally nothing in common with either glands or follicles as defined on a preceding page: they are broadly pear-shaped bodies whose bases usually extend into the submucosa, which is locally thickened in connection therewith, and whose apices when large project as rounded eminences upon the surface of the mucosa covered with a single layer of columnar epithelium, both crypts and villi being wanting at that point: in structure each is a dense mass of adenoid tissue in the main uniformly disposed, but with a slight diminution in density toward the centre of the mass, containing a capillary network and surrounded by numerous lymphatics: the nodules are surrounded by the fibrous tissue of the mucosa, which is here quite dense, but they have no definite capsule.

The solitary nodules of adenoid tissue give place to a great extent in the lower portion of the intestine to clusters of similar bodies sometimes called agminated glands, but better known as Peyer's patches. Where these occur the nuucosa and submucosa are both thicker than in other portions of the intestine: the nodules are closely crowded together and in the centre of the mass become confluent: 
the conical apices of most of then project upon the surface of the mucosa: the epithelium of the projections (as is the case to some extent with that of the solitary nodules just described) becomes infiltrated with leucocytes as in the case of that investing the tonsils, often to such an extent as to be no longer clearly distinguishable, large numbers of leucocytes thus constantly entering the intestinal cavity.

At the margin of the folds which constitute the ileocolic valve the villi cease abruptly; and as we pass the margin in question we come upon the wall of the large intestine, including its greater portion, the colon, with its anterior prolongation, the caecum (ending in the vermiform appendix), and its posterior continuation, the rectum.

The mucosa of the colon, like that of the rest of the large intestine, is devoid of villi. It is crowded throughout its whole extent with tubular follicles resembling the crypts of the small intestine, but larger and showing ordinarily a larger proportion of goblet cells. The interstitial adenoid tissue is scanty, but large solitary nodules occasionally occur. The muscularis mucosae does not differ materially from that of the small intestine.

The submucosa is a layer of moderate thickness, containing the larger vessels and the plexus of Meissner. The musculosa is well developed: the inner or circular layer is thickened uniformly, while the outer layer is chiefly gathered into three longitudinal bands. The outer surface is covered for a portion of its extent with a serosa. 
The caecum is essentially similar in structure to the colon. The appendix vermiformis is a rudimentary structure, variable in size and development: its mucosa contains numerous follicles, like those of the colon, and also solitary nodules of adenoid tissue: its musculosa consists of two layers, the outer or longitudinal differing from that of the colon in being of uniform thickness and thicker than the inner or circular layer.

As the alimentary canal is continued downward to form: the rectum, its structure undergoes important changes in each of the fundamental layers, in connection with the modification which takes place in the function of the canal: these will as before, be described in connection with the layers successively.

The mucosa of the rectum, like that of the colon, is devoid of villi: it is much thicker than that of the colon, increasing in thickness downwards to the anal opening. In addition to temporary foldings, chiefly longitudinal, which exist when the tube is empty, there are present three or four transverse folds, semilunar in shape, known as the valves of Houston, and near the terminus several longitudinal folds, the columns of Morgagni; their relations to subjacent structures will be mentioned later. The epithelium of the greater portions of the rectum is columnar, like that of the small and the large intestines: just above the anus there is in man a transition from simple columnar to stratified squamous epithelium continuous with that of the surface of the body: this transition takes place upon 
the columus of Morgagni higher up than within the dejressions which lie between then. Follicles or crypts like those of the colon abound in the mucosa of the greater portions of the rectum: they disappear at the level of the commencement of the columns of Morgagni. In addition to a small amount of diffuse adenoid tissuc, occasional solitary nodules are found: they are less numerous relatively than in the colon.

The fibrous structure of the mucosa of the rectum is denser than that of the colon, particularly toward the lower extremity, where there is a marked increase in the proportion of elastic fibres and a diminution in the amount of adenoid tissue, the fibrous layer finally passing without abrupt transition into the corium of the skin. The muscularis mucosae is gradually increased in extent, and consists chiefly of longitudinal fibres: at the lower portion these are gathered together in several stout bundles, which, with the overlying folds of the mucosa, form the columns of Morgagni above described: these are continued into tendinous bundles which are inserted into the skin in the immediate vicinity of the anal opening.

The submucosa of the rectum becomes considerably thickened toward its lower extremity, in connection with the increased mobility of the mucosa, and is in addition reinforced by the presence of numerous elastic fibres: it contains, moreover, a certain amount of adenoid tissue, in this respect differing markedly from the same layer in other portions of the canal. A distinct plexus of Meissner is present. 
The musculosa of the rectum undergoes marked increase in thickness from above downward in both the circular and the longitudinal layer. In the former, there is in addition to the gradual increase in volume a tendency to divide into bundles of fibres of gradually increasing size: at its lowermost limit a number of these bundles are aggregated together to form the internal sphincter muscle which surrounds the anal opening: distinct thickenings of the circular layer also underlie the valves of Houston. The longitudinal layer, as it passes downward, also undergoes subdivision, the resultant bundles of fibres diverging more and more from the circular layer, and being roughly divisible into three strata; an inner, the bundles of which are interwoven with those that form the internal sphincter; a middle, whose bundles terminate along the boundary of the external sphincter (an extrinsic muscular structure compcsed of striped fibres); and an outer stratum whose bundles unite with the levatores ani and the recto-coccygeal muscles.

The extrinsic glands connected with the alimentary canal are but two in number, the pancreas and the liver, both of them opening into the duodenal portion of the small intestine, of which they are outgrowths. The pancreas is in most respects similar in structure to a large salivary gland of the serous type; its connective tissue framework as well as its blood and lymph vascular supply being the same, and the form of the alveoli similar, as well as their arrange- 
ment in lobules and lobes. The epithelium of the alveoli resembles that of a serous gland in its granular appearance, and in the position of the nucleus; the lumen is also very small. Certain differences are, however, to be noted. The alveoli are as a rule longer and more generally tubular in form: the epithelial cells are taller and narrower, as a rule, approaching to the columnar form: there have been described under the name of centroacinar cells, certain spindle-shaped elements occupying the lumen near the union of the alveolus with the intermediate tubule; their origin and function are alike uncertain. The intermediate tubules, with their characteristic flattened epithelium, are more extensive than in the salivary glands, replacing in great measure the intralobular ducts. The pancreas is also characterized by the presence between the alveoli of peculiar groups or clusters of intertubular cells which form nodular masses situated in the intralobular connective tissue or the interlobular septa; each mass having a definite tuft of capillaries: these bodies whose nature is not clearly understood, are by some regarded as newly formed or embryonic alveoli.

The liver is at once the largest and the most highly modified of all the digestive glands. While it must be regarded as formed by the modification of a primarily tubular structure, the multiplication of the glandular epithelial cells has obliterated the lumen of the tubule in each instance, the secretion formed by the epithelium being discharged through the agency of intercellular channels which are unlike anything found in any other portion of the human body. This extreme modification in the arrange- 
ment of the glandular epithelium is also accompanied by an equally great modification in the arrangement of the blood vessels, the capillary network apparently penetrating the epithelial masses; thus forming what at first sight seems to be an exception to the general rule that epithelia are devoid of blood vessels. The structure of the liver will therefore best be understood if we begin by examining the blood supply and the framework of skeletal tissue with which it is associated.

The surface of the liver is invested by a thin capsule of fibrous tissue, surmounted by the peritoneal endothelium. From this capsule thin lamellae penetrate the surface of the gland as interlobular septa: in the transverse fissure it becomes continuous at the porta (which corresponds to the hilum of an ordinary gland) with an important ingrowth of connective tissue, the so-called capsule of Glisson, which forms by far the larger part of the interlobular tissue, becoming continuous with the ingrowths from the capsule. The porta is the place of entrance for the nervesupply of the liver, and for the large portal vein and the smaller hepatic artery; as well as of exit for the bile duct and for the principal lymphatic trunk: these four vessels and their ramifications, together with strands of nerve-fibres, are usually found in close proximity, surrounded by a certain amount of connective tissue, the whole constituting what is known as a portal canal. The blood leaves the liver by means of the hepatic veins, whose branches are formed by the union of the sublobular veins, the origin of which will be presently described: the sublobular and hepatic veins are not accompanied in their 
course by branches of other vessels, a character by means of which they caln be readily distinguished from the branches of the portal vein.

The lobules of the liver, sometimes (but less correctly) termed the acini or alveoli, are masses of hepatic cells, penetrated by capillary networks, polyhedral in form as the result of pressure, and in man something over a millimetre in diameter. Those at the surface of the liver have the axis vertical or nearly so to that surface: but there is no such regularity of position in the case of those more deeply situated. The interlobular septa are in a few mammals (of which the pig is one) quite stout and conspicuous : in man they are far less developed; and the boundaries of the lobules are in consequence not always readily determined. From certain points on the septa a very scanty framework of connective tissue traverses the interior of the lobule, accompanying the capillaries: its presence even in small quantity is a fact of importance in forming a clear conception of the essential structure of the liver.

The branches of the portal yein end in veinlets situated in the septa and hence known as interlobular veins, each lobule having several surrounding it: these give off capillaries (in a manner similar to arteries elsewhere) which form a network whose meshes converge toward the axis of the lobule: this is occupied by a single vessel, the central or intralobular vein, into which the capillaries empty. The intralobular vein passes at the base of the lobule into a sublobular vein, the hepatic veins being as has been stated, formed by the confluence of the sublobular veins. 
The branches of the hepatic artery accompany those of the portal vein to the lobules, where they divide into interlobular arterioles situated in the septa, together with the interlobular veins: like the latter, they terminate in capillaries; these are, however, situated chiefly in the connective tissue of the septa and the walls of the veins, a portion of them only penetrating the lobules for a sufficient distance to form channels of communication with the capillary network of the lobule, as a means of discharge of the blood from the arterioles. The portal vein and its final branches, the interlobular veins, are therefore to be regarded as the channels by means of which the blood is submitted to the glandular action of the hepatic cells; the hepatic artery being probably in large part, if not altogether the channel of nutrition for the skeletal framework and vascular mechanism of the organ.

The network of capillaries with its accompanying scanty connective tissue forming, according to some observers, perivascular lymph channels, is interwoven with another and somewhat coarser network, that of the strands of liver cells or hepatic cords. These are polyhedral epithelial cells about twenty micra in average diameter, with granular protoplasm and central spherical nuclei, which perform the complex secretory function of the liver. The size of these cords are such that nearly every cell is brought at some point in contact with a capillary; the surface of the cell being in many cases slightly excavated along the line of contact.

Between the hepatic cells is found a network of minute passages usually not more than a micron in diameter, the 
so-called bile capillaries or, as they are otherwise termed the bile canaliculi: these are so situated that they traverse the surface of the cell along a side or an angle opposite that in contact with the blood capillaries, never passing between the latter and the cells. At the surface of the lobule the bile canaliculi communicate with small interlobular bile ducts whose fattened epithelium is continuous with the hepatic cells, and whose basement membrane is resolved into the scanty connective tissue of the lobule. These unite as they pass to the portal canals to form the smaller bile ducts situated therein; the epithelium becoming columnar and the bascment membranc stouter. As the smaller bile ducts come together to form the larger trunks found in the more central region of the liver the cells of the columnar epithelium become taller and are seen to rest upon a distinct membrana propria: while the fibrous layer beneath is reinforced by smooth muscular fibres: the largest ducts have in addition small mucous glands in their walls. The structure of the duct leading to the intestine, and of the gall bladder as well, is essentially the same as that of the largest ducts within the liver.

If we recall the structure of a gland of the serous type it will be remembered that the epithelial cells which line the alveoli are so large as to reduce the lumen to a very slender and often imperceptible channel between their apices: the bile canaliculi may with propriety be compared to such channels. The alreoli of ordinary glands may be either spheroidal or elongated and tubular, the interstices between them containing a variable amount of connective 
tissue which supports a capillary network, whose meshes conform to the structure and arrangement of the alveoli. In the lower vertebrates the liver consists of tubular alveoli essentially similar to those of other glands. If we conceive of such tubules in the mammalian liver as becoming elongated and branched, and finally anastomosing, we shall understand the structure and arrangement of the hepatic cords. According to this view the anastomoses formed obliterate the boundaries of the alveoli; but we may regard as belonging to one such division all the bile canaliculi with their surrounding epithelium which lie nearest to and presumably discharge into one of the interlobular bile ducts: the beginnings of the ducts, with their flattened epithelium, corresponding in position and structure with intermediate tubules or intercalary ducts of other glands: the lobule is thus seen to be in fact as well as in name a lobule; that is, a collection of acini or alveoli ; and the application of either of the latter titles to it is misleading. The most peculiar features in the structure of the liver are those connected with the blood supply. 


\section{CHAPTER X'VI.}

THE RESPIRATORY APPARATUS.

In the description of the alimentary canal which has just been given, the conspicuous layers, whose modifications in the various regions have been discussed, are those most readily demonstrable by the knife of the anatomist: they are those, moreover, which naturally result from the double function of the greater part of the canal, the inner layer, or mucosa, being in substance a glandular layer by means of which the nutritious portion of the food is brought into a condition suitable for the accompanying process of absorption; the outer layer, or musculosa, being in effect a mechanism by which the food mass is caused to traverse this glandular surface; while the submucosa makes possible the necessary movements of the mucosa and the musculosa on each other. We should, however, bear in mind the continuity of the submucosa with the fibrous structure of the mucosa on the one hand. and on the other with the interstitial connective tissue of the musculosa, and through it with the fibrosa or serosa: considering this, and bearing in mind the embryonic origin of the tissues present, it will be quite clear that another very natural division of the wall of the alimentary canal, based on histological rather than anatomical characters, would recognize two primary layers of tissues (differing 
vastly in extent), the epithelial layer, hypoblastic in its origin; and the musculo-skeletal (and vascular) layer derived from the mesoblast, extending from the basement membrane, just beneath the epithelium within, to the fibrosa (or, in the intestine, to the fibrous basis of the serosa) without: the presence of this fibrous layer as one of the constituents of the alimentary canal should be clearly borne in mind.

It is by an outgrowth from the pharyngeal region of the alimentary canal that the respiratory apparatus is formed, and its structure throughout its whole extent is derived from such modifications of a musculo-skeletal layer lined with epithelium as are required for the proper performance of the functions of the various regions. These are in the trachea and bronchial tubes such as will serve to maintain the patency of these channels for the passage of the air and in some measure to regulate the same: and in the airsacs such as will permit the freest interchange of gases between the air which they contain and the capillaries within their walls.

The trachea is plainly seen to be composed of three well-defined layers, similarly disposed to those which appear as the chief factors of the alimentary canal. The inner of these is the mucosa; it differs in some important respects from the layer of that name in the region just mentioned. It is lined with what is usually termed a stratified columnar ciliated epithelium: the layer is but a few cells deep; those at the surface are cylindrical or prismatic, with tapering bases, their free extremities in most cases beset with numerous fine cilia, whose united 
action causes constant currents toward the mouth; here and there goblet eclls occur; beneath the superficial cells, or interspersed between their bases, are elongated and more or less spindle-shaped cells, which are probably destined to replace them; still lower are pyriform and spheroidal cells, many of which multiply rapidly by cell-division, replacing the older superficial cells as occasion requires, resembling thus in function the deepest portion of the stratified squamous epithelium of the oesoplagus.

The epithelium of the trachea rests upon a basement membrane, a homogeneous, elastic layer of considerable thickness, perforated by occasional fine canals. This is followed abruptly by a fibrous layer, whose bundles are irregularly and somewhat loosely disposed and are intermingled with a considerable number of elastic fibres: there is a well but not greatly developed network of small blood vessęls, accompanied by nerves and lymphatics, and a considerable amount of adenoid infiltration. Beneath the fibrous layer, and continuous therewith, is the elastic layer, composed of a dense network of elastic fibres, most of which are longitudinally disposed, which form the inner boundary of the mucosa: it is best developed in the dorsal portion of the trachea.

The submucosa, like that of the alimentary canal, is a layer of areolar tissue serving to unite the mucosa with the denser layer beyond it. In addition to the larger blood vessels from which the blood supply of the mucosa is derived, and their associated lymphatics, it contains nunerous small glands of the mucous type, whose long ducts, lined with cuboidal epithelium, traverse the mucosa 
to open on its surface. These glands are, as a rule, most abundant in those portions of the submucosa which are situated opposite the intervals between the successive fibrous rings of the trachea. Here and there in the submucosa an occasional adenoid nodule may be found, frequently associated with a gland or its duct.

No single word will readily indicate the complex structure of the outer layer of the trachea: if we for convenience make use of the term fibrosa in referring to it, we shall designate it by its most constant though not most conspicuous factor. It is in effect a tube of dense fibrous membrane, rich in elastic fibres, reinforced at regular intervals by the incomplete rings of cartilage which are the most prominent components of the trachea, and bearing on the inner surface of its dorsal portion the rudiments of a muscular layer. The rings are composed of hyaline cartilage which is far less brittle than usual: they are imbedded in the fibrous layer, which is continuous with the perichondrium of each, and situated rather toward its inner than its outer limit. The muscular layer occupies an elongated rectangular area nearly identical with that bounded by the lines connecting the dorsal ends of the incomplete cartilaginous rings, but somewhat more extensive laterally: to the band of muscular tissue thus formed, the name of the tracheal muscle is given. It consists entirely of smooth muscular fibres; the great majority of these are arranged in transverse bundles disposed in groups which are separated by occasional transverse septa of fibrous tissue; external to these are a few thin and short longitudinal bundles forming an imperfectly defined layer: 
the musenlar layer is invested outwardly by the fibrous layer which it in some measure replaces, the latter being here much thinner than in other portions of the trachea. The bundles of the transverse layer are inserted between the rings upon the fibrous layer; those opposite the rings are in man inserted on their inner surface; in some of the lower mammals they are inserted on the ends and in others on the onter surface of the rings. The longitudinal bundles are inserted upon the ends of the rings and upon the fibrous layer. It is a noteworthy fact that in the clorsal portions of the trachea some of the mucous glands are situated external to the muscular layer, their ducts penetrating it as well as the other layers of tissue beneath the epithelium.

The bronchi, or right and left divisions of the trachea, while they differ from it anatomically, particularly in the form of the cartilages, resemble it in all essential respects as regards their histological structure. As they enter the lungs they branch and subdivide repeatedly, their immediate continuations and their subdivisions, with the exeeption of the smallest, being known as the bronchial tubes, or, as they are sometimes termed, the intrapulmonary bronchi: by the time they are reduced to a diameter of one millimetre, or thereabouts, they are known from their size and structure as bronchioles; the smallest of these are never less than half a millimetre in diameter.

The largest bronchial tubes are essentially like the extra-pulmonary bronchi in structure: as we pass toward the bronchioles, their structure undergoes marked though 
gradual modification: that of a tube of medium size may be described as follows. The epithelium, like that of the trachea and larger bronchi, is stratified, columnar and ciliated, and rests on a homogeneous basement membrane.

Beneath this is a fibrous layer containing a moderate amount of adenoid tissue, and numerous elastic fibres no longer forming a continuous layer, but gathered into strands, which form the bases of the folds into which the inner portion of the mucosa is frequently thrown: external to the adeno-fibrous layer is a well-defined muscularis mucosae, composed of smooth fibres transversely disposed, this layer, which is of variable thickness from point to point along the tube, is sometimes designated the bronchial muscle.

External to the muscular layer is the submucosa, composed here, as in the trachea and bronchi, of areolar tissue containing mucous glands and plexuses of blood and lymph vessels. The outermost layer, that which we have for convenience termed the fibrosa, is the one which first shows signs of reduction: the fibrous membrane is by no means as dense, nor as clearly defined, either from the submucosa within or from the adjacent tissues without, as in the trachea; the cartilaginous rings of the latter are represented by plates of cartilage of varying size and shape; and there is nothing present in this layer that may be regarded as corresponding structurally to the tracheal muscle. Occasional lobules of fat may be seen, and the mucous glnnds not unfrequently penetrate into this layer, which thus tends to approach in its structure that of the submucosa. 
As we pass toward the smaller bronchial tubes the epithelinm becomes gradually reduced to a single layer of columnar ciliated eells resting upon a basement membrane. The fibrous layer beneath becomes much thinner; the relative amount of adenoid tissue becomes less and less, and elastic fibres become far less numerous, though they do not altogether disappear. The muscular layer, on the other hand, for a time at least, increases in relative thickness, becoming one of the most conspicuous features of small tubes. The submucosa and fibrosa become blended into one layer of loose fibrous tissue rich in lymphatics and containing blood vessels, the mucous glands disappearing from the former, together with the cartilaginous plates (and the nodules which succeed them) from the latter.

Within the bronchioles (otherwise designated the terminal bronchi) still further reductions of structure take place: the epithelium changes from columnar to cubical, loses its cilia, and later becomes more or less flattened, forming a single layer of polyhedral granular cells upon the basement membrane. The latter rests on a thin layer of fibrous tissue with longitudinal elastic fibres: the muscular layer is reduced to scattered bundles and later to isolated fibres, without finally disappearing altogether; while the submucosa and the fibrosa become blended with each other and with the fibrous layer of the mucosa.

'The bronchioles lead into larger pyramidal or irregular shaped spaces, the infundibula, into each of which open by wide apertures a large number of the spheroidal or 
polyhedral air-sacs or alveoli which are the ultimate chambers of the lung: each infundibulum with its associated alveoli making up one of the conponent lobules of that organ. The principal change in passing from the bronchiole to the infundibulum is found in the epithelial layer: the low granular cells with which the distal extremity of the bronchiole is lined are found in the infundibulum in patches which become smaller and less numerous as we proceed to its farther extremity: between them are found larger and thinner transparent cells which form a simple squamous epithelium to which the distinctive title of respiratory epithelium is applied. The basement membrane, the longitudinal network of elastic fibres, and the layer of scattered muscular fibres are continued without essential change. The fibrous portion of the wall of the bronchiole is represented by scattered branched connective tissue corpuscles situated in the interstices between the elastic and muscular fibres.

The alveoli are in the main continuations of the walls of the infundibulum. The epithelium consists almost entirely of the large flat cells above mentioned, the smaller granular cells being scattered sparingly among them either singly or in groups of two or three: between the cells, and in particular at the angle where three or four meet, are occasional stomata, minute openings which communicate with the lymph spaces below. About the mouth of each alveolus there is an annular bundle of elastic fibres from which is given off a network, which, together with a small amount of fibrous tissue and a few connective tissue corpuscles, forms the wall of the alveolus and the support of the epi- 
thelium and capillary network: from the form and disposition of the alveoli it results that a single layer thus formed does duty in great measure for two adjacent alveoli. The capillary network contained in the interalveolar septum thus formed is exceedingly clense; and its loops pass from side to side of the septum in a serpentinecourse, thus bringing the blood contained within them as near as possible to the air in each of the alveoli.

The lymph spaces in the alveolar walls communicate with the lymphatics situated in the connective tissue septa which lic between the lobules. Each lobule, as thus bounded, is irregularly pyramidal in form, its apex being situated at the bronchiole, toward which the limiting septa tend: peripherally, the interlobular septa are continuous with the denser layers of fibrous tissue which form the investment of the lobes: the latter, in their turn, being continuous with the pleura which forms the serous investment of the surface of the whole lung.

The larynx is a special modification of the proximal end of the trachea: it differs in its histological structure from the latter in the following particulars. Its epithelium is in most portions stratified, columnar and ciliated, as in the trachea: that of the true vocal cords and of the epiglottis and a portion of the intervening surface is stratified squamous: in that covering the under surface of the epiglottis numerous taste buds are imbedded. The mucosa differs from that of the trachea, chiefly in the greater amount of adenoid tissue, in places resembling the phar$\mathrm{ynx}$ in this respect: the elastic fibres which run throughout its extent are greatly increased in number in the rocal 
cords, where they constitute the chief part of the mucosa. The principal cartilages are hyaline, like those of the trachea: those of Santorini, of Wrisberg and of Luschka are reticular, as is the epiglottis. The proper muscles of the larynx are composed of striped fibres, resembling in this respect the musculosa of the upper portion of the oesophagus.

The course and arrangement of the blood vessels of the lung are subjects rather for anatomical than histological discussion. It should be borne in mind, however, in studying sections of that organ, that the lung has a double blood supply: the branches of the pulmonary artery accompanying the bronchial tubes to their common destination in the lobules of the lung; while the smaller bronchial arteries, derived from the aorta, are distributed to the walls of the air passages themselves and to the surrounding structures, as vessels of nutrient supply. A similar relation subsists between the bronchial veins, which empty into the ascending vena cava, and the branches of the pulmonary veins.

The lymphatics of the lung are divisible in a somewhat similar manner into two groups, those associated with the bronchial tubes, and those associated with the air sacs. The former, or bronchial lymphatics, have their origin in the lymph spaces of the bronchial mucosa, forming a plexus in the submucosa which empties into larger trunks leading to the root of thelung. The second group is compound of two sets, the deep or vascular lymphatics, having their origin in the connective tissue of most of the lobules of the lung, and the superficial or, as they are also termed, 
the subpleural lymphatics, which arise in the vicinity of the lobules near the surface and enter into the plexus which underlies the pleura: the latter communicates with the thoracic cavity br means of occasional stomata. The deep and superficial plexus alike cmpty into trunks which lead to the root of the lung, there to enter, in company with those from the bronchial lymphaties, into the bronchial lymph nodes.

It is a common custom to speak of the lung as cssentially similar in structure to a gland, the alveoli being compared with the similarly named divisions of the latter, the infundibula and bronchioles to the ductules and intralobular ducts, and the bronchial tubes to the larger ducts. Comparative anatomy shows that the primary condition of the lung is that of a large sac-like cutgrowth of the alimentary canal, its unquestionable homologue in the fishlike vertebrates being the swin-bladder. In some of these forms it undergoes more or less subdivision by foldings of its inner surface, and assumes something of a respiratory function; its connection with the alimentary canal remaining simple and entirely membranous: in the lower airbreathing vertebrates the area of respiratory surface is increased to a limited extent only by peripheral sacculation, while a rudimentary trachea and larynx appears: it is only in the higher reptiles, the birds, and the mammals, that the lung assumes the compact and spongy structure due to compound sacculation and associated with the presence of a well dereloped system of bronchial tubes. Its origin is therefore seen to be the reverse of that of a large 
gland, which is developed by an increase in the number of originally small alveoli.

While the respiratory tract is to be regarded as a subdivided saccular outgrowth of the alimentary canal, we must not expect to be able to recognize essential similarity of detailed structure in organs differing markedly in function: a general comparison may, however, aid in understanding and remembering the character and arrangement of the tissues present. The epithelium is, of course, continuous throughout. The mucous membrane of the alimentary canal, with its varying amount of adenoid tissue and its subjacent muscular layer, is represented in the air-passages by the adeno-fibro-elastic layer, to which in the bronchial tubes a muscularis mucosae is added. The submucosa of one is continued into that of the other without essential modification. The outer layer of the larger air-passayes may best be regarded as corresponding to the fibrosa of the pharynx and oesophagus, reinforced by the tracheal and bronchial cartilages. The musculosa of the alimentary canal is represented only by the muscular area of the trachea with its well developed transverse and rudimentary longitudinal layer. 


\section{CHAPTER XVII.}

THE URINARY ORGANS.

The urinary organs include the glandular kidneys; their ducts, the ureters; the bladder, to which the latter lead; and the urethra, through which the contents of the bladder are discharged. The urethra of the female is strictly a urinary tract, and is throughout its entire extent a portion of the ventral outgrowth of the alinentary canal from a part of which the bladder is eventually formed: it will therefore be described in this connection. The prostatic portion of the male urethra includes all that part of the tract homologous with the urethra of the female; its remaining portion is a common channel for the urine and the seminal fluid, and is formed in connection with structures accessory to reproduction: the description of its whole extent will therefore be deferred until it can be taken up in connection with them in a subsequent chapter.

If a kidney be cut through from the eonvex surface to the hilum, either longitudinally or transversely, the surface of the cut section shows to the unaided eye certain features of importance to the study of its histology. The solid portion is seen to be curved around a central cavity, the pelvis of the kidney; into this project a number (varying with the direction of the section) of conical papillae, each of which is surrounded by a cup-like extension of the pel- 
vic cavity termed a calyx. The solid portion itself can be readily seen to be divided with considerable sharpness into an outer region, the cortex, forming about one third of the depth, and an inner, the medulla; the latter can be again distinctly subdivided into the boundary layer next the cortex, and forming about one fourth of the entire depth, and the papillary portion, which includes the remainder. The papillary portion is distinctly but uniformly striated: in the boundary layer radial tracts, termed medullary rays, similar in appearance to those of the papillary substance alternate with tracts characterized by increased transparency.

The entire mass of radiating tracts extending from the apex of a papilla to the meeting of the cortex and the boundary layer constitutes what is known as a pyramid of Malpighi; there are rarely less than ten or more than twenty of them in a single human kidney: in some of the lower mammals they are numerous, as in man; in others there is a single papillary ridge which projects into the pelvis along its length, or a single large central papilla: kidneys such as the latter are termed umpyramidal. If the pyramids of Malpighi be conceived of as extended across the cortex, the kidney would be divided into a corresponding number of parts commonly called lobules: if, however, we are to compare these glands with others on the basis of the arrangement of their ducts, these regions will with greater propriety be termed lobes: in the human kidney they are not structurally separated, but in that of some mammals, as the otter, each is invested by a capsule of its own, and is but slightly attached to its fellows: a condi- 
tion characteristic of the human kidncy during foctal life. In all multipyanidal kidneys, like that of man, the corticall portion of each lobe extends around and beyond the base of the pyramid toward the pelvis of the kidney : these interpyramidal masses, composed in part of portions of the cortical substance of the adjacent lobules, and in part of blood vessels whose origin and course will be presently described, are known as the columns of Bertin.

The medullary rays seen in the boundary layer are less readily traceable in the cortex: they are, however, continued into that layer, growing smaller as they approach the outer surface, and disappearing altogether before reaching it. These prolongations of the medullary rays are known as the pyramids of Ferrein : their bases, as will be readily understood, rest on the bases of the pyramids of Malpighi, each of which gives rise to a large number of them. The intervening portions of the cortex make up what is known as the labyrinth: a definite portion thereof, not marked off by any visible separation, is structurally continuous with each pyramid of Ferrein. Each pyramid with its associated portion of the labyrinth, and its continuation by means of the medullary ray to the apex of the pyramid of Malpighi, may, as we shall see, be with propriety regarded as corresponding in extent to a lobule of other glands. Scattered throughout the labyrinth are small rounded bodies, the Malpighian corpuscles, barely visible to the naked eye. Beyond the cortex may be readily seen the tough fibrous capsule which invests the whole gland.

The kidney, like the liver, is characterized by the posses- 
sion of a specially modified blood supply, the most important features of which are visible to the naked eye or with a low power of the microscope. If a section be made as above indicated through a well injected organ the following facts may be noted. The renal artery, entering at the hilum, divides into four or five branches which traverse the lining of the pelvis, their subdivisions entering the columns of Bertin. As they pass along the latter they give off twigs to the cortical substance present, and on reaching the level of the bases of the pyramids of Malpighi give rise to an arched plexus through whose meshes the pyramids of Ferrein pass to the cortex. From the arcuate arteries of this region branches are given off which run to the surface of the kidney, known as the radiate or (from their position between the cortical areas surrounding the pyramids of Ferrein) the interlobular arteries: from these are given off twigs which supply the cortical substance in a manner presently to be described: their extremities terminate in the capillary network of the capsule of the kidney. From the arcuate arteries also arise near the point of origin of the interlobular branches slender vessels, the arteriae rectae, which supply the medullary portion, passing directly toward the apex of the papilla.

There may also be seen in the cortical portion of the kidney, and receiving $t$ wigs which proceed from its substance, radiate or interlobular veins situated in close proximity to the arteries of that name. They arise just beneath the the capsule by small vessels having a stellate arrangement (the stellules of Verheyen), and tra verse the cortex to enter into arcuate veins in the main similarly disposed to the 
arteries of the boundary region; they resemble the latter in receiving vena rectae from the medullary portion, and unite to form trunks which pass by way of the columns of Bertin to traverse the lining of the pelvis and come together at or near the hilum to form the renal vein. The vasa recta pass toward the papillae in gromps which alternate in the boundary layer with the medullary rays, forming the tracts of greater transparency above mentioned.

The kidney is a compound tubular gland made up of lobes and lobules which, as we have seen, are not sharply defined from each other by fibrous septa. Its component tubules differ in a marked degree from those of any other gland in the definiteness of their course; the variation in size and in the character of the epithelium of the different regions of each; and in the peculiar relations which they sustain to their blood supply. With the exception of the blood-vessels and their accompanying lymphatics and nerves, together with the small amount of connective tissue in which these are imbedded, and of a very scanty interstitial tissue, the whole substance of the kidney, both cortical and medullary, is made up of these tubules.

Each uriniferous tubule is made up throughout its whole extent of a homogencous basement membrane lined with a single layes of epithelium. It has its origin in a Malpighian body, the extremity of the tubule being there expanded to form a thin walled sac whose distal portion is inverted into the proximal, forming a capsule of Bowman: into the cavity of invagination thus formed is thrust a spheroidal mass of capillaries termed a glomerulus: its 
relations will be described later. The capsule is lined throughout with a simple squamous epithelium; and with the accompanying glomerulus makes up the Malpighian body. The tubule leares the capsule at a point opposite the inversion for the glomerulus by a constricted neck lined with small cuboidal cells, expanding at once to form the proximal convoluted tubule: this is lined with cuboidal cells, whose outlines are irregular and interlock in such manner as to render it almost impossible to distinguish the boundaries of adjacent cells when seen in longitudinal section; the portion of the cell next the basement membrane is rertically striated, and is, under the influence of certain reagents, separable into rodlike processes; the free surface bears cilia-like processes projecting into the Iumen. The tubule passes by sweeping curves toward the prramid of Ferrein: as it enters it it turns toward the boundary layer in wary curres as the spiral tubule of Schachowa: its structure is essentially like that of the convoluted tubule, the epithelium being distinctly "rodded."

Entering the boundary layer, the tubule suddenly becomes much smaller and nearly straight in its course toward the papilla: it is here known as the descending tubule of Henle: this is the smallest portion of the whole tubule; its epithelium has the form of plate-likecells, whose nuclei cause a central thickening which projects into the conspicuous lumen, making its course apparently irregular. Shortly after reaching the papillary portion the tubule bends upward, forming Henle's loop, the diameter increases slightly, and the epithelium assumes the form of 
low polyhedral cells, greatly reducing the lumen. From the loop the ascending tubule of Henle passes upward through the boundary layer without essential modification, save a slight increase in diameter, as a straight or slightly wavy tubule.

The ascending tubule enters the cortex and travels for a longer or shorter distance in the pyramid of Ferrein, finally bending abruptly to enter the labyrinth as an irregular tubule, whose size and the position of whose lumen varies greatly in accordance with irregular variations in the height of the striated epithelium, the lumen remaining minute througkout its whole extent : it pursues a zigzag course toward the Malpighian body whence the tubule arose. In the vicinity of the latter it resumes a nearly uniform diameter and exchanges its angular course for regularcurves: it is now known as the distal convoluted tubule: in size, form, and structure, it is identical with the proximal. Like the latter, its course tends toward the pyranid of Ferrein; as it proceeds, it narrows into a junctional tubule, or, as it is also called, an arched collecting tubule, with low cuboidal epithelium and a relatively largelumen. It passes toward the axis of the pyramid to enter a straight collecting tubule somewhat larger, but otherwise similar in structure, which may also receive other junctional tubules from point to point as it passes toward the boundary layer.

The straight collecting tubule passes along the medullary ray through the boundary layer unchanged in form or size: after it enters the papillary portion it joins at an acute angle with similar tubules, the resultant tubules be- 
coming larger with each union: the largest (and terminal) tubes so formed, known as the ducts of Bellini, are lined with a simple columnar epithelium : their openings, visible to the naked eye, are scattered over the apices of the papillae.

The interlobular arteries, as has been previously stated, pass from the boundary to end in the capillaries of thecortex. Along their course through the cortex they give off on every side short arterioles which go to the neighboring Malpighian bodies : these, which are known as the vasa afferentia, on reaching these bodies give rise to the spheroidal masses of capillaries called glomeruli, the arteriole entering the glomerulus at a point opposite the neck of the capsule: the capillaries unite again to form small vessels, the vasa efferentia, which leave the glomeruli where the afferent vessels enter.

The efferent vessels, it will be seen, sustain to the glomeruli the relation of veins : they do not, however, proceed to the interlobular veins, but divide shortly after leaving the glomeruli to give rise to the cortical network of capillaries, which is made up throughout the labyrinth of short irregular meshes interwoven with the convoluted and irregular tubules, throughout the pyramids of Ferrein of long meshes running in the direction of the pyramid. The capillary network is not distinguishable by any known means into areas corresponding to the Malpighian bodies, the individual tubules, the lobules, or even the lobes of the kidney, being apparently continuous throughout the cortex of the wliole kidney. 
Here and there in the capillary network the radicles of small veins are formed, chiefly in the vicinity of the interlobular veins, to which they lead. The veins in question, arising from the stellate veins just beneath the capsule, gather in their course the cortical veinlets and pass to the arenate veins of the plexus lying in the boundary. They thus form the channels of return for the blood which leaves the interlobular arteries by way of the vasa afferentia, flowing, as should be noted, through two sets of capillaries, those of the glomeruli and those of the cortex, as well as though the intervening vasa efferentia.

The vasa recta, as has been stated, leave the arteries and veins of the boundary in close proximity to the interlobular vessels, in some cases springing as branches from their bases. They pass in the transparent striae of the boundary layer to the papilla, the arteries being resolved along the way into the medullary capillaries, which form a network with greatly clongated meshes running in the direction of the tubules between which they chiefly lie: in the tip of the papilla the meshes are much shorter, forming a denser network about the ducts of Bellini. The capillaries are gathered up into the radicles of the veins, which lie in close proximity to the arteries. Occasionally the small vessels which arise from that portion of the cortical network of capillaries nearest the boundary layer, instead of entering the interlobular veins, pass downward into the medulla: these, which are known as false vasa recta, sooner or later divide again into capillaries which enter into the medullary network. The vasa recta divide the medulla into regions corresponding to the lobules. 
The capsule of the kidney is a thin but tough fibrous membrane, somewhat lamellated in structure, especially toward the outer surface, and having in its deep_portion a scanty plexus of smooth muscular fibres. At the hilum the capsule is continuous with the fibrosa of the ureter. Its surface is invested with a small amount of adventitious areolar tissue which in some cases contains numerous fat lobules, and by which it is connected ventrally with the fibrous layer of the peritoneum, and dorsally with the fascia of the adjacent muscles. A plexus of lymphatics has been described in the capsule whose channels connect with spaces in the superficial portion of the cortex : it unites at the hilum with lymphatics which accompany the blood vessels along and from the medullary rays.

The lining which invests the pelvis of the kidney and its prolongations, the calyces, may be regarded as the continuation of the inner coats of the ureter, and may, like the wall of the latter, be regarded as consisting of an epithelial and a musculo-skeletal layer. The epithelium is of the transitional type, which is found only upon urinary surfaces: its peculiarities will be discussed in connection with the bladder, in whose structure they are most readily demonstrable. Immediately beneath is a thin but dense fibrous membrane which, with the epithelium, makes up the mucosa of the pelvis. This constitutes the sole investment of the papillae, the two layers of the mucosa being continuous with the epithelium and basement membrane respectively of the uriniferous tubules at the mouths of the ducts of Bellini. As we pass along the surface of the calyx, however, the mucosa begins to be separated 
from the surface of the columns of Bertin by scattered nuscular fibres, which increase in quantity as we approach the margin of the fold which surrounds the tip of the papilla: here a well defined muscular ringis formed, which has been compared to the transverse layer of the musculosa; it may be regarded as in a certain sense a sphincter of the papilla. The general surface of the pelvis is lined by the mucosa and the muscular layer, there being present between the two an inconspicuous submucosa of areolar tissue, which also contains a small amount of adenoid tissue and scattered mucous glands.

The ureter, as has been stated, consists of an epithelial and a musculo-skeletal layer; the components of the latter being so distributed as to form with the epithelium a mucosa, a submucosa, a musculosa, and a fibrosa. The mucosa is a continuation of that just described as lining the pelvis of the kidney, with which it agrees in structure in every essential respect : it is relatively greater in quantity, being thrown, like that of the oesophagus, into longitudinal folds. The submucosa is correspondingly increased in quantity : as in the bladder, it contains a small amount of diffuse adenoid tissue, scattered nodules having also been described, as have occasional mucous glands. The musculosa shows throughout the whole length of the uretertwo well defined layers, an inner longitudinal and an outer transverse; and along the lower portion traces of a third layer, external to the circular, are found, in the form of scattered longitudinal bundles. Each of the principal layers contains a comparatively large amount of interstitial connective tissue as compared with the nuscular 
layers of the alimentary canal: outwardly this is continuous with a well defined but not very dense fibrosa.

The bladder resembles the ureter in the essential histological structure of its wall. The epithelium which lines the mucosa resembles that of the pelvis of the kidney and of the ureter, as has been stated: the term transitional generally applied to.it, has, as it is generally defined, little meaning; it serves, however, to connote certain characteristics pertaining to epithelium found only on urinary surfaces, and distinguishing it from stratified squamous epithelium, with which it is often compared. The most marked pecularity of transitional epithelium is the power possessed by all of its cells (and not the deeper layers only, as is the case with stratified squamous epithelium) of changing and regaining its form in connection with the stretching or relaxation of the membrane beneath: this can be niost readily seen by comparing sections of the collapsed bladder and of one distended by a hardening fluid: both conditions will therefore be described.

In the former case the transitional epithelium is seen to consist of three distinct forms of cells arranged in what may perhaps be termed as many layers, though, as will be seen, the boundaries which separate them are not strongly marked. The surface is invested with a single layer of cells which are almost spheroidal or cuboidal above (though usually not as deep as they are wide), the upper surface being either flattish or slightly convex when the mucosa is neither stretched nor pressed together, and almost hemispherical when the bladder is strongly contracted: the lower surface of the superficial cells is sculptured by con- 
cavities which fit closely the surfaces of the cells of the next layer: two nuclei are sometimes seen in a single cell, and it is quite possible that the superficial cells still retain the power of cell-division. The next layer consists of large pear-shajed cells, their rounded ends fitting into the cxcavations upon the under surfaces of the superficialcells, and their smaller tapering extremities extending to the basement membrane beneath. The spaces between the large ends of the pyriform cells and the membrane are occupied by the constituents of the third layer, which is one or two cells deep, and consists of smaller closely packed spheroidal or polyherlral cells.

If the bladder be distended, the whole epithelial layer becomes much thinner: the superficial cells become flattened, approaching squamous cells in form; they never, however, loose their characteristic sculpturing: the pyriform cells become greatly shortened: and the spheroidal cells correspondingly flattened. A knowledge of the appearance of the elements in both these conditions is highly important on account of the frequent appearance of bits of epithelium in morbid urine. It should be remembered also, that these changes doubtless take place regularly with the daily periodic changes in the state of the bladder. It is well, too, to note the fact that the cells which compose transitional epithelium are always closely in contact, whatever changes of form they may undergo: and also that this epithelium has a remarkable power of resisting diffusion into the blood vessels beneath of the soluble constituents of the urine.

The mucous membrane of the bladder is much thicker 
and firmer than that of the ureter, and the transition to the submucosa is much nore abrupt. As in the ureter, a muscularis mucosae is wanting, while a small amount of adenoid tissue is present. The submucosa contains numerous elastic fibres, and occasional mucous glands, particularly toward the base.

The musculosa consists throughout of smooth muscular fibres whose bundles are in a general way (and particularly at the equator of the bladder) arranged in three layers, a middle circular and an outer and inner longitudinal: the bundles are, however, quite irregularly disposed, and there is much interstitial connective tissue: it is, therefore, not always easy to recognize the layers. At the base of the bladder the circular layer is increased in quantity to form the internal sphincter. The interstitial connective tissue is continuous externally with a rather loosely woven fibrosa, which is over a part of the outer surface of the bladder invested with serous endothelium.

The female urethra continues the wall of the bladder to the mucous membrane of the vestibule. In its course the epithelium passes from transitional to stratified squamous, the remainder of the mucosa undergoing no important change. The submucosa contains numerous elastic fibres and near the bladder a number of mucous glands: its deeper layer is highly vascular. The musculosa consists of an inner circular and an outer longitudinal layer of smooth fibres, and there is no well defined fibrosa. 


\section{CHAPTER XYIII.}

THE MALE REPRODLCTIVE ORGANS.

The male and female reproductive bodies, or gonads, are in their origin, mode of development, and primary position essentially similar bodies. The reproductive elements produced in them differ so widely, however, in their activities as to call for widely differing mechanisms for their discharge: mechanisms which are nevertheless derived from the modification of intimately allied structures, whose development is always closely associated with that of the urinary apparatus. For this reason the description of the early stages of the latter will be deferred until the completion of this and the subsequent chapter.

The male gonads, or testes, each with its associated epididymis, are in the adult human subject suspended by the spermatic cords in saccular folds of the skin confluent below the penis and forming the scrotum. The latter is formed, as will be more fully described later, by the pushing down of the abdominal wall on either side of the base of the penis: its structure therefore conforms to that of the body wall, subject, howerer, to special modifications in each of its constituent layers.

The skin of the scrotum is thin, corrugated, rich in brownish pigment and in sebaceous glands, and has scat- 
tered over its surface flattened curling hairs with conspicuous bulbs. The superficial fascia of the groin and adjacent parts is continued into the scrotum to form a characteristic tunic, the dartos, which is best developed in the forepart of the scrotum: it is quite highly vascular, and contains numerous smooth muscular fibres; it is consequently of a reddish-brown color. The right and left dartos tunics unite in the mid-plane to form a partition, the septum scroti. The corrugation of the skin of the scrotum is caused by the constriction of the muscular fibres of the dartos.

Immediately internal to the dartos is a denser and firmer fibrous layer, thin and transparent, known as the spermatic fascia: it is derived from the tendon of the external oblique muscle of the abdominal wall. Within and closely associated with the spermatic fascia is a layer of areolar tissue which contains numerous bundles of striped muscular fibres variously disposed, constituting a more or less continuous muscular layer termed the cremaster, and formed from an extension of the external oblique muscle. Still farther within, the fascia transversalis is continued in the scrotal wall by the infundibuliform fascia, a fibrous layer separated from the preceding by loose areolar tissue and immediately underlying the parietal portion of the tunica vaginalis, a serous membrane derived from the peritoneum, which lines the scrotum and is reflected upon the spermatic cord and testis.

The successive layers characteristic of the scrotal wall are, therefore, from without inwards, the skin, the dartos tunic, the spermatic fascia, the cremaster muscle, the in- 
fundibuliform fascia, and the tunica vaginalis. Of these the dartos forms the basis of the median septum, while those internal to it invest the cavities which are separated thereby.

The spermatic cord of either side is composed of the vessels and nerves of the testis together with the duct of discharge, known as the vas deferens: they are imbedded in areolar tissue and surrounded by the continuations of the coverings of the testis. The structure of the duct will be described later.

The visceral portion of the tunica vaginalis invests the surface of the testis except its posterior border, along which it is reflected to become continuous with the parietal portion: it is frequently termed the tunica adnata. Beneath it lies the proper capsule of the testis, the tunica albuginea, a dense white fibrous layer of considerable thickness: along the posterior margin this is continued into the interior for some distance as a wedge-shaped fibrous reticulum known as the mediastinum testis, and also as the corpus Highmori: from the mediastinum radiate stout straight bands of fibrous tissue, the septa or trabeculae, which unite with the peripheral albuginea, thus imperfectly dividing the body of the testis into a number of irregularly pyramidal lobules. The inner stratum of the albuginea is quite vaseular, and is sometimes distinguished as the tunica vasculosa: from it vascular trunks pass along the septa and form the blood supply of the lobules. 
Each lobule consists of a variable number of seminiferous tubules supported by delicate lamellae of interstitial tissue continuous with the stout fibrous septa as well as with the proper membranes of the tubules: within these lamellae peculiar epithelioid cells are found either singly or in groups, whose origin and function are still uncertain; they are known as the interstitial cells of the testis.

Each seminiferous tubule begins near the periphery of the testis with an irregularly contorted portion extending from its rounded extremity nearly to the mediastinum and known as the convoluted tubule, or the seminiferous tubule in the strict sense: these occasionally branch near their free extremities, and are said to anastomose in some instances. As they approach the mediastinum they become smaller and less irregular, and unite to form the straight or conducting tubules, which lie in the apices of the pyramidal lobules. On entering the reticular mediastinum the latter anastomose freely to form a network of tubules of variable size, forming the rete testis, whose meshes correspond with the spaces of the mediastinum.

The membrana propria of the convoluted tubules consists of several lamellae of endothelioid cells with flattened oval nuclei. Upon this membrane rests an epithelial layer several cells deep, from whose inner strata are derived the male reproductive elements or spermatozoa. The basement membrane of the straight tubules is a continuation of that of the convoluted: it is lined with a single layer of cuboidal epithelium. In the rete testis the membrane becomes continuous with the reticular framework of the mediastinum, and can no longer be distinguished: the 
channels are lined with a single laver of flattened epithelial cells.

The arrangement of the epithelial cells of the convoluted tubules, and the changes which they undergo in the process of forming the spermatozoa, which is known as spermatogenesis, have been the subject of much controversy and cannot yet be said to be fully understood. Different methods have been described with positiveness not only in different classes of animals, but in different orders of the mammals, and even in different members of the same order. Our knowledge of the facts in the human subject are, as $i 1$ most cases, less perfect than of those in the lower animals. In addition, the same terms have been applied by different writers to what are certainly different stages. The following account is based on that given by Schaefer in the tenth edition of Quain's Anatomy.

Next to the basement membrane is found a layer of cells most of which are cubical, clear, and possessed of nuclei which are in the resting or network phase: here and there dividing nucleiare seen : these cells may be termed parietal cells or spermatogonia. Scattered here and there among them are larger cells which project between the more internal layers: these are known as sustentacular cells: when much elongated and joined to bundles of developing spernatozoa they form the columns of Sertoli.

IIithin the parietal layer is seen a middle layer of somewhat larger spheroidal cells whose nuclei show various phases of division, the intermediate or spermatogenic cells. The layer may be one, two or more cells in depth; 
its constituents are probably derived primarily from the cells of the parietal layer, but increase in number by lateral divisions. They are by some authors termed spermatocysts.

The inner layer of distinctly cellular elements consists of smaller and more numerous cells derived from the intermediatelayer, the spermatoblasts (or spermatids of some writers): these are probably directly transformed into the spermatozoa. When first formed they compose a layer of closely packed small granular cells: they subsequently become more and more elongated vertically and collected into small groups, each of which becomes connected with one of the sustentacular cells above mentioned to form a column of Sertoli : later the bundle of spermatozoa derived from each group of spermatoblasts becomes separated from its sustentacular cell; the constituent elements are set free, and accumulate in large numbers in the lumen of the tubule.

The mature spermatozoön consists of an oval and flattened head, about four and a half micra long, two to three broad, and one to two thick; a cylindrical middle part or body about six micra long and less than one in diameter; and a tapering cilia-like tail forty to fifty micra long. The head consists chiefly if not entirely of the nucleus of the spermatoblast: the origin of the body and the tail is not so certain. In the lower animals the form and structure of spermatozoa vary greatly.

The pyramidal lobules and the body of Highmore, with their investment, the tunica albuginea, compose the whole of the gonad proper or testis in the strict sense. Closely 
associated therewith and often regarded as a portion thereof, though in reality the beginning of the efferent apparatus, is the epididymis, a tubular mass attached to the testis in the region of the mediastinum. Associated with the latter are certain rudimentary organs known respectively as the hydatids of Morgagni, lying between the head of the epididymis and the upper end of the testis, the vas aberrans, attached to the lower end of the epididymis, and the organ of Giraldes, found near the base of the spermatic cord.

The channels of the rete testis anastomose freely throughout the whole of the mediastinum or body of Highmore. Those of the upper or anterior portion open into the efferent tubules, also known as vasa efferentia, from twelve to twenty in number, which penetrate the albuginea and enter the epididymis, of which they form a part: at first straight, they soon become coiled in conical masses, the coni vasculosi, whose bases are turned away from the testis. These aggregated conical bodies, together with the upper portions of the canal of the epididymis, into which the efferent tubules open, form the globus major, or caput epididymis. Their constituent tubules are as large as the convoluted tubules of the testis: they are lined with a cuboidal or short columnar ciliated epithelium, beneath which is a well defined membrana propria surrounded by a thin transverse layer of smooth muscular fibres.

The canal of the epididymis, exceclingly flexuous from the point of its origin in the extremities of the uppermost vasa efferentia, becomes disposed in numerous 
small irregular coils in the middle region and is continued at the lower portion as a densely convoluted mass, the globus minor. At its origin it is twice the diameter of the vasa efferentia: lower it becomes smaller, and is enlarged again in the globus minor, from which it is continued as the beginning of the spermatic duct or vas deferens. It is lined throughout its course with tall columnar cells (between whose bases smaller rounded cells occur): these cells are provided with unusually long cilia throughout the greater portion of the tube, the cilia disappearing in the lower portion. Beneath the underlying membrane is a thin circular layer of smooth muscular fibres continuous with that of the vasa efferentia, which is surrounded by a thin longitudinal layer. The convolutions of the tube are bound together by interstitial areolar tissue which is here and there replaced by incomplete fibrous septa', which partially divide the 'epididymis into irregular lobules.

The hydatids of Morgagni are small saccular bodies lying between the globus major and the upper end of the testis. One of these, the stalked hydatid, is provided with a short peduncle, is usually present, and has a homologue in the female organs of reproduction. The others, the sessile hydatids, are variable in number and sometimes wanting: they are found in the male only. Both stalked and sessile hydatids are lined with cuboidal epithelium upon which cilia have been described.

The vas aberrans is a long narrow blind tube, a diverti- 
culum of the canal of the epicliclymis, which arises from the latter at or near the point where it becomes continnous with the vas deferens. Lilie the canal, it is exceedingly tortuous in its course, forming an clongated convoluter mass which extends upward among the vessels of the spermatic cord. It resembles the vas deferens in structure. It is almost invariably present, is sometines branched, and in some cases more than one such structure occurs.

The organ of Giraldes, also called the paradidymis, is a small body found on the front of the spermatic cord just above the globus major. it consists of sereral disconnected irregularly branched tubules lined with columnar ciliated epithelium. Their coiled masses form irregular nodules imbedded in the connective tissue of the regions between the cord and the epididymis.

The spermatic duct, or vas deferens, is the continuation of the canal of the epididymis. It is considerably larger and more complex in structure than the canal, showing like many of the tubular structures of the body, a definite mucosa, submucosa, and musculosa. The mucosa consists of a stout membrane sometimes thrown into longitudinal folds, and bearing a non-ciliated columnar epithelium : the submucosa is composed of areolar tissue somewhat laminated in arrangement: the musculosa is thick and yellowish in color and comprises an inner circular and an onter longitudinal layer of smooth muscular fibres, external to which is a fibrous adventitia. At the 
commencement of the duct there is also a longitudinal layer of muscular fibres internal to the circular layer.

The ampulla, or sacculated enlargement of the duct situated near its junction with the seminal vesicle, resembles the rest of the duct in structure, save that the various coats are somewhat thinner. The tubular diverticula of the rasa deferentia known as the seminal vesicles are like the ampullae in structure. The spermatic duct or vas deferens of either side unites with its associated seminal vesicle to form the ejaculatory duct, or common seminal duct, which completes the passage way from the seminiferous tubules of the testis to the urethra: in this region the walls of the tube are much thinner than in the vas deferens and the external fibrous adventitia disappears as the duct enters the substance of the prostate gland.

The male urethra, into which the common seminal ducts empty within the region surrounded by the prostate gland, is by virtue of that fact divisible into two distinct regions, the urinary and the urino-genital: it is the former alone that corresponds to the female urethra. By its anatomical relations it is also divided into the prostatic, the membranous, and the penial urethra: the former includes the first of the two regions above mentioned and a portion of the other. Histologically the structure differs in the several regions chiefly in the character of the epithelium, in the special structures found in the mucosa of the penial region, and in the composition of the musculosa.

The prostatic urethra of the male resembles the female urethra in being essentially a continuation of the wall of 
the bladder. It has a mucosa lined with transitional epithelium, which rests upon a membrane rich in elastic fibres. Beneath is a lighly vascular submucosa, and beyond this a musculosa which consists of an inner longitudinal and outer circular layer of smooth nuuscular fibres. In front of the openings of the common seminal ducts the epithelium passes by a 'gradual modification from the transitional to a somewhat stratified colımnar form. The membranous urethra continues the structure of the anterior portion of the prostatic, and in addition receives a distinct layer of striped muscular fibres from the adjacent compressor urethrae.

In the penial urethra the epithelium is composed of a single layer of columnar cells except at the fossa navicularis, where it passes into stratified squamous epithelium continuous with that of the surface of the glans. Here and there the mucosa exhibits irregular depressions of variable size, known as lacunae Morgagni: it also has connected with it numerous small racemose glands, the glands of Littre, which are also sparingly found in other portions of the urethra; they are lined with cuboidal or low columnar glandular cells.

The penis consists essentially of three masses of what is commonly called erectile tissue, the right and left corpora cavernosa, and the median inferior corpus spongiosum; the latter being traversed throughout its length by the penial urethra, and having its distal portion expanded to form the glans penis: the whole, of course, invested by the somewhat modified integument. The form and rela- 
tions of these bodies are matters for anatomical discussion: we are here concerned with their histological structure only.

What is known as erectile tissue consists primarily " simply of a somewhat circumscribed collection of larger and smaller veins which under certain circumstances may become distended with blood, thus causing the parts in which they lie to expand." Its specialization consists chiefly in the enlargement of the veins to form irregular sinuses, or cavernae, and their frequent anastomosis; the development and modification of the circumscribing skeletal tissues; and accessory modifications of the arteries of supply. That the cavernous sinuses are to be regarded as veins is shown not only by the structure of their walls, but also by the fact that the blood reaches them chiefly if not entirely through capillaries. It will be seen from what has just been said that erectile tissue is not constant in structure as are adenoid and other compound tissues that have been previously described. The form assumed in each locality where it occurs will therefore be briefly stated.

The corpora cavernosa are surrounded and united by a stout fibrous envelope, termed, like that of the testis, the tunica albuginea; it consists of bundles of white fibres chiefly disposed in a longitudinal direction and mixed with numerous elastic fibres: within, the white fibres are chiefly circularly disposed, surrounding each of the two corpora to form an individual sheath; these two sheaths are 
confluent in the mid-plane through the greater part of the penis, forming a septum which is incomplete by virtue of the presence of slit-like apertures through which the erectile tissue becomes continuous from side to side: these apertures are most numerous in the anterior part of the penis.

From the fibrous sheath numerous stout trabeculae pass inward to form a reticulum whose meshes are the cavernous sinuses. They are composed chiefly of white fibrous tissue, with more or fewer elastic fibres intermingled, and contain in addition numerous bundles of smooth muscular fibres: their surfaces are lined with the vascular endothelium of the sinuses. The trabeculae are stoutest and most numerous near the surface: the sinuses are correspondingly largest at the centre of the body; they are also larger near the extremity of the penis than at the base, in which region their long diameter is as a rule placed transversely to the penis. The small arteries which follow the trabeculae in many cases project from their surfaces in peculiarly curled and coiled loops; they are hence known as helicine arteries: they are said in some cases to open directly into the sinuses, but such a direct communication between an artery and a modified vein is not easily demonstrated under conditions which exclude the possibility of error.

The corpus spongiosum differs from the corpora cavernosa histologically in the thinness and increased elasticity of its fibrous tunic, which contains so much elastic tissue as to be vellowish in color; in the smaller size and greater 
uniformity of the trabeculae; and in the lesser amount of muscular tissue which they 'contain. The venous sinuses are smaller and more uniform, forming a spongy mass, from which the name is derived: their greatest dimensions are as a rule longitudinally disposed.

In the glans the meshes are quite small and uniform in size: the erectile tissue passes insensibly into the lower strata of the integument, with which its surface is invested. The derma is thin and highly vascular over the surface of the glans, and the epidermis has the form of a stratified squamous epithelium devoid of the division into layers characteristic of the cuticle and resembling in character that found on the oesophageal mucous membrane. Glands arewanting, except upon the corona and the cervix, where modified sebaceous glands, the glands of Tyson, are abundant. Special nerve terminals, the so-called genital corpuscles, are present, as are Pacinian bodies.

The skin of the penis is quite thin, highly elastic, and very movable, and contains but a very little fat: thelarger portion is devoid of hair also: as it passes around the free margin of the prepuce it changes its structure and the character of its epithelium, the lining of the prepuce, like the investment of the glans, having the appearance of a mucous membrane. At the base it passes on into that of the pubes, which is quite thick, beset with coarse hairs, and provided with a dense fatty layer.

The urino-genital tract of the male has associated with it certain glandular bodies, the prostate gland, which sur- 
rounds the proximal region of the urethra, and the glands of Cowper, paired organs opening into it near the point where it enters the corpus spongiosum. Opening into it ventrally in close proximity to the apertures of the ejactlatory ducts is an interesting rudiment, the sinus pocularis, otherwise known as the uterus masculinus. These structures will next be described.

The prostate is a glandular body which differs from most organs of the kind in the fact that not only its capsule but also its stroma contains a very considerable amount of smooth muscular tissue. This muscular tissue is in continuity with the musculosa of the urethra and of the ejaculatory ducts, and posteriorly with that of the bladder. The capsule is divisible into two layers, between which is found the prostatic venous plexus : from it trabeculae pass inward to form the framework of the gland, consisting, in addition to the smooth muscular tissue already mentioned, of a very small amount of white fibrous tissue and a larger quantity of elastic fibres. The alveoli are tubular, frequently quite elongated and irregular in shape, their walls sometimes showing conspicuous folds: the epithelium is columnar and simple save that frequently small and spheroidal cells are found at the base of the columnar cells. The ducts, which are numerous, are lined with columnar epithelium which changes into stratified as it approaches their openings upon the urethra.

Cowper's glands are small bodies of the racemose type, each consisting of several small lobes. Their capsules and 
supporting framework resemble those of the prostate to some extent in the presence in each of a small amount of smooth muscular fibre: a well defined longitudinal layer of smooth muscular fibres is also present in the wall of the principal duct. The acini resemble those of a mucous salivary gland in form and in the general appearance of the glandular epithelium: there is a conspicuous Iumen, the cells are pyramidal, and the nuclei are situated near the base. Nothing resembling the crescents or demilunes of the mucous glands has been observed. The lobar ducts are lined with cuboidal epithelium, which passes into columnar in the principal ducts.

The sinus pocularis is the homologue in the male of the vagina and uterus of the female. It is a diverticulum of the prostatic urethra having a well-defined muscular wall and a mucosa containing a number of short tubular glands which resemble the uterine glands in their form and structure. 


\section{CHAPTER XIX.}

THE FEMALE REPROIUCTIVE ORGANS.

The female reproductive apparatus consists of the female gonads, or ovaries, in which the reproductive elements are formed, the oviducts, or Fallopian tubes, by which they are conveyed from the ovaries; the uterus, in which they are received, and in which the fertilized ovum or oosperm develops into the embryo; the vagina, by which the uterus communicates with the exterior, and the parts composing the vulva, which immediately surrounds the opening of the vagina. As in the case of the male, there are also present certain rudimentary bodies, chiefly in the vicinity of the gonad.

The ovary, like the testis, is an organ in which specialized cells, epithelial in their origin, are matured and liberated: the sexual elements differ, however, in an antipodal manner as regards their size, activity, destination, mode of transportation thereto, and mode of liberation: there is a corresponding difference in the structure of the organs which produce them, the ovary having nothing of that tubular structure seen in the testis and giving to that body a close resemblance to a gland.

The framework or stroma of the ovary lacks the abundant white fibrous tissue found in the capsule and trabecu- 
lae of the testis: it consists chiefly of a peculiar form of connective tissue characterized by the presence of elongated nucleated cells which are frequently spindle shaped, and by the scarcity of true fibrous tissue, either white or elastic. It contains numerous smooth muscular fibres, which are most abundant in the deeper portions. Torvard the surface the stroma becomes more dense, forming quite a well-defined superficial layer, to which the name of the tunica albuginea has been given; it lacks the firmness and definiteness of the layer so designated in the testis. At the base of the ovary the stroma is especially rich in blood vessels: the region occupied by them is known as the zona vasculosa.

The region between the albuginea and the zona vasculosa constitutes the parenchyma of the ovary. It is rather indefinitely divided into a cortical and a medullary portion by the character of the Graafian follicles contained in it. It also contains, scattered irregularly through it, groups of interstitial cells similar to those found in the testis.

The surface of the ovary is invested with a layer of cells which are structurally continuous with the serous endothelium of the peritoneum, but which differ therefrom in form and function. They are cuboidal or low columnar in shape, and constitute the germinal epithelium: they have no proper basement membrane, but rest directly upon the tunica albuginea. Here and there may be seen, especially in the embryo, certain cells which are larger and more rounded in form : these are the primitive ova. These, during foetal life and possibly in childhood sink into the 
stronat, accompanied by tubular or spheroidal nests of epithelial cells : it is doubtful whether this ever takes place in the adult: it is also at present a matter of question whether the primitive ova increase in number by division after they have passed into the stroma, or whether all so situated have come from the epithelium of the surface of the ovary.

The cortical region of the parenchyma is crowled with the spheroidal masses of cells formed in the manner just described, each consisting of one or sometimes two primitive ova surrounded by a layer of epithelial cells. These are the prinitive Graafian follicles. In those immediately beneath the albuginea the surrounding layer is usually but a single cell deep: at first flattened, and hardly distinguishable from the cells of the adjacent stroma, its cells soon become cuboidal in form. At the same time the fibres of the stroma tend to assume a disposition concentric to the follicle, forming the beginning of the theca folliculi.

As the follicles grow older they tend to sink deeper into the stroma of the ovary; the cells of the enveloping layer at the same time proliferating, and the layer becoming several cells thick. Shortly afterward the ovum leaves its central position for one nearer one side of the follicle, usuually that farthest from the surface of the ovary, while a cleavage takes place in the cellular layer toward the other side, the space formed becoming infiltrated with a clear fluid, the liquor folliculi. The follicles now rapidly increase in size, at the same time sinking into the medullary region, where they are seen as large vesicles filled 
with fluid, invested by a well-defined theca, and lined by a layer of small isodiametric cells of irregular form, the layer being several cells deep: it is now known as the membrana granulosa. Attached to it at one side of the follicle is the rounded heap of similar cells which contains the ovum: it is termed the discus or cumulus proligerus.

The follicles still increasing in size, their outer wall now tends to approach the surface of the ovary, the fully matured follicle finally projecting somewhat from the surface, by whose rupture the contained ovum is eventually to be liberated. The theca is now well defined and consists of two layers, an inner or vascular, and an outer or fibrous layer. The cells of the membrana granulosa next the theca and those of the cumulus next the ovum are distinctly columnar in form. The most conspicuous as well as the most important body present is the mature ovarian ovum. This is a spheroidal body now much larger than the primitive ovum from which it was developed, although small as compared with the ova of many of the lower vertebrates. It is in the human subject about two-tenths of a millimetre in diameter. It is invested by a thick covering appearing when seen with microscopes like those used by the earlier observers to be quite clear: as its optical section forms a girdle or zone of considerable breadth about the ovum it was named by Von Baer the zona pellucida. Careful examination by modern instruments and methods demonstrate that it contains innumerable radial striae: it is therefore now commonly called the zona striata, or still more accurately the striated membrane. 
Several eminent and accurate observers have described a delicate membrane, which they call the vitelline membrane, internal to the layer just described: its presence cannot be readily demonstrated with ecrtainty.

Within the envelope just described is the vitellus, or yolk, wrongly so called, since it does not correspond to the body so termed in the eggs of many lower vertebrates: it is a homogenous protoplasmic mass, semi-fluid in consisteney and highly granular. It contains, usually in an eccentric position, a large spherical nucleus which was named by Purkinje the germinal vesicle: the nuclear contents exhibit a coarse network characteristic of the phase of complete rest: there is usually but a single nucleolus, which is quite large and rounded, and was called by Wagner the germinal spot.

When the ovum is discharged by the rupture of the follick upon the surface of the ovary, the follicular cavity is at first filled with a clot of blood. It is quickly invaded by growths from the wall of the follicle formed in part of rapidly proliferating cells of the membrana granulosa, in part of folds and processes from the theca: it has been as. serted that the interstitial cells previously mentioned also enter to a large extent into the ingrowing structure. The result is the formation (about the shrunken and discolored clot as a centre) of a mass of mingled cells and fibres known as a corpus luteum: this is at first sharply defined by the presence of the theca, but gradually loses its definiteness, and bccomes continuous with the mass of the ovary, the peculiar spurious tissue thus formed composing quite a 
large part of that organ in age. The corpus luteum formed concurrently with pregnancy is large and well-defined and is regarded as characteristic: but corpora lutea equally large and distinct sometimes (though more rarely) occur under other conditions.

The oviducts, commonly termed the Fallopian tubes, while they vary in form in the several regions distinguished by the anatomist, are quite uniform in their histological structure throughout their whole extent. Continuous at the isthmus with the uterus, they open at the fimbriated extremities into the peritoneal cavity: they consequently present the only instance of direct continuity between a mucous and a serous surface. Like nearly all the larger tubular struetures in the body, the wall is divisible into a mucosa, a submucosa and a musculosa; to which is added a serosa derived from their investment by the marginal fold of the broad ligament.

The mucosa consists of a well developed fibrous membrane moderately rich in elastic fibres, and well supplied witlı blood vessels and lymphatics, which supports a layer of simple columnar ciliated epithelium. An imperfectly developed muscularis mucosae, consisting of longitudinal bundles of smooth fibres, is also present. The mucosa throughout its extent is thrown into longitudinal folds which in the ampulla and particularly in the infundibulum are very extensive and have secondary folds upon their surfaces, giving to the cross section a peculiar arborescent appcarance. As seen in such sections the bases of these folds often present the appearance of tubular glands; but 
true glands are not present. The inner surface of the fimbriac is lined with the mucosa, while the outer surface is covered with the serosa: the two becoming confluent along the sides.

The submucosa is a simple layer of areolar tissue of but sliglt depth. It is continuous with that of the uterus, like which it enntains small ganglia and scattered multipolar cells, forming the rudiments of a plexus. The musculosa consists of an inner circular and an outer longitudinal layer of smooth muscular fibres, the latter being but imperfectly developer. The serosa consists of a thin fibrous membrane supporting the serous end othelium characteristic of the surface of the peritonemm.

Attached to the extremity of the tube or to one of the fimbriae is frequently found a pedunculated cyst or stalked hydatid of Morgagni. It is the homologue of the body bearing the same name in the male reproductive apparatus and resembles it in general structure, the cavity of the sac and also of the pervious portion of the stalk being lined with cuboidal or columnar epithelium.

Situated in the broad ligament between the ovary and the ampulla of the oviduct is a rvell-defined mass of irregularly convoluted tubules, known as the parovarium. It is also called, from its discoverer, the organ of Rosenmueller: Waldeyer has proposed for it the name of the epoophoron. The constituent tubules are lined with low colunnar epithelium: they converge toward each other, without uniting, at the ends nearest the ovary: the other 
extremities diverge somewhat, and terminate in a longitudinal tube which runs parallel with the oviduct: in some of the lower mammals this tube is quite extensive and is known as the duct of Gartner, a term also applied to it in the human subject by many. Somewhat nearer to the uterus than the parovarium a smaller and more irregular group of rudimentary tubules occurs, similar in structure to those just described. These have been designated by Waldeyer the paroophoron. The homologies of these rudiments will be discussed later.

The uterus presents but two distinct regions histologically, the fundus and body agreeing in structure and differing from the cervix. The most characteristic features of the upper region are found in the mucosa, the stroma of which is greatly modified, while the muscularis attains a greater development than does the structure bearing that name in any other portion of the body. The surface is invested with a single layer of columnar ciliated cells directly continuous with that lining the Fallopian tube. Beneath this is a very thick mucous membrane containing but a very small quantity of fibres and composed in large part of spindle shaped cells similar to those found in the stroma of the ovary, loosely interwoven: the spongy mass so formed contains numerous lymph spaces and leucocytes. Imbedded in it are great numbers of tubular uterine glands, wayy or convoluted in their course, not infrequently branched, and penetrating to the base of the stroma and quite frequently betwcen the bundles of fibres of the muscular layer: they are bounded by a delicate basement mem- 
brane which supports columuar cells similar to those lining the uterine wall: near the blind extremity of the tube the columnar cells entirely fill its cavity: but tliroughout the greater part of its extent there is a distinct lumen.

The muscularis mucosace is the chief muscular coat of the uterine wall; greatly developed at all times, it is enormously hypertrophied during pregnaney, partly by the great increase in number. It consists of bundles of fibres interwoven witl a sparingamount of interstitial connective tissue, and running in various directions: their disposition is apparently quite irregular, and cannot be described briefly with clearness: it is, moreover, subject to considerable variations : it can perhaps be best understood by regarding it as consisting chiefly of circularly disposed bundles which are arranged on the fundus in two sets, one concentric to the insertion of each of the two oviducts, and which become gradually combined to form a single set as they approach the lower extremity of the body.

There is associated with the great development of the muscularis mucosae a corresponding reduction of the submucosa, there being less independent movement of the mucosa and musculosa in this case than in almost any of the similar hollow structures. There is, however, a distinct zone of connective tissue discernible just exterior to the muscularis mucosae characterized particularly by the presence of numerous bloodvessels and lymphatics, and by scattered nervous elements. It is of such slight extent as to be by some described as wanting.

The musculosa consists of two distinct layers of smooth fibres both quite thin and rarying in their relative devel- 
opment in different parts of the organ. The inner or circular layer is the more uniform in thickness and in the arrangement of its fibres: the fibres of the outer layer are in the main longitudinally disposed, but are somewhat irregularly arranged upon the fundus, in accordance with its irregularities of form. This layer also gives off bundles of muscular fibres extending out into the ligaments of the uterus. The musculosa is invested by a serosa which is a continuation of the peritoneum.

"The cervix differs from the region just described chiefly in the structure of the mucosa, the stroma of which is much firmer and richer in fibres, both white and elastic, the membrane being thrown into characteristic folds, and in the lower portion beset with minute papillae. The upper two-thirds is lined with columnar ciliated epithelium continuous with that of the upper regions: this passes belorv into the stratified squamous epithelium which invests the papillated lower third. There are present both tubular and saccular glands said to be lined in each case with columnar ciliated epithelium: the saccular glands contain also goblet cells and secrete the thick mucus found in the cervix. Here and there spheroidal bodies filled with a clear yellowish fluid can be seen with the naked eye: they are probably occluded and enlarged mucous glands, and are known as ovula Nabothi. The muscularis mucosae is well developed and consists chiefly of circular bundles: these are accumulated in greater numbers at $t=$ upper and lower extremities of the cervix to form the sphincters of the regions in question.

The submucosa is not conspicuous. The musculosa re- 
sembles in structure the same portion of the wall of the body of the uterus: the inner circular and outer longitudinal layers are clearly defined. The region of the cervix toward the rectum is invested with a peritoneal serosa: that toward the bladder is separated from that organ by an adventitia of areolar tissue. The portion of the cervix that projects into the ragina to form the os uteri agrees in structure on its inner aspect with the cervix: on its onter it is a continuation of the vaginal wall.

The vagina differs from the uterus in structure in accordance with its differing and double function, it serving at once as the channel by which the male reproductive elements are brought into proximity with the female elements, and as the avenue of discharge for the foetus at its maturity. Its wall is muscular, dilatable, and highly elastic, somewhat erectile, and provided with a definite reïnforcement of adenoid tissue; a feature possessed by no other portion of the reproductive tract.

The mucosa of the vagina is lined with stratified squamous epithelium, which rests npon a thick mucous membrane. The surface of the latter is beset with minute papillae which project into the deeper portions of the epithelium but do not produce a noticeable roughness of its surface, the only irregularities observable being those due to the well-marked folds or rugae. The upper portion is a dense fibrous layer rich in elastic fibres: below this in the rugae are networks of large reins supported by fibrous tissue containing numerous bundles of smooth muscular fibres which may be regarded as representing the muscu- 
laris mucosae, elsewhere absent: a ridge of rudimentary erectile tissue is thus formed beneath each ruga. Leucocytes abound in the mucosa, and scattered nodules of adenoid tissue are found: in the anterior wall near the orifice there is a well-defined adenoid layer. Special nerve terminals, the genital corpuscles of Krause, as found in the mucosa of the vagina. It is doubtful whether glands of any sort are present.

The submucosa is quite loose in structure and contains a venous network whose meshes run chiefly in the direction of the vagina. Beyond the submucosa is the musculosa, which is not sharply defined, as in most cases, into distinct strata: the inner bundles are in the main circularly disposed, and the outer bundles longitudinally; the two regions being, however, blended by numerous oblique bundles. A well-marked fibrosa invests the musculosa: it is composed largely of elastic tissue and is best developed on the anterior wall: it also contains an extensive plexus of large veins intermingled with bundles of smooth muscular fibres and forming a layer of erectile tissue best developed near the lower extremity.

The hymen agrees in its structure with a fold of the mucosa of the vagina, and can perhaps be regarded as derived therefrom, though its presence in rare instances in cases of absence of the vagina has caused this mode of origin to' be questioned by those who regard it as a fold of the skin of the vestibule.

The vulva includes a number of parts or regions each characterized by certain histological features worthy of 
brief mention. The surface of the area known as the vestibule is covered by a mucous membrane continuous with that of the vagina and of the urethra at their respective orifices. It is covered with stratified squamous epithelium, contain numerous elastic fibres, and is feebly erectile: it also contains numerous simple mucous glands. At the lower limit of the vestibular area are seen on either side of the vaginal orifice the openings of the ducts of the glands of Bartholin, small racemose glands of the mucous type homologous with the glands of Cowper in the male subject. Beneath the mucous membrane of the vestibulc and somewhat external to the proper limits of the vestibular surface are paired clongated masses of erectile tissue, the bulbi vestibuli, whose converging upper extremities are continucus with smaller plexuses whose vessels are confluent above with those of the glans clitoridis. The bulbar regions may be regarded as corresponding to the bilateral bulbous portions of the corpus spongiosum of the male subject.

The clitoris consists of two small corpora cavernosa identical in structure and relations with those of the male, and a small glans of spongy erectile tissue, which is of course imperforate. Its surface contains numerous genital corpuseles. Its preputial fold is continuous with the upper and its fraenum with the lower of the anterior dirisions of the labia minora. The latter, while resembling the surface of the restibule in color and texture, may be regarded as folds of the skin: they contain numerous large sebaceous glands, but sweat glands are wanting, as arc also hairs: their inner surface contains numerous genital 
corpuscles. Fat is wanting in the subcutaneous connective tissue, but large irregular venous channels are present, with smooth muscular fibres, composing here as elsewhere a loose form of erectile tissue. The labia majora are well defined folds of the skin whose inner surfaces resemble in appearance the outer surfaces of the labia minora, with which they are confluent, but differ from them in the presence of occasional modified sweat glands and minute hairs, associated with the sebaceous glands common to both. The thick and rounded margin of the fold affords a gradual transition from the moist stratified ${ }_{3}^{*}$ squamous epithelium of the mucous type found upon the greater portion of the vulvar surface to the epidermis of the skin, with which its outer surface agrees in general structure. In the deeper portions of the integument of the labia majora is found a layer of tissue similar to that forming the dartos turic of the male scrotum, with which the labia correspond. Like the divisions of that structure they converge above to be united upon the pubic eminence in the region known as the mons veneris, characterized, as in the male, by an abundance of coarse curling hairs, of numcrous enlarged sudoriparous glands, and by a dense mass of subcutaneous fat.

The mammary glands, whilc essentially tcgumentary organs, differ so greatly from all other dermal glands as to require consideration apart from the latter: their functional relations to reproduction render it appropriate to 
discuss them at this time. I'sually but not always rudimentary in the malesubject, they are normally but not invariably fully developed in the female. Each mammary gland so called is in reality an aggregate of fifteen or twenty distinct glands, if we regard that term as strictly designating a secretory body provided with a duct which opens independently, since each of the ducts opens by a separate orifice upon the skin of the nipple: but their union into a single anatomical structure is so intimate that it is more convenient to designate each of these regions as a lobe of a componnd racemose gland. The structure of these lobes and of the whole organ varies greatly in relation to functional activity; but it is characteristic of it at all times that it possesses an unusually large proportion of connective tissue and fat in its composition.

Before the gland has been called into functional activity the lactiferous ducts are present, as well as the ducts of the lobules by whose confluence they are formed: the latter have at the extremities rudimentary acini, which are, however, relatively few in number, and consist of masses of epithelial cells. Acini, lobules, and lobes are alike inbedded in an extensive stroma of connective tissue which forms stout septa not only between the lobes but between their subdivisions as well; while a considerable amount of subcutaneous and interstitial adipose tissue is present.

As pregnancy advances the acini become larger and more numerons, still consisting, howerer, of solid masses of cells. At the time of delivery the central cells undergo fatty degeneration and form the colostrum corpuscles of the milk of comnencing lactation. In the fully active 
gland the acini are spheroidal, comparatively large, and are lined by a single layer of cells which when at rest are flattened, but during secretion become cuboidal or columnar in form, their extremities containing one or more large oil-droplets in each instance : the latter are liberated by the rupture of the cell substance, a portion of which is probably contributed to the secretion. The basement membrane upon which the epithelium rests consists of an endothelioid layer of connective tissue corpuscles : the intralobular stroma is greatly reduced in proportional quantity. The terminal branches of the ducts have a thin basement membrane like that of the alveoli, which is lined by a single layer of flattened cells, their appearance rescmbling that of the ductules of the salivary glands : the larger lactiferous ducts have stouter walls, and cuboidal epithelium; these empty into the still larger channels, the galactophorous ducts, one of which leads, as has been stated, from each lobe to an independent orifice upon the skin of the nipple. These large ducts have stout walls of fibrous and elastic tissue, containing a few smooth muscular fibres: they are lined with columnar epithelium save in their outermost portions, where the epithelium becomes stratified. Each has an enlargement, the ampulla, near its termination at the nipple, whose structure does not differ from that of the rest of the duct.

In the intervals between lactation the mammary glands assume a resting condition in many respects similar to their primitive state. They always contain, however, a smaller amount of dense fibrous tissue and a larger amount of fat, and are consequently much less firm in 
texture. At the close of the reproductive period they begin to undergo a retrograde metamorphosis, the acini and smaller duets disappearing, the larger ducts collapsing, and the shrunken organ consisting chiefly of a mass of connective tissue and fat.

The nipple is a cylindrical projection from the surface of the gland, covered with deeply pigmented skin and composed of the extremities of the lactiferous ducts, associated bloodvessels, and smooth muscular fibres arranged in circular and longitudinal bundles. The dermal papilla are rich in nerve terminals: there is no subcutaneous fat: scattered in the surface are the small racenose glands of Montgomery: the areola at its base contains sweat-glands and numerous sebaceous glands.

The intimate relations existing between the urinary and reproductive systems and the homologies between the male and female sexual organs cannot be clearly stated without a description of their formation in the embryo, accompanied by a statement of some at least of the facts of their comparative anatomy. No attempt will be made at this time to discuss systematically either the embryology or the morphology of these organs, but such account of each will be alone given as appcars necessary to the intelligent comprehension of the relations and homologies above referred to.

The structure fundamental to the whole of the urogenital apparatus is what is known as a nephridium. 
In the great majority of the classes of the higher invertebrates the elimination of nitrogenous waste products takes place through the agency of organs designated by that term. A nephridium is essentially a tubular structure opening at one extremity upon the surface of the body (either directly or indirectly), and at the other communicating with the body cavity, or coelom, by a more or less funnel-shaped extremity termed the nephrostome. Its wall is lined with an epithelium which is glandular throughout a large portion of its extent: the funnel-shaped internal opening is commonly and the larger portion of the rest of the tube frequently ciliated, the ciliary movement invariably sweeping toward the external opening. The tube may be simple and quite direct in its course, or long, convoluted, and divided into specialized regions. Where a well developed vascular system is present the more or less coiled nephridial tube is usually provided with a rich net-work of capillaries. Nephridia may be simple: a single pair opening right and left on the surface of the body, as in many mollusks; or a pair being found in each of the majority of the segments of the body, as in the annelids, where they were first observed, and designated from their disposition segmental organs: or they may be compound, a number of funnel-bearing and ciliated tubules opening symmetrically into lateral tubes which discharge the secretion of the tubules upon the surface of the body or into a posterior cloacal sac, as in the rotifers. Without entering into a discussion of the homologies that may exist between the nephridia of the various 
classes of invertebrates, or between those of either of them and those of the vertebrates, it may be said that the urinary apparatus of the latter conforms, in a general way at least, to the plan last described.

The gonads, in which the reproductive elements are formed, are in most classes of Metazoa developed within the body-cavity, or coelom, into which they protrude, and into which the reproductive elements, when fully mature, are in many species discharged. In some of the lower forms where this takes place, and in which the reproductive elements are produced in immense numbers, the body wall becomes distended by their presence and finally liberates them by rupturing, the parent organism being thereby destroyed; a condition comparable to that of the so-called ammual plants, which grow, blossom, ripen a single crop of sceds, and die. In other cases the nephridia serve as channels for the escape of the reproductive clements : it will be noted that the small and actively moving spermatozoa would pass far more readily through the nephridial tubules than the large and passive ova; and it is probably true in the case of some species that the female is destroyed by the rupture of the body wall after the ripening of the first crop of ova, while the male elements are liberated through the nephridia, the parent organism surviving. In most of the higher classes of animals there are distinct channels of discharge, the gonaducts, for the reproductive elements: these are in some cases clearly formed by the modification of nephridia.

The vertebrate urinary aparatus consists in effect of a series of nepliridial tubules arranged along the dorsal wall 
of the body cavity on either side of the mid-plane and opening into right and left ducts of discharge. The disposition, form and relations of the tubules, and the origin and position of the duct of discharge of the functional kidney undergo important modifications in the various classes of rertebrates. Taking the group as a whole the series of tubules may be said to be divided into three regions, the pronephros or head-kidney, the mesonephros or primitive kidney, and the metanephros or permanent kidney of the higher vertebrates. Each of these regions needs brief consideration.

The pronephros is best dereloped in the anamnia (cyclostomes, fish-like vertebrates, and amphibia), in all of which it is present as a well-defined structure in the embryo, and in some of which it is functional in the adult. The tubules are always few in number, sometimes but one on each side, open upon the body cavity by distinct nephrostomes, and discharge into ducts leading to the cloaca and known as the segmental ducts. Near the opening of the nephrostomes there is found on each side a process of the coelomic wall containing a mass of capillaries and constituting a prominent glomus: the region of the coelom where this occurs is either partially or in some cases wholly constricted off from the rest of the body-carity so as to form "what is practically an enormous Malpighian body:" thus foreshadowing the arrangement found in the permanent kidney of the mammals. The development of the pronephros is embryonic and rudimentary in the sharks and their allies among the fish-like vertebrates, and in all amniota (reptiles, birds, and mammals): in thelast named 
class it is doubtfully represented in the arlult male and female by rudimentary structures connected with the surprarenal capsule.

The mesonephros is the functional kidney of all anamnia except the sharks and their allies. In this class and in the various classes of the amniota it is represented by the embryonic structure termed the Wolffian body. It consists primarily of serially arranged tubules plainly humologous with those of the pronephros, although their mode of development is not identical, being somewhat accelerated; a point of importance in connection with the origin of the netanephros. These tubules become rariously coiled and convoluted, and may give rise to branches like themselves: in many anamnia they open upon the peritoneal surface by nephrostomes: they have associated with then glomeruli resembling in their origin the glomus just described in connection with the pronephros: in some cases several tubules open upon a single glomerulus. They discharge into a modification of the segmental duct known as the mesonephric or Wolffian duct: it differs from the primary segmental duct in undergoing (in some species) longitudinal cleavage to give rise to a second canal called the Muellerian duct.

The ripened gonads of many anamnia discharge the reproductive elements into the body cavity by rupture, from which they escape through openings posteriorly and ventrally placed and known as abdominal pores. In other cases abdominal pores are wanting: in the female the ova pass out through the Müllerian duct or oviduct; in the male the testis lics opposite the anterior end of the 
primitive kidney, or Wolffian body; diverticula grow out from the Wolffian tubules of that region and become connected with the testis, forming channels of escape for the spermatozoa, which thus reach the Wolffian duct; the latter therefore functions both as a ureter and a spermiduct.

In the selachians (the sharks and their allies), and in all amniota a diverticulum is given off from the posterior portion of the Wolffian duct. In the former class this becomes connected with a mass of serially disposed tubules arising posterior to the Wolffian body, the metanephros, or permanent kidney; the duct in question being the true ureter. In the amniota the ureter grows out toward a mass of cells in which true uriniferous tubules with their associated Malpighian corpuscles are being formed. It is not certain that this structure is strictly homologous with the selachian metanephros: it may, perhaps, be so regarded, the difference in the mode of development being due to an intensified acceleration of growth similar to that already mentioned in the case of the Wolffian body. The latter structure never acts as a kidney in the higher vertebrates, its sole function being connected with the transmission of the reproductive elements of the male: the Wolffian duct becomes the spermiduct or vas deferens: in the female the whole structure is functionless and rudimentary.

This digression into the field of comparative anatomy will not be without value if it aids in making clear the brief statement of the development and homologies of the male and female urogenital apparatus of the human sub- 
ject based upon the facts mentioned therein, which is now to be entered upon.

Early in the development of the embryo there may be seen growing downward from the dorsal wall of the borly eavity on either side a well-clefined eminence, the Wolffian or excretory ridge : along its base are found two ducts, the Wolffian and Miillerian. Just mesad of the excretory ridge, and separated from it by so shallow a groove at first as almost to seem a modification of its mesial surface, is a second and smaller ridge, the germinal ridge. The latter becones the gonad: the epithelium of its surface early beconce columnar and shows here and there numerous primordial ova; the characteristic cells being so termed without regard to the future sex. The changes of position which the gonads undergo in each sex will be mentioned later.

The cmbryonic pronephros is formed at the anterior extremity of the excretory ridge. The posterior portion, as it derelopes backward, beconnes the blastema or mass of cells in which the uriniferous tubules of the kidney are formed : it is joined by the ureter, whose extrenity branches and forms the pelvis and calyx of the kidney, and possibly to some extent the collecting tubules: the exact relation of the two intergrowing structures is not yet fullyknown. At first the most posterior, the kidney gradually advances in position until it oceupies a location anterior to all the associated structures.

The middle region of the excretory ridge becomes the Wolffian body: in both sexes it develops as a series of transverse tubules in relation with the longitudinal Wolffian duct. In the male the tubules of the anterior portion 
become connected with the testis, forming the coni vasculosi of the epididymis, and possibly the rete testis as well: those of the posterior portion, corresponding to the strictly renal portion of the primitive kidney of the anamnia, become rudimentary and form the vasa aberrantia and the paradidymis, or organ of Giraldes. The Wolffian duct becomes the convoluted tubule of the epididymis with its continuation, the vas deferens, the latter giving off the seminal vesicles as it is transformed into the ejaculatory duct. In the female the whole structure, being functionless becomes rudimentary: the anterior portion of the tubules, corresponding to the epididymis, becomes the parovarium or epoöphoron; the posterior portion becomes the paroöphoron: the Wolffian duct becomes the rudimentary duct of Gartner.

The Miillerian duct undergoes corresponding differentiation. In the female, where it is functional, the upper portion terminates in the fimbriated extremity: the middle portion becomes the Fallopian tube, or oviduct in the strict sense. The lower portions coalesce on the mid-line, the upper region of the median structure forming the uterus and the lower the vagina: a discussion of the mode of their coalescence would take us again into the domain of comparative anatomy. In the male the Müllerian duct is, like the Wolffian duct of the female, altogether functionless. It early disappears throughout the greater part of its extent: the upper portion is perhaps represented by the sessile hydatid of the testis: the coalescedlower portions form the uterus masculinus, which sometimes shows traces of a vaginal region. 
In all amniota there is found very carly in embryonic life a vesicular diverticulum of the ventral wall of the intestine at a joint near its posterior termination: this outgrowth is called the allantois. In the mammals a considerable portion of it is enclosed within the body cavity: the distal portion of this becomes enlargerl to form the urinary bladder; a narrow region corresponding to the true urethra of both sexes connects it with a proximal cnlargement termed the urogenital sinus: the latter opens in common with the intestine into a short cloaca formed by a depression of the ventral surface of the body. The Miillerian and Wolffian ducts open into the sinus: the ureters at first open into the Wolffian duct, from which they are derived; later they open independently into the sinus: as growth advances they shift their position upward, until they reach their permanent point of discharge on the surface of the bladder.

The mammalian cloaca is from the first a very shallow depression: a transverse fold soon separates it into a posterior anal portion, and an anterior region which is the continuation of the urogenital sinus. Just in front of it there is found the genital eminence, whose posterior surface is grooved, the margins of the groove forming the genital folds; in front of its base the skin of the pubis is thrown into a thick fold (the future mons veneris) which is prolonged backward right and left in the genital ridges. In the male the genital eminence clongates; corpora cavernosa are formed in it: the genital folds coalesce from behind foward, converting the groove on the posterior surface of the eminence into a canal which is the continuation of 
the narrow and elongated sinus; while the development of erectile tissue in the walls of the canal gives rise to the corpus spongiosum: the canal becomes the urethra of the penis. In the female the eminence remains small and becomes the clitoris : the sinus becomes short and broad and is represented by the vestibule: the genital folds become the labia minores; the genital riclges the labia majores.

Glandular diverticula of the sinus are found in both sexes. The prostate of the male may be regarded as so derived; there-is no corresponding structure in the female: the glands of Cowper and the glands of Bartholin are homologous specializations of urethral structures. The change of position of the gonads has been already referred to. Situated at first in the more anterior region of the abdominal portions of the body cavity, they undergo an apparent shifting backward in both sexes. The change is least in the female, where they find a permanent resting place within the pelvis. In the male they reach the brim of the pelvis, penetrate the abdominal wall, and push their way into the genital ridges: these enlarge, become saccular, and coalesce below the united genital fold to form the scrotum. 


\section{CIAPTER XX.}

- THE VASCULAR SYSTEM.

On account of the part played by the smaller arteries, reins and lymphatics as components of the organs of the body in which they occur, the structure of such ressels was described in one of the earlier chapters of this book. The larger vessels must themselves be regarded as organs meriting separate consideration equally with the heart, which is the central organ of the vascular system.

The arteries of the body differ most conspicuously from the arterioles found in the various organs by the relative increase of the media: but each of the three layers undergoes both increase and modification. The intima is lined, as in the smaller vessels, by endothelial cells elongated in the direction of the tube: but this endothelium rests upon a subendothelial layer of fibrous tissue with branched corpuscles that disappears as we pass to the finer subdivisions of the ressel: with increase in the size of the artery it becomes more fully dereloped. This layer is directly in contact outwardly with the elastic layer, which is well developed, especially in the larger arteries, where it has the form of a fenestrated membrane, the membrana elastica intimae.

The media consists largely of transversely disposed smooth muscular fibres, particularly in the smaller ar- 
teries of the limbs: in large arteries, however, there is a distinct admixture of elastic tissue in the form of a network of fibres; this is connected with the elastic layer of the intima, and pervades the whole muscular coat: it increases in proportion with the size of the vessel. The muscular fibres of the media are quite short, and are very irregular in form, lacking the definite spindle shape characteristic of smooth fibres in most places where they occur. In some of the larger arteries many of the muscular bundles of the inner part of the media are longitudinally disposed.

The adventitia is the stoutest and most resistant of the coats of the arteries. It is rich in elastic tissue, especially toward the media, the larger arteries exhibiting just external to that coat a distinct elastic layer, the membrana elastica externa; this is followed by a region rich in elastic fibres: more outwardly the adventitia consists almost wholly of closely felted bundles of white fibrous tissue which at its outer surface passes over into the interstitial areolar tissue found between the vessel in question and the adjacent organs. In some of the larger arteries longitudinal bundles of smooth muscular fibres are found.

In connection with the discussion of the respiratory tract regarded as a diverticulum of the alimentary canal, it was pointed out that the coats of the latter were designated by characters readily demonstrable with the dissecting knife, but that the proper division based upon histological characters would be into an epithelial and a musculo-skeletal layer. The coats of an artery as above described are also examples of structures clearly distinguishable by anatomical methods: but a consideration of 
the histology of the wall of an artery will show the correctness of the description that has been proposed for it ats "composed of muscular and elastic tissue lined internally by endothelium and strengthened externally by a layer of connective tissue."

The features which have been mentioned as characteristic of the largest arteries are intensified in the structure of the aorta. In it the elastic layer of the intima is not so distinctly membranous, being composed chicfly of fibres which pass into those of the media, the two coats not being sharply defined. The media itself not only contains a very large amount of elastic tissue in proportion to the muscular tissue present, but is also rëinforced by a considerable quantity of white fibrous tissue, the coat being characterized more especially by its strength and elasticity than by its contractility. As in some of the larger arteries there are both longitudinal and transvere bundles of muscular fibres. The adrentitia is not sharply defined from the media, and is relatively thin. The pulmonary artery agrces in most respects with the aorta in structure. The larger arteries and veins have, like other organs of the body, their own small vessels of supply; these are called the vasa vasorum.

While the heart is quite a complex organ from the anatomical standpoint, its histological structure is comparatively simple. It may be regarded as essentially a hollow mass of muscular fibres of a peculiar sort, having on its outside an investing sleletal layer, and a similar lin- 
ing inwardly, each of the layers being bounded by an endothelium. The outer layer, or epicardium, is the cardiac portion of the pericardium. It is invested with serous endothelium which rests upon a membrane whose outer portion consists chiefly of white fibrous tissue, but which contains in its deeper layer a considerable quantity of elastic fibres arranged in a loose and indefinite meshwork. Beneath the membrane is a stratum of areolar tissue which is rich in fat cells, and in which run the vessels and nerves of the wall of the heart; in the auricles there are numerous small ganglia connected with the nerves. The lining membrane, or endocardium, is not unlike the epicardium: its investing endothelium, while continuous with that lining the arteries and veins, and agreeing in function with vascular endothelium, is composed of cells which are not elongated in form, but resemble rather in outline those found on serous surfaces. The membrane contains a ferv muscular fibres, and the subjacent connective tissue but a limited quantity of fat cells. In the auricles the elastic tissue of the membrane is quite well developed.

The myocardium or muscular layer of the heart varies greatly in thickness, being most developed in the ventricular wall and least in some portions of the auricles. The peculiar cardiac muscular elements of which it is composed have already been described: they are arranged in bundles which form the fibres and lamellae visible to the naked eye: the disposition of the latter is a subject of anatomical rather than histological study. Between the bundles is a very delicate framervork of connective tissue 
which supports the abundant blood and lymph capillaries: pattehes of adenoid tissue are also of occasional occurrence. The peculiar fibres of Purkinje found just beneath the endocardium of some mammals are of doubtful occurrence in man: they are large cellular elements (frequently with two nuclei) whose central portion consists of clear protoplasm but whose surface has undergone striation; they may perhaps be regarded as imperfectly developed cardiac fibres.

The columnae carneae and the papillary muscles are alike processes of the myocardium: in them the muscular fibres are chiefly disposed in a longitudinal direction, and the endocardial membrane upon their surfaces becomes almost tendinous in structure; the latter passes over from the surface of the papillary muscles into the chordae tendineae, whose central strands of fibrous tissue are in the larger cords reinforced by scattered bundles of muscular fibres.

The valves of the heart are folds of the endocardium containing bundles of fibrous tissue and a variable quantity of elastic tissue, the latter being present in greatest quantity in those places subject to the greatest pressure produced by the heart's action on the blood: the semilunar valves are farther reinforced by the presence in each of a nodule composed largely of elastic tissue, the corpus arantii.

The large veins differ from the corresponding arteries in the relative thinness of the media and the thickness of the adventitia, and in the smaller amount of elastic tissue throughout the entire structure. The endothelial cells lin- 
ing the intima of the larger veins are but slightly if at all elongated, resembling those of the endocardium in their polygonal outline: in the smaller tributaries the form characteristic of vascular endothelium is assumed. The media of the two venae cavae is a continuation of the myocardium of the right auricle, and contains cardiac muscular elements : that of the larger veins generally contains but a small quantity of muscular tissue, intermingled with bundles of white fibres, which replace the elastic tissue similarly situated in the larger arteries. The media of some veins, notably those of the nervous axis and of the bones, is entirely devoid of muscular tissue. In a few cases the muscular bundles situated in the inner part of the media are longitudinal in their direction. The adventitia of the veins consists chiefly of a stout layer of felted bundles of fibrous tissue, containing a moderate amount of elastic fibres. In the portal, renal, and some other veins, the adventitia contains numerous bundles of smooth muscular fibres longitudinally disposed. The valves of the veins are folds of the intima, strengthened by bundles of fibrous tissue arranged parallel to their free borders, and containing a small amount of elastic tissue: muscular bundles from the media sometimes extend into the base.

The lymphatic vessels resemble the blood vessels in the fact that their walls are composed of an inner, a middle, and an outer coat: each of the three coats is, however, much thinner than in the case of the blood vessels, the middle and outer being especially so. It is customary to 
say that they resemble the veins in structure: it is more accurate to say that in the relative thickness of the coats and particularly in the proportion of muscular tissue they approach the arteries: they resemble the veins in the structure of the intima and in its development into valvular folds: the adrentitia is relatively to the other coats weaker and simpler than in either arteries or veins. This is not the case, however, with the most highly specialized of all the lymphatic vessels, the thoracic duct, whose adventitia is quite stout and contains longitudinal bundles of smooth muscular fibres: the intima of the duct is also reinforced with a longitudinal network of elastic fibres. In the smaller lymphatic vessels the adventitia disappears; the media contains bundles of smooth muscular fibres obliquely disposed, in addition to the ordinary transverse bundles.

The development of the heart and of the larger vascular trunks takes place in such a manner that it is difficult to discuss it without either taking for granted a knowledge of or entering into a description of the manner in which the ground plan of the embryo body is laid down. It is therefore necessary to defer it until after the subject of Embryology has been taken up by the student.

Reference may with convenience at this time be again made to the great serous membranes which line the principal cavities of the body; since these latter are best re- 
garded as enormous lymph cavities. Their general structure and particularly that of their characteristic epithelium has been discussed in a previous chapter: it remains to speak briefly of some of the features characteristic of each (in so far as they have distinguishing characteristics) and to describe some allied though different structures usually associated with them.

The right and left pleurae, which invest the lungs, line the thoracic cavities and bound the mediastinum which separates the latter, while they have the general character of serous membranes, vary somewhat in structure in different localities. They are thickest over the ribs, where the subserous layer of areolar tissue permits of the ready removal of the membrane: the stomata of the endothelium are said to occur over the iritercostal spaces only. The membrane becomes thinner and more adherent as it passes onto the surface of the diaphragm. On the surface of the lungs it is quite thin and closely attached, the connective tissue becoming continuous with that of the framework of the organ: the endothelial cells of the pulmonary pleura are also taller and more granular. The pericardium, or heart sac, is in reality but little more than a double serous membrane: its outer portion being derived from the pleurae and its inner forming the proper pericardial membrane which is reflected upon the heart as the epicardium: between the two membranes is a layer of areolar tissue containing a small quantity of fat and numerous 'blood vessels and lymphatics.

The peritoneum, which lines the cavity of the abdomen, is the largest and most complicated of the serous mem- 
branes. Like the pleura, it is thiclier in its parictal than its visceral portion. The subserous layer of areolar tissue is less developed along the ventral nidline and on the under surface of the diaphran than elsewhere in the parictal peritoneum, which is consequently most closely adherent in these regions: that of the visceral portions is in every case closely connected with the skeletal structures of the organs invested. Certain of its folds, termed ligaments, from their mechanical relations to the organs with which they are connected, for example, the spleen, the liver, and the uterus, have their applied fibrous membranes in close contact. Others, such as the omenta, have between the membranes a layer of areolar tissue in which a greater or less amount of fat may be developed. In the mesentery the intervening layer contains, in addition to a variable amount of fat, an extensive system of blood and lymph ressels: associated with the latter are the numerous nodules of adenoid tissue commonly called the lacteal glands: their structure will be described in the following chapter in connection with other similar bodies. The tunica vaginalis of the scrotum and testis must be regarded as an offset from the peritoneum: its structure and relations have been sufficiently described in a previous chapter.

The meninges of the brain and spinal cord, and in particular the pia mater, have been regarded as serous membranes: they differ, however, in structure and relations alike from the ordinary membranes of that name, and will best be discussed in conncction with the nervous axis. The perilymphatic and endolymphatic surfaces of the internal 
ear will be considered in connection with the description of that organ.

The synovial membranes, which line the capsules of joints, the sheaths of tendons, etc., may here be considered, although they differ materially in structure from the serous membranes with which they are often associated as regards both their organization and also the characteristic fluid which fills the cavities bounded by them. They are in effect rather dense membranous layers of connective tissue, devoid of any well-defined endothelial investment: here and there cells and patches of cells may be seen upon their surfaces, some of which are sufficiently close together to assume the polygonal outline characteristic of endothelium; others, hovever, are distinctly branched, differing in no essential from ordinary connective tissue corpuscles: their affinity to endothelium will perhaps be evident if we recall the definition of it previously given to the effect that it is a layer of connective tissue corpuscles investing a free surface. Fringed vascular folds occur upon synovial membranes which frequently bear smaller processes, the synovial villi, in which a central strand of fibrous tissue is invested with a layer of small rounded cells. Articular synovial membranes pass so gradually into the fibro-cartilage which borders the true articular cartilage of the joint that it is not possible to define the boundary between the two: even the cellular elements gradually losing their processes and presenting the appearance of cartilage corpuscles. 


\section{CHAPTER XXI.}

THE DICTLESS BODIES.

The organs here included under the above title are very frequently referred to by the name of the ductless glands. If the term gland be used in its older and looser sense as a designation for any soft parenchymatous body, then a distinction between such of those bodies as are provided with and those devoid of duets is natural and justifiable. It is better, however, to use the term in its narrower and more definite application to bodies composed essentially of acini or tubules lined with epithelial cells whose functtion is to secrete a specific solution or soluble substance, ordinarily removed through a definite channel of discharge. If the term gland be thus employed, there is but one (and a portion of another) of the bodies here considered to which the expression ductless gland may with any propriety be applied: as used to designate the others it is not only erroneous, but tends to give rise to.misleading conceptions, The expression ductless bodies, while not without objections, is therefore preferable to the older title. The name of adenoid bodies has also been proposed, but is apt to lead to the falsc idea of a community of structure in all of the bodies in question.

It is quite important to note in this connection that the caption given to this chanter, unlike any other used hith- 
erto, does not designate any system of organs associated with the performance of one of the great functions or groups of functions, or characterized by any common structure or by similar anatomical or morphological relations : their association under one heading is more than anything else a matter of convenience; and the order of their consideration largely arbitrary, though not altogether so. The lymphatic bodies, from their close structural and functional relation to the lymphatic vessels, might with eq'xal propriety be described in connection with the vascular system: the spleen, differing in important respects from the bodies just named, resembles them in its close relation to the circulatory system: the thymus has much in common with them in its structure: to all these bodies (and to these alone) the term adenoid bodies might with propriety be applied, owing to the prevalence in them of the tissue of that name.

The thymus, in addition to the adenoid tissue of which it is largely composed, contains definite masses of epithelial elements whose derivation will be discussed when that body is described: the thyroid is largely composed of epithelial cells which line acini; to it more than to any other of the bodies here considered may the title of ductless gland be with propriety applied, as is shown by its embryonic development. Resembling the thymus and the thyroid in the origin of some of their elements (and in little else) are the parathyroids, situated on either side of each lobe of the thyroid; and the carotid glands; they are closely resembled in structure, though not in origin, by the coccygeal gland; the term gland is still univer- 
sally applied to the last two; they have been called, from their associations, the arterial glands.

The suprarenal capsules, or the adrenals, as they are sometines termed, are double structures, consisting in part of a mass of nervous tissue: they are resembled in this respect by the pituitary body, which consists in part of a mass somewlat analogons to the thyroid, and in part of an atrophied lobe of the brain: the pineal body is altogether derived from the modification of a portion of the brain, and might, in common with the pituitary body, be described in connection with that organ. This brief enumeration will suffice to show how heterogenous are the bodies here associated as regards both structure and anatomical relations: the function of most of them is at present entirely unknown. An account of the details of their structure will now be given.

The simplest lymphatic bodies are those rounded masses of adenoid tissue bounded by a more or less definite fibbrous layer which have already been mentioned in connection with the description of the alimentary canal. The lymphatic follicles, as they are commonly called, of the intestine, whether solitary or clustered (as in the Peyer's patches of the ileum), and the similar masses whose somewhat confluent aggregations form the tonsils, are cxamples of what way perhaps best be called lymphatic nodules. They consist essentially of splieroidal lumps of adenoid tissue somewhat more dense in the outer than the inner portion, but showing no division into lobes. They are pervaded by capillary networks, and may be invested 
by a large lymph sinus or by a plexus of small lymphatic ressels. It is not easy to demonstrate among the latter distinctly efferent or afferent trunks: and from the usual position of these bodies in mucous membranes, and from what we now know of the important bacteriophagous function of leucocytes upon mucous surfaces it may be questioned whether those formed in the lymphatic nodules do not find their chief destination there rather than in the lymph stream.

The larger and more deeply seated lymphatic bodies commonly termed lymphatic glands, together with the altogether similar bodies found in the mesentery and called lacteal glands, for both of which the much better name of lymphatic nodes has of late years come into use, are in reality integral parts of the lymphatic and therefore of the circulatory system. Each is a rounded body showing a distinct depression, the hilum, on one side, at which point the blood vessels of the interior enter, and from which one or more efferent lymphatics leave the organ. The surface is invested with a stout fibrous capsule, containing scattered bundles of smooth muscular fibres in the larger nodes: it has a proper network of blood vessels, and into it at various points pass afferent lympahtics which traverse it quite obliquely, sometimes forming small plexuses or sinuses within it before communicating with the lymph channels within.

The interior is divided into a cortical and a medullary portion: from the capsule stout trabeculae of fibrous tissue (sometimes containing smooth muscular fibres) pass inward: they are frequently broad and lamellar in form 
and divide the cortex imperfectly into subequal lobules sometimes called the cortical follicles and compared to the lymphatic nodules (or so-called follicles) already describerl, from which, however, they differ in important respects: the inner extremities of their trabeculae subdivide, communicating by their branches with a coarse network of fibrous tissue which forms the framework of the medullary portion.

The spaces of the network just mentioned are occupied by another network of rounded strands of adenoid tissue, the medullary cords, which become continuous at their extremities with the solid cortical lobules of the same tissue situated between the trabeculae. It will be remembered that adenoid tissue consists in effect of retiform tissue whose interstices are filled with lymphoblasts: the medullary cords and cortical lobules of adenoid tissue are in each case smaller than the cavities in which they are situated, the surrounding spaces containing a coarser retiform tissue (devoid of lymphoblasts and presenting but little resistance to the passage of fluids) which connects the cords and lobules with the medullary and trabecular framework. A network of passages throughout the whole node, known as the lymph sinuses or lymph channels, is thus formed, into which the afferent lymphatics open after passing through the capsule, and from which the efferent lymphatics lead.

The medullary portion of the lymphatic node extends to the surface at the hilum, the artery of supply entering it directly: the capillary network of the interior is situated almost entirely in the deeper portion of the adenoid 
strands and masses. The lymph channels of the medulla converge at the hilum to form a plexus, from which a single efferent trunk may lead, or, in the larger nodes, several smaller vessels which unite outside the node to form a single trunk. Pacinian bodies are of frequent occurrence in the interstitial connective tissue just without the capsule at the hilun.

The relation between thelymphatic nodes and thelymph stream, as regards the formation of lymphocytes and their transformation in the blood stream into leucocytes, has been discussed in a previous chapter. The minute islands of adenoid tissue occasionally found either on or within the walls of lymphatic vessels, and known as perilymphatic or endolymphatic nodules, may be regarded as rudimentary organs of the same kind.

The spleen is as closely related to the blood vascular as the lymphatic nodes to the lymphatic portion of the circulatory system: it may possibly be regarded as derived from the modification of one of the last named bodies, though differing from them greatly not only in its vascular relations, but also in its internal structure. It is interesting to note that in some of the lower mammals numerous small accessory spleen-like nodules are normally present in other regions of the body. Similar bodies are sometimes found in man in the vicinity of the principal organ, of which they may be regarded as diverticula.

The spleen is invested by a serosa derived from the peritoneum which rests upon a stout capsule of fibrous tissue which, like that of the lymphatic nodes, contains occa- 
sional smooth muscular fibres: it differs from that of the bodies last mentioned in the greater predominence of elastic fibres, making the organ highly distensible. At the hilum the capsule is continued in to the spleen to form large trabeculae which branch and subdivide within, eventually becoming continuous with the branches of similar though small trabeculae which pass inward from the capsule at numerous points: the trabeculae, like the capsule, contain numerous elastic fibres, and some muscular fibres: the interior of the organ is pervaded by the large-meshed reticular framework thus produced. Continuous with this framework is a coarse retiform tissue whose fibrous network is invested with branched corpuscles: in many cases the fibrous element is quite scanty, and the reticulum consists of little more than branched corpuscles connected with each other by the tips of their branches, the so-called reticular cells of the spleen. The intervals between these cells are filled with blood which contains rather more than the usual proportion of colorless corpuscles and rather less of the colored: there are present also numerous unbranched amoeboid cells somewhat larger than colorless corpuscles, the spleen-cells: these, the reticular cells, and the plasma of the blood itself contains disintegrating colored corpuscles, and pigment granules derived therefrom: the whole constitutes the spleen pulp, a reddish brown mass to which the characteristic color of the organ is due.

The splenic artery divides into several branches just before reaching the organ: these enter at the hilum, following the stout trabecular continuations of the capsule above mentioned: within the latter they branch, their branches

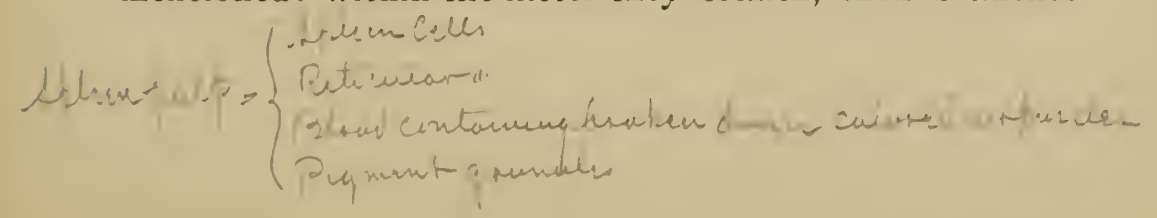




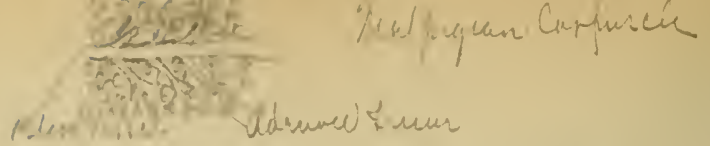

in some cases following the subdivisions of the trabeculae. In other cases small branches leave the trabeculae and become divided into brush-like tufts of arterioles: on emerging, their adventitia, heretofore continuous with the fibrous tissue of the framework of the organ, becomes replaced by a layer of adenoid tissue: here and there this sheath is suddenly enlarged to form spheroidal masses which may be as much as a millimetre in diameter, though usually less than half as large: they are known as the Malpighian corpuscles of the spleen, and are readily visible to the naked eye as whitish spots in the dark brown pulp. The adenoid tissue of the corpuscles is permeated by capillaries given off from the arterioles enclosed; it is quite loose in the centre but denser at the surface, where it passes over abruptly into the retiform tissue of the pulp. The corpuscles are found surrounding small arteries and apparently strung upon them, or upon their subdivisions, in which case they look like lateral outgrowths.

On leaving the corpuscles the arteries divide into capillaries, which, like those arising from the smaller divisions of the arteries which follow the framework of the spleen more closely, finally open into the spaces of the tissue of the pulp, the endothelial cells of the capillaries gradually becoming looser, branching, and finally passing over into the reticular cells; thus affording the only instance in the body where the blood leaves the definite vessels proper to it and circulates in the interstices of the tissues; a condition largely characteristic of the circulation of all invertebrates. The veinlets of the pulp originate in the same way that the arterioles terminate, or rather its converse: 
the reticular cells passing over into branched and loosely disposed endothelial cells which later become elosely united to form the lining of the commencing vessels. The latter soon enter the trabeculae, where they are gathered into larger veins: these anastomose freely within the trabeeulae, finally uniting to form the few large trunlis that leave the hilum.

The thymus is a bilobed adenoid body situated just beneath the sternum in the upper part of the thorax and extending into the lower part of the neck in the embryo and the infant: it is gradually reduced to a mere vestige in the adult. The whole organ is invested by a thin capsule of fibrous tissue, beneath which it is subdivided into a num. ber of irregular lobules each but a few millimetres in diameter. The fibrous tissue envelope of each lobule gives off trabeculae which penetrate the interior in the same manner as the similar structures in a lymphatic node. The lobule in consequence exhibits a cortical and a medullary portion. The cortex is composed of nodules of adenoid tissue not unlike those found in a tonsil: the medulla is a mass of adenoid tissue much less dense than that of the cortex, the transition from the one to the other being so rapid as to be quite conspicuous in sections. The trabeculae are continuous with the retiform tissue of the cortex and medulla alike, but there is nodistinct medullary framework of fibrous tissue and no segregation of the adenoid tissue in medullary cords: nor are there any lymph channels in either cortex or medulla.

The most characteristic feature, of the thymus is the 
presence in the medulla of what are known as Hassall's corpuscles, or, as that histologist termed them, concentric corpuscles. These are peculiar nest-like groups of epithelioid cells which are now known to be derived from the breaking up of right and left tubular diverticula from the cervical hypoblast. Each corpuscle consists of a central granular mass containing one or more spheroidal cells, surrounded by two or three layers of concentric flattened cells : compound corpuscles sometimes occur, two or three ordinary corpuscles being inrested by a common layer of concentric cells. The adenoid tissue of the organ contains a rich capillary network, and is the place of origin of numerous large lymphatics.

The thyroid resembles the thymus in being relatively large in foetal life and infancy: it differs from that organ in its persistence and evident functional importance in the adult, as indicated by the grave consequences of its complete extirpation. Like the tubular structures which eventually break up into the concentric corpuscles of the thymus, its characteristic elements are derived from the cervical hypoblast. It is at first provided with a duct, whose rudiment becomes the foramen caecum of the dorsum of the tongue: the duct in question in rare instances persists; in the great majority of cases it aborts, converting the organ into a true ductless gland.

Unlike most glandular bodies, the thyroid is not provided with a well-defined capsule. It is invested by a layer of areolar tissue considerably denser than that connecting it with adjacent organs but not passing over into a dis- 
tinct fibrous membrane. Areolar tissue of variable density pervades the interior of the organ, forming the supporting framework of its structure, the characteristic feature of which is the presence of great numbers of vesicles united into imperfect lobules. The vesicles are spheroidal, polyhedral, or sometimes tubular in form, their walls consisting of a single layer of cuboidal epithelium. The interior of the resicle is filled with a glairy yellowish colloid substance which frequently contains leucocytes and detached epithelial cells. A distinction has been, made by so:ne observers between the colloid cells, which are actively engaged in secreting the fluid contained in the vesicles, and the reserve cells. A definite basement membrane cannot be clearly discerned, the epithelial cells appearing to rest directly upon the interstitial septa of areolar tissue already mentioned: the areolae of the septa not infrequently contain the colloid secretion of the cells : elements resembling plasma cells are found in the interstitial tissue. The thyroid is highly vascular, the arteries being relatively quite large, and anastomosing freely: the vesicles are surrounded by a rich capillary network: the lymphatics are also large and numerous, and the presence of colloid substance in their interior may sometimes be detceted.

Imbedded in the substance of the thyroid upon both the lateral and the mesial surfaces of the lobes are small bodies a few millimeters in dianeter to which the name of parathyroids has been given. They resemble the thyroid in color and appearance, but differ from it in structure, 
consisting of solid strands of epithelioid cells apparently anastomosing, their interspaces being occupied by numerous blood vessels. They have been regarded by some observers as masses of embryonic thyroid tissue: this view is denied by others, who regard their structure as more nearly approaching that of the carotid glands. There is usually associated with each a small mass of adenoid tissue containing concentric corpuscles and in other respects resembling the substance of the thymus.

The carotid glands, situated in the angle between the branches of the common carotid artery, are small irregularly shaped bodies whose envelope of connective tissue is continued inward to form a supporting framework imbedded in which are nodular masses of epithelioid cells richly supplied with capillaries. They resemble the parathyroids in their origin from the cervical hypoblast, and both are probably to be regarded as rudiments of larger and more important organs.

The coccygeal gland is another body of quite similar structure to those just described, and probably also rudimentary in its character. The epithelioid cells which constitute its distinguishing feature are to some extent disposed in columnar strands as in the parathyroids. Eberth has described among them nests of cells resembling concentric corpuscles. Attempts have been made to show that the elements of this body are largely nervous in character, but this view of their nature lacks confirmation. The mode of development is not known. 
The suprarenal capsules, or, in the language of comparative anatomy, the adrenal bodies, since their position is usually near but not upon the kidneys, as is the case in man, are in some respects the most complex in structure of all the ductless borlies, to no other of which are they nearly allied. Each on seetion shows to the naked ese a distinct vellowish cortex, radially striated, and a dark brownish homogeneous medulla, the two being clearly defined from each other. The surface is invested by a thin but firm fibrous capsule whose deeper portion shows scattered bundles of smooth muscular fibres: from it tough fibrous septa enter the interior of the organ to form the cortical framework, which is limited internally by a continuous layer of connective tissue which bounds the medulla. The interior of the latter is also perraded by a framework of fibrous tissue.

The cortex is divided by the difference in the disposition of its septa and in the consequent mode of segregation of its elements into three distinct zones which pass into each other without great abruptness: these are the thin zona glomerulosa just beneath the capsule, the zona fasciculata next within, which forms by far the greater portion of the cortex, and the zona reticularis, little if at all thicker than the outer zone, which lies next the medullary sheath "of connective tissue. The spaces of the fibrous framework are occupied in the outer zone by rounded nodules, in the middle by columnar masses, and in the inner by a network of strands of closely packed polyhedral cells of moderate size whose protoplasm shows numerous small oil globules to which the color of the cortex is largely due. 
The cells of the inner zone are darker in color, frequently containing brownish pigment: those of the outer in some animals are occasionally columnar in form, being disposed about an ill-defined lumen in the centre of the nodule.

The medulla contains within the fibrous stroma irregular cords and masses of cells larger and much more loosely arranged than those of the cortex: they are devoid of oil globules and frequently exhibit branching processes. A rich plexus of non-medullated nerve fibres is present, and connected with great number of ganglion cells either scattered or clustered in groups of varying size. Numerous small ganglia are also found upon the nerves just external to the hilum.

The arteries of supply enter the surface of the capsule by numerous small branches: within, the vessels are distributed to the cortex along its framework, the capillaries not pervading the cellular masses as in the parathyroids, carotid glands, and coccygeal gland: thence they pass to the medulla, which contains a large plexus of veins whose branches unite into one at the hilum. The cortex is well supplied with lymphatics which communicate both with those of the capsule and with those of the medulla.

In the angles of the irregularly pyramidal adrenals of the human subject the cortex is folded upon itself, the medulla not extending into the fold; the two layers of the zona reticularis are, however, separated by a continuation of the connective tissue layer which surrounds the medulla. The distinctness between the cortex and the medulla is associated with an important difference in their embryonic development. The two arise independently of each 
other, and, indeed, remain so throughout life in some of the fish-like vertebrates: the cortex arises as an outgrowth from the peritonenm in close proximity to the mesonephros: the medulla is lerived from an extension of the adjacent sympathetic chain of ganglia: from its elose connection with which and from its richness in nervous elements many are inclined to regard the adrenals as essentially portions of the nervons system.

The pituitary body is also known as the hypophysis cerebri. It is a double structure, consisting of an anterior and a posterior portion: it wuuld be well if the former term could be restricted to the first of these and the latter to the other, since they are essentially different alike in structure and in origin. The posterior division is in reality a downgrowth of the brain, as the second term implies: it is the rudiment in man and mammals of what is a distinct and important lobe of the brain in the fish-like vertebrates. The anterior is an upgrowth from the epiblast which lines the oral invagination, and is in substance an epithelial body: it is also a rudiment of what was probably in the earlier vertebrates or their invertebrate ancestors an important glandular organ; its pathological relations indicate that it still has a persistent though as yet unknown function. The contact and cohesion of the two bodies is confined to the mammals: in all other vertebrates they remain distinct.

The anterior lobe is larger than the posterior, and is of a darker reddish color. It consists of spheroidal and simple or branched tubular acini; their closed cavities are lined 
either by a mass of polyhedral epithelioid cells which fill the cavity, or by a layer of true epithelial cells which surround a distinct though sometimes irregular lumen frequently filled with colloid substance similar to that found in the thyroid: in -some of the larger tubules cilia have been observed upon the cells. Betreen the vesicles and tubules is a framework of connective tissue which supports the numerous blood vessels and lymphatics and is continuous with the fibrous capsule.

The posterior lobe is at first a hollow diverticulum of the 'trixt-brain: in man and all mammals its cavity is nearly or quite obliterated, and it becomes a small solid mass. The nervous tissues characteristic of the inferior lobe of the brain of the fish-like vertebrates fail to develope in the higher forms, their place being taken by an ingrowth of ressels and of bundles of fibrous tissue: within the meshes of the latter are found numerous peculiar fusiform or stellate cells which are frequently pigmented. Where a restige of the cavity remains it is lined with columnar ciliated cells similar to those found lining the cavity of the third rentricle. The relation of this portion of the pituitary body to the brain is so close that the whole is frequently described in connection with that organ: but the larger and apparently more important anterior portion resembles the thyroid so much both in structure and in origin as to justify its description among the anomolous ductless bodies.

The pineal body, otherwise known as the epiphysis cerebri has already been spoken of in connection with the 
pituitary body. Like the posterior portion of that organ, it is strictly a portion of the brain; and its structure should be included in a full account of that organ. Like its analogue first mentioned, howerer, it is in mammals altogether rudimentary and completely devoid of true nervous tissue: it has therefore no longer any histological relation with the nervous axis and may as a matter of convenience be described at this time. It consists essentially of a number of closed spheroidal or tubular acini lined or in most cases wholly filled with polyhedral epithelial cells, and supported by dense interstitial connective tissue. Anong the epithelial cells, as well as on the outer surface of the body, are numerous gritty calcareous particles known as brain-sand: this is also found in some other portions of the brain. The pineal body in some of the lower vertebrates contains true nervous tissue and is connected with a peculiar median sense organ sometimes called the parietal or pineal eye.

Attention was called in the opening paragraphs of this book to the frequent use of the term Physiological Anatony as a synonym for Histological Anatomy. The distinction between the two is very well illustrated by the facts in the case of the bodies described in this chapter. It was alike the hope and the expectation of the earlier histologists and physiologists that the investigation of the elemental structure of each organ of the body would throw great light upon its functions. This has proved to be the case in many instances, and physiology has been 
under correspondingly great obligations to histology, which it has been quick to acknowledge: so ready, indeed, that the student new to the subject is to some extent liable to loose sight of the important fact that in not a few instances no such happy result has followed upon a dvances in our knowledge of minute structure. While, for example, the difference in the form and relations of the cells lining the alveoli of serous and of mucous glands respectively can be correlated with the difference in the character of the fluids secreted by them, no one could have foretold, given the facts of structure, the associated difference in function; there is still less evident relation between structure and function in the case of the cardiac and pyloric glands of the stomach; and none at all that can as yet be discerned between the form and arrangement of the hepatic cells and the secretion of bile. What is true in numerous other instances is eminently so in the case of the ductless bodies: we have in them examples of quite complex organs whose histological anatomy has in each case been very carefully studied; but whose function is in every instance, save that of those which consist chiefly of adenoid tissue, almost if not altogether unknown. 


\section{CHAPTER XXII.}

TIIE CENTRAL NERVOUS SYSTEM.

The ductless bodies afford us instances of organs exhibiting quite complex histological structure, concerning whose functions little or nothing is known. A case not exactly the converse of this is presented by the nervous axis; whose physiological anatomy is exceedingly complex, but whose histological structure is far less so. For example, experiments show that the white matter of either side of the spinal cord is resolvable into a number of more or less distinct tracts, none of which presents any single structural feature or any combination of features by which it can be demonstrated: much the same may be said of the physiological centres that have been experimentally located in the grey matter of the cord; in no case can their positions be demonstrated by histological methods.

Failure to distinguish between the provinces of plysiological and of histological anatomy has led many writers upon the latter to include in their description of the nervous axis many facts (in themselves of the highest importance) which are demonstrable only by methods that are essentially physiological: to the confusion of the student, who is frequently led to expect that his sections will show him more than our present histological methods at least make possible; and being disappointed is apt to 
doubt the ralidity of the statements which he has read. The present chapter will undertake no more than a brief description of such structural features as can with certainty be made out by histological methods; in other words, by a study of the form, relations, and groupings of the structural elements present. The consideration of the different regions of the brain will follow that of the spinal cord: and both will be preceded by a short account of the membranes which invest the nervous axis or line the cavity in which it is contained.

The meninges, or lining and investing membranes connected with the nervous axis, are three in number: of these the outer, known as the dura mater, or meninx fibrosa, lines more or less closely the spinal canal and the cavity of the skull; the inner, called the pia mater, or meninx vasculosa, closely invests the surface of the cord and the brain; while the third, the arachnoid, or meninx serosa, situated between the first and the second, is structurally connected with the latter, the two being derived from the differentiation of a single investing layer. On account of the intimate relation between these two meninges they are by some anatomists described as one, under the name of the leptomeninx, the outer membrane being termed the pachymeninx: a view which is supported by the comparat ve anatomy of these structures as well as by their embryology; it is also true, however, that the two meninges so designated are themselves formed from a single mass of indifferent tissue originally filling the space between the nervous axis and its case. 
The dura is a thick and strong mass of white fibrous tissue, mixed with a small amount of elastic fibres: the constituent bundles are disposed chiefly in a longitudinal direction in the spinal portion of the membrane, those of the cranial portion being variously disposed. In the latter region the durat is closely adherent to the cranial periosteum, particularly at the base of the brain; dorsally the two fibrons layers are less intimately united; it is, indeed, customary to speak of the dura as forming the intracranial periosteum, and as composed of two layers; but the interpretation here indicated is more in accordance with the facts of structure. The inner surface of the cranial dura is invested throughout with serous endothelium; a similar structure has been described upon the outer surface in places where it is free from the periosteum. The spinal dura is covered on both sides with a similar investment. In addition to flattened connective tissue corpuscles, both the cranial and the spinal dura contain numerous granule cells. The cranial dura is separated from the cranial periostenm here and there by the large sinuses which receive the blood from the reins of the brain, and by the accessory or parasinoidal spaces, but is not itself highly vascular: the same is true of the spinal dura, between which and the periosteal lining of the spinal canal is found the internal spinal plexus. Ossification occurs normally in the principal folds of the cranial dura (the falx and the tentorium) in some mammals.

The pia consists of two more or less clearly distinguished layers, an inner or investing layer, closely applied to the subjacent nervous mass, with whose connective tissue framework it is directly continuous; and an outer or vascular stratum, rich in small blood ressels whose branches enter the nervous tissue beneath. The whole membrane 
is made up of interlacing bundles of white fibres, mixed with occasional elastic fibres; in the spinal pia the prevailing direction of the bundles is longitudinal. The outer layer of the pia is connected with the arachnoid by numerous trabeculae of connective tissue, which pass across the subarachnoid space; this is quite extensive along the spinal cord, and in sume places around the brain; a nearly continuous series of definitely arranged strands passes from the pia at the sides of the spinal cord across to the inner surface of the dura, traversing the arachnoid; the groups of internally converging bundles are found between the spinal nerves, with which they alternate; the whole forms the denticulate ligament of either side. Upon the free surface of the pis and along the surfaces of the trabeculae and the ligaments just described are found flattened connective tissue corpuscles, endothelioid in form and position. In the stroma of the pia plasma and granule cells occur, and in some animals great numbers of pigment cells.

The arachnoid is composed of loosely interwoven delicate bundles of fibres, the intervening meshes containing numerous flattened corpuscles: the outer surface is invested with a layer of serous endothelium; it is near to but very sparingly connected with the dura. The inner surface corresponds to the outer surface of the pia, with which it is united by the loose mesh work of trabeculae above described.

The relations of the meninges to each other and to the adjacent structures are as yet but imperfectly understood, neither their structure nor their embryonic development being as yet fully known. Such facts as are known concerning the latter, and such light as is afforded by comparative anatomy, appear to justify the view which 
regards the subdural space as the primary eleavage of the mass of connective tissue which in the embryo and in the lowest vertebrates lies between the nervous axis and the walls of the cerebrospinal canal; the portion outside this cleft becoming the dura or pachymeninx, and that internal to it the leptomeninx or arachno-pial membrane; if this view be correct, the supradural (or so-called "epidural") and the subarachnoid spaces must be regarded as secondary. As a modification of this view it has been suggested that the arachnoid is in reality reflected over the inner surface of the dura, thus forming a continuous serous membrane which surrounds a serous cavity for which the name of the arachnoid space (as a substitute for the more familiar nane of subdural space) has been proposed; and this interpretation has some facts in its support.

The spinal cord, surrounded by its meninges and supported by them, hangs freely in the spinal canal; throughout a great part of its extent it is nearly eylindrical; in the cervical and lumbar enlargements its transverse diameter is distinetly greater than the dorsoventral. It is divided into symmetrical halves by the so-called anterior and posterior fissures; the former of these, the ventral fissure of comparative anatomy, is a distinct furrow from a fourth to a third of the diameter of the cord in depth, containing a fold of the pia which bears an important relation to the blood supply of the cord: the latter, or dorsal fissure, while deeper than the former, is not a true cleft, the right and left masses being separated simply by a stout median septum given off from the inner surface of the pia. Other septa of a similar nature, but less extensive, are given off from the pia at various points along the sides of the cord, and contribute in some measure to its subdivision. 
When viewed in cross section the cord appears to the naked eye to be made up of two differently appearing substances known from their color as the white and the gray matter. The latter is in each half of the cord almost entirely surrounded by the former, but not uniformly so; from its central portion on either side a narrow ridge projects dorsally (and slightly outward) almost to the surface of the cord; from its appearance in cross section it is known as the posterior or dorsal cornu; in a similar manner the gray matter projects ventrally and outward to form an anterior or ventral cornu which is much thicker than the dorsal, but does not approach the surface so nearly; in the thoracic portion of the cord a slightly projecting ridge extending directly outward between the dorsal and ventral cornu constitutes the socalled lateral cornu. The gray matter of the two sides of the cord is continued inward in the mid-region throughout the extent of the cord to form the gray commissure, by which the two halves are connected, and in which runs the central canal; in consequence of the disposition of the gray matter of the cord its figure as seen in cross section is irregularly $\mathrm{H}$-shaped.

The white matter also exhibits certain conspicuous subdivisions, due in part to the disposition of the gray matter, in part to the mode of origin of the spinal nerves. The bundles of fibres which are gathered together at regular intervals outside the cord to form the posterior or dorsal roots of the spinal nerves enter the cord close to the dorsal cornu along a well-defined line on either side, which lies in a shallow groove. Between the dorsal cornu of either side and the median septum, which extends in ward to the gray commissure, lies the posterior or dorsal column of the side in question; it is limited externally by the line of entrance of the dorsal roots, between which and 
the dorsal midline a well-marked septal process of the pia subdivides the column into two important tracts to be presently described. Between the dorsal and the rentral connu of each side is situated the lateral column; and between the rentral cornu and the ventral fissure the anterior or ventral column. As has heen already stated, the ventral cornu does not approach very closely to the surface, and the fibre-bundles which enter into the anterior or ventral roots of the spinal nerves are given off irregularly over a region of considerable wilth; there is therefore no clearly defined boundary either externally or internally between the lateral and the ventral columns; the whole region from the dorsal cornu to the ventral fissure is therefore sometimes spoken of as the anterolateral or lateroventral column. The ventral columns of the two sides are connected with each other dorsad of the ventral fissure by a narrow layer of white matter called the white commissure.

The appearances thus far described can all be readily scen, most of them with the naked eye; the histological structure of which they are the expression, in some respects excedingly simple, is in others of such complexity that it has hitherto taxed the resources of histological technique to the utmost. It has long been known that the gray matter contains numerous multipolar nerve corpuscles of varying size and of a distinct but not sharply defined arrangement; their branching processes; non-medullated nerve fibres; and numbers of the neuroglia cells mentioned in a previous chapter; that the central canal is lined with a layer of columnar cells which are sometimes ciliated; that the white matter is composed chiefly of medullated nerve fibres, mingled with which are numerous neuroglia cells like those of the gray matter: that the pial septa already mentioned subdivide in the interior of the cord to 
form a framework along which are distributed the internal vessels of the cord, the general disposition of which can readily be determined In brief, the corrl is known to consist of multipolar corpuscles and nerve fibres supported largely by neuroglia cells and provided with a definite blood-supply. The complexity of the cord depends not upon the number of kinds of tissue elements present, no other active organ in the body of equal size and importance containing so few ; but upon the arrangement of the corpuscles and fibres, and particularly upon the relations existing between them; and it is only recently that the latter has been at all satisfactorily determined ly means of technical processes of great efficiency and corresponding delicacy. It will be profitable to consider first the more conspicuous and therefore longer known features of the histological anatomy of the cord, and subsequently the minuter details that have more recently been discovered.

Beginning with the gray matter, the most conspicuous and in every sense the most important elements are the multipolar corpuscles scattered throughout it. While they at first seem to be quite irregularly distributed, the examination of a number of successive sections from the same region of the cord, and their comparison with similar series fromother regions will demonstrate that the corpuscles are arranged in groups extending along the length of the cord throughout the whole or definite portions of its extent with sufficient regularity to warrant their designation as distinct ganglionic columns. Of these the most readily distinguishable on account alike of its extent and the size of its constituent corpuscles is the column of the ventral cornu, or, from the known distribution of the axis-cylinder processes of most of its corpuscles to the ventral roots of the spinal nerves, the motor-corpuscle col- 
umn; this may agatin be more or less distinctly divided in some portions of the cord into a mesial tract, situated adjacent to the ventral fissure (which probably supplies motor fibres to the nerves of the dorsal muscles of the trunk); a ventrolateral tract, contiguous to the mesial and extending to the outer side of the cornu, (which probably supplies fibres to the nerves of the lateral and ventral nuscles of the trunk); these two tracts, which are confluent in the thoracic portion of the cord, are quite constant throughout its whole extent; and a third, the.dorsolateral tract, which is situated, as its name implies, in the outer side of the cornu and dorsad of the second above mentioned; it is present chiefly in the cervical and lumbar enlargements (and probablysupplies fibres to the brachial and sacral plexuses). Still a nother group, more centrally located, can be distinguished in some sections; but it is nuch less constant than those above described The corpuscles of the ventral cornu are the largest found in the cord, their diameters ranging in most instances from sixty-five to one hundred and thirty micra.

At the base of the ventral cornu and near the gray commissure is a group of much smaller corpuscles, rarely exceeding thirty micra in diameter, the mediocentral tract; it is well developed in the thoracic portions of the cord, but much less so in the cervical and the lumbar. At the base of the so-called lateral cornu, also in the thoracic region, there is a group of corpuscles of similar size, the mediolateral tract, or, as it is called, the column of the lateral cornu.

The dorsal cornu exhibits at its juncture with the gray commissure a well-marked column whichextends from the level of the seventh cervical to that of the third lumbar nerve; throughout the thoracic region it is quite conspicwous, being roughly eylindrical in form and quite sharply defined by the arrangement of the adjacent fibres; it was 
the first column of corpuscles to be clearly recognized, and is known from its discoverer as Clarke's column. Stilling proposed for it the name of the dorsal (thoracic) nucleus, and for similarly placed aggregations situated respectively at the level of the third and fourth cervical nerves and the second and third sacral the names of the cervical and the sacral nucleus. The corpuscles of Clarke's column are next to those of the anterior cornu in size, being from thirty to ninety micra in diameter. Small corpuscles, from twenty to thirty micra in diameter, are scattered through the rest of the cornu with little definite arrangement; those close to the mesial margin are in some cases quite distinctly elongated parallel thereto and are known as marginal corpuscles; near the middle of the cornu the gray matter is broken up along the mesial side and to some extent along the lateral side also by bundles of fibres; the reticular formations thus produced have associated with them irregularly defined groups of corpuscles. The posterior cornu is capped dorsally by a translucent mass, rich in glia cells, known as the gelatinous substance of Rolando; it contains numerous small rounded elements, about fifteen micra in diameter, generally regarded as nerve corpuscles, as well as other larger elements, unquestionably nervous, some of which are marginal in form and position. Mention may also here be made of the fact that various observers have described outlying corpuscles scattered among the fibres of the white columns, both dorsal and lateroventral.

While the corpuscles are the most conspicuous elements of the gray matter, they form but a small portion thereof. By far the larger portion consists of a densely felted mass of fibres of various kinds; including small medullated fibres, nonmedullated fibres, axis-cylinder processes and their branches, and the dendritic subdivisions of the protoplasmic processes of the corpuscles. These were 
formerly supposed to be continuous and to form the socalled reticulum of the gray matter; but the evidence of recent investigations by methods giving results of great lelicacy leads to the belief that no such continuity exists; what is now generally believed to be the true relation of the corpuscles and the fibres of the gray matter will be indicated later. To the interlacing fibres and fibrillac already mentioned are added the numerous delicate filaments proceeding from the glia cells which with the connective tissue elements present make up what is sometimes called the spongy substance of the gray matter. About the central canal there lies a translucent layer similar to that which caps the dorsal cornua, the central gelatinous substance.

The white matter of the cord consists, as has already been said, chiefly of medullated nerve fibres; these vary greatly in size, the smallest being but one or two micra in diameter, while the largest may have a diameter of over twenty-five micra. The great majority of these fibres are longitudinally disposed, the most conspicuous exception to this being found in the white commissure, through which fibres pass at greatly varying degrees of obliquity. Between the medullated fibres are numerous neuroglia cells so disposed as to form an interstitial framework between the subdivisions of the pial septa. Along the surface of the septa the neuroglia cells are gathered in great numbers, forming a definite investment which is continuous outwardly with a well defined layer of considerable thickness which lines the inner surface of the pia.

While it is possible to recognize readily that certain regions of the cord, presently to be indicated, contain chiefly either larger or smaller medullated fibres, through most portions the fibres vary so much and so irregularly in size that no such division into tracts can be made as in 
the gray matter, based on the size and arrangement of the fibres; the only conspicuous visible feature on which a subdivision can be based is the presence of the important secondary septum already mentioned as situated between the median septum and the dorsal cornu of either side; this passes obliquely toward the ventral edge of the median septum, thus dividing the dorsal column into two well defined portions, long known respectively as the column of Goll (next to the nedian septum) and the column of Burdach (next to the dorsal cornu). The remainder of the cord has been more or less accurately subdivided into tracts by other methods; while these tracts cannot be distinguished by any means now in our possession in sections of the normal adult cord, some knowledge of them is necessary in order to understand the meaning of some of the finer details of structure developed by recent histological researches in both the white and gray matter: a brief account of them and of the methods by which they have been determined will therefore be given.

We owe chiefly to Flechsig the discovery that the medul. lated nerve fibres of the different tracts of the cord attain their full development at different periods of embryonic and even of infantile life; the difference in question being apparently correlated with similar differences in the calling into activity of different powers and faculties of the nervous system: the study of the spinal cords of embryos at various stages of advancement thus revealing significant differences in structure not discernible in the cord of the adult. To Waller we are indebted for pointing out that an axis-cylinder when severed from the corpuscle of which it is a process rapidly undergoes degeneration: it follows from this that in cases of lesion of the cord, either pathological or experimental, not only single fibres but also tracts composed of fibres of a similar character will un. 
dergo degeneration in a manner definitely related to the place of lesion. Without entering into the physiological significance of the changes involved, it may be said that degeneration on the side of the lesion toward the brain is called ascending; and that on the opposite side of the lesion descending; and that the same terms are applied to the tracts in which the changes in question occur. The method of Flechsig and that based on the Wallerian law of degeneration give us results which coineide to such an extent as to determine quite clearly the limit of some of the tracts about to be mentioned; the evidence in favor of the existence of others, while generally regarded as satisfactory, is by no means as conclusive.

None of the tracts which are thus shown to exist in the white matter of the spinal cord are more clearly definable than those which pass from the pyramids of the medulla oblongata into the ventral and lateral columns of the cord. The fibres of the pyramids decussating while still in the medulla, the great majority of them enter a large compact bundle whose cross section is an irregularly triangular area lying (in the human spinal cord) between the dorsal cornu, from which it is separated by a thin layer of fibres, and the lateral surface of the cord, from which it is also separated by a layer of fibres save in the lumbar region, where it extends to the surface; it is known as the lateral (or the crossed) pyramidal tract. In man the fibres of the pyramid do not, as a rule, all decussate in the medulla, a small tract passing down as a thin layer on the portion of the surface of the ventral column which lies within the ventral fissure on the same side as the pyramid from which it proceeds; this tract is therefore called the anterior (or the direct) pyramidal tract; it does not extend beyond the middle of the thoracic region of the cord. It is probable that decussation goes on between the right and left tracts throughout their whole course, the fibres passing 
through the white commissure, instead of occurring all at once $i_{n}$ the medulla: in some mammals the pyramidal decussation is complete, and there is in consequence no direct pyranirlal tract: this is sometimes the case in the human subject The existence of both pyramidal tracts was rlemonstrated by Tuerck, though his name is usually associated with the smaller and less constant of the two, which is co nınonly designated the column of Tuerck.

Far less clearly defined and less constant in position is another descending tract, the ventrolateral, or anterior marginal bundle of Loewenthal: it consists of a thin layer of fibres situated upon or near the surface of the ventral and a good portion of the lateral columns: its fibres proceed fro $n$ the cerebellar cortex of the same side.

In close contact with the ventrolateral descending cerebellar tract, the fibres of the two mingling to a greater or less extent, lies the ventrolateral ascending cerebellar tract, or anterolateral ascending tract of Gowers: like its companion, it is throughout the larger part of its course a thin layer of fibres, which is situated between the tract just mentioned and the surface of the cord: it is thickest in its most dorsal portion, and is limited in that direction by the crossed pyramidal tract.

Dorsad of the tract of Gowers and external to the crossed pyramidal tract is the dorsolateral ascending cerebellar tract, or the direct cerebellar tract of Flechsig. It begins in the lower part of the thoracic portion of the cord (below which level the crossed pyramidal tract comes to the surface of the cord) and extends from there upwards, passing through the restiform body in the medulla oblongata to reach the middle lobe of the cerebellum. Like the pyramidal tracts and unlike those just described, the tract of Flechsig is very clearly defined. Between its dorsal border and the line of entrance of the dorsal roots of the spinal nerves, limited externally by the surface of the cord, is a narrow tract, the marginal zone of Lissauer. 
Attempts have been made to farthersubdivide the white matter of the ventral and lateral columns; but the results on which these attempts are based are thus far so conflicting as to render the conelusions drawn therefrom quite doubtful: for the present it is best to include the whole of the territory enclosing the ventral cornu and perforated by the fibre-bundles of the ventral roots of the spinal nerves (excepting, of course, the tracts already designated) under the title of the ventro-lateral root zone.

The columns of Goll and of Burdach, situated in the dorsal region of the white matter, have already been described as limiterl structurally: they may be otherwise distinguished, according to their function, as the dorsomedian and the dorso-lateral ascending tracts. Imbedded within the latter may be detected a small bundle of fibres with deseending degeneration, known from its outline when seen in cross section as the comma.

We have seen that some of the tracts above described, both ascending and descending. are in direct relation with the brain: others are doubtless composed entirely or in large measure of fibres that begin and end in the cord itself: others, and particularly those of the dorsal tracts, are in direct relation with the spinal nerves; and these latter organs are in such close connection with the cord as to merit mention in this connectıon.

Each spinal nerve possesses, as is well known, a dorsal and a ventral root. The latter consists of efferent fibres chiefly if not solely motor in function, which arise from the axis-cylinder processes of the corpuscles of the ventral cornu, as has been stated, and pass almost directly out of the cord: they therefore make no important contributions to its columns. The dorsal root, in addition to its ganglion, which will be farther discussed in a subsequent paragraph, contains a few fibres probably motor in function: it consists chiefly of efferent or so called sensory fibres which are some- 
what definitely divided into two groups, a mesial and a lateral, in each bundle; they penetrate the surface of the cord more or less obliquely and then bifurcate, giving rise to ascending and descending branches, the disposition of whose terminal and collateral arborizations will be described later. Recent researches by Cajal indicate that the fibres of the lateral group, which are slender, have their bifurcation in the marginal zone of Lissauer and the adjacent part of the lateral column; their collaterals are few and delicate and end in the dorsal cornu: the fibres of the mesial group, which are stouter, reach the columns of Goll and Burdach, and there bifurcate: their collaterals form by far the larger portion of those subsequently to be described as derived from the dorsal column, and in particular those which form the channels whereby those impulses are transmitted which are involved in simple reflex movements.

The white matter of the cord, therefore, consists of medullated nerve fibres which may be divided according to their origin and destination into three groups, the members of which are not structurally distinguishable: those which pass from the cord to end in the brain; those, commissural in character, which pass from one portion of the cord to end in another; and those which pass to the cord from the brain or from the spinal nerves. From the description of the nervous elements given in a preceding chapter it will be evident that each of these fibres consists essentially of the axis-cylinder process of a corpuscle, and ends in an arborization, giving off along its course one or more collaterals. It is probable, but not certain, that these collaterals have their terminal arborizations in regions of the gray matter of the cord homologous with that in which the terminal arborization of the fibre itself is situated.

Leaving out of consideration for the present the fibres 
which pass from the cord to the brain, it may be said that the terminal arborizations of fibres, whether collateral or principal, which enter the gray matter of the cord are in -lose contiguity or actual contact with the bodies or the dendritic processes of the corpuscles of the gray matter: the latter play the part of conductors (and not a nutritive role merely), and connection is thus established as efficiently as by the continuity of substance once supposed to exist. An impulse thus transmitted calls forth the activity of the corpuscle in question, resulting in a discharge along its axis-cylinder process which undergoes a similar distribution.

Regarding the final arborization of a fibre as essentially similar to those of the collaterals, and therefore to beclassified with them, we shall make the first step toward a conception of the physiological anatomy of the cord by an enquiry into the distribution of these structures as they leave the various regions of the white matter. The following account thereof, as well as that of the corpuscles of the gray matter to be subsequently given, is taken almost wholly from Cajal.

Collaterals of the ventral (anterior) column. These are larger than those from any other portion of the cord: springing from the large axis cylinders which compose this column they pass dorsad in irregular groups to be distributed within the ventral cornu and particularly about the motor corpuscles. Some bundles pass to the mid-plane of the cord and are distributed in the ventral cornu of the opposite side, constituting the ventral (or anterior) com. missure of collaterals, situated largely dorsad of the ventral commissure forned of axis cylinders.

Collaterals of the lateral column. These pass invard to be distributed chiefly in the central region of the gray 
matter of the same side: some. however, pass to the mid. plane, dorsad of the central canal, where they form a portion of the dorsal (posterior) or gray commissure: they are divided in it into two bundles, a ventral and a nedian, and are distributed in the central and to some extent the dorsal region of the opposite side

Collaterals of the dorsal (posterior) column. The tracts of Goll and of Burdach, and the marginal zone of Lissauer, from which these collaterals are chiefly derived, are formed in great part of the continuations of the fibres of the posterior roots of the spinal nerves. Four groups of collaterals may be distinguished.

Sensitivo-motor (or reflexo-motor) collaterals: these arise not only from the continuations of the fibres of the posterior root but also trom the fibres themselves before their bifurcation; passing across the gray matter, they terminate in the ventral cornu of the same side.

Dorsal cornu collaterals: these, like the preceding, are very numerous: they traverse the substance of Rolando in groups to form immediately ventrad thereof and throughout the substance of the dorsal cornu a dense network composed of the intercrossing of their terminal arborizations.

Clarke's column collaterals: small bundles pass ventrally from the tract of Goll to terminate in the column of Clarke of the same side. there forming a thick network about the corpuscles of the column.

Commissural Collaterals: arising chiefly in the tract of Goll numerous small bundles pass to the most dorsal portion of the gray commissure, which they traverse, to be distributed in the dorsal cornu of the opposite side: thus forming the dorsal bundle of the commissure.

Thus, it will be seen, each white column gives off two 
kinds of collaterals: those which furnish their terminal arborizations to the gray matter of the same side, and those, commissural in character, which are destined to ramify in the gray matter of the opposite side. In either case their relations are eventually directly with the corpuscles of the gray matter, whose disposition may now be further considered. Excepting in the substance of Rolando, where some elements of special form are found, the corpuscles of the dorsal, central, and ventral regions differ but little, save in size. The only important distinction to be noted in them pertains to the final disposition of their axis-cylinder processes: on this basis five groups or kinds of corpuscles may be distinguished: of these the first four send, as will be seen, their axis-cylinder processes out of the gray matter into the white, there to become medul. lated: they may be therefore distinguished as corpuscles with long axis-cylinder processes (corpuscles of the first class); while the axis-cylinder processes of the fifth end in the gray matter not far from their point of origin: they are therefore corpuscles with short axis-cylinder processes (corpuscles of the second class, corpuscles of Golgi). The five kinds of corpuscles are as follows:

Radical corpuscles, or corpuscles directly related to the roots of the spinal nerves. These are the motor corpuscles of the ventral cornua, and comprise the largest corpuscles of the cord: their axis-cylinder processes are thick and devoid of collaterals and pass in most cases directly through the lateroventral column to enter the ventral roots of the spinal nerves. From a few of the corpuscles the axis-cylinder processes traverse the gray matter to leave the cord by the dorsal root: they pass through the spinal ganglia, however, without entering into relation with their corpuscles, and must be regarded as in all probability motor in function. 
The dendrites of these corpuscles are stout, long, and very much branched. They may be distinguished as ventro-external, dorsal, and interial (mesial); the latter branch dichotomously in the vicinity of the ventral (anterior) commissure; some of the branches pass the niid-plane and enter the ventral cornu of the opposite side, intercrossing with corresponding processes therefrom and forming the protoplasmic commissure of Cajal. 'The ventro-external processes terminate in the lateroventral column; and the posterior in different regions of the ventral cornu.

Commissural Corpuscles: these are smaller than those just described, and provided with fewer and shorter dendrites. Golgi demonstrated their presence in all of the regions of the gray matter, and that the axis-cylinder processes pass to the mid-plane which theycross ventrally (in the white commissure) to be continued to the ventrolateral column of the opposite side. Cajal has shown that they there undergo not a single continuation, but a $\mathrm{T}$ division: this indicates that the cominissural axis-cylinder process, on reaching the white matter of the opposite side, divides into an ascending and a deseending fibre of the column.

Columnar corpuscles: we may thus designate the numerous medium-sized corpuscles scattered throughout the whole of the gray matter, of which the axis-cylinder processes enter into vertical 'fibres' of their own side.' The greater number of the corpuscles of this kind which occur in the ventral cornu send their processes to the lateroventral column: those which are situated in the dorsal cornu direct them toward the most dorsal portion of the lateral column in many cases, though some of the corpuscles found in the substance of Rolando and the internal portion of the dorsal cornu send their processes to the dorsal column: 
As regards the column of Clarke, two kinds of corpuseles can be demonstrated: commissural corpuseles, whose processes enter the ventral commissure ; and columnar corpuscles, whose processes pass to the lateral column to become continuous with the fibres of the cerebellar tract. This continuation takes place by two methods; by the formation of a bend, which furnishes a single conductor, ascending or descending; and by a T-division, which forms two conductors or vertical branches, one ascending and the other descending.

Pluricolumnar corpuscles: Elements are so termed by Cajal of which the axis-cylinder process is divided while still in the gray matter into two or more portions which enter into as many nerve fibres belonging to different columns : thus, for example, an element of this kind may send one fibre to the ventral column of its own side and another to that of the opposite side; in another the process may diride into a fibre for the dorsal column and another for the lateral or ventral, etc.

Van Gehuchten has proposed for the corpuscles here designated commissural, columnar, and pluricolumnar the names of heteromeral, tautomeral, and hecateromeral corpuscles respectively.

Short process corpuscles: these, which are found chiefly in the dorsal portion of the gray matter, have slender and flexuous axis-cylinder processes which speedily end in arborizations situated in proximity to other and adjacent corpuscles.

The substance of Rolando merits special mention on account of the peculiarities of some of the corpuscles contained therein. The latter belong chiefly to the columnar and short process types, with some pluricolumnar cor- 
puscles; whilst cummissural corpuscles are not known with certainty to occur. Those characteristic of the region are of three principal forms disposed in as many concentric zones, passing from without inward, as follows.

The marginal corpuscles are large fusiform or flattened elements situated between the substance of Rolando and the dorsal column of white matter, thus forming a discontinuous layer. The dendritic processes line the surface of the dorsal column and there ramify : the axis-cylinder process, arising sometimes from the border of the corpuscles, sometimes from one of its processes, is directed ventrally across the substance of Rolando; it then changes its direction to reach the posterior portion of the lateral column, with one of the fibres of which it becomes continuous.

The pyriform or fusiform corpuscles are the smallest elements of the cord: their shape is quite variable, but forms indicated by the terms above are prevalent. It is characteristic of them that they are elongated dorsoventrally and have great numbers of crooked and intermingled dendrites, the greater portion of which arise from a ventrally directed stalk which is prolonged almost to the head of the dorsal cornu. The axis-cylinder process generally arises from the posterior portion of the corpuscle and passes either dorsally or laterally to become continuous with one of the fibres of the dorsal column.

The stellate corpuscles are situated nearest to the head of the dorsal cornu: they unite the substance of Rolando with that region by means of their abundant spinous dendrites. The axis-cylinder process is sometimes directed lengthwise of the cord; it then comports itself as a portion of a short process corpuscle, and appears to end in the substance of Rolando itself: at other times it is directed cither mesially, to become continuous with a fibre of the column of Burdach, or laterally, to form a slender fibre of the marginal zone of Lissauer. 
By a conparison of this description of the corpuscles as based upon the destination of their axis-cylinder processes with that previously given of their rlistribution in columnar tracts along the cord, it will be seen that these latter are in uearly every instance composed of corpuscles of varying relations, wat even the columas of the ventral cornu consisting solely of so called motor corpuscles: Each of these elongated clusters may therefore be regarded as consisting of corpuscles so coördinated in function as to justify the title of nuclear or ganglionic columns frequently applied to them.

The corpuscles of the spinal ganglia, while they are. situated without the corrl, should always be associated with that structure in any attempt to form a complete conception of the central nervous mechanism, since their efferent axis-cylinder processes enter extensively into relation with the dorsal columns and cornua. Their spheroidal or pyriform contour has been described in a previous chapter, as has also the manner in which two medullated fibres are derived from the single pole or process borne by the body of the corpuscle. They are unique in the fact that nne of these fibres puts them in communication with dendritic or receptive terminals which are far more remote in most instances than those of any other nervous element.

The central canal of the cord is lined with a columnar epithelial layer of ependyma cells which are frequently but not always ciliated. These are in the embryo continued by slender prolongations which reach to the pia, forming the primary framework of the cord: such continuations persist in the lower vertebrates, but their presence in adult birds and mammals is not yet well established. In connection with the ependyma cells, and possibly derived therefrom, there are found in the adult cord of the 
higher vertebrates numerous neuroglia cells which are particularly abundant in the white matter, immediately: beneath the pia and along the septa and blood vessels, in the substance of Rolando, and in the central gelatinous, substance.

The blood supply of the cord merits special mention. A single median ventral spinal artery (the anterior spinal of human anatomy) runs along the ventral margin of. the fold of the pia which enters the ventral fissure: while a pair of dorsal spinal arteries (or posterior, spinals): are situated just rentrad of the dorsal roots of the spinal nerves: branches of these arteries ramify in the pia tr) form an extensive plexus. From the, ventral trunk, small, vessels, the central arterioles of Ross, in, number several times as many as the vertebrae follow the fold of the pia into the median fissure as far as the white commissure. Here they turn alternately right and left to reach

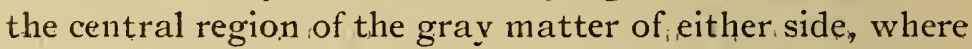
they break up into small arterioles and finally into capillaries: the central arterioles are distributed chiefly to the gray matter, though some of their divisions penetrate the white matter, particularly of the lateral and ventral columns.

The dorsal vessels and the pial plexus give off great numbers of peripheral arterioles which follow the dorsal median septum or the other less prominent septa into the cord: their terminal divisions are found not only in the white matter but also in the, outer portion of the gray matter and throughout the dorsal cornua. Each arteriole, whether central or peripheral, has, its own proper capillary area, anastomoses between adjacent arterioles not being known to occur.

Similarly disposed central and peripheral venules carry the blood from the capillary networks to the irregu- 
Har plexuses of veins in the pia and to the principal venous trunks: these are two in number, a ventral which follows the rentril artery more or lese closely, and a dorsal, which overlies the median dorsal septum and is not the companion of any artery.

"The brain is the modified and specialized anterior end of the nervous axis. As we pass from the spinal cord into the medulla oblongata, and thence: through the region of the pous', into the crura cerebri, we find that the fibrous tracts which can be recognized in the white matter of the cord here become subdivided and variously modified, some of then soon disappearing as such, while others may be traced almost to the most anterior portions of the brain; while new fibrous tracts variously related, may be detected by the method of Waller and particularly by that of Flechsig. 'The' central canal expands here and there to form the rentricular cavities' of the brain; while its ependymal lining frequently coming in contact with the pial investment through the absence of intervening nervous tissues; is often throwin into vascular folds of greater or less extent. The'gray'matter,' which in the cord surrounds the central canal, now lies chiefly in its floor and sides, and is penetrated and subdivided by the diversified fibre tracts already referred to. The ganglionic columns, which in the cord were continuous throughout the whole or large portions of its structure, are now broken up into more or less definite nuclear aggregates of corpuscles, serving as centres for specific cranial nerves: some of these nuclei may perhaps be homologized with portions of some of the ganglionic columns; while for others no such relation is discernible.

In addition to this central prolongation and modification of the cord, other structures appear connected there 
with which, while they must unquestionably be regarded as developments of the axial region, are of such size and structural importance as to be properly regarded as substantially additions thereto. These, like the cord, and the basal portions of the brain as well, are composed of more or less definite fibre tracts and corpuscular areas, related to each other and to the more axial structures.

Within recent years great progress has been made in the process of unraveling this complex structure, and it is safe to say that the general topography of the brain is known. To attempt to sketch it, however, would take far more space than the range of the present work contemplates, and would take us largely into a field where, while the method has been and must be chiefly that of the histologist, the results belong rather to the domain of the anatomist. Medullated fibres, axis-cylinder processes with their collaterals, and multipolar corpuscles are much the same in appearance and in relations throughout a large portion of the brain as in the spinal cord: and we are concerned from a histological standpoint only with those regions of the brain in which new forms of nervous elements appear or in which some special mode of combination is demonstrable. The chief of these are the cerebellum, the cerebral hemispheres, and the olfactory bulbs; an account of the cerebellum and of the hemispheres will now be given: that of the olfactory bulb will be deferred until the sense organ with which it is connected has been described.

The cerebellar cortex is a superficial layer of gray matter whose well marked folds form the laminae visible on the surface of the organ to the naked eye: the middle of each fold is occupied by a mass of white fibres in direct relation to the gray matter. The latter shows to the naked eye two distinct strata; an outer and paler known 
as the molecular layer, and an inner, of a rusty brown color, called the granular layer. Between these, and partially imbeded in each, is a nearly continuous stratum of large corpuscles, the most characteristic of the cercbellar cortex, the corpuscles of Purkinje. They are pyriform or flask-shaped, the large extremity being directed inward: from the latter an axis-cylinder process is given off which passes through the granular layer to enter the white matter as a medullated nerve fibre; luring its course through the granular layer it gives off collaterals which in many cases turn backward to enter the molecular layer.

The outer extremity of the corpuscle is prolonged for a greater or less distance, but usually soon divides into two principal branches, which rapidly and repeatedly subdivide to give rise to large numbers of dendritic processes, many of which are continued to the surface of the cortex: their surface is beset with short processes which end bluntly. The ramification is in every case almost entirely confined to a plane transverse to the lamella in which the corpuscle is situated.

The great majority of the corpuscles of the granular layer are exceedingly small, with large nuclei and very scanty surrounding protoplasm: their great numbers, and their appearance when stained with carmine or other similar stains led to the name above given for the region in which they occur. For a long time their nervous character was doubted or denied. The more recent technical methods have demonstrated it beyond question, and they are now known as granule corpuscles. Their bodies contain a relatively large quantity of rusty brown pigment, to which the characteristic color of the layer is due. A few protoplasmic processes are given off by each corpuscle: these branch sparingly to end in a small number of dendrites with thickened extremities. From the body of the corpuscle, or frequently from one of the processes, a 
slencler axis-cylinder process is given off, which passes without collaterals into the molecular layer and there undergoes a $\mathrm{T}$-division to form two slender tangential fibres whose course is always in the direction of the lamella in which they occur and therefore at right angles to the plane of the dendrites of the corpuscles of Purkinje, with which they are in close contact as they pass. The tangential fibres have been shown in some of the smaller vertebrates to run the whole length of the lamellae in which they are situated.

In addition to the small granule corpuscles there are present in the inner layer, though in small numbers, (t) ther nervous elements. They are situated near the outer limit of the layer and are nearly as large as the corpuscles of Purkinje, which they somewhat resemble in form. Their onter region sends off numerous protoplasmic processes, which branch irregularly in every direction to form large numbers of dendrites: these project chiefly into the molecular layer, though many of them lie altogether within the granular layer. From the inner region there is given off a slender axis-cylinder process, which branches freely almost from its origin, the whole giving rise to an extensive arborization-plexus which is situated entirely within the granular layer. These corpuscles therefore befong to Golgi's second type.

The finely dotted appearance to which the molecular layer owes its name, seen when the lamella is cut transversely, is largely due to the cut ends of the tangential fibres. There are present in this layer two kinds of corpuscles. In the deeper portion are seen numerous corpuscles of medium size and irregular form, whose dendritic processes branch sparingly but extend for some distance into the surrounding region: the axis-cylinder process takes a course generally parallel to the surface of the cortex and gives off frequent collaterals; these pass inward 
to be applied in each instance to the body of a corpuscle of Purkinje, upon which, or about the base of the axis-cylinder process, they terminate with little if any subdivision: annumber of such fibrils surround each corpuscle of Purkinje, forming a nest or basket about it: the corpuseles from which the proced are therefore known as basket corpuscles.

Throughout the molecular layer, but chiefy in the outer portion thereot, are found :mmerous siellate corpuscles, which though smaller in sim, resemble the elements just described in their general form and in the appearance of their sparingly branched dendrites. The destination of their axis-eylinder processes is not known

The axis-cylinder processe's of the corpuscles of Purkinje give rise to the only fibres of the central white matter of the lamella known to be sent inward from the cerebellar cortex. The fibres which pass out into it have been shown to terminate in two different methods. Some of them end in the granular layer, where theirextremities branch sparingly, the subdivisions terminating in enlargements in such a way as to give to the whole somewhat the appearance of a tuft of moss: they have therefore been designated mossy fibres. The others find their way to the corpuseles of Purkinje, traverse their surfaces, and subdivide to follow the branchings of the dendritic processes, thus forming a terminal arhorization which adheres thereto like a vine to a tree: they have therefore received the name of climbing fibres.

It will be seen from the above description of the cerebellar cortex that each corpuscle of Purkinje is in relation with three sets of discharging terminals: the tangential fibres of the granule corpuscles, the collaterals of the basket corpuscles, and the arborizations of the climbing fibres. We are at present entirely ignorant of the functional relations which are based on this structure. 
The cerebral cortex has been regaried as composed of several distinct layers which differ from each other as regards the form and size of the contained corpuscles. As our knowledge has increased, the boundaries between these layers have been found to be less sharply defined than was at first supposed. Three can with certainty be distinguished: the outer, or so called molecular layer, the middle, or pyramidal layer, and the inner, or polymorphous layer.

The molecular layer, like that of the cerebellar cortex, owes its characteristic appearance largely to the cut ends of the collaterals and slender fibres which are densely interworen in it and to their terminals. Its outermost portion contains numerous neuroglia cells, which just beneath the pia form an almost continuous stratum, as in the spinal cord: this has been described as a distinct layer of the cortex. Scattered throughout the molecularlayer are numerous nerrous elements, the corpuscles of Cajal, that histologist having first demonstrated their distinguishing characteristics. Two forms have been described by him, the fusiform and the stellate. The former are, as their name implies, spindle shaped, and give off from either end a polar process which runs parallel to the surface of the cortex: the two processes cannot be distinguished structurally, and each may take on the character of an axiscylinder process: from each collaterals are given off at right angles or nearly so, which are invariably directed toward the surface of the cortex. In the second form the number of similar processes is increased to three or more. In each case the processes terminate eventually in ramifications which are turned toward the cortical surface.

Cajal has also described in the molecular layer a third form of corpuscle under the name of polygonal; these have several protoplasmic processes which end in dendrites 
which mayextend beyond the molecular layer to enter that beneath it. The axis-cylinder process may arise either from the body of the corpuscle or from one of the processes: its terminal subdivisions are confined to the molecular layer.

The pyramidal layer is very commonly divided into two strita, the layer of small pyramids, next the molecular layer, and the layer of large pyramids, immediately subjacent. The elements characteristic of these two layers are, however, so nearly alike in everything but size, and the transition from the one to the other is so gradual in this respect, that they mav, at least for the present, be advantageously considered as one.

The most numerous of the elements peculiar to this layer are the pyramidal corpuseles: their form is indicated by their name. The base of the pyramid is turned away from the surface of the cortex, the apex being directed rertically upward and continued into a long tapering ascending stem which, even from the corpuscles most deeply placed. extends nearly or quite to the molecular layer: it terminates by subdivisions into a tuft of protoplasmic processes; similar processes are given off at right angles along its course; while others are given off from the body of the corpuscle, and particularly from the angles of its base: all these processes are probably to be regarded as dendritic: their subdivisions are distributed chiefly to the surrounding substance of the prramidal layer, sare those of the apical tuft, which are largely situated in the molecular layer. An axis-cylinder process is given off from the base of each pyramidal corpuscle, usually from a point near the centre: it is always directed toward the white matter beneath the cortex: collaterals are, however, given off while it is still in the gray matter, some of which run horizontally to terminal ramifications within the pyramidal 
layer, while others bend upward at a right angle to terminate in the molecular layer.

Within the lower portion of the pvramidal layer are also found, scattered here and there, certain elements confined to the cerebral cortex, the corpuscles of Martinotti: they are also found in the third or polymorphous layer. They are spindle shaped, roughly pyramidal, or irregular in form, their distinguishing characteristic being the distribution of the dendritic processes chiefly out ward and downward, and an axis-cylinder process which generally arises from the uppermost portion of the corpuscle, though sometimes from one of the ascending protoplasmic processes, and ascends toward the molecular layer in which its ramifications are usually situated: in some instances the terminals lie wholly or in part in the uppermost portion of the pyramidal layer.

The polymorphous layer is so called from the occurrence therein of elements which vary greatly in form as well as in size: they may be ovoid, spindle shaped, pyramidal, or polygonal. They agree, however, in the fact that their long axes are as a rule disposed horizontally to the surface of the cortex, and that when a terminal or apical stalk is present it is never vertically directed as in the pyramidal layer. Some of the elements present are, as has just been indicated, ascending corpuscles of Martinotti: others belong to the second type of Golgi, having short axis-cylinder processes which break up into terminal ramifications in the immediate vicinity of the corpuscle. Still others give off long axis-cylinder processes which bend downward to enter the white matter and become medullated fibres of varying distribution.

The deeper portion of the polymorphous layer contains chiefly small fusiform corpuscles, which has led to its distinction on the part of some histologists as a separate 
layer: this is more clearly defined in the region of the island of Reil than elsewhore, where the stratum in question is separated from the rest of the cortex by intervening white matter, forming the layer visible to the naked eye, known as the claustrum. In must portions of the cortex the stratum in quistion is not clearly definable from the rest of the polymorphous layer.

Brief mention may perhaps be made of the composition of the subjacent white fibrous layer, although the various fibres and tracts are not histologically distinguishable, save to a certain extent by the methods of Waller and of Flechsig. Fibres formed by the development of medullary sheaths about axis-cylinder processes which descend from the corpuscles of the cortical gray matter may pass on downward as projection fibres to the basal ganglia, the hindbrain, or the spinal cord itself: other fibres pass as association fibres to other portions, more or less remote, of the cortex of the same hemisphere: while others still pass, chiefly by way of the corpus callosum, as commissural fibres to regions of the cortex of the opposite hemisphere: not unfrequently an axis-cylinder process may become a projection or an association fibre, and one or nore of its collaterals an association or a commissural fibre: or the converse may occur. Still other fibres pass upward into the cortex by way of projection, association, or commissural tracts to end there, the terminal arborizations being situated either in the molecular or the upper portion of the pyramidal layer.

The neuroglia of the brain does not differ from that of the spinal cord to such an extent as to merit a detailed description in so brief an account of the organ as is here given. Much the same may be said of the ependyma, which lines the rentricles and passage ways of the brain: 
like that of the central canal of the cord, it is composed chiefly of columnar cells, whose free extremities bear for a time at least cilia-like processes not known to be vibratile. Mention should be made of the plexuses of the rentricles, formed by infoldings of the pia and the ependyma, and consisting chiefly of a rich network of small bloodvessels supported by the former and invested by the latter. An outline of the blood supply of the cord was given above: that of the brain is far too complex and too much a matter of gross anatomy to be described here. Neither will any account be attempted in this connection of the derelopmental history of the nervous axis, beyond the statement that it is formed entirely from an infolding of the outer or epiblastic layer. 
CHIAPTER XXII. THE ORGANS OF SPliCIAI, SEXSE. 321

\section{CHAPTER IXIII.}

THE ORGANS OF SPECIAI, SENSE.

As was stated in a previous chapter, there are certain organs in which specially modified receiving terminals are associated with more or less highly modified forms of epithelium and with other special structures of a skeletal character to form in each case an apparatus for the reception of a specific and clearly defined impression; their stimulation giving rise to sensations of flavor, odor, sound, or light, commonly called special, as distinguished from the more diffused and less clearly definable sensations of temperature, contact, resistance, etc., received by the more widely scattered and possibly less specialized terminals destribed in the chapter referred to.

In each case the special receiving apparatus involved has associated therewith other special structures, chiefly skeletal. whose function it is to render more intense or more specific the impression received: these associated structures being, equally with the nervous apparatus in question, essential factors of the organ of special sense. As in the case of the brain, a full description of these structures belongs rather to the province of anatomy than to that of histology, and would require far more space than can with propriety be given here: an account of the histological composition of the essential apparatus will in each case be given, together with mention of any characteristic features noteworthy in the tissues of the accessory parts, some previous knowledge of the anatomy of the organs in question being presumed. 
The immediate organs of taste are the taste-buds, so called from their spheroidal form, which are situated in large numbers upon both the outer and the inner sides of the valleys which surround the circumvallate papillae; on the fungiform papillae; and particularly upon the loose folds just in front of the anterior pillars of the fauces which in man represent the more definitely circumscribed foliate papillae of some of the lower mammals: they are also found on the soft palate and the epiglottis, and are scattered here and there over the surface of the tongue. They are spheroidal bodies, almost completely embedded in the stratified squamous epithelium of the surface where they occur: the long axis is directed vertically or nearly so to the surface, and the outer extremity tapers slightly, on which account their form is sometimes described as flask shaped. The mass consists of a number of elongated epithelial cells, of which some are spindle shaped, or flattened, and are known as sustentacular cells: a layer of these completely covers the outer surface, their grouping recalling somewhat the surface segmentation of a cantclope: others are scattered irregularly throughout the interior. Between them lie other cells whose bodies, except just around the large nucleus, are slender and almost filamentous; these are the so called gustatory cells. The outer extremity of each ends in a ciliary process, the taste-hair, which projects with its fellows through a small circular opening in the squamous epithelium known as the gustatory pore: its inner extremity is slender, often bifurcated, and frequently more extensively branched; its subdivisions, which are sometimes varicose, reach to the base of the taste-bud.

Numerous attempts have been made to demonstrate a structural relation between the elements just described and the nerve fibres which pass to the taste-buds from the subdivisions of the glossopharyngeal nerve, but thus far 
without suecess. This nerve, like the dorsal root of a spinal nerve, bears a ganglion near its point of union with the nervous axis: examination by the chromate and silver method shows that the axis eylinders of the nerve fibres end in the täste-buds by branching among the cells in the interior, forming what are known as intrabulbar ramifications: the homology existing between the glossopharyn. geal and the spinal nerves would indicate that these are to be regarded as dendritic processes at the ends of long afferent fibres, similar to the "free endings" in the epidermis described in the chapter on the nervous tissues. According to this view it is questionable whether the so called gustatory cells are in reality nervous in character, and some have regarded them and the sustentacular cells as alike modified epithelial elements whose form and arrangement favors the stimulation of the nerve terminals. There is, however, a close relationship between the senses of taste and of smell; and the structure of the receiving apparatus of the latter suggests an explanation of the structure of the taste-buds in which the gustatory cell would form the first member in a series of nervous elements. Reference will be made to this after the organ of smell has been described: the statements already made, however, represent the present extent of our knowledge of the facts in the case.

Mention should be made liere of the fact that some of the medullated nerve fibres of the subdivisions of the glossopharyngeal nerve going to the taste-buds terminate by free endings in the stratified epithelium immediately surrounding those structures, forming what are termed peribulbar ramifications: these are generally regarded as fibres of general and not of special sensibility. The glands of a serous type, known as the glands of Ebner, which are closely associated with the taste-buds, have been de- 
scribed in connection with the tongue. They are to he distinctly regarded as accessory to the apparatus of taste perception, the fluid secreted by them aiding in the solution of substances whose flavor is to be perceived by the taste-buds.

The sense of taste resembles most forms of general bodily sensation in requiring the actual contact of the object perceived: the remaining special senses resemble the thermal sense in being capable of giving knowledge of objects at a distance. Of these the first and as regards its receiving mechanism the simplest is that of smell. The accessory muscular and skeletal structures which make up the facial region known as the nose require no special description from a histological standpoint. The air passages which they enclose are lined with a mucous membrane knuwn as the pituitary or the Schneiderian membrane: the vestibule, into which the nostril opens on either side, is lined with stratified squamous epithelium continuous at the margin of the nostril with the epidermis, of which it is a modification : the remainder is divided into two portions, the lower or respiratory and the upper or olfactory: the former is lined with stratified ciliated columnar epithelium, similar to that of other respiratory passages, beneath which is a highly vascular membrane which contains a considerable amount of adenoid tissue here and there gathered into distinct nodules, and numerous racemose glands, some of which are mucous and others are serous in character: large numbers of goblet cells are also distributed throughout the epithelium.

The olfactory region of the nasal mucosa can be distinguished with the naked eye by means of its well marked pigmentation, it being of a yellow color in man and scme 
of the lower mammals, and of a yellowish brown in others. The fibrous layer is more highly vaseular than in the respiratory region, but contains less adenoid tissue: it contains numerous glands, the glands of Bowman, which differ from the racemose glands above mentioned in being tubular, rarely branched, and but slightly bent or convoluted: the distal extremity is frequently the largest, the tube tapering toward the duct, which is always slender, and opens either upon the mucous surface or occasionally into a small ciliated crypt: the epithelium of the glands of Bowman is of the serous type, but the tubules resemble those of mucous glands in having a conspicuous lumen: ordinary racemose glands are also occasionally found in the olfactory region.

The epithelial laver of the olfactory region is composed chiefly of two kinds of elements. The first comprises the non-ciliated columnar supporting cells: these are chiefly prismatic in form throughout the greater portion of their extent, but with tapering inner extremities, and with oval nuclei situated at an approximately uniform distance from the surface: other more deeply situated epithelial cells are pyramidal in form, their bases resting on the fibrous layer; they may perhaps be regarded as immature supporting cells. Interspersed among the columnar epithelial cells are large numbers of slender elements of the seeond kind, whose outer extremities terminate in tufts of hair-like processes, the olfactory hairs, which project above the general surface: the middle portion is suddenly thickened to contain large spheroidal nuclei: these are the olfactory cells: their slender varicose inner portions are now known to be continuous with the medullated fibres of the nerves of smell. They must therefore be regarded as nervous elements, the thickened middle portion which contains the nucleus constituting the body of the corpuscle, and the peripheral portion a greatly reduced dendritic region con- 
sisting of a single protoplasmic process; while the proximal portion passes over into an axis-cylinder process which shortly becomes a non-medullated nerve fibre.

The olfactory nerve-fibres can be followed through the cribriform plate to their passage into the surface of the olfactory bulbs, whose structure may now be considererl: as has been stated in a previous chapter, they constitute a distinct region of the brain; but their histological structure is so intimately associated with their relation to the sense of smell as to make their description appropriate in this connection. Each olfactory bulb is a rounded mass at the anterior extremity of the longer or shorter olfactory tract (or olfactory nerve, improperly so called): the whole is an outgrowth from the hemisphere and originally contains a cavity, the olfactory ventricle, which is a diverticulum of the lateral ventricle: in many mammals this cavity persists throughout life; in some it persists in the bulb, that of the tract being obliterated; in man and the Primates generally it disappears altogether in the adult.

In passing across a section of the olfactory bulb from the surface in close proximity to the cribriform plate to the ependymal lining of the olfactory ventricle a more or less distinct stratification may be observed: the number of layers distinguished by different observers varies according to the degree of subdivision recognized: Cajal designates five, distinguished by histological characteristics demonstrable with the aid of the silver chromate nethod, in addition to the ependymal layer, which is wanting in those forms in which the bulb is solid.

The first of these is the superficial layer of nerve fibres: this is a thin stratum of slender non-medullated fibres arranged in a felted mass: it is composed cxclusively of the constituents of the bundles which pass through the perforations of the cribriform plate, whose origin, as we have seen, is in the axis-cylinder processes of 
the olfactory cells. The fibres leave the layer inwardly cither singly or in small gromps to enter the second stra(umu, or layer of olfactory glomeruli: the bodies whose presence distinguishes this layer have long been known to histologists-as splueroidal masses present in large numbers near the surface of the bulb: it is only recently that their structure has been at all understood: they are composed in part by the dense tufts of varicose fibrils which form the terminal arborizations of the olfactory fibres entering them from the superficial layer; in part by the similarly tulted dendritic ramifications of the extremities of proeesses derived from corpuscles situated in a deeper layer to be presently described: they are, therefore, the places where ingoing impulses are transmitted from the first to the second of a series of nervous elements.

The third stratum is termed by Cajal the molecular layer: as is the case with other structures sinilarly designated in various parts of the nervous axis, the finely punctate appearance which characterizes it when seen in section is duc to the cut ends of numerous fibres, and of fibre-like processes from the corpuscles of the layer next adjacent. Cajal describes in addition, as peculiar to this layer, certain clongated or fusiform corpuscles whose peripheral extrenities are continued by slender processes which run to the glomeruli and there terminate in small dendritic tufts which are subsidiary to those of the cor puscles of the layer next within: their proximal extremities give rise to axis-cylinder processes which run to the innermost layer and there bend strongly to pass toward the olfactory tracts, which they enter as medullated fibres.

The layer of mitral corpuscles is the fourth of the successive zones: it consists of large nervous elements chicfly disposed in a single stratum, whose general form is indicated by their title. The base of each corpuscle is directed 
toward the outer surface of the bulb: it gives off, in mammals usually from a point near its centre, a stout descending process which traverses the molecular layer to form in one of the glomeruli the important dendritic ramification already described as one of the essential constituents of each of those borlies. From the margin of the base are given off stout protoplasmic processes which diverge greatly, their ramifications interlacing to form a layer in which the corpuscles lie: their finer subdivisions extend obliquely into the molecular layer. The in wardly directed apex of the corpuscle gives rise to a stout axis-cylinder process which penetrates the layer next within and there bends abruptly to run backward in that layer, giving off collaterals whose terminal ramifications are in the molecular layer, and eventually to become the axis-cylinder of a medullated fibre of the olfactory tract.

The form and relations of the mitral corpuscles are subject in different vertebrates to variations in detail that are of such importance, as bearing upon their functions, as to merit description here. In mammals generally each mitral corpuscle bears but a single descending process: this may, however, divide and send branches to more than one glomerulus. In birds each mitral corpuscle gives off several descending processes to as many glomeruli: in either of these two ways a single corpuscle is put in relation with a number of the bipolar nervous elements of the olfactory mucosa. In some mammals, hovever, the glomeruli are relatively large, and each receives the dendritic ramifications of several descending processes from as many mitral corpuscles: in such cases a single bipolar element may transmit a stimulus to several mitral corpuscles: this latter condition obtains in the olfactory bulbs of mammals possessed of a high degree of olfactory sensibility.

Within the layer of mitral corpuscles is found the granular layer or deep layer of fibres: both of these terms being 
ap)lied to the fifth stratum as here defined., Omitting fro.n consideration the ependymal lining of the cavity of the bulb, by some regaded as belonging to this layer. but which does not differ in any essential respect from the ependyma which everywhe lines the cavities of the nervous axis, the stratum consists almost exclusively of the two kinds of nervous elements indicated by the titles above given. The principal constituents are the nervous fibres. which represent the axis-cylinder processes already describer as entering this layer from the subjacent corpuseles: as these pass along the length of the bulb they give off numerous collaterals, of which some run horizontally to end among the adjacent granules; others descend vertically to terminate by interlacing ramifications among the lateral protoplasmic processes of the mitral corpuscles.

The name of granule corpuscles is used to designate the abundant cellular elements, probably nervous in character, which are grouped in numerous clusters throughout the layer, the fibres above mentioned running in interlacing bundles among these clusters. They vary more or less in form, but are usually provided at their inner extremities with several short, slender, rapidly branching processes: the outer extremity bears a single stouter process which runs to the inner surface of the molecular laycr, there to ramify among the lateral processes of the mitral corpuscles. Other corpuscular elements, which are more doubtfully nervous in function, have been described in this layer.

The medullated fibres of this layer pass through the olfactory tract to enter the hemisphere and there to be distributed to their destinations in the cortex. In addition, Cajal describes in the tract efferent fibres which pass into the deep fibre layer of the bulb to end in arborizations which are situated chiefly among the central processes of 
the granule corpuscles. In those mammals in which the cavity of the bulb is obliterated in the adult, the ependymal lining is replaced by a gelatinous mass containing numerous neuroglia cells. The dorsal portion of the bulb is in mammals generally far simpler in strueture than the ventral, the latter, by virtue of its position, being brought into far more intimate relations with the olfactory mucosa.

At the close of the description of the structure of the taste-buds reference was made to the close relationship of the senses of taste and of smell, and a possible resemblance in structure in the two organs was intimated. That resemblance, if it exists, is chiefly between the gustatory and the olfactory cells: the former are strikingly like the latter as regards their general form, and particularly as regards the central nucleated portion and the peripheral process. As we pass inward, however, the likeness is less evident: the olfactory cell is plainly a nervous element, being continued by an axis-cylinder process which ends by arborizations in onc of the glomeruli of the olfactory bulb: if the gustatory cell is a nervous element, its inner portion must be regarded as a corresponding arborization-region, very greatly reduced, and probably discharging the impulses which it transmits upon the intrabulbar ramifications of the fibres of the glossopharyngeal nerve. Such an arrangement, if it exists, is without parallel as far as known; but would find its nearest representation in the olfactory apparatus. If, on the other hand, the gustatory cells are epithelial, and not nervous, the strueture of the taste-bud approaches most nearly to that of a tactile or pressure-organ, a form of sensation having littlc relation to the sense of taste, which resembles that of smell (and no other sense) in that it enables us to take cognizance of stimuli that must be regarded as 
essentially chemical. It should be noted that true gustatory sensations are also received on portions of the tongue in which taste-buds have not been found, and that these organs have been described upon surfaces other than that of the tongue which are certainly not gustatory. We are here undoubterly confronted with a problem whose solution depends upon discoveries yet to be made.

The apparatus of sight is far more complex in structure than that of smell, alike in its essential portions and in those which are accessory thereto. The former include the capsule, fibrous in man and in the mammals generally throughout the larger portion of its wall (though partly cartilaginous or bony in some vertebrates); the apparatus of refraction, with its mechanisms of adjustment; and the structures directly involved in the reception of light stimuli and their conversion into nervous impulses. The accessory parts are the protecting cyelids; the investing membrane common to them and to the eyeball; and the glands whose secretions maintain the proper condition of this mcmbrane. It will be convenient to proceed, in description, from the more external accessory parts to the more decply seated and more complex essential structures: in each case considering anatomical characters only in so far as necessary for the elucidation of the histology of the parts in question.

The eyelids are essentially muscular folds of the skin, modified chiefly upon their inner surfaces. The outer surface resembles the skin of adjacent portions of the face in 
the presence of diminutive hairs, accompanied by small sebaceous glands, and by occasional sweat glands: it is thrown into small irregular folds. The underlying corium is loose in texture: it also differs from that of the rest of the skin of the face in the presence of considerable numbers of branched pigment corpuscles. At the free margin of the lid the surface curves inward; the corium becomes more dense: and the hair follicles are suddenly enlarged for the derelopment of the long. stout, and recurved cilia, or eyelashes. Sebaceous glands open into the follicles of the cilia, as do also some of the ducts of modified swe.at glands known as the glands of Moll, others opening freely at the surface.

As the integument approaches the inner surface of the lid it bends almost at a right angle at the palpebral border, and at the same time becomes modified in structure to form the palpebral conjunctiva, which lines the surface of the lid in contact with the ereball. Beneath the integument is situated the orbicularis muscle, composed of striated fibres whose bundles run in a general way parallel to the palpebral border: the group of bundles situated just within the border fold, and separated from the mass of the orbicularis by the follicles of the cilia, is distinguished as the ciliary or marginal muscle, or as the muscle of Riolan. Just interior to the orbicularis muscle lies the palpebral fascia, a layer of fibrous tissue which separates the tegumental from the conjunctival portion of the lid: in the upper lid it is blended with the tendon of the levator muscle.

The palpebral conjunctiva consists of a laver of stratified columnar epithelium containing scattered gohlet cells, and resting upon a definite basement membrane: and a dense mass of fibrous tissue, the tarsus, or the tarsal cartilage (erroneously so-called, as it is entirely deroid of cartilage corpuscles). The stratified columnar epithelium of the 
conjunctiva passes gradually at the palpebral border into the stratified squamous epithelium of the integument: the tarsus may be regarded as the continuation of the denser portion of the tegumentary corium. Epon the inner surface of the lid there ean be seen with the naked eye. a number of icrtical rows of apparently granular masses, of a yellowish color. These are the tarsal or Meibomian glands, compound structures of the sebaceous type which are imbedded in the tarsus: each consists of a straight or somewhat curved conducting tube or duct lined with cuboidal epithelium, into the sides of which open numerous sebaceous saccules resembling in every essential those found in connection with the hair follicles; the ducts open by minute orifices upon the margin of the lid, their mouths being lined for a short distance. with stratified squamous epithelium.

Along the proximal margin of the tarsus, and partly imbedded therein are scattered branched tubular glands of the serous type, the accessory tear glands: they discharge their secretion upon the adjacent conjunctival surface. The conjunctival surface of this vicinity is frequently thrown into folds, chiefly involving the epithelium, whose appearance in cross section has led to their being described as glands. The connective tissue between the basement membrane of the conjunctiva and the tarsal plate contains diffuse adenoid tissue which is occasionally gathered into nodules in the human subject: in some of the lower mammals these nodules are quite numerous and well-defined.

Beyond the base of the eyelids the conjunctiva passes over upon the eyeball at the fornix conjunctivae. Goblet cells are more numerous here than upon the palpebral surface; the fibrous portion contains a number of distinct adenoid nodules, and a few mucous glands: inwardly, it passes over into a loose layer of subconjunctival areolar 
tissue which permits of a considerable amount of motion. The continuation of the conjunctiva upon the eyeball will be best described in connection with that structure. The plica semilunaris, a vertical curved fold at the inner angle of the eye, representing the third eyelid of many lower vertebrates, is a mere fold of conjunctiva; it contains internally in some mammals, and sometimes in man, a thin slip of hyaline cartilage: as well as a rudimentary racemose gland regarded as representing the Harderian gland generally present in the eyes of those vertebrates which have a functional third eyelid. The adjacent caruncle is a rounded fatty mass, with an investment agreeing with the integument in structure and containing minute hairs and modified sweat glands. The conjunctiva, which is highly sensitive, is richly supplied with the nerve terminals already described as end-bulbs.

The lachrymal gland, situated in the supero-lateral portion of the orbit, consists of two somewhat distinct portions, sometimes described as the superior and inferior lachrymal glands. The whole mass consists of an aggregation of compound racemose glands which open by independent ducts upon the conjunctival surface in the region of the superior fornix. The acini, which may be either simple or branched, are lined by granular cells with large spherical nuclei, agreeing in this respect with the alveoli of serous glands; from which they differ, however, by the presence in each of a distinct and sometimes a large lumen. They open into ductules lined by flattened or low columnar cells: these lead into ducts whose epithelium is distinctly columnar, and in which a second layer of small cells has been described as situated near the basement membrane.

The secretion of the lachrymal gland, after washing the surface of the eyeball, is carried away by the lachrymal 
canals. which open on the palpehral borders near their inner extremities. Each canal is lined with stratified squamous epithelium, which rests upon a fibrous layer rich in clastic fibres: external to this is a layer of striated muscular fibres which are generally disposed longitudinally. The canals discharge into the lachrymal sac, which is continued to the nasal cavity by the nasal or lachrymal duct. The sac and the duct are both composed of an elastic fibrous layer containing considerable adenoid tissue, and lined by a mucous membrane which is invested by columnar epithelium resembling that of the nasal cavity.

The visual capsule consists of two distinct strata; the outer, or skeletal, which is known throughout the greater portion of the eyeball as the sclerotic, but is transformed in front to form the transparent cornea; and the inner, or musculo-vascular, which is composed of the posterior choroid, and the anterior iris : the essential nervous structure of the eye lies immediately interior to the choroid. The cornea is a part of the refracting apparatus of the eye, and the iris a portion of the regulatory mechanism: but each may be conveniently described in connection with the stratum of which it is a portion.

The whitish sclerotic is a dense fibrous layer resembling somewhat a greatly thickened membrane; the interlacing fibre bundles are arranged chiefly in antero-posterior and in transverse directions: elastic fibres are sparingly present: the fixed corpuseles are flattened, and lie in definite lacunae of irregular form. The inner layer is rich in brownish pigment and is known as the lamina fusca: between it and the outer layer of the choroid are extensive lymph spaces lined with endothelium and traversed by bloodressels and strands of connectire tissue. The sclerotic is nearly twice as thick in its posterior as in its anterior portion: where the optic nerve enters the eye the sclerotic be- 
comes continuous with the sheath of that cylindrical body: the circular area enclosed is suddenly thinned, and is pierced by a number of small openings; it is therefore designated the lamina cribrosa. Over the larger portion of the sclerotic its outer surface is invested by a thin layer of connective tissue loosely uniting it to the capsule of Tenon, a membranous sac lined with endothelium and enclosing the space of Tenon by means of which the eyeball is separated from the fat masses lining the orbit. In front the sclerotic. is invested, as far as the scleral sulcus by which it is separated from the cornea, by the scleral conjunctiva : this consists chiefly of stratified squamous epithelium resting upon a thin fibrous membrane which is connected to the sclerotic by a scanty layer of looser connective tissue: it contains numerous end-bulbs, and, as is well known, is extremely sensitive.

The cornea is readily distinguishable from the sclerotic, not only by its transparency, but also by its greater convexity. Its outer surface is covered by a layer of stratified squamous epithelium continuous with that of the scleral conjunctiva: the layer is several cells deep, the outer elements being strongly flattened, but retaining their nuclei, and the inner being digitated in a manner similar to the prickle-cells of the epidermis. The deepest cells rest on a thin, dense, homogeneous layer of closely felted fibres, the membrane of Bowman, or external limiting membrane, which possibly represents the fibrous portion of the conjunctiva. Beneath this membrane, and closely connected with it is the substantia propria of the cornea, a mass of the corneal tissue described in detail in a previous chàpter: at its margin it passes over into the substance of the sclerotic, of which it is presumably a modification. Internally this mass is invested with a thin homogeneous elastic internal limiting membrane, otherwise known as the membrane of Descemet: its inner surface is covered 
with a layer of endothelium and bounds the anterior chamber of the eye. Around its margin the membrane of Descentet is continued by a number of processes to form the pectinate ligament by which the cornea is attached to the iris.

The choroid is nearly coextensive with the sclerotic. It consists of a vascular layer of fibrous tissue which is exceedingly rich in large pigment corpuscles, imparting to it a color which varies from brown to black: in the human eve it is dark brown in color. Its outermost portion, consisting entirely of pigmented connective tissue, forms a layer distinguished as the lamina suprachoroidea: it lies immediately within the lamina fusca of the sclerotic, from which it is largely separated, as has been already stated, by extensive lymph spaces lined with endothelium. The body of the choroid is rich in bloodvessels, which are disposed in two strata; an outer containing the arteries and veins, which are arranged in a characteristic manner, and an inner, the capillary tunic, or tunic of Ruysch: the fibrous structure between the two is a layer of connective tissue rich in elastic fibres which in some mammals is so well dereloped as to form a distinct layer which is visible through the capillary tunic and the retina, and is known as the tapetum. Within the capillary tunic is a thin transparent layer, the membrane of Bruch, or vitreous membrane.

The anterior portion of the choroid is modified by the foldings of its innersurface known as the ciliary processes, and by the thickening due to the presence of the layer of bundles of smootl muscular fibres termed the ciliary muscle: the whole region, including a marginal zone, the ciliary ring, in which the capillary tunic is less well developed than in the choroid generally, is sometimes designated the ciliary body. The ciliary processes, upwards of serenty in number in the human eye, are meridion- 
ally disposed folds which begin just anterior to the ciliary ring and rise gradually to the height of a half of a millimetre or so, to terminate abruptly at the margin of the iris: like the rest of the choroid, they are quite vascular, the vessels being imbedded in a pigmented stroma of connective tissue, and are limited internally by the vitreous membrane. Upon their surfaces are pouch-like depressions lined by the epithelial layer, presently to be describer, with which the vitreous membrane is invested in this region; these have been called ciliary glands: their glandular function is, however, doubtful.

The ciliary muscle is by some regarded as a portion of the choroid, by others as interposed between it and the sclerotic. It is composed of bundles of smooth muscular fibres (of striated fibres in birds), most of which arise from the pectinate ligament at the region where the sclerotic, the cornea, and the iris come together: of these the greater number run meridionally to be inserted into the choroid, and are therefore sometimes regarded as forming a distinct muscle, the tensor choroideae: the remainder, known as radial bundles, run obliquely to those just described, assuming a direction which tends toward the centre of the eye, and being inserted in the ciliary processes. Other bundles, internally situated, are arranged in a more or less definite circular tract, known as the ring-muscle of Mueller. The ciliary muscle as a whole is triangular in cross section: it is thickest in hypermetropic eyes, due largely to an increase in the size of the ring-muscle.

The stroma of the choroid is continued forward from beyond the ciliary body to form the principal portion of the iris: the latter is highly vascular, but not so much so as the rest of the musculo-vascular layer: it is also somewhat different in texture, approaching more nearly to the structure of retiform tissue. It contains numerous pigment corpuscles, of different colors in different persons, on whose 
presence the color of the iris depends: an exception to this ocenrs in cases where the iris is blue: here pigment corpuscles are wanting in the stroma, the color depending entirely on the appearance of the post-iridal pigment (to be described"later) as seen through the body of the iris.

The anterior surface of the stroma is somewhat condensed, and leaves a layer of endothelial corpuscles continuous at the irido-corneal angle with those which invest the nembrane of Descemet. The posterior surface is formed by a homogenous layer continuous with the vitreous membrane of the choroid and the ciliary body : against it lies the layer of pigment corpuscles above referred to. Imbedded in the stroma of the iris near the pupillary margin is an angular layer of smooth muscular fibres, the sphincter pupillae: near the posterior surface are radiating bundles forming a thin layer which is not continuous, known as the dilator pupillae: its existence is questioned by some histologists, the demonstration of the scattered bundles of smooth muscular fibres, as distinguished from the adjacent bloodvessels and bundles of connective tissue, being quite difficult.

The region lying between the outer margin of the iris and the sclero-corneal suleus is one of great importance; the iris, the choroid, the ciliary muscle, the cornea and the sclera all coming together in this vicinity. Just external to the irido-corneal angle, and among the fasciculi which make up the pectinate ligament, lies a loose network of trabeculae of white and elastic fibres whose interstitial cavities, imperfectly lined with endothelial cells, are known as the spaces of Fontana: they communicate freely with the anterior chamber of the eye and contain the same fluid. External to these and fairly within the sclerotic portion of the region is situated an annular space, irregularly flattened and in places subdivided: it is called the canal of Schlemm: whether it is a lymphatic 
or a renous channel, and whether or not it communicates with the spaces of Fontana are still matters of dispute.

The parts concerned with the processes of refraction by means of which distinct images of things seen are formed on the sensitive surface within the eye are the cornea, a description of which has already been given; the aqueous humor, a watery fluid in which leucocytes are occissionally found, but containing no other tissue elements, which fills the space between the cornea and the capsule of the lens: the crystalline lens, with its capsule, by means of which it is suspended at right angles to the eye immediately behind the iris; and the vitreous humor, which fills the cavity posterior to the lens. The regulatory mechanisms are the iris, which, by modifying the size of the pupillary aperture, governs the amount of light which passes through the lens and indirectly (to some extent) the sharpness of the image formed by it; and the ciliary muscle, whose action modifies the convexity of the lens and thus affects its definition: an account of these having already been given, there remain for description the lens and the vitreous humor, with the capsules by which they are surrounded.

The crystalline lens is composed of an epithelial layer and a fibrous mass whose components are modified epithelial corpuscles. The epithelial layer consists of cuboidal elements which furm nearly the whole of the anterior surface: as they approach the equator they become columnar, and as they reach that region become greatly elongated and assume the shape of the long hexagonal prismatic fibres of which the greater part of the lens is composed: at the equator these retain their nuclei for some time after birth, but those of the greater portion of the mass are quickly lost.

The fibres run from the anterior to the posterior por- 
tion of the mass, being so disposed that their extremities conce together in each region along raliating sutural planes primarily three in number; the sutures of the anterior region alternate with those of the posterior region in position; as a consequence, the fibres pass obliquely from one region to another: the degree of obliquity is increased by the fact that the length of the fibres is such that those which arise nearest the centre of the anterior region terminate posteriorly nearest the equator; and vice versa. As a consequence of this arrangement of the fibres, stellate figures are formed which can be easily seen in the artificially hardened lens, and traces of which have been discovered in the living eye by the aid of the ophthalmoscope. Hardening in alcohol reveals a tendency to lamination, particularly in the outer portion, the laminae peeling off in triangular patches which separate along the sutural planes.

The capsule of the lens is a transparent elastic sac which completely encloses that body. It is apparently homogenous in structure in the adult, but is regarded by some as composed of two laminae: an inner, cuticular in character, formed by the activity of the epithelial elements within while still embryonic: and an outer, composed of fibrous tissue. It is thicker in front than behind, in relation with the greater change of curvature which takes place in the more highly convex posterior surface in visual adjustments. The support of the capsule and lens in place will be described later.

The vitreous humor, or vitreous body (as it alsocalled), is a semi-fluid mass of extreme tranparency derived from the modification of a quantity of gelatinous tissue by the infiltration of lymph to such an extent that over ninetyeight per cent. of its substance is water. Slender transparent fibres are scattered through the mass, and occasional corpuscles are found in it: these are generally of ex- 
ceedingly irregular shape, and are often extensively vacuolated; they are probably modified leucocytes. Under certain methods of hardening the vitreous body can be seen to present evidences of a laminar structure; whether this is real, or the result of the treatment employed, is not yet certain.

The vitreous body is invested by a thin transparent capsule, the hyaloid membrane, which is structureless throughout the greater portion of its extent. Opposite the optic: nerve it is reflected forward to line the slender hyaloid canal which perforates the vitreous borly, terminating in front at a point opposite the centre of the posterior surface of the crystalline lens: here the hyaloid membrane is reflected outward from the anterior extremity of the canal to line the patellary fossa, on the anterior surface of the vitreous body, which receives the convexity of the lens and its capsule, the latter being in contact with the hyaloid membrane.

At the margin of the patellary fossa the hyaloid mem. brane lining it becomes continuous with that investing the outer surface of the vitreous body: here the membrane is distinctly fibrous, the fibres in some cases penetrating the gelatinous mass within. It gives off from its outer surface a fibrous layer which closely invests the ciliary processes as the zone of Zinn, or zonula ciliaris: its free portion extends beyond the ciliary processes to be inserted upon the capsule of the lens at its equator, thus forming the suspensory ligament of the lens above mentioned. The mode of insertion of the suspensory ligament is such as to leave a narrow circular space between the two layers of the hyaloid, known as the canal of Pettit.

The structures directly involved in the reception of light stimuli and their conversion into nervous impulses are contained in the retina, a highly complex organ formed by 
the modification of a direct ontgrowth from the brain. This outgrowth, at first vesicular in form, is afterwards doubled upon itself in such a manner as to form a spheroidal cup composed of two layers and situated chiefly between the vitreous humor and the choroid, its basal stall-like portion becoming the optic nerve. The fibres of the optic nerve are continued over the inner surface of the retina, in a manner to be presently described, as far as the outer or posterior extremities of the ciliary processes; the sinuous line which marks the limit of their distribution being known as the ora serrata. In front of this line the surface of the ciliary processes is invested by a much simpler ciliary portion of the retina, wheh is in turn continued into the iridal portion, or uvea, which lines the inner surface of the iris: the structure of these outlying portions will be best understood after a description of that of the principal portion of the retina.

When examined by the ordinary methods of hardening and staining the retina shows in transverse section a $111 \mathrm{~m}$ ber of distinct strata or layers, tolerably uniform in structure througliout the gieater portion of its extent. These are usually stated as eight in number: here, however, as in the other sense organs, our views have in recent years been greatly modified by the results of the chromate and silver method. An account of the eight layers will first be given, and the relation of their components as now understood subsequently considered.

Beginning at the inner or anterior surface of the retina, there may be discerned next to the hyaloid membrane which invests the vitreous body a delicate layer which is apparently (and only apparently) continuous: it has been designated the internal limiting membrane: it is in reality a mosaic formed by the thin expanded ends of supporting structural elements, the fibres of Mueller, which 
pass vertically toward (but not to) the outer surface of the retina.

Next to the internal limiting membrane, so called, is seen the first definite stratum of the retina, the layer of nerve fibres. These, which are non-medullated in most cases, are arranged in small bundles which form a plexiform meshwork over the inner surface, radiating from the optic nerve, or, more exactly, converging to it from all portions of the retina. This layer, like nearly all the others, is quite transparent, and is itself insensitive to light.

The layer of nerve fibres is succeeded outwardly by the ganglionic layer, a stratum of relatively large multipolar nerve corpuscles, either spheroidal or pyriform in shape, whose axis-cylinder processes are continuous with fibres of the preceding layer, and whose other processes ramify in the layer next beyond. The ganglionic layer varies in thickness in different portions of the retina, being in some places two or three corpuscles deep, but over the greater portion of its surface consisting of a single layer of corpuscles: toward the ora serrata these become separated from each other by considerable intervals.

Immediately beyond the ganglionic layer is situated the inner molecular layer: this, which is in most portions of the retina the thickest of the visible strata, is apparently composed of a granular mass, which is in reality the expression in section of the cut extremities of the ramifying processes of the corpuscular elements of the layers next adjacent.

External to the inner molecular layer is seen the inner nuclear layer, composed chiefly of closely aggregated bipolar and multipolar nerve corpuscles, the former predominating. The corpuscles vary greatly in size, but are, on the average, decidedly smaller than those of the ganglionic layer: the disposition of their processes will be de- 
CIAPTEK XXII. TIE ORGANS OF SPECIA, SENSE, Z I.J

scribed later. Nucleated enlargements of the sustentacular elements, or fibres of Mueller, are also found in this laver to some extent.

The inner muclear layer is followed by the outer molecular layer, a cranular stratum closely rescmbling in its appearance the inner molecular layer, but differing from it greatly in extent, being usually the thinnest of the varions layers of the retina.

Beyond the onter molecular layer, again, is seen a layer of corpuscular clements, the so called outer nuclear layer. which as ordinarily seen resembles the inner nuclear layer as closely as do the two molecular layers: nearly all of the constituent elements are distinctly bipolar, and, as will presently be shown, their relations are quite different from those of the elements of the inner of the two apparently similar layers. The corpuscles of this layer are, furthermore, closely connected with the elements of the succeding layer in a manner which differentiates them sharply from any other retinal elements.

The outer surface of the outer nuclear layer is sharply defined, the sustentacular tissue of the retina here terminating so abruptly as to lead to the description of a definite external limiting membrane: recent researches have shown that the application of the term membrane in this connection is even less justifiable than in the case of the inner boundary of the retina.

External to the outer nuclear layer, and apparently resting upon the so-called external limiting membrane, is the bacillary layer, or layer of rods and cones. It consists exclusively of the two kinds of elements designated by the latter of these titles. Those termed rods are by far the most numerous in nearly all portions of the retina: each consists of an inner or basal portion, somewhat thicker in the middle than at the extremities, and an outer or terminal portion, slightly longer than the basal in man 
and most mammals, which is of nearly uniform diameter throughout its entire length. The outer segment of each rorl is transversely striated, and can be resolved into a number of thin disks by the aid of certain reagents : the outer portion of the basal segment is longitudinally striated. The cones resemble the rods in consisting of two segments: the inner of these is much stouter than the basal segments of the adjacent rods, and is thicker at the base than at the outer extremity: like the corresponding regions of the rods, the outer portion of the basal segment is longitudinally striated. Upon its free extremity is seated the outer segment, which is shorter than that of the rods, and tapers to a point: it shows transverse striations.

The layer of rods and cones was for a long time regarded as the limiting stratum of the retina, the adjacent layer of pigment cells being associated with the choroid, with which it is in close contact. With advancing knowledge of the embryological development of the eye, however, it has become evident that it must be regarded as retinal in nature. It consists of a single stratum of prismatic cells, hexagonal in form and so heavily loaded with pigment as to hide the large central nucleus: the outer surface of the cell, in contact with the choroid, is smooth: the inner is prolonged by numerous slender processes which extend between the rods and cones of the adjacent layer to a distance which varies in relation with the intensity of the stimulus acting upon the retina.

The layers of the retina, as above described, are now linown to be the expression as seen under the more familiar methods of preparation of a system of nervous elements arranged in a manner not unlike that which is found in the other organs of special sense: their disposition may be briefly described as follows, disregarding for the present the layer of pigment cells just mentioned.

The rods and the cones of the bacillary layer are in real- 
ity structurally contiuuous with the elements of the outer nuclear layer in such a manner that they may with propriety be regarded as their peripheral prolongations, or as their greatly modifierl dendritic portions. Each rod is continied withis the external limiting membrane by a slender filament of greater or less extent which terminates at the nuter pole of one of the spindle shitped corpuscles of the nuclear layer: the body of the corpuscle is transversely striated in a characteristic manner: from its inner pole it gives off a fine varicose filament, the homologue of the ixis-cylinder process, which extends to the outer molecular layer and there terminates in a small knob-like expansion, representing a greatly modificd terminal arborization the rod-corpuscles are situated at various levels in the outer nuclear layer from the outer to the inner surface, their peripheral and central filamentous prolongations varying in length in a corresponding manner.

The base of each cone is continued beneath the external limiting membrane by a stout strand of protoplasm which passes almost immediately into the nucleated corpuscle, the latter being situated just within the membrane: the corpuscle is continued inward by a stout smooth fibre which passes directly across the outer nuclear layer to end within the surface of the outer molecular layer by a disk-like expansion from whose margin slender filaments are given off, forming a rudimentary arborization.

The rod and cone elements, including both the bacillary and the nuclear portions, as far as the outer molecular layer, may be regarded as forming the first of the three groups of nervous elements proper to the visual apparatus: they are frequently distinguished as the neuroepithelial layer, or the layer of visual cells.

The outer molecular layer, like the glomeruli of the olfactory bulb, may be regarded as chiefly made up of the interlacement of arborizations and dendrites, the central 
terminals of the rod and cone elements here coming into relation with the peripheral terminals of the corpuseles of the inner nuclear layer; or, as it is now frequently designated, the layer of bipolar corpuscles.

Each of these corpuscles is prolonged peripherally by a filament which terminates at the outer molecular layer by a group of dendritic processes: Cajal has shown that those of some of them pass the outer portions of that layer to form close tufts about the knob-like terminals of the rod-elements; the central processes (or axis-cylinder processes) of the same corpuscles passing to the innermost portion of the inner molecular layer: for these he has proposed the name of rod-bipolars. The others he has shown to ramify extensively in the inner portion of the outer molecular layer, in relation with the terminals of the cone-elements; while their central processes terminate in arborizations which are situated at various levels in the stratified inner molecular layer: these he calls conebipolars.

The same investigator has demonstrated in the outermost portion of the layer of bipolar corpuscles elements varying in size, whose dendrites ramify in the outer molecular layer and whose axis-cylinder processes run for longer or shorter distances horizontally to end in arborizations distributed in the same layer; for which reason he calls them the horizontal corpuscles of the retina. In the innermost portion of the same layer of corpuscles he has described pear-sliaped amacrine corpuscles of varying size, whose processes branch and ramify in the inner molecular layer at various levels corresponding to those indicated in connection with the terminals of the conebipolars. The nature and functions of the horizontal and amacrine corpuscles of this layer may perhaps stiil be regarded as matters of question: the bipolar corpuscles 


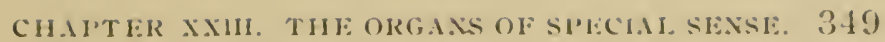

clearly form the sceond members of the series of nervous elements inrolved in visual sensation.

The inner molecular layer resembles the outer (and, indeed, all the so-ealled molecular layers of the nervous sy'stem) in consisting chiefly of an interlacement of ecintral and peripheral terminal filaments. It show's, as has been indicated, evidence of stratification, due to the termination, at niore or less definite levels, of the central processes of the cone-bipolars, and the associated horizontal distribution of their arborizations; in relation not only with the terminals of the processes of the amacrine cells, but also with those of the dendrites of the corpuscles of the layer next within.

The layer of ganglion corpuscles, the third and innermost members of the visual series, is composed of elements which vary much in size: according to Cajal, the smallest corpuscles send their dendrites into the innermost stratum of the inner molecular layer: the largest to the ontermost stratum: and those of intermediate size in like manner to the intervening strata; the arborizations of the terminals from the rod-ljipolars being distributed in all cases in the innermost stratum. From each of these corpuscles an axis-cylinder process is given off which eventually becomes one of the fibres of the optic nerve, its terminal arborizations being situated in the brain. Cajal lias also described in the optic nerve fibres which come from the brain and enter the retina, terminating by arborizations within the layer of bipolar corpuscles: he regards them as convering centrifugal impulses.

The layer of bipolar corpuscles and that of ganglionic corpuscles, taken together, have been designated the cerebral layer, as distinguished from the nenro-epithelial layer or layer of visual cells. The cerebral and neuroepithelial layers, taken together, are formed from the anterior (and principal) lamina of the collapsed optic vesi- 
cle, the layer of pigment cells alone representing the posterior lamina.

At the macula lutea the retinal layers are notably thickened, the layer of ganglionic corpuscles in particular becoming several cells deep. Passing towards the centre of the macula, the layers become rapidly thinned to form the fovea centralis, in which cone-elements only are present in the neuro-epithelial layer, and cone-bipolars in the cerebral layer, the central processes of the latter passing obliquely outward to enter the inner granular layer at the margin of the fovea. Where the optic nerve pierces the retina the retinal structures are of course wanting.

The characteristic retinal layers disappear at the ora serrata, the layer of visual cells first becoming absent. Over the ciliary portion of the retina the posterior lamina of the optic vesicle is represented by a layer of pigment cells as elsewhere: the anterior lamina by a layer of columnar cells lying between the pigment layer and the hyaloid membrane: they have large oval nuclei near their outer extremities. In the iridal portion of the retina both laminae are represented by layers of pigment cells. The masses of retinal pigment cells between the ciliary processes form the so-called ciliary glands already mentioned.

The apparatus of hearing, like that of sight, comprises a receiving and a transmitting mechanism in addition to the structure which contains the special terminal organs involved. The receiving neuro-epithelium is in some respects more complex than in any of the other organs of special sense: the accessory mechanisms are far simpler than those of the apparatus of sight. 
The piuna consists essentially of a sheet of yellow fibrocartilage eovered by integument: funnel-shaped or variously modified in mammals generally, it is in man crumpled and comparatively rudimentary, but retains its characteristic structure. In the lobe of the car the eartilage is replaced by a mass of fat. The skin upon the outer or convex surface does not in man differ materially from that of the adjacent portion of the head: that of the inner surface is thin and but slightly mobile upon the subjacent cartilage, and is devoid of sweat glands. The hairs of the integument of the pinna are in man very small, with relatively large sebaceous glands. The small intrinsic muscles which pass from certain folds of the cartilage to others, beneath the integument, are composed of slender striated fil)res.

The external auditory meatus, in part cartilaginous and in part bony, is lined by a closely adhering tegumentary layer, continuous with the skin upon the inner side of the pinna, which grows thinner and simpler in structure as it passes inward. The portion of the skin which invests the surface of the outer or cartilaginous portion of the tube contains fine liairs which, like those of the pinna, are accompanied by well developed sebaceous glands: the fibrous tissue subjacent to the corium contains in addition numerous convoluted tubular ceruminous glands which greatly resemble sweat glands in form and structure but are larger and more closely aggregated: they are farther characterized by their brownish color and the lighly refracting fatty particles seen in their secretion. The lining of the deeper bony portion of the neatus is . devoid alike of hairs and of glands.

The membrana tympani, which separates the external meatus from the middle ear, is composed of a fibrous layer inrested outwardly by a continuation of the integ- 
ument from the bony wall of the meatus, and inwardly by the mucous nembrane which lines the whole of the tympanic cavity. The fibrous layer consists chiefly of radiating bundles diverging chiefly from the point of attachment of the malleus: there are in addition circularly disposed bundles of fibres, chiefly near the margin of the membrane, which form a so-called inner layer. The tegumentary layer resembles that of which it is a continuation: the mucous layer consists of a thin menbrane rich in elastic fibres which bears a single layer of cuboidal epitheliutu whose component cells are deroid of cilia.

The auditory ossicles possess to sone extent the character of dense bone, their thicker portions showing distinct though small Haversian systems of lamellae: definite marrow cavities exist in the interior of the principal masses of the malleus and incus. The articular surfaces are in each case invested with hyaline cartilage. The muscles connected with the ossicles are composed of striated fibres. Both bones and muscles are invested with the mucous membrane which lines the tympanic carity.

The Eustachian tube, which connects the tympanic cavity with the pharynx, has a bony wall in its posterior portion; in the anterior portion the wall is in part composed of hyaline cartilage, sparingly reinforced by bundles of white fibres, and in part of dense fibrous membrane. It is lined throughout its extent by a mucosa which is a continuation of that of the pharyux, and is in turn continued by the lining of the tympanic cavity : like that of the pharynx, the mucosa is invested with a layer of stratified columnar ciliated epithelium. In the cartilaginous portion of the tube there is a submucosa which contains numerous mucous glands and a considerable, quantity of liffuse adenoid tissue; in this respect, again, recalling the structure of the pharynx. In the bony posterior portion 
the mucosa is deroid of glands and atheres more closely: to the wall of the tube.

The cavity of the tympanum, like that of the mastoid cells leading out from it, may be regarded as an expansion of that of the Eustachian tube. It is lined with a mucous membrane which has already been frequently referred to: between the membrane and the bony wall of the cavity is a submucosa consisting of interlaced fibrous bundles anong which are seen 11 umerous spheroidal bodies in many way rescmbling Pacinian corpuscles.

The disposition of this fibrous network, the irregularities of the bony surfaces involved, and the structures present in the tympanic cavity coopperate to throw the mucosa into consplcuous folds; their disposition is a matter for the anatomist rather than for the histologist. The epithelium of the tympanic cavity is columnar ciliated over the greater portion of the surface; that of the mastoid cells is deroid of cilia. The existence of distinct glands in the mucosa of the tympanum is a matter of question.

The inner ear is in the strict sense the organ of hearing. the middle and outer regions being merely accessory thereto. It consists of the membranous labyrinth, in which the specially modified neuro-epithelial structures inrolved in audition are situated, enclosed in the cavity within the periotic mass known as the bony labyrinth. The membranous labyrinth is formed by the ingrowth of the integument of the side of the head: this is at first a simple saccular or flask-shaped cavity lined with epithelium derived from the ectoderm, and communicating with the surface by a small aperture. Later, this aperture is obliterated and the sac is divided into two principal regions, the utricle and the saccule, which are in the adult only indirectly connected. The three semicircular canals 
are developments of the wall of the utricle and together with it form the labyrinth in the limited sense in which the term was fornerly used. The cochlea is an exterision of the saccule.

The bony walls of the cavity which contains the utricle and the semicircular canals are lined with a thin periosteum invested by flattened connective tissue corpuscles which form an endothelium. The membranous structures enclosed within are adherent to the periosteum along one side of each canal and upon a portion of the surface of the utricle: throughout the rest of their extent they are separated therefrom by a space filled with perilymph which is traversed by frequent trabeculae of fibrous tissue, the free surface being similarly invested. The membranous wall consists of a layer of connective tissue containing numerous elastic fibres, within which is a dense clear tunica propria, whose surface throughout the canals shows numerous low papillary eminences; lining the tunica is a layer of polygonal pavement-epithelium cells.

In the ampulla of each of the semicircular canals the tunica propria is much thickened along a projecting ridge, the transverse septum, upon whose summit is situated a crista acustica, or ampullar area of auditory neuro-epithelium. In passing from the general surface of the ampulla upon the sides of the septum the pavement epithelium becomes first cuboidal and then columnar in form, the columnar cells being surmounted by a distinct cuticular layer. Within the crista the epithelium consists of cells of two sorts: fibre cells, whose elongated bodies extend through the whole epithelium, their bases being larger than their free extremities, and their nuclei being variously situated within the basal half; and hair-cells, cylindrical elements which are situated in the outer half of the epithelium only, their nuclei being situated near 
their rounded inner extremities, and their free ends bearing long tipering filaments, the auditory hairs.

Branches of the auditory nerve are distributed to each crista: as the fibres enter the epithelium they loose the medullary sheath, and quickly divide into fibrils which ranify extensively in the vicinity of the hair-cells, their free extremities heing in every case in direct contact with these epithelial elements: the relation between the nerve terminals and the epithelial cells must be regarded as similar to and as specializations of that elsewhere deseribed in connection with the free endings of nerve fibre in the epidermis.

In material hardened for section cutting the surface of each crista is found to be covered by a dome-shaped mass of a clear colorless substance of unknown composition and origin, in which the auditory hairs are imbedded: to this mass the term cupula is applied. Under suitable reagents the auditory hairs can be made to break up into numerous fine cilia-like filaments, indieating that the hairs are compound structures.

The surface of the utricle bears a large patch of neuroepithelium, the macula acustica or macula cribrosa, as it is sometimes termed, essentially similar in structure and in the mode of nerve supply to one of the cristac of the ampullae. There is not such a marked thickening of the subjacent tunica propria, and the auditory hairs are not as long as those of the ampullar organs: the surface of the macula is invested by a soft gelatinous mass in which are imbedded numbers of crystals of calcium carbonate known as otoliths. A macula in every way similar to that of the utricle is found in the saccule.

The cochlea, a development of a portion of the saccule, with which it is directly comnected in the lower vertebrates and in the embryo, is in the mammal in great measure constricted off from that region in the adult, be- 
ing connected with it only by a slender tubular passage, the canalis reuniens. It should be regarded, however, as a tubular diverticulum of that division of the primary auditory vesicle, differing from the rest of the membranous labyrinth in its spirally coiled form. its mode of attachment, and particularly in the complexity of its neuroepithelium, which here attains a degree of specialization found in no other organ

Regarding, for convenience, the position of the whole structure as so far shifted from that which it occupies in the living body as to bring the base of the spiral into a horizontal plane, the apex puinting upivard, the cochlear tube may be said to be adherent outwardly for about one third of its surface to the bouy wall of the containing cavity; and to be connected inwardly with the central bony spiral lamina by two flat membranes, the lower of which, the basilar membrane, is nearly horizontal in this position, while the upper, the membrane of Reissner, slopes at an angle of about forty-five degrees: the tube is therefore approximately triangular in cross section.

The periosteum of the outer wall is much thickened along the area of adhesion of the cochlear tube to form the spiral ligament, the greatest elevation being at the point of attachment of the basilar membrane, where a fibrous ridge is found known as the crista basilaris; a short distance above this a second ridge is seen, the vascular prominence, containing one or more conspicuous blnodvessels: the somewhat concave surlace between this and the ridge to which the membrane of Reissner is attached, known as the stria vascularis, exhibits a histological structure without parallel in the entire body. It contains a rich network of capillaries, imbedded in elements apparently epithelial in character, and commonly so described: the superficial cells (which entirely overlie the capillaries) are certainly in continuity with the epithe- 
lium lining the rest of the tube; those sitnated between the capillaries may rery possibly be epithelioid connective tissue corpuscles not unlike those known to occur elsewhere.

The membrane of Reissner is an exceelingly delicate sheet of connective tissue invested on the side toward the scala restibuli with a layer of endothelium some of whose cells are pigmented: the inner side is lined, like the greater portion of the membranous labyrinth, by a pavenent epithelium composed of polyhedral cells: the three component layers are of nearly equal thickness. The inner and lower edge of the membrane is united to the middle or inner portion of the limbus, a peculiar thickening of the periosteum of the upper surface of the bony spiral lamina.

The portion of the limbus situated outwardly from the attachment of the membrane of Reissner terminates abruptly by a border excavated by the spiral groove, which is bounded by an upper and a lower lip. The upper surface of the upper lip is ridged and grooved and its margin developed into numerous tonguc-like processes, the auditory teeth: the surface of the ridges and the teeth is invested by polyhedral parenient epithelium: that of the grooves is columnar: this is continued over the spiral groove by a layer of cuboidal cells continuous at the lower lip of the groove with the epithelial structures upon the upper surface of the basilar menbrane. The lower lip extends to the margin of the bony spiral lamina.

The basilar membrane extends from this margin to the basilar crest of the spiral ligament. Its middle layer consists of a sheet of homogeneous ground substance containing scattered nuclei, and having embedded in it an immense number of straight stout fibres running radially from the spiral lamina to the basilar crest. The surface toward the scala tympani is eovered by a layer of connective tis- 
sue whose elements do not take on a definite endothelial form, but are largely spindle-shaped fibres disposed at right angles to the fibres of the middle layer. The inner surface is invested with epithelium continuous with that lining the rest of the tube: that of the outer half of the membrane, or zona pectinata, is but slightly modified: that of the inner half, or zona tecta, is greatly modified to form the characteristic structure of the cochlea.

This structure, the organ of Corti, is a neuro-epithelium not unlike those found in the cristae and maculae acusticae: being composed, like those bodies, of hair cells and supporting cells: its greater complexity is due chiefly to the form and arrangement of the latter elements. The central feature is a series of arches formed by the convergence above of an inner and an outer rod of Corti, the outer rods being longer and more slanting than the inner: the triangular space beneath them, which runs the whole length of the cochlea, being known as the tunnel of Corti. Each rod consists of a broad basal portion, or foot, a slender shaft, and an enlarged head, that of the inner rod having a concave surface upon its outer side into which is fitted a corresponding convexity upon the inner aspect of the head of the outer rod: both the inner and the outer rods bear outwardly directed flattened phalangeal processes, those of the inner rods overlapping the inner portions of the processes of the outer rods. Both inner and outer rods are invested with a layer of protoplasm which is accumulated at the base on the side toward the tunnel in a mass containing an oval nucleus. The inner rods are narrower and more numerous than the outer.

On the inner side of the upper extremities of the inner rods is situated a row of inner hair cells, cylindrical in form, and, like those of the auditory structures, only extending through the upper half of the layer: the upper extremity of each bears a number of hair-like processes: 
the lower extremity is rounded and contains a spherical nucleus. Internal to the inner hair cells are columnar supporting cells which pass gradually over into the epithelium of the spiral groove.

On the outer side of the heads of the outer rods are rows, three or four in number, of outer hair cells, essentially like those of the inner row. Between them are the upper extremities of the cells of Deiters, elements somewhat resembling the rods of Corti: each has a spindle-shaped basal portion containing a spheroidal nucleus, and a slender rigid upper portion which terminates in an ontwardly directed phalanx. The phalangeal processes of the rods of Cortiand the phalanges of the cells of Deiters are united by their angles to form a reticular membrane through whose apertures the extremities of the outer hair-cells project. Between the outer rods, the hair-cells, and the cells of Deiters are intervals, the spaces of Nuel, which communicate with each other and with the tunnel of Corti, the whole being filled with a semifluid substance.

The organ of Corti may be said to be limited by the hair cells and the cells of Deiters : the latter pass over outwardly into tall columnar elements, the cells of Hensen, whose nuclei are situated in their large upper extremities. These pass rather abruptly into the shorter columnar cells of Claudius, between which and the epithelium of the outer wall of the tube a gradual transition is seen along the surface of the zona pectinata.

The bundles of nerve fibres distributed along the cochlea pass along the under surface of the bony spiral lamina to its margin from the spiral ganglion of the modiolus. Here they penetrate the basilar membrane: the fibres loose their medullary sheath and are distributed to the epithelium in a manner quite similar to that described in the account of the cristae, some of the fibres traversing the tunnel of Corti to reach the vicinity of the outer 
hair cells. From the margin of the upper lip of the limbus a cuticular fold, the membrana tectoria, extends out as far as the outer cells. It probably rests upon the organ of Corti during life.

A comparison of the essential structures of the various organs of special sense shows that they agree in being modified epithelia containing more or less specialized terminals of nervous elements. These epithelia are in 'each instance derived from the ectoderm: in the case of the retina indirectly, the organ in question being formed as a diverticulum of the nervous axis, which is itself formed from an infolding of the ectoderm: in the case of the other sense organs the derivation from the ectoderm is direct. The nerve terminals of the organs of taste and of hearing resemble each other in consisting of fibrils ramifying between the specialized epithelial cells, though these senses are not at all related as regards the character of the stimuli to which they respond. Similarly, the terminals of the organ of smell and of sight. are somewhat alike, greatly as these senses differ. Farther investigation may explain these apparent resemblances and differences and exhibit a still deeper unity of structure in the mechanisms of special sense. 


\section{INDEX.}

\begin{tabular}{|c|c|}
\hline PAGE & Pagee \\
\hline ACHROMATIC SPINDLE............... 120 & Blood ................................. 74 \\
\hline Achromatiu......................... 117 & — corpuscles.................... 74 \\
\hline Adenoid nodules........180, 183, 271 & — platelets..................... 44,82 \\
\hline Adenoid tissuc, $40,80,178,183,196$ & Bone corpuscles...................... 51 \\
\hline Adipose tissuc......................... $\quad 39$ & — nutrition of ...................... 57 \\
\hline Adrenals................................ 281 & - structure of...............32, 50, 53 \\
\hline Adventitia............92, 94, 260, 264 & Brain................................. 311 \\
\hline Agminated glands................... 180 & Bronchi ............................... 195 \\
\hline Allantois .............................. 257 & Bronchial muscle................... 196 \\
\hline Alveoli, pulmonary................. 188 & Bronchioles ........................... 197 \\
\hline Amacrine corpuscles...........102, 111 & Brunner, glands of.. ............. 177 \\
\hline Amitotic division..................... 119 & \\
\hline Amoeboid motion...................33, 80 & Caecum............................... 182 \\
\hline Ampulla .............................. 226 & Calyces of kidney..............204, 212 \\
\hline Ampullac, auditory ................ 354 & Canal of Schlemm................... 339 \\
\hline Aorta .................................. 261 & Canaliculi........................49, 51 \\
\hline Apolar corpuscles................. 110 & Capillaries............................91, 93 \\
\hline Appendix vermiformis............. 182 & Capsule of Bowman............... 207 \\
\hline Arborizations..................109, 111 & — of Glisson....................... 186 \\
\hline Areas of Cohnheim.................. 88 & — of lens.............................. 341 \\
\hline Areolae $. . . . . \ldots \ldots \ldots \ldots \ldots \ldots . . . . . \ldots, 59,66$ & — of Tenon........................ 334; \\
\hline Areolar tissuc......................... 38 & Cardiac fibres......................... 85 \\
\hline Arteries .....................91, 92, 259 & Carotid glands........................ 280 \\
\hline Articular corpuscles................ 105 & Cartilage.......................25, 29,30 \\
\hline Auditory meatus..................... 551 & — calcified.......................... 27 \\
\hline sicles........................... 362 & — cellular.............................. \\
\hline- teeth............................... 347 & — elastic .............................. \\
\hline Auerbach, plexus of...........173, 174 & — hyaline............................. \\
\hline Axilemna............................ 108 & — ossification in................... \\
\hline Axis-cylinder..................101, 105 & — reticular........................ 27 \\
\hline Axis-cylinder process.........102, 110 & $\begin{array}{l}\text { - transformation of...........64, } 65 \\
\text { - vascularization of............. } 63\end{array}$ \\
\hline BACILLARY LAYLER................. 345 & Cartilage bone....................... Gil \\
\hline Bellini, ducts of ...................... 210 & Caruncle.................................. 334 \\
\hline Bertin, columus of.................. 205 & Cell-division ........................2ో, 11! \\
\hline Bile capillaries...................... 189 & Cells..............................14, 115 \\
\hline Bipolar corpuscles.............102, 109 & — of Claudius..................... 359 \\
\hline Bladder, urinary ..............214, 257 & - colloid..... ...................... 278 \\
\hline Blastoderm ........................ 128 & — of Deiters...................... 359 \\
\hline
\end{tabular}


Cells of Hensen ..................... 359 - tactile..........................103, 104

Cellular tissue.......................... 38

Cementum 164,166

Central canal of cord.........292, 309

Centres of ossification............. 61

Centroacinar cells ................... 185

Cerebellar cortıx...................... 312

Cerebral cortex........................ 316

Ceruminous glands................. 144.

Cervix uteri ......................... 242

Chondrin.............................. 29

Chondroclasts......................... 56

Chondrogen ............................. 29

Chordae tendinea.................... 263

Choroid................................. 337

Chromatin............................. 117

Chromoplasm . ...................... 117

Chromosomes ........................ 120

Ciliary processes..................... 337

Circumferential lamellae .......... 52

Clitoris

245,258

Cloaca...................................... 257

Coelom.................................. 250

Coccygeal gland....................... 280

Cochlea .................................. 355

Cohnheim, areas of................ 88

Collagen............................... 29

Collaterals .............................. 111

- of cord. ........................... 303

Colloid cells........................... 278

Columnae carnac..................... 263

Columns of Bertin.................. 205

__ of Burdach........................ 298

— Clarke's ............................ 296

— of Goll............................. 298

— of Morgani...................... 182

— of Sertoli.......................... 221

_ of spinal cord ................. 292

— of Tuerck......................... 300

Coni vasculosi......................... 223

Conjunctiva ........................... 332

Connective tissues............24, 32, 38

Contractile tissues................. 83

Cord, spermatic..................... 217

- spinal............................. 291
Corium............................138, 155

Cornea .................................. 336

Corneal tissue.......................32, 48

Corpora cavernosa.................. 228

Corpus Arantii ...................... 263

— Highmori..................219, 223

luteum............................ 237

—_ spongiostum ...................... 229

Corpuscles...........................14, 23

- accessory...................... 36

_- adventitious ................. 36

— amacrine...................102, 111

- apolar............................ 110

— articular.......................... 105

— basket............................. 315

—_ bipolar......................102, 109

— blood .............................. 73

— bone.............................. 51

— of Cajal.......................... 316

- colored ............................ 74

- colorless.......................74, 77

concentric ..................... 278

corneal............................. 49

— fixed.............................31, 36

— genital............................. 230, 244

— of Grandry................... 103

- of Hassall....................... 278

- Malpighian.................205, 276

_ of Martinotti.................. 318

__ of Melssner..................... 104

_... migratory......................33, 36

_ mitral ........................... 327

— multipolar.................102, 110

_ of muscle........................ 87

- nerve.......................102, 111

_ nerve-fibre....................... 101

— of Purkinje. ..................... 313

— pyramidal...................... 317

red ................................ 74

— of retina ......................... 348

— of spinal cord................. 305

— tactile............................ 104

— unipolar.....................102, 110

- of Vater.......................... 105

- white............................... 74

Cowper, glands of .................. 231 
Cremaster 218

Crescents of Giannuzi. 158

Cristin acustica

Crusta petrosa. 354

Crypts of Lielerkuhn

Crystalline letns

Cumulus proligerus.

Cupula

Cytologr

DAKTOS 218

DeBore, enclothelium of.. 178

Deiters, process of. 102

Demilunes of Heidenhain

159

llendrites. $102,109,110$

Dense bone 52,69

- formation of........... 64

Dental papilia 167

Ientinal tubules. 165

Dentine $32,45.164$

Deutoplasm 116

Discharging terminals. 106

Discus proligerus

Disks, tactile.

Division, amitotic

-_ karyokinetic

Dobic's line.

Dorsal cornua.

Duct of Gartuer.

Ductless budies.

Duodienum

Dụra

E.IR 350

Ebner, glands of. 170

I:ct nderm 128

İctoplasm... 116

Elastic cartilage.

_- fibres 34

- membrane

- - tissuc...

Elastin

Elenentary particles

Ènamel.

$16+, 166$

germ lincl-bullos of Krause. 104

Endlings, free nerve................. 103

Endocardium ......................... 262

Eitdochoudral bonc...............64, 67

Eindomysium......................... 90

Èndoneurium .......................... 112

Endoplasm............................ 116

Endosteum............................ 59

Endothelium........................20, +4

— of DeBove..................... 178

End-plates, motor.................... 106

Iintoderm ............................. 128

Eosinophile cells..................... 37

- lencocytes....................... 79

Ependyma............................. 309

Epiblast .............................. 12\&

Epicardium .......................... 262

Epiclermis.............................. 135

Epididymis.....................217, 223

Epineurium ............................ 112

Epiphysis cerebri..................... 2sंt

Epithelium.......................... 17

— ciliated ............................ 19

- columnar ......................... si

- germinal ........................ 2... 2.

- glandular............................. 18

- pavement......................... 18

- polyhedrai..................... 18

_ respiratory...................... 198

-

- spheroidal........................ 19

— squamous ........................ 18

- stratificl.......................... 19

— transitional ..................19, 214.

Ероöphoron ........................... 239

Erectile tissuc........................ 228

Erectores fili ........................... 150

Eirythroblasts ......................55, 81

Erythrucytes......................... Tt

Eyelids................................. 331

F.ICTORS OF STRLCTURE............ 14

Fillopian tubes...................... . 23s

Fasciculi, muscular................. s9

Fat cclls ................... ... 37 
Fenestrated membrane........... 42

Ferrein, pyramids of............... $2(15$

Fer tilized ovum....................... 86

Fibres.................................. 34

— elastic............................... 34

- gray..........................101, 107

— medullated......................... 161

— of Mueller.......................... 344

_... non-medullated.................. 101

_. of Purkinjc....................... 563

— of Remak....................... 101

— smooth muscular............... 84

— striated.............................. 87

_... of Tomes ........................... 165

- white...................34, 101, 107

Fibrillae, muscular.................. 88

— primitive.......................... 107

Fibrin................................... 73

Fibro-cartilage....................... 27

Fibrosa.......173, 194, 196, 216, 24.4

Fibrous membrane.................. 41

- tissues................31, 32, 42, 45

Fields of Cohnheim................. 88

Fixed corpuscles......................31, 36

Follicles ................................ 157

- intestinal ........................... 177

Foveolae ................................. 56

Free nerve endings................. 103

Funiculus .............................. 112

GANGLIA

113

Ganglionic columns.................. 294

Gartner, duct of...................... 240

Gelatin..................................... 29

Gelatinous fibres..................... 101

- tissue ................................ 32

Genital corpuscles.......105, 230, 244.

— eminence ........................... 257

— ridges .............................. 257

Germinal epithelinm................. 234.

— ridge.............................. 255

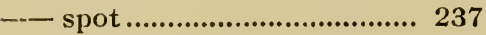

— vesicle............................... 237

Gianuzzi, crescents of............ 159

Giant cells.............................. 55

Giraldes, organ of................. 223
Glands.................................. 157

-

- of Brunner....................... 177

— cardiac.............................. 175

— carotid............................ 280

— ceruminous.................144, 351

—— coccygeal ......................... 280

— of "owper........................ 231

— of Ebuer........................... 170

- gastric ............................ 175

—_ lachrynıal ....................... 334

-.. -of Littre............................ 227

_ mammary. ......................... 246

— Meibomian.................145, 333

— of Moll............................ 332

- of mouth......................... 160

— mucous ............................. 158

— peptic.................................. 175

— prostate........................... 231

— pyloric ............................... 175

__ salivary .......................... 161

—— sebaceous......................... 144

— serous ............................. 158

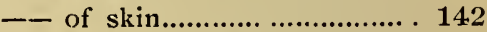

— sudoriparous..................... 152

— of Tyson....................... 230

— unicellular....................... 156

— uterine ............................. 240

Glandular epithelium................ 18

Glans penis............................ 230

Glia-cells............................46, 113

Glisson, capsule of.................. 186

Glomeruli, renal..................... 207

- olfactory.......................... 327

Goblet cells .........................19. 156

Golgi, organs of................... 103

Gonads ................................... 217

Graaffian follicles..................... 234.

Grandry, corpuscles of............. 104

Granule cells.... ...................... 37

Gray commissure................... 292

fibres.......................101, 107

matter of cord................. 292

Gums................................. 154

HAEMATOBLASTS................... 82 
Ilacmoglobin ...................... 76

Hairs................................ 146

Hassall's corpuscles.............. 27x

Ilaversian cauals.................. 52 spices ....................... 53 systems......................52, 166

Head kidney ........................ 252

Hleart .................................... 261

Ileidemhain, demilunes of......... 159

Henle's layer...... ................. 148 loop .................................. 208

sheath......................... 113

Hequatic cords ....................... 18s

IHorny latyer ......................... 135

Houston, valves of................. 182

Howship's lacunac.................. 56

Huxley's layer........... ........... 148

Hyaline cartilage.................... 26

Hyaloid membrane................. $3+2$

Hyaloplasm ........................... 115

Hydatids of Morgagni.......223, 224

stalked. ..................... 239

Hymen ................................ 24t

Hypoblast........................... 128

Hypophysis cerebri.............. 283

INCREMENTAL LANES OF SALTER, 165 Infundibula, pulınınary.......... 197 Intima....................92, 259, 264 Interglobular spaces............... 165 Interlobular cells of pancreas.. 185 Internal splineter................ 1.44 Internodes......................... 101

Interstitial lamellae............... 52

Intestinal follicles................... 177

Intramembranous ossification, 60,61 Involuntary musculat tissue.... 84

JELLY OF WIIARTON.

KARYOKINISIS 119

Kidneys 203

— bloodsupply of ............... 205

- permancnt. 252 primitive
Krause, end-bulbs of .............. 104

— membrane of ................. 88

L.АНА .МАјRА ..................246, 257

- minora........ ..........245, 257

Lachrymal glands................... 334

Lacteal glands....................... 267

Lacunae, of bone...................49, 50

— Howship's........................ 56

- - of Morgagui ................ 227

Lamellae, circumferential....... 52

- interstitial........................ 52

Lamellated tissues................ $\quad+7$

Lamina cribrosa .................... 335

—— fusca................................ 335

- - suprachoroidea............... 337

Large intestine ...................... 181

Larynx............................... 199

L.ateral cornu........................ 292

L.encocytes .............33, 36, $7+, 7 \tau$

Lieberkuhn, crypts of.............. 177

Lines of Schreger ................ 165

Lingual papillae... ................ 169

Littre, glands of..................... 227

I.iver.................................... 185

Lyinph ............................... 96

- capillaries .....................92, 96

— vessels..................92, 97, 264

L.ymphatic glands................80, 272

Lymphobiasts ..... ............. 81

Lymphocytes ....................... 80

Lymphoid tissue .................. 80

. Macela ACI'stica.................. 355

Malpighian corpuscles.......205, 276

Malpighi, lacunae of ............. 227

- pyramids of ................... 20 4

Mammary glauds .................. 240

Marrow................... 40, 53, 54, 81

Matrix .............................. 23

Media........................92, 259. 264

Mediastinum testis ................. 219

Medullated fibres..............101, 146

Medullary sheath .................... 101

Meihomian glands.................. 14t

Meissner, corpuscles of............. int 
Meissner,plex us of $172,174,178,183$

Melanin. 37

Membrana granulosa.............. 236

- propria.......................... 41

- tectoria ........................... 360

Membrane, basilar................. 356

— bone ............................... 61

— of Bowman..................... 336

__ of Descemet.................... 336

__ of Krause......................... 88

—_ Nasinytli's...................... 166

— periodontal ...................... 166

- serous............................. 98

— $t$ mmpanic....................... 351

Membranous labyrinth. ......... 353

Meninges.........................267, 288

Menisci, tactile..................... 104

Merkel, tactile cells of ......... 103

Mesenchyma ......................... 130

Mesentery ........................... 267

Mesoblast ........................... 128

Mesoderm ............................. 128

Mesogaster ........................... 177

Mesonephros...................252, 254

Metanephros........................ 252

Microcytes ............................ 75

Migratory corpuscles.............33, 36

Mitosis............................... 119

Mons veneris......................... 246

Morgagni, columns of.............. 182

_. hydatids of... ............ 223, 224

Motor end-plate .................. 106

II ucosa, .....154, 155, 172, 175, 177 .

$181,182,192,215,238,240,243$

Mucous glands...................... 158

- layer of skin.................... 135

— membranes...................... 153

— tissire.............................. 32

Muellerian duct ..................... 253

Multipolar corpuscles.........102, 110

Muscle ............................... 89

— bronchial....................... 196

- corpuscles ........................ 87

- papillary .......................... 263

__ of Riolan....................... 332

- tracheal......................... 194
Muscular tissues...................... 84

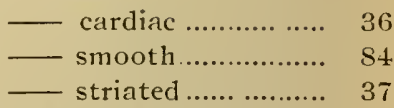

M uscularis mucosa....1\$6, 172,174 , 176. 178, 183, 241.

Musculosa, 172, 174. 177, 1\$1, 184, 216. 239, 241, 244.

Myelin ............................... 101

Myeloplaxes ...................... 55

Myocardium ........................... 262

NAILS................................... 151

Nasmyth's membrane............. 166

Nephridium .......................... 249

Nephrostome......................... 250

Nerve corpuscles...............102, 111

— fibres ........................101, 109

__ fibre corpuscles ............... 101

— terminals ...................... 102

Nerves ................................... 112

Nerrous tissues ...................... 99

Neurilemma .....................101, 109

Neuro-epithelium,......222, $325,3+7$, $354,308,360$.

Neuroglia........................4. 4,113

Neurokeratin ......................... 108

Neuroplasm .......................... 107

Nodes of Ranvier .................. 101

Nodules, adenoid................1 $1 \times 0,183$

Non-medullated fibres.........101, 105

Nuclear division....................... 118

Nucleoli. ..............................- 117

Nucleus..........................16, 116

OnONTOBLASTS ....................... 164

Oesophagus.......................... 174

Olfactory bulbs...................... $32 \overline{5}$

— cells ................................ 325

— glomeruli....................... 327

— hairs ............................ 325

Omentum .....................177, 267

Oosperm ............................... 128

Organ ..............................14, 127

— of Corti........................... 358

- - of firaldes .................... 223 
Orgitll of folgi..................... . 103

-

Os uteri ................................. 2 243

Osler's granules ..................

()ssein.............................. 51

Osseous tissue...................... 50

Ossificatioll ............................ 59

- - centres of......................... is

- in cartilage ....................60. 63

- - in membrane.................60, 61

()steoblasts .........................5t, 59

Osteoclasts .......................... $\overline{5} 6$

()steogrenetic fibres ................ 62

- layer ...........................54, 59

- tissue .............................. 66;

()toliths............................. 355

Ova, !nimitive..................... 234

- primordial ....................... 255

Ovary................................. 233

()villucts .......................238, 253

Ovula Nabothi..................... 242

Ovum.......................... 124,236

PАсімแ. noun:s................105, 230

l'alate................................. 154

P'ancreas .............................. 184

Pinniculus arlipnsus.............. 140

['apillac, foliate....................... 322

— of kiduey....................... 203

- of lingual....................... 16!

Papillary muscles................... 263

l'arablast........................... 130

l'aradidymis ......................... 225

Patraplasm ............................. 116

l'aratlyyroids ......................... 279

l'arietal cells......................... 176

Parooploron. ...................... 240

I'arovarium .......................... 239

Pavement epithelium.............. Is

Pelvis of kidney ..................... 212

Penis ..........................227, 257

P'eptic cells ........................... 17 17

P'ericardinm ........................... 266

Periehendral hone................64. 69

Perichondrium .................... 30
Periodontal membrane........... 166

Perimysium........................... 90

Perineurium ......................... 112

Periosteum ..............53, 54.66, 68.

Peritoneum.......................... 266

Perivascular lymphatics.......... 98

Permanent marrow............. 67

Peyer's patches...................... 180

P'fluegrer, tubes of .................... 161

Phary 1 x.............................. 173

P'ia ..................................... 289

J'igment cells....................... . 37

Pineal body ........................ 284

Pituitary body........................ 2\$3

Plain muscular tissue.............. 24

Plasma of blood................. 73

- cells.............................. 37

Platelets. blood.................... 74, $\$ 2$

P'leurae................................... 266;

Plexus of Aucrbach... 173, 174, 177

- of Meissner..172, 17t, 178, 183

Plica semilunaris..................... 333

Poles of nerve corpuscles......... 102

Polyliedral epithelium.............. 1s

Portal canals. ...................... 186

Prickle cells............................ 19

Primary areolae.................. 65, 66

- matrow ........................... 67

- vascular invasion ............. 67

Primitive fibrillae................. 107

— ova .............................. 234

- sheath............................. 101

Process, axis cylinder.............. 102

— of Deiters....................... 102

Pronephros........................... 252

Prostate gland........................ 231

Protoplasm..................... 15, 115

Protoplasmic processes......102, 110

Pulmonary artery................... 261

Pupil, muscles of ...................... 339

Pylorus................................ 179

Pyramids of Ferrein ................ 205

- of Malpighi..................... 20 4

Pyriform corpuscles...........101, 109 
RANYIER, NODES OF.

101

Receiving terminals

Rectum

102

Red corpuscles...................... 74

- marrow .......................... 55

Remak, fibres of..................... 100

Rete mucosum ....................... 135

— testis............................. 220

Reticular cartilage.................. 27

Reticulum.........................115, 121

Retiform tissue....................... 40

Retina................................ 344

Retinal pigment.................... 346

Retzius. stripes of................. 166

Ring-muscle......................... 338

Root-sheath of hair ............... 147

SAliva................................. 163

Salivary glands.... ................. 161

Salter, incremental lines of........ 165

Sarcolemma ......................... 87

Sarcoplasm .......................... 88

Sarcous elements................... 88

Schachowa, spiral tubule of .... 208

Schmidt, medullary segments of 108

Schreger, lines of..................... 165

Schwann, white substance of... 101

Sclerotic .................................. 335

Scrotum ........................217, 258

Sebaceous glands................... 144

Secondary areolae.................65, 66

Segmental ducts..................... 252

- organs......................... 250

Segmentation......................... 128

Seminal vesicles ..................... 226

Seminiferous tubules............... 220

Serosa.............173, 177, 181, 239

Serous endothelium..............20, 98

- glands.

158,159

- membranes

$.99,265$

Sertoli, columns of................. 221

Sharpey's fibres.................... 53

Sheath, Henle's.................... 113

Simple epithelium. .................. 19

Sinus pocularis
Skeletal tissues.................... 45

Skin....135, 141, 217, 230, 331, 351

Snıall intestine...................... 179

Small vessels......................... 91

Smooth muscular fibres........... 84

Sole-plate ............................ 106

Solitary follicles.................... 170

Spaces of Fontana................... 339

—— interglobular................... 165

Spermatic cord........................ 217

Spermatozoa ...................220, 222

Spermiduct............................ 254

Spheroidal epithelium.............. 18

Spinal cord........................... 291

— ganglia .......................... 309

- nerves ............................. 301

Spleen ................................. 274

Spirem ..................................... 119

Spongioplasm ....................... 115

Spongy bone ........................... 52

Squamous epithelium............... 18

Stalked hydatid ...................... 239

Stellate corpuscles................... 113

Stellules of Verhuyen.............. 206

Stigmata ................................ 94

Stomach................................ 175

Stomata...........................98, 198

Stratified epithelium................ 19

Stratum adiposum................. 140

—— corneum......................... 137

—_ epitrichinn1 .................... 137

— granulostum ...................... 136

- - lucid um ....................137, 152

—_ Malpighii ...................136, 152

—— papillare.......................... 139

— reticulare ......................... 139

—_ squamosum .................... 13i

Stria vascularis...................... 356

Striated muscular fibres... ....... 87

Striped muscular fibres ......... 87

Stripes of Retzius... ............... 166

Subcutanca ........................... 140

Submucosa.........154, 156, 172, 174

$177,178,181,183,193,196,216$ $239,241,244$. 
Substance of Rolandlo........295, 307

sudoriparous glands .............. 14"2

Suprarenal capsules................. 2,

Simpathetic sisten................ 110

symovial membranes.............. 26s

TACTII: Cl:L.................103, 104

- corpuscles ....................... 104

— disks............................. 104

— hairs............................... 150

Taste-buds ........................... 322

Teeth................................. 16t

Tendlon cells............................ 43

- tissue ............................ $\$ 2$

Terminals, discharging............ 106

— nerve.............................. 102

- receiving .......................... 10 2

Test is

217,219

Theca folliculi......................... 235

Thoracic duct....................... 265

Thymus.............................. 27

Thyroid... .............................. 27s

Tissue.................................. 13

Tomes, fibres of...................... 165

Tongue................................. 168

Tonsils ..............................171, 173

Trabeculac of sjongy bone...... 53

Tracheal.................................. 192

Tracheal muscle..................... 194

Tracts of cord........................ 299

Transitional epithelium............ 19

Tubes of Pflueger.................... 16 i

Tunica albuginea........219, 229, 234

Tympanum ........................... 353

U'MBILICAL CORD ...................... 33

Uniceilular glands.................. 156

Unipolar coı puscles............102, 110

Ureter.................................... 213

Urethra, female...................... 216

- male................................ 226

Lrinary bladder................214, 257

liriniferous tubules................. 207

Urogenital sinus
Viterine glands....................... 240

Uterus................................. 240

- masculinus..................... 231

VAGixa ............................. 243

Valves of heart...................... 263

— of Houston................... 182

— of veins............................ 264

Vas aberrans...................223, 224

—_ deferens ..............219, 224, 225

Vasa efferential....................... 223

— vasorum...................... 261

Vascular endothelium...........20,90

Vascularization of cartilage.... 63

Vater, corpuscies of.................. 105

leins.........................91, 94. 263

Ventral cornu. ....................... 292

Verluuven, stellules of.. ............ 206

Vermiform appendix............... 18:

Vessels. ................................ 91

Vestibule ................................. 245

Villi.................................... 177

Vitelline membrane ................. 237

Vitellus ................................. 237

Vitreous body.....................33, 341

Volkmann's canals.. .............. 52

Vulva ................................... 24t

WHARTOX'S JELLY.................. 33

Wibite commissure................. 293

— fibres ..................34, 101, 107

fibro-cartilage ................. 28

— fibrous tissue................. +2

— matter of cord ................ 292

- substance of Schwann..... 101

Wolffian body......................... 253

— duct................................. 253

YELL.OW FIBRES....................... 34

— fibro-cartilage................. 27

— marrew............................ 56

ZONA PELLCCIDA..................... 236

- striata............................. 236

— vasculosa......................... 234

Zone of Zinn......................... 343 


(4)

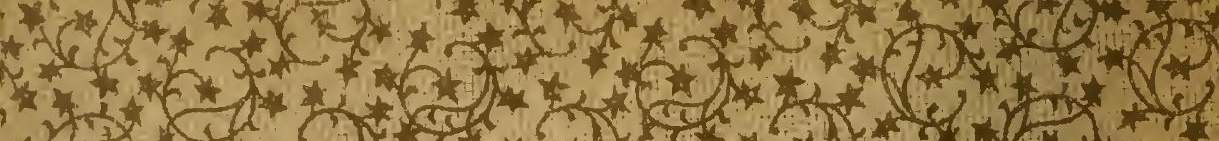

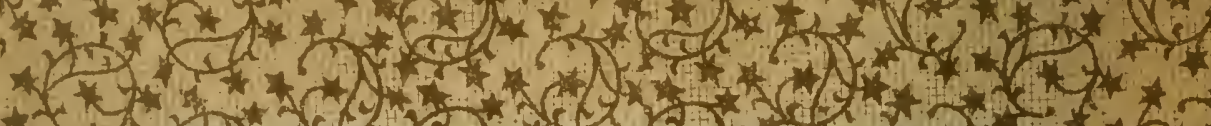

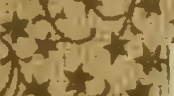
$2+4$

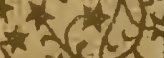
(t) $+7$

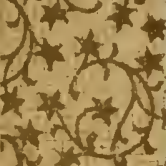

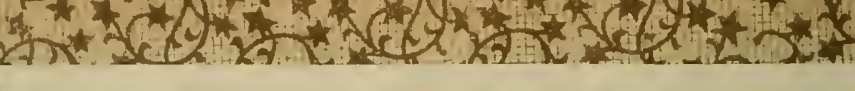

\section{COLUMBIA UNIVERSITY LIBRARIES}

This book is due on the date indicated below, or at the expiration of a definite period after the date of borrowing, as provided by the library rules or by special arrangement with the Librarian in charge.

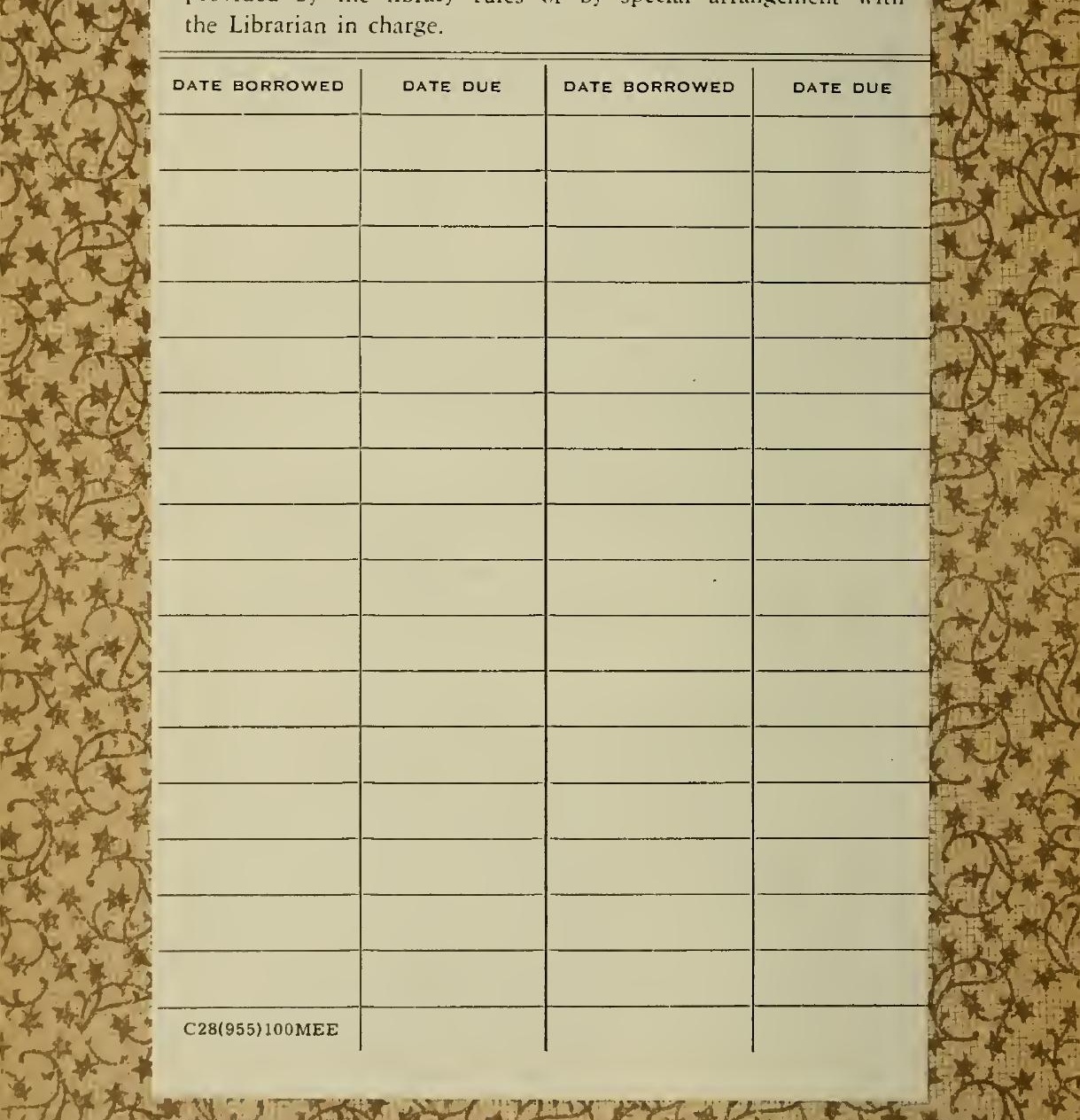

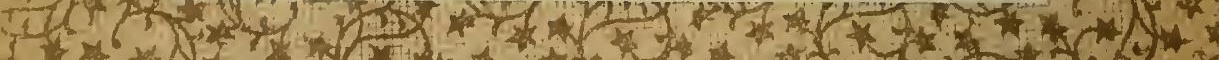

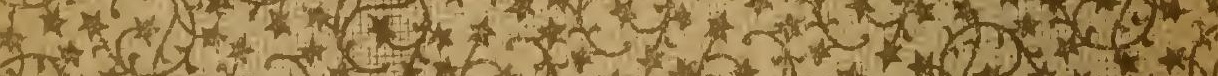

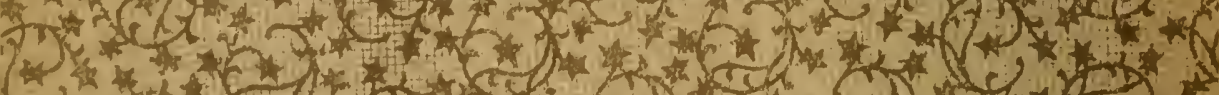

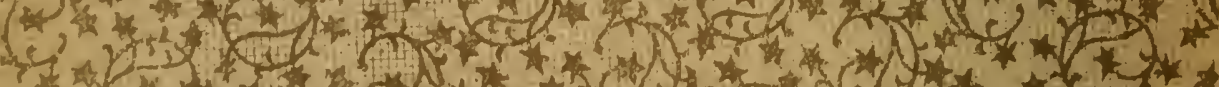
* * 
H

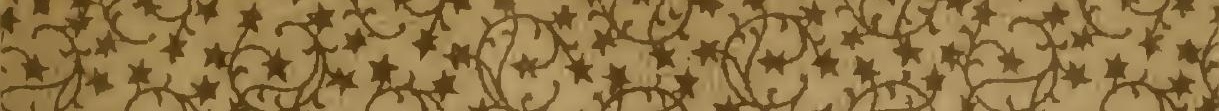

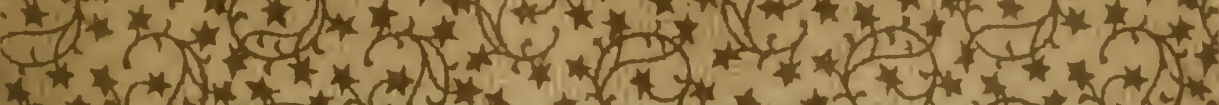

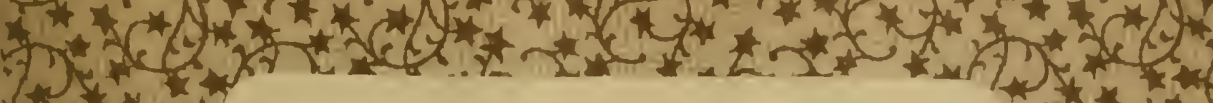

(t)

$+7$

ix*tiv

int

tex

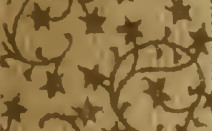

it.

$+1$

$+x^{*}$

$x$

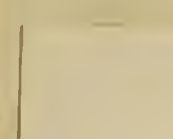

Tuttle

Principles of histology.

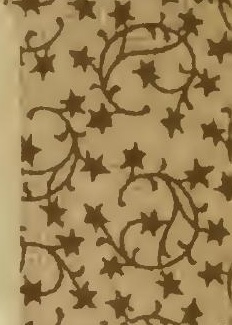

QM551

T88

V.I

1898

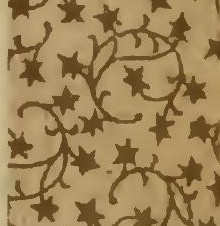

Din क. स $x \times$ is : int $27 x$ $1,4,45$ tanc $x^{2} x_{4}$ $7 *$

$$
\begin{aligned}
& \text { QM. } 551 \\
& T 88
\end{aligned}
$$

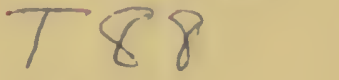

(t)
$1 / 1$

1898

Dit $2 x$

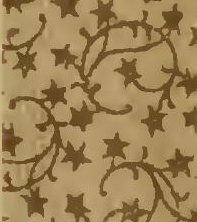
$n+26 x$ Nat 12 1 . $+x+2$

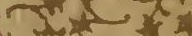

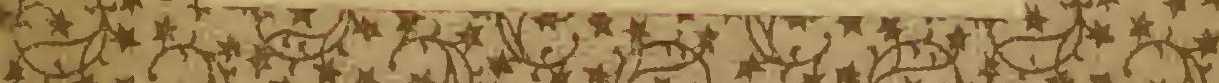

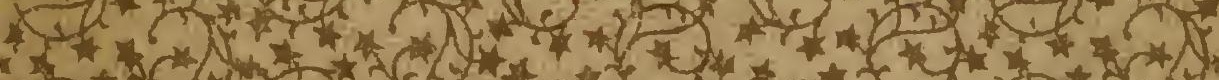

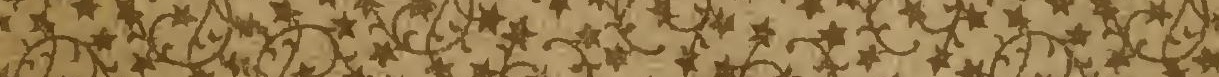

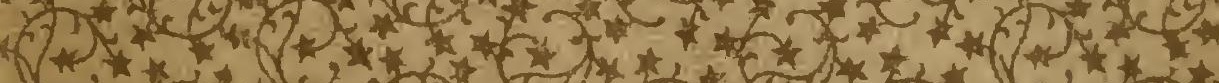
1. * * n - 
